\title{
Otimização Energética em Tempo Real da Operação de Sistemas de Abastecimento de Água.
}

Dissertação apresentada à Escola de Engenharia de São Carlos da Universidade de São Paulo, como parte dos requisitos para obtenção do título de Mestre em Hidráulica e Saneamento.

Área de Concentração: Hidráulica e Saneamento

Orientadora: Prof ${ }^{\mathrm{a}}$ Tit. Luisa Fernanda Ribeiro Reis

SÃO CARLOS - SP

2009 
AUTORIZO A REPRODUÇÃO E DIVULGAÇÃO TOTAL OU PARCIAL DESTE TRABALHO, POR QUALQUER MEIO CONVENCIONAL OU ELETRÔNICO, PARA FINS DE ESTUDO E PESQUISA, DESDE QUE CITADA A FONTE

Cunha, Alice Araújo Rodrigues da
Otimização energética em tempo real da operação de sistemas
de abastecimento de água / Alice Araújo
Rodrigues da Cunha i orientadora Luisa Fernanda Ribeiro
Reis. - São Carlos, 2009.
Dissertação (Mestrado-Programa de pés-Graduação e Área
de Concentração em Hidráulica e Saneamento) -- Escola de
Engenharia de São Carlos da Universidade de são Paulo,
2009.
1. Otimização em tempo real. 2. Operação de sistemas
de abastecimento de água. 3. Algoritmo genético.
Eficiência energética. I. Título.


Candidata: Engenheira ALICE ARAÚJO RODRIGUES DA CUNHA

Dissertação defendida e julgada em 12/05/2009 perante a Comissão Julgadora:

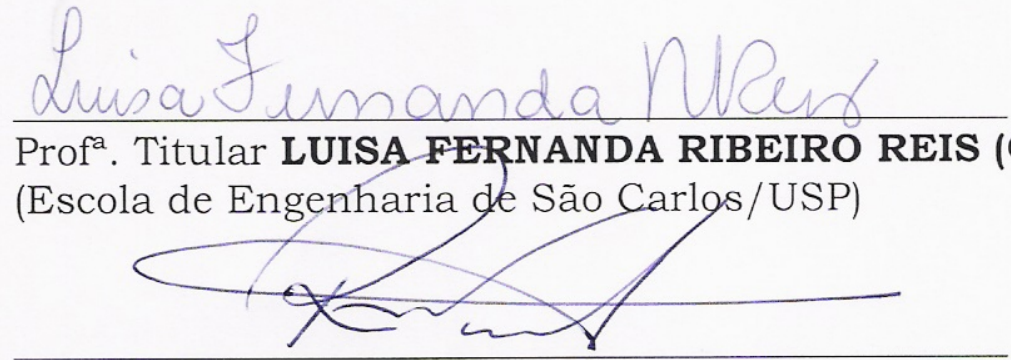

Prof. Associado RODRIGO DE MELO PORTO

(Escola de Engenharia de São Carlos/USP)

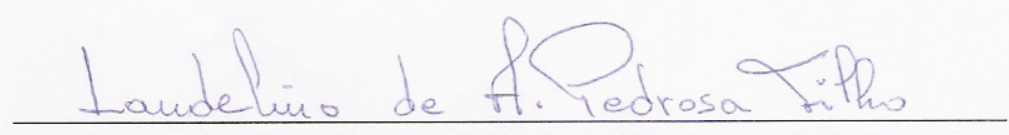

Prof. Dr. LAUDELINO DE ARAUJO PEDROSA FILHO

(Universidade Federal da Paraiba/UFPB)
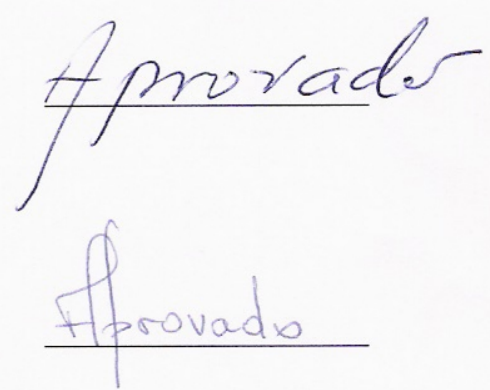
Ao meu pai, engenheiro Francisco Humberto, idealizador deste sonho e grande incentivador. 


\section{AGRADECIMENTOS}

- A Deus.

- A toda minha família, principalmente minha "mammys" e meus irmãos.

- À Professora Luisa Fernanda pela paciência, atenção, apoio e orientação.

- Ao Doutor Laudelino Pedrosa pelo inestimável auxílio.

- Aos colegas do LabSim Fausto, Frederico, Kátia, Milena e Thiago.

- Aos amigos de São Carlos, especialmente Luis, Micheli, Milena, Nayara, Ricardo e Valter.

- A todos os professores, funcionários e colegas do Departamento de Hidráulica e Saneamento da EESC-USP.

- A todos da SENHA ENGENHARIA que sempre contribuíram para minha formação profissional.

- Aos amigos de Goiânia, por suportarem a ausência, o mal-humor e muito me apoiarem: Ana Flávia, Bruna, Débora, Diego, Izabella, Ju, Letícia, Lorena, Lud, Lu, Marlene, Mayra e Paulinha.

Enfim, a todos que de alguma maneira contribuíram para a realização deste trabalho. 


\section{RESUMO}

Cunha, A.A.R. Otimização Energética em Tempo Real da Operação de Sistemas de Abastecimento de Água. 2008. 179 p. Dissertação Mestrado - Escola de Engenharia, Universidade de São Paulo, São Carlos.

Este trabalho apresenta um modelo computacional para otimização energética de sistemas de abastecimento em tempo real. Tal modelo é composto por três módulos principais: (1) um Módulo de Simulação Hidráulica que descreve o comportamento do sistema - EPANET; (2) um Módulo de Previsão de Demandas que realiza a previsão das demandas futuras aplicável à utilização no tempo real (curto prazo), desenvolvido por Odan (2008); e, por fim, (3) um Módulo Otimizador estruturado em linguagem $\mathrm{C}++$ que implementa a biblioteca de Algoritmos Genéticos do MIT - Massachusetts Institute of Technology and Matthew Wall, a GAlib, que permite determinar as rotinas operacionais (acionamento de válvulas e bombas) de forma à minimizar o custo de energia elétrica no sistema. O processo de otimização é divido em duas rotinas, Nível Estratégico e Tempo Real. Na otimização em Nível Estratégico, a partir das Curvas Típicas de Demanda para cada nó de demanda do macro-sistema considerado, determina-se o conjunto de controles que minimizam os custos de energia elétrica, respeitando as restrições hidráulicas do sistema. Para cada conjunto de controles otimizados têm-se os níveis que os reservatórios irão atingir ao final de cada hora durante o horizonte de planejamento considerado, denominados Níveis Metas. Tais níveis servem de guia para a segunda etapa de otimização. A Operação em Tempo Real se inicia com o recebimento dos dados sobre as condições atuais do sistema: níveis dos reservatórios e demandas da última hora. A partir das demandas informadas, o Módulo de Previsão de Demandas gera todas as demandas para o horizonte de planejamento. Alimenta-se então o Otimizador em Tempo Real com os níveis atuais dos reservatórios, os níveis metas e a previsão de demandas, obtêm-se o conjunto de regras operacionais ótimas para o horizonte de planejamento, sendo que são implementadas apenas as regras para a hora atual. E repete-se todo o processo a cada hora. Este modelo foi aplicado a um sistema de abastecimento de água. Os resultados obtidos demonstraram a eficiência do modelo em achar soluções factíveis de serem implementadas e com redução dos custos com energia elétrica.

Palavras-chave: otimização em tempo real, operação de sistemas de abastecimento de água, algoritmo genético, eficiência energética. 


\section{ABSTRACT}

Cunha, A.A.R. Real-time Optimization of Water Supply System Operation. 2008. 179 p. Master of Sciences Degree Thesis - São Carlos School of Engineering, University of São Paulo, São Carlos.

This work presents a computational model for real-time optimization of water-distribution networks operation. An integrated software tool has been developed which is composed of three main modules: (i) a hydraulic simulator that performs the extended period simulation of the system (EPANET); (ii) a short-term demand-forecasting model, based on the moving Fourier series; and (iii) an optimization module, using genetic algorithm, to minimize pumping costs. The optimization process is divided in two routines, the off-line optimization and the on-line optimization. The aim of the first routine is to find the ideal operation levels for the reservoirs which are used as guidance for the on-line optimization. The schedules to be implemented in the network are determined, however, by an on-line optimization which runs a new optimization processes at each SCADA (Supervisory Control and Data Acquisition) update. In the off-line optimization, near-optimal pump and valve settings for a selected operating horizon are found on the basis of the typical 24-hour water demand cycle in which each reservoir must also start and end with the same water level. The levels of the reservoirs at the end of each hour in this optimization process, called Ideal Levels, are considered in the on-line optimization as a constraint that represents a penalty added to the objective function whenever a reservoir level is below the Ideal Level at the end of each hourly operation. The on-line optimization starts updating the state of the network transmitted from the SCADA system and the demand forecast for the next 24-hour period. Near-optimal pump and valve settings for a selected operating horizon are then determined but only the control settings for the next hourly time step are used to implement the operation. At the next SCADA update (next-time step), the whole process is repeated on a continuous basis and a new operating strategy is computed. In this way, the control process moves forward in time, correcting any discrepancies as it progresses. This integrated software tool has been applied to a small example network. The results obtained from this application have shown that the proposed model offers a practical tool for finding feasible operation strategies for a water pipeline system, obtaining reductions in pumping energy costs.

Keywords: real time optimization, water-distribution networks operation, genetic algorithm, energy costs. 


\section{LISTA DE FIGURAS}

Figura 2.1 - Representação no EPANET do sistema estudado por Moreira (2008)................28

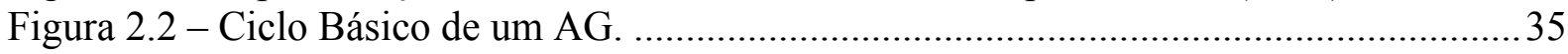

Figura 3.1 - Fluxograma do Modelo de Operação Otimizada em Tempo Real Proposto. ..... 48

Figura 3.2 - Diagrama de Fluxo da Otimização em Nível Estratégico.....................................55

Figura 3.3 - Sub-rotina leitura do arquivo ga1.in para Otimização em Nível Estratégico.......56

Figura 3.4 - Arquivo ga1.in para Otimização em Nível Estratégico. ....................................57

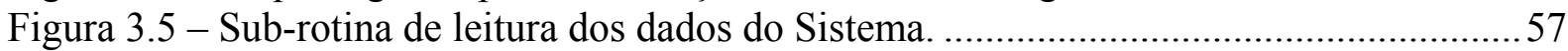

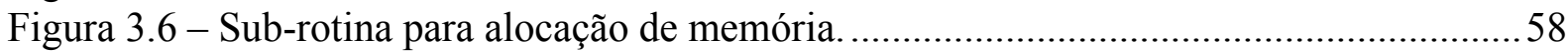

Figura 3.7 - Sub-rotina para geração da população inicial de solução para o AG. …..............58

Figura 3.8- Sub-rotina para obtenção do valor da função de aptidão. .....................................59

Figura 3.9 - Diagrama de Fluxo da Otimização em Tempo Real.............................................. 62

Figura 3.10 - Vetor solução de duas bombas e duas válvulas, horizonte de planejamento $T$. .64

Figura 3.11 - Códigos de Alerta e respectivas mensagens. Fonte: Toolkit (Rossman, 2000)..69

Figura 4.1 - Topologia do Sistema Objeto de Estudo.

Figura 4.2 - Tarifa horo-sazonal verde e azul para o Sub-Grupo A4, convencional para o Sub-

Grupo A4 e convencional para o Sub-Grupo A3. Fonte: Pedrosa (2006)...............................79

Figura 4.3 - Curvas Típicas de Demanda para todos os dias da semana. ............................... 80

Figura 5.1 - Organização da Aplicação do Modelo Desenvolvido........................................ 83

Figura 5.2 - Representação no EPANET do Sistema Estudado........................................... 88

Figura 5.3 - Representação esquemática do vetor solução..................................................91

Figura 5.4 - Evolução do valor da função de aptidão para diferentes tamanhos de população.

Figura 5.5 - Evolução da função de aptidão para os diferentes operadores de seleção. ..........95

Figura 5.6 - Evolução da função de aptidão para os diferentes operadores de cruzamento. ...96

Figura 5.7 - Funções de aptidão para diferentes probabilidades de cruzamento. ....................97

Figura 5.8 - Funções de aptidão para diferentes probabilidades de mutação. ..........................98

Figura 5.9 - Evolução da função de aptidão para diferentes níveis iniciais nos reservatório.100

Figura 5.10 - Diferença entre níveis dos reservatórios e níveis meta para diferentes $\lambda_{4}$...... 103

Figura 5.11 - Custo com energia elétrica (R\$) para diferentes valores de $\lambda_{4}$....................... 104

Figura 5.12 - Padrão adimensional de demanda associado ao nó de consumo a jusante (a) do

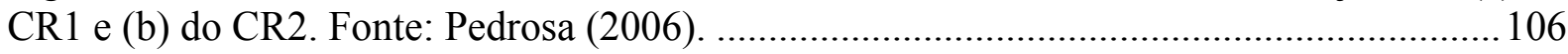

Figura 5.13 - Distribuição temporal das pressões nos nós (a) Rede 1 e (b) Rede 2.............. 107

Figura 5.14 - Distribuição temporal dos níveis dos reservatórios para otimização considerando o enquadramento tarifário atual (NAotim), a alteração do enquadramento tarifário (NAotim nova tarf) e (NAoperacional) - Reservatórios R1 e R3 ........................... 108

Figura 5.15 - Distribuição temporal dos níveis dos reservatórios para otimização considerando o enquadramento tarifário atual (NAotim), a alteração do enquadramento tarifário (NAotim nova tarf) e (NAoperacional) - Reservatórios R4 e R5 ............................. 109

Figura 5.16 - - Curvas de Demanda Típica dos Dias úteis, Sábados e Domingos. ................ 112

Figura 5.17 - Número de bombas em funcionamento nas otimizações estratégicas. ............. 114

Figura 5.18 - Distribuição temporal das pressões nos nós (a) Rede 1 e (b) Rede 2, com a otimização em nível estratégico. ................................................................................... 115

Figura 5.19 - Regras de operação das bombas resultantes da otimização estratégica.......... 117

Figura 5.20 - Regras de operação das válvulas resultantes da otimização estratégica. ......... 118 
Figura 5.21 - Operação Otimizada em Nível Estratégico dos reservatórios R2 e R3.

Figura 5.22 - Operação Otimizada em Nível Estratégico dos reservatórios R4 e R5.

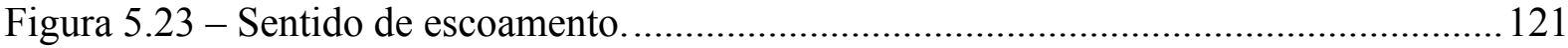

Figura 5.24 - Sentidos de fluxo no CR2 ................................................................. 121

Figura 5.25 - Fluxograma das Otimizações em Tempo Real realizadas................................ 123

Figura 5.26 - Custo diário de bombeamento otimizado em tempo real - Dias Úteis............. 125

Figura 5.27 - Valores das penalidades divididos por seus respectivos coeficientes.............. 126

Figura 5.28 - Regras de operação otimizadas - Sábado...................................................... 127

Figura 5.29 - Regras de operação otimizadas - Domingo................................................. 128

Figura 5.30 - Regras de operação otimizadas - Segunda-feira. .......................................... 128

Figura 5.31 - Níveis dos reservatórios - estratégias operacionais otimizadas sábados.......... 130

Figura 5.32 - Níveis dos reservatórios - estratégias operacionais otimizadas domingos....... 131

Figura 5.33 - Níveis dos reservatórios - estratégias operacionais otimizadas segundas-feiras.

Figura 5.34 - Tempo computacional gasto com as otimizações em tempo real. ................... 133

Figura 5.35 - Custo de bombeamento para as otimizações em tempo real dos sábados. ...... 134

Figura 5.36 - Custo de bombeamento para as otimizações em tempo real dos domingos. .... 134

Figura 5.37 - Custo de bombeamento para as otimizações em tempo real - Segunda-feira..135

Figura 5.38 - Comparação das Demandas Reais Adimensionalizadas (Histórico) com as

Demandas Previstas pelo módulo de Previsão de Demandas - Sábado (07/Fevereiro)......... 136

Figura 5.39 - Diferença entre as Demandas Adimensionalizadas Observadas e Previstas. .. 138

Figura 5.40 - Custos de Bombeamento otimizados utilizando demandas reais e previstas... 139

Figura 5.41 - Níveis dos reservatórios - estratégias operacionais otimizadas em tempo real

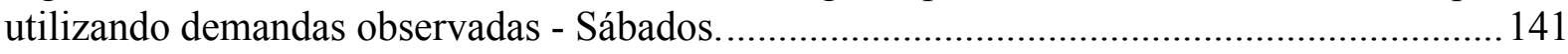

Figura 5.42 - Tempo Computacional das otimizações utilizando as demandas históricas e as demandas previstas 


\section{LISTA DE TABELAS}

Tabela 2.1 - Custos mensais de energia elétrica e comparativo entre o Planejamento da operação do SAAE, Estratégico e Operacional atualizado, Moreira (2008).

Tabela 4.1 - Dados dos conjuntos moto bombas do CR1. Fonte: Pedrosa (2006). 76

Tabela 5.1 - Valores adotados nas análises de sensibilidade dos operadores e parâmetros do

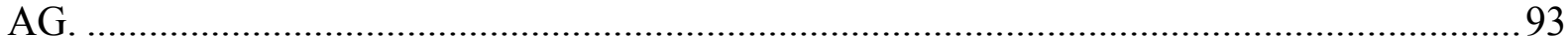

Tabela 5.2 - Operadores e parâmetros genéticos adotados...................................................99

Tabela 5.3 - Análise de sensibilidade do coeficiente de penalidade $3\left(\lambda_{3}\right) \ldots \ldots \ldots \ldots \ldots \ldots \ldots \ldots \ldots . . . . . . . . . . .102$

Tabela 5.4 - Consumo médio diário por unidade, real e otimizado...................................... 110

Tabela 5.5 - Resultados da otimização para as diferentes Curvas de Demanda Típica......... 113

Tabela 5.6 - Quantidade de acionamentos nas otimizações em nível estratégico. ................. 116

Tabela 5.7 - Custo de Bombeamento Tempo Real - Com Dados de Demandas Previstos.... 124

Tabela 5.8 - Resultados das Penalidades-Com Dados de Demandas Previstos 


\section{SUMÁRIO}

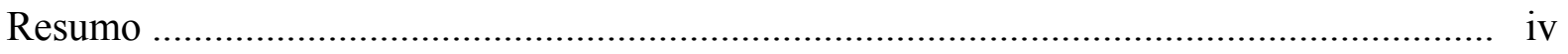

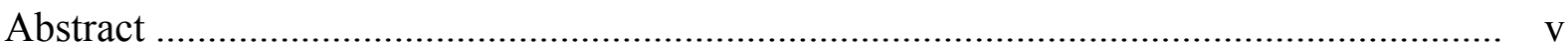

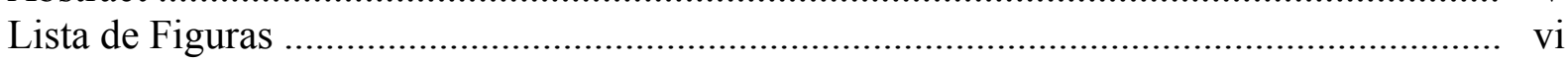

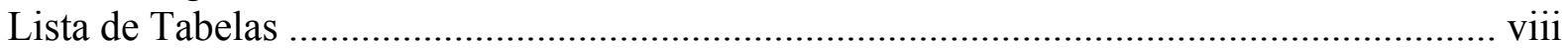

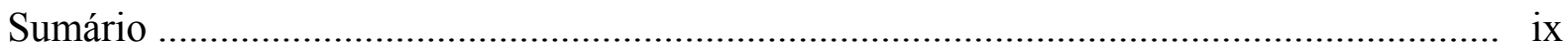

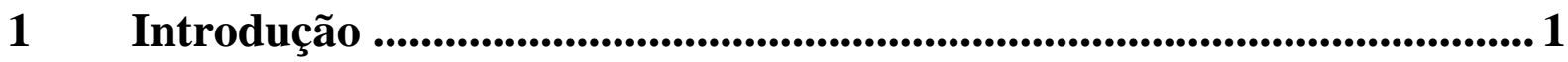

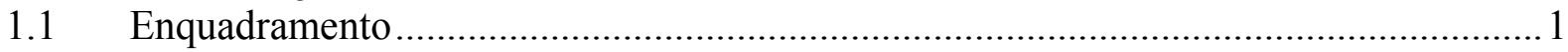

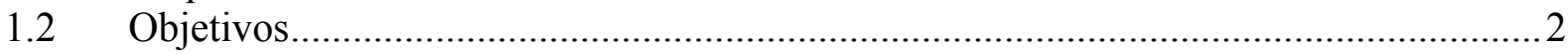

1.3 Estrutura e Conteúdo do Trabalho................................................................................

2 Revisão Bibliográfica ........................................................................5

2.1 Operação de Sistemas de Abastecimento de Água.......................................................5

2.2 Otimização da Operação de Sistemas de Abastecimento de Água .............................. 8

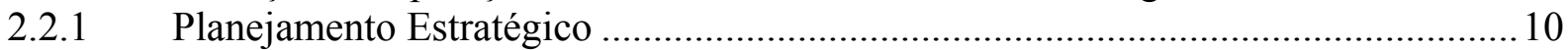

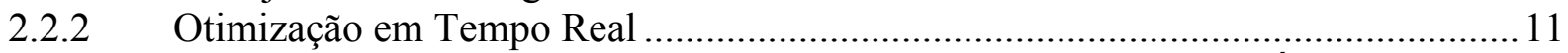

2.3 Técnicas de Otimização Aplicáveis a Sistemas de Abastecimento de Água ...............31

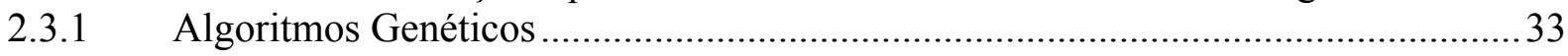

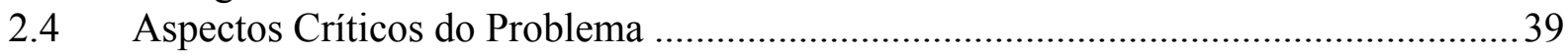

$3 \quad$ Modelo Otimizador ................................................................................ 45

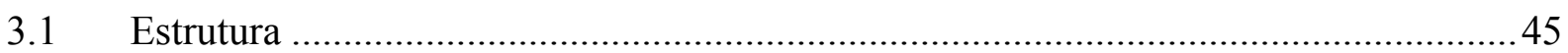

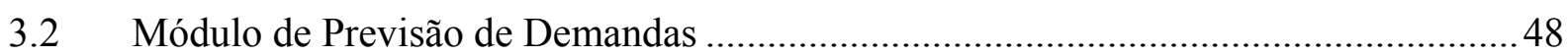

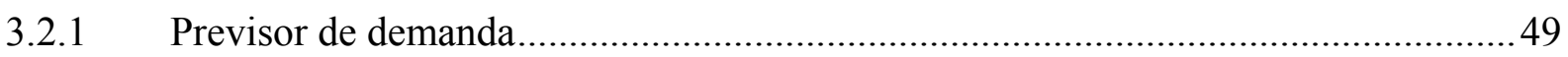

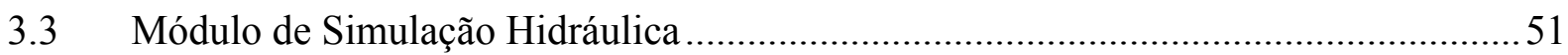

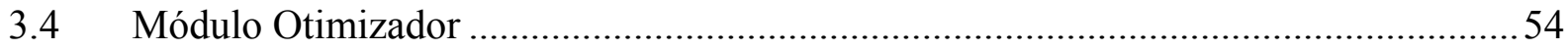

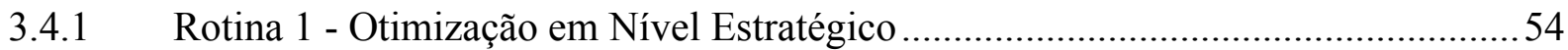

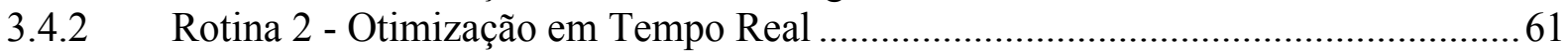

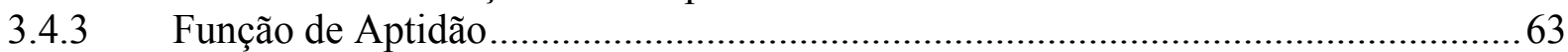

3.4.4 Algoritmos Genéticos - Operadores e Parâmetros ................................................... 71

$4 \quad$ Sistema Objeto de Estudo _....................................................................73

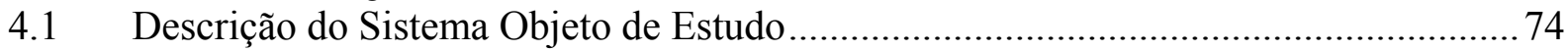

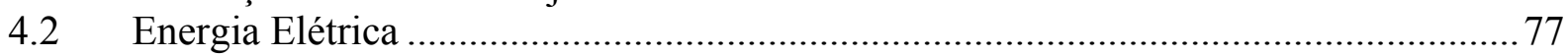

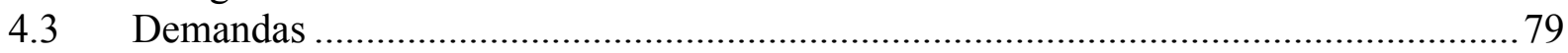

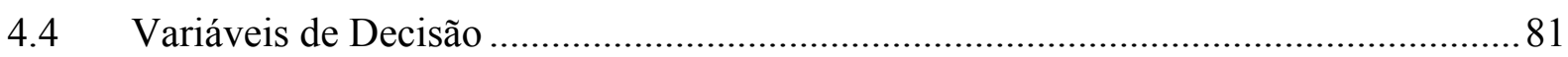

$5 \quad$ Aplicação do Modelo Desenvolvido.........................................................83

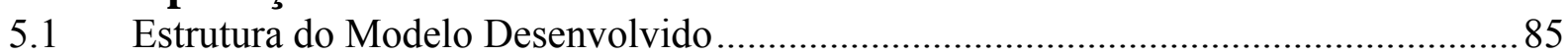

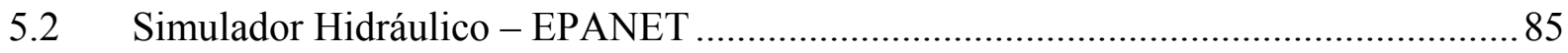

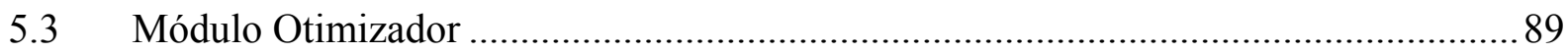

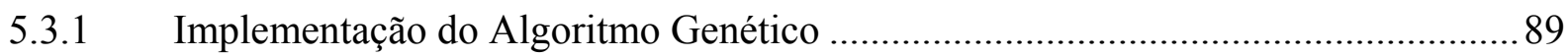

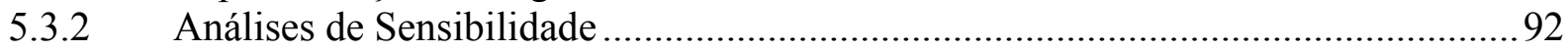

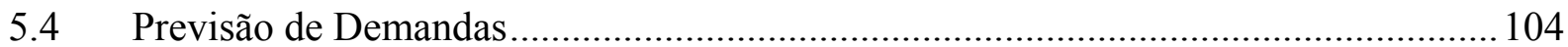

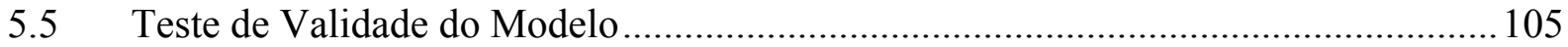

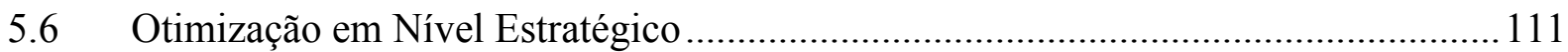

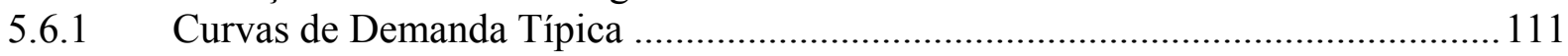


5.6.2 Resultados da Otimização em Nível Estratégico.............................................. 112

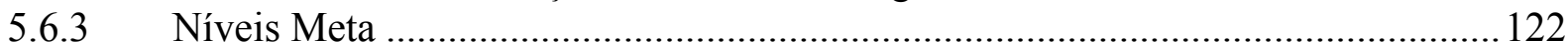

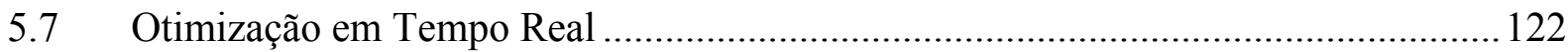

5.7.1 Resultados da Otimização em Tempo Real com Previsão de Demandas ............... 124

5.7.2 Avaliação da Influência da Previsão no Resultado da Otimização ......................... 135

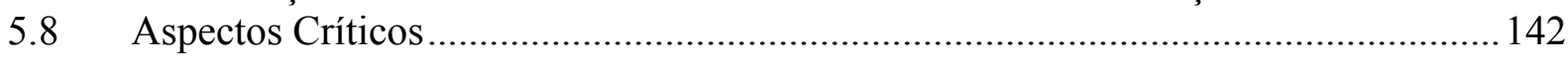

6 Conclusões e Recomendações ...................................................... 145

6.1 Recomendações para Estudos Futuros ................................................................. 146

7 Referências Bibliográficas........................................................ 149

Apêndice A - Rotinas do Otimizador em Tempo Real.................................. 155 Apêndice B - Padrões de Demandas observadas e previstas utilizadas na Otimização em Tempo Real .............................................................................. 171 
“A vida não consiste apenas em ter boas cartas na mão e sim em jogar bem as que se tem.' Josh Billings

\section{Introdução}

\subsection{Enquadramento}

Em todo o mundo, no setor de saneamento básico, principalmente no segmento de sistemas de abastecimento de água, ocorrem perdas significativas de energia e água.

Atualmente as ações de combate às essas perdas são medidas imprescindíveis e inadiáveis para garantir a sustentação econômica da grande maioria das empresas de saneamento existentes no Brasil e no mundo.

De acordo com dados do Serviço Nacional de Informação em Saneamento (SNIS, 2005), as perdas de água (físicas e de faturamento) nos sistemas de abastecimento do Brasil são da ordem de $40 \%$, chegando a $70 \%$ em algumas cidades.

Já as perdas de energia são extremamente difíceis de mensurar. Estas se devem principalmente às próprias perdas de água, à baixa eficiência dos equipamentos eletromecânicos, à ausência de medição e à falta de monitoramento dos principais parâmetros que regulam o sistema e à procedimentos operacionais inadequados. 
De acordo com o Programa Nacional de Conservação de Energia Elétrica para o Saneamento (PROCEL SANEAR, 2005), mais de dois e meio por cento do consumo total de energia elétrica do Brasil, o equivalente a aproximadamente 9,6 bilhões de kWh/ano, são consumidos por prestadores de serviços de água e esgotamento sanitário.

Nos últimos anos a repercussão do custo da energia elétrica no setor de saneamento no Brasil tem se acentuado significativamente e já constitui o segundo item de despesas de algumas empresas prestadoras destes serviços. Segundo Tsutiya (2004) mais de 90\% desses gastos com energia elétrica devem-se às elevatórias dos sistemas de abastecimento de água.

A otimização da operação dos sistemas de abastecimento de água, objeto deste trabalho, constitui uma das principais medidas operacionais visando à redução das perdas energéticas, uma vez que o grande número de elementos passíveis de terem seus estados de funcionamento alterados a cada instante, torna complexa a tarefa dos operadores desses sistemas. Assim, a operação consiste basicamente em definir, num determinado instante, qual a melhor combinação do estado operacional das bombas e coeficiente de abertura das válvulas, de forma a tornar o sistema mais eficiente em termos energéticos. Sem um planejamento otimizado, os sistemas de distribuição de água para abastecimento continuarão a desperdiçar uma parcela razoável de energia elétrica.

\subsection{Objetivos}

O objetivo principal deste trabalho de pesquisa consiste em desenvolver e testar um modelo de otimização energética para a operação em tempo real aplicável a um sistema de distribuição de água para abastecimento público. Tal objetivo foi alcançado mediante as seguintes fases de desenvolvimento: 
i. definição do sistema objeto de estudo e aquisição dos dados necessários;

ii. desenvolvimento de um modelo computacional aplicável ao sub-sistema em questão composto por dois módulos: (1) um Módulo de Simulação Hidráulica que descreve o comportamento do sistema - EPANET; e, por fim, (2) um Módulo Otimizador estruturado em linguagem $\mathrm{C}++$ que implementa a biblioteca de Algoritmos Genéticos do MIT - Massachusetts Institute of Technology and Matthew Wall, a GAlib, acoplado ao EPANET, que permite determinar as rotinas operacionais (acionamento de válvulas e bombas) de forma à minimizar o custo de energia elétrica no sistema;

iii. análise, interpretação dos resultados obtidos e recomendações de modos de operação que minimizem os custos de energia elétrica.

\subsection{Estrutura e Conteúdo do Trabalho}

Esta dissertação é organizada em sete capítulos. Após este capítulo introdutório, o capítulo 2 apresenta uma revisão bibliográfica sobre o tema principal dessa dissertação, a otimização da operação de sistemas de abastecimento de água em tempo real, englobando os principais trabalhos disponíveis na literatura especializada sobre o tema e uma breve descrição da técnica de otimização aqui utilizada, os Algoritmos Genéticos.

No capítulo 3, apresenta-se a estrutura do modelo computacional desenvolvido, constituído pelos módulos de previsão de demandas, simulação hidráulica e otimização operacional, as interações entre os módulos e as aplicações específicas de cada módulo.

O capítulo 4 traz a completa descrição do sistema objeto de estudo, bem como todos os dados levantados necessários ao desenvolvimento do trabalho. Já no capítulo 5 constam os resultados principais da aplicação do modelo neste sistema. 
Na última parte do trabalho (capítulo 6) apresentam-se a síntese e as conclusões gerais do estudo, bem como a indicação de novas áreas de desenvolvimento e as recomendações para trabalhos futuros. 
"A little experience often upsets a lot of theory."

Cadman

\section{Revisão Bibliográfica}

\subsection{Operação de Sistemas de Abastecimento de Água}

O objetivo da operação de sistemas de abastecimento de água é o atendimento confiável das necessidades de consumo, a custos operacionais mínimo, tais como os de consumo de energia e manutenção. $\mathrm{O}$ atendimento de tal requisito implica num melhor aproveitamento do sistema de transporte e reservação.

Pode-se então dizer que a operação de um sistema é a seqüência de manobras exercidas sobre os seus elementos ativo, tais como válvulas e bombas, de forma a atender aos objetivos descritos acima.

Essa operação pode ser realizada de diferentes formas: controle manual, automático, automático programado e centralizado.

No controle manual, os elementos do sistema são manobrados por operadores locais, que possuem pouca ou nenhuma informação a respeito do restante do sistema. O controle automático, mantém a mesma simplicidade do controle manual, prescindindo do operador humano (reservatórios controlados por bóias, elevatórias operadas por pressostatos, etc.) $\mathrm{O}$ controle automático programado é baseado em Controladores Lógicos Programados (PLC). Já no controle centralizado, o processo de operação fica a cargo de uma central de controle, que 
se baseia em dados do sistema obtidos através de radio, telefone ou telemetria. Sendo que o controle pode ser exercido por operadores locais que recebem ordens da central, ou ainda por um operador central que controla remotamente os elementos do sistema.

Independente da forma de operação utilizada o que acontece na maioria dos sistemas do mundo inteiro é que as regras operacionais implementadas são de natureza empírica, e visam, principalmente, à garantia da continuidade do abastecimento público, sem vistas à minimização dos custos com energia elétrica.

A equipe de planejamento da operação geralmente define as regras (fixas ou variáveis) de controle dos sistemas, baseada em informações e experiências anteriores e no conhecimento do estado atual do sistema. As regras são transmitidas à equipe responsável pelo controle do sistema, que por sua vez, implementa tais regras e retorna os resultados das operações efetuadas ao setor de planejamento, para avaliação do desempenho e as adequações necessárias.

Verifica-se que o trabalho no setor de operações em um sistema de abastecimento requer decisões eficientes e em tempo real. A aplicação de uma regra operacional inadequada pode ser desastrosa para a operação do sistema.

Segundo Zahed (1990), para que se possa otimizar as regras operacionais de um sistema de distribuição de água são necessárias a definição clara dos objetivos a serem alcançados, o conhecimento do sistema e de dados previsionais, além da disponibilidade de um modelo para otimização dessas regras.

Os objetivos a serem alcançados devem envolver diferentes aspectos de natureza técnica, econômica, social e política. Do ponto de vista técnico restringe-se a minimizar os custos de operação e/ou garantir a confiabilidade do sistema. Nas ocasiões em que há oferta e demandas equilibradas, o objetivo da operação pode ser voltado à minimização de custos operacionais, de forma a maximizar os benefícios líquidos. Quando o sistema apresenta 
demanda superior à capacidade de produção, o objetivo passa a ser o de minimizar os prejuízos causados pela escassez do recurso oferecido.

O conhecimento do sistema, sua topologia e as características hidráulicas e mecânicas dos elementos que o compõe, é base fundamental para que o simulador hidráulico utilizado represente da forma mais fiel possível o comportamento do sistema em análise. Já a previsão das demandas permite que o modelo desenvolvido represente as condições de operação do sistema.

Os modelos de otimização da operação, objeto principal deste trabalho, vêm sendo estudados por inúmeros pesquisadores desde a década de 80 .

A preocupação com o planejamento da operação dos sistemas urbanos de abastecimento de água ganhou destaque nas últimas décadas. A complexidade dos sistemas acompanhou o crescimento e a diversificação da demanda e, assim, surgiram dificuldades operacionais. $\mathrm{Na}$ tentativa de gerir os sistemas, houve a necessidade da aplicação da análise de sistemas como ferramenta de apoio para que os operadores pudessem tomar decisões de maneira estruturada. A aplicação da análise de sistemas na engenharia de recursos hídricos é um campo relativamente novo e vem se aprimorando paralelamente ao desenvolvimento dos recursos computacionais, haja vista que os grandes sistemas necessitam de análises complexas, envolvendo muitas variáveis, praticamente impossíveis de serem efetuadas sem o uso de ferramenta computacional.

No item 2.2, a seguir, é feita a revisão bibliográfica dos principais modelos matemáticos desenvolvidos para a otimização da operação de sistemas de abastecimento de água. 


\subsection{Otimização da Operação de Sistemas de Abastecimento de Água}

A problemática da otimização da operação de sistemas de distribuição de água para abastecimento pode ser abordada basicamente sob os enfoques do Planejamento Operacional

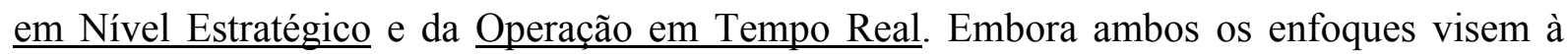
determinação de estratégias operacionais otimizadas relativas à operação de componentes tais como válvulas e bombas dos sistemas, dizendo respeito, portanto, à determinação das variáveis de decisão relativas ao status de funcionamento ideal para tais dispositivos a cada intervalo de tempo do horizonte de planejamento considerado, eles respondem a necessidades de ordem prática distintas.

De forma sintética, o problema de otimização sob o enfoque do Planejamento Operacional em Nível Estratégico apóia-se em curvas de demanda típicas (médias) conhecidas e níveis d'água iniciais estabelecidos para os reservatórios com vistas à determinação das trajetórias operacionais ótimas, de maneira que os níveis d'água dos reservatórios no final do horizonte de planejamento considerado, geralmente diário (de 24 horas), coincidam com os iniciais. Pode-se dizer que as estratégias assim obtidas não são diretamente aplicáveis à operação, embora constituam ferramentas importantes aos propósitos de avaliação dos respectivos sistemas (capacidades de armanezamento e transporte, adequação das bombas, atendimento das demandas, etc.). O Planejamento Operacional Estratégico possibilita, por exemplo, a investigação do comportamento dos níveis dos reservatórios, que pode ser reveladora no sentido de apontar subutilização ou insuficiência de capacidade. Além disso, oferecem subsídios a importantes decisões relativas à contratação de tarifas de energia elétrica, etc.

Pelas razões apontadas, verifica-se uma tendência crescente das companhias de abastecimento de lançarem mão do Planejamento Operacional Estratégico e a literatura 
especializada apresenta diversos estudos que tratam desse problema, empregando diferentes técnicas de otimização, a saber, programação linear, não linear e dinâmica, simulated annealing, redes neurais artificiais (RNA), algoritmos genéticos (AGs), etc. Dentre elas, a técnica dos algoritmos genéticos vem se destacando pela sua habilidade em resolver problemas não lineares, possibilidade de serem diretamente conectados com módulos externos de avaliação da função objetivo (no caso dos sistemas de abastecimento, módulo de simulação hidráulica), como exige o problema em foco, sem necessitar de suposições simplificadoras, cálculo de derivadas, etc.

As soluções do Planejamento Operacional Estratégico correspondem, entretanto, a um plano estratégico estático por natureza. Uma vez formulado, o plano está atrasado devido às constantes mudanças a que os sistemas geralmente estão sujeitos. Assim, analisando o problema com o qual os operadores se deparam no dia a dia, percebe-se que a estratégia operacional estabelecida sob o enfoque do Planejamento Operacional Estratégico se inviabiliza devido a fatores como ocorrência de demandas distintos daqueles preconizados pela curva típica e de níveis de reservatórios diferentes daqueles previstos para o final de cada intervalo de tempo (hora). O ideal do ponto de vista prático é então que as decisões sejam tomadas com base nas condições que se configuram a cada intervalo de tempo. Como as decisões tomadas no presente afetam a operação dos períodos seguintes, devem-se considerar as incertezas relativas às demandas de períodos (horas) à frente para que decisões operacionais mais acertadas sejam tomadas. Esse tipo de análise impõe, portanto, o uso de uma modelo operacional alimentado por dados de previsão de demanda em tempo real, ou seja, estimados a partir de dados constantemente atualizados. Dessa maneira, a Operação em Tempo Real transforma uma estratégia operacional estática em uma estratégia operacional "viva"; um plano estratégico para uma estratégia constantemente em construção. Ela oferece à operação a capacidade de ajustar-se continuamente, apontando decisões mais adequadas 
mesmo quando o que se deve fazer não se mostra tão óbvio. A Operação em Tempo Real permite que continuamente se faça uma definição estratégica e que novas possibilidades sejam identificadas.

É desejável ainda que a Operação em Tempo Real represente uma aproximação para as respostas produzidas pelo modelo de Planejamento Operacional Estratégico. Assim, a Operação em Tempo Real, representa um desafio ainda maior. Esse fato se confirma tanto pela escassez de trabalhos publicados sobre o tema (descritos adiante) como pela maneira mais usual de operação dos sistemas realizada na prática: a sentimento, de acordo com a experiência e capacidade intuitiva do operador. Reconhece-se, no entanto que, embora bons resultados possam ser produzidos dessa maneira, eles certamente podem ser melhorados.

Com vistas ao desenvolvimento de um modelo otimizador para a operação de sistemas de distribuição de água em tempo real, será necessário tratar o problema de otimização em duas etapas: a primeira, de Planejamento Operacional em Nível Estratégico; e, a segunda da Operação em Tempo Real propriamente dita. A literatura foi, portanto, analisada objetivando o tratamento dessas duas abordagens complementares do problema, conforme apresentado a seguir nos itens 2.2.1 e 2.2.2.

\subsubsection{Planejamento Estratégico}

Segundo Carrijo (2004), inúmeros estudos foram desenvolvidos no sentido de implementar rotinas de operação estratégica, normalmente baseados em alguma técnica de programação matemática como programação linear, não-linear, dinâmica, redes neurais artificiais e, mais recentemente, métodos de busca direta como Algoritmos Genéticos (AGs), Ant Colony Optimization Algorithms e Simulated Annealing. O autor apresentou uma completa revisão bibliográfica sobre os trabalhos desenvolvidos nesta área. 


\subsubsection{Otimização em Tempo Real}

Dentre os trabalhos desenvolvidos sobre a operação em Tempo Real destacam-se os escritos por: Coulbeck (1987) e (1988); Lansey \& Awumah (1994); Nitivattananon et al. (1996); Orr et al. (1999); Vicente (2005); Ribeiro (2005); Jamieson et al.(2007); e, Moreira (2008). Alguns softwares comerciais também foram desenvolvidos para solucionar o problema da otimização da operação de sistemas de abastecimento de água em tempo real, conforme descritos adiante.

Segundo Coulbeck (1987), os resultados de pesquisas desenvolvendo algoritmos nas áreas de computação matemática e técnicas de controle de engenharia para sistemas de abastecimento de água levaram ao desenvolvimento de uma série de programas computacionais, dentre os quais destacam-se:

- GINAS: um programa computacional desenvolvido para modelar e simular o comportamento dos sistemas de abastecimento e distribuição de água.

- GIPADS: desenvolvido para representar o funcionamento das bombas de maneira adequada para uso em modelos de simulação e algoritmos de otimização.

- GICAC: um pacote de calibração que prevê o ajuste automático de certos parâmetros do modelo, tais como coeficientes de perda de carga.

- GIPOS: otimiza sub-sistemas compostos de grupos de bombas em paralelo de velocidades fixa e variadas, suprindo um único reservatório a partir de uma única fonte hídrica.

- GIMPOS: otimiza sub-sistemas com múltiplas fontes de suprimento de água conduzindo a um único reservatório. 
- GIPAD: é usado para previsão de demandas diárias ou semanais. As previsões são baseadas na extrapolação dos dados de tendências de demandas armazenados e correntes.

- TELSIM: faz a interface entre os dados de telemetria e o simulador hidráulico GINAS.

Coulbeck (1987) cita ainda aplicações destes programas computacionais a alguns sistemas de abastecimento de água de cidades no Reino Unido e, apesar desse trabalho ser bastante arrojado, principalmente considerando a época em que foi desenvolvido, os dados disponíveis sobre as técnicas utilizadas são insuficientes para qualquer avaliação.

Coulbeck et al. (1988) descreveram os módulos básicos e procedimentos necessários para o sucesso da implementação da otimização da operação de sistemas de distribuição de água em tempo real automática, ou seja, sem a interferência do operador do sistema. $\mathrm{O}$ esquema inclui módulos de previsão de demandas, otimização da operação das bombas e simulador hidráulico, todos acoplados ao sistema de telemetria. Ou seja, a partir do sistema de telemetria interligado TELSIM obtém-se os dados atuais do sistema; com base nesses dados, o previsor de demandas GIPAD gera as novas estimativas de demandas para as próximas 24 horas; com base nessa previsão, na estrutura tarifária da energia elétrica, nos dados atuais do sistema (níveis de reservatórios, status de bombas e válvulas e etc.), interligados à esquematização do sistema de distribuição de água modelados no GIPAD e GINAS, o otimizador GIPOS gera os comandos para operação ótima deste sistema para as próximas 24 horas; e, finalmente, estes comandos são repassados ao sistema novamente pelo TELSIM. A cada nova atualização de dados pelo sistema de telemetria, novos comandos operacionais otimizados para as próximas 24 horas são gerados. Assim, possíveis erros gerados durante todo o processo são corrigidos, o que caracteriza a operação em tempo real. É citado também que esse esquema vinha sendo aplicado a um sistema de distribuição de água de uma cidade 
no Reino Unido, sem que fosse apresentado qualquer resultado desta implementação. Apesar desse trabalho ser mais detalhado que o anterior (Coulbeck, 1987) e trazer as bases necessárias para operação de sistemas de distribuição de água em tempo real, também não apresenta as técnicas utilizadas.

Lansey \& Awumah (1994) desenvolveram uma aproximação para incluir o acionamento de bombas como variáveis de decisão de um modelo de minimização dos custos de operação de sistemas de abastecimento de água utilizando programação dinâmica.

O objetivo era criar regras de operação para o horizonte de planejamento de 24 horas, de forma a minimizar os custos com energia elétrica, limitando o número de acionamentos das bombas. Segundo os autores, regras operacionais com grande quantidade de acionamentos (liga/desliga) das bombas podem até reduzir os custos com energia elétrica; no entanto, podem aumentar consideravelmente os custos de manutenção das bombas. Tais custos não foram quantificados, todavia admitiu-se que quanto maior for o número de acionamentos das bombas maior seria o custo de manutenção.

Nitivattananon et al. (1996) apresentaram um modelo de otimização para a operação em tempo real que utiliza a técnica de programação dinâmica associada a métodos heurísticos para discretizar as vazões e rearranjar a estratégia de liga/desliga das bombas.

Os autores propuseram a decomposição do problema de duas maneiras: (1) decomposição espacial, através da qual o sistema original é dividido em vários sub-sistemas, reduzindo a dimensionalidade dos problemas para viabilizar o emprego da técnica de programação dinâmica e tornar o tempo de processamento computacional apropriado à proposta de tempo real; e, (2) decomposição temporal, que admite o problema de otimização 
em dois níveis, longo e curto prazo, cobrindo os períodos de planejamento mensal e operacional (diário), respectivamente, ambos discretizados em intervalos horários.

A proposta do modelo de longo prazo é obter as máximas vazões das bombas para estimar os custos da demanda de energia para cada estação de bombeamento. O procedimento parte de uma solução inicial factível e então, um algoritmo de otimalidade progressiva é aplicado sobre o período de planejamento e os diversos sub-sistemas, simultaneamente. O problema de otimização é resolvido para cada processo iterativo (um passo de tempo). A cada iteração, a trajetória dos volumes dos reservatórios é mantida fixa, exceto para um par de passos temporais adjacentes. Apenas o volume do reservatório desse intervalo de tempo pode variar e a melhor vazão da bomba é assim encontrada. Este processo continua ao longo de vários passos de tempo até os volumes dos reservatórios convergirem (a diferença entre dois valores sucessivos computados obedeça a certo nível de tolerância pré-especificado). Finalmente, o conjunto de soluções em termos das vazões das bombas é discretizado e assim é possível estimar as demandas de energia.

O modelo de curto prazo é utilizado para atualizar as soluções do modelo de longo prazo. Os dois modelos são similares, com exceção do período de planejamento; as vazões das bombas no modelo de curto prazo devem ser discretas; e a demanda calculada no modelo de longo prazo é utilizada como uma restrição adicional nas demandas máxima no modelo de curto de prazo.

Este modelo de otimização foi aplicado a parte do sistema de distribuição de água da cidade de Pittsburgh, com o objetivo de comparar os custos obtidos usando o modelo otimizador criado com os respectivos custos estimados com base nas rotinas de operação praticadas, para um ano teste.

O modelo de longo prazo foi simulado para um mês de faturamento no verão e outro no inverno. Durante estes mesmos meses, o modelo de curto prazo determinou as operações 
ótimas diárias das bombas, usando os dados históricos de demanda do ano de 1989. O tempo computacional gasto foi de 1 e 30 minutos para os modelos de curto ( 24 horas) e longo prazo (30 dias), respectivamente.

A comparação entre os valores de energia elétrica estimados de acordo com a operação praticada para o ano estudado e os valores calculados de acordo com a operação otimizada das bombas apontou uma redução média de $20 \%$ a favor da otimização, variando de 5,1 a $24,1 \%$ de acordo com a estação de bombeamento.

Da forma como apresentado, o modelo e sua aplicação se enquadram melhor como Planejamento Operacional Estratégico do que Operação em Tempo Real, uma vez que a operação ótima para 24 horas não é atualizada a cada intervalo de tempo, de acordo com os níveis dos reservatórios do sistema e as demandas verificadas a cada hora, o que caracterizaria o tempo real. No entanto, entende-se que estas atualizações horárias poderiam ser introduzidas no modelo de geração da estratégia operacional ótima para as 24 horas, sendo implementada apenas as decisões relativas ao primeiro intervalo horário a cada vez.

Orr et al. (1999) apresentaram basicamente uma visão geral sobre as principais características e considerações para execução de modelagem hidráulica em tempo real de sistema de abastecimento de água e a integração e gerenciamento das informações de um sistema SCADA (Supervisory Control And Data Acquisition) com o simulador.

Segundo os autores, uma implementação dos procedimentos de modelagem em tempo real foi incorporada com o suporte de um pacote de modelagem hidráulica largamente utilizado $\left(\mathrm{H}_{2} \mathrm{ONET}\right)$, como parte de um procedimento de modelagem padrão. No entanto, o artigo não apresenta detalhes dessa implementação. 
Vicente (2005) propôs um modelo operacional composto de uma ferramenta de otimização integrada com um sistema SCADA, um módulo de previsão de demandas e um simulador hidráulico comercial. Esse modelo foi aplicado a parte do sistema adutor metropolitano de São Paulo, com o objetivo de minimizar o consumo de energia elétrica associado à operação de bombeamento.

O modelo previsor de demandas, baseado na Série de Fourier, atualiza coeficientes harmônicos de forma diária, com ciclos de 7 dias e correção através de um coeficiente que relaciona os valores previstos com os observados em um período de tempo imediatamente anterior à previsão.

O modelo utiliza o simulador hidráulico WaterCAD para o cálculo hidráulico e programação linear - software Premiun Solver Platform, Frontline Systens, Inc - para o processo de otimização, fazendo uso de procedimento iterativo para contornar os problemas relativos às não-linearidades inerentes ao problema.

A comunicação entre o modelo de previsão e o SCADA é rápida. A previsão de demanda para as 24 horas em todos os reservatórios é feita em até 12 minutos, verificada a cada 30 minutos e recalculada a cada 3 horas.

A simulação hidráulica para o horizonte de planejamento e a otimização das operações de bombeamento consomem, em média, 45 minutos de processamento computacional, sendo que o tempo para o modelo convergir depende da solução inicial. Salienta-se que este tempo demandado acaba por dificultar a utilização deste modelo na operação em tempo real.

O estudo de caso realizado confirmou a economia de energia elétrica através da execução do conjunto de controles otimizados gerados pelo modelo proposto. No entanto, este modelo otimizador nem sempre apresentou resultados factíveis, principalmente devido à não inclusão de todas as restrições hidráulicas reais. 
Apesar de o trabalho propor a otimização da operação em tempo real e citar que o problema desenvolvido é um problema de planejamento operacional com um horizonte diário, em que a freqüência de operação é horária, não foi aplicada a Operação em Tempo Real, com intervalos de atualização dos dados do sistema pelo SCADA horários, e sim o Planejamento Operacional em Nível Estratégico das bombas para o horizonte de planejamento de 24 horas com atualização dos dados do sistema pelo SCADA apenas da primeira hora.

Ribeiro (2005) também propôs um modelo operacional para avaliação dos AGs como ferramenta de otimização de sistemas de abastecimento de água em tempo real. Esse é composto pelo simulador hidráulico EPANET 2.0, algoritmo de otimização via técnica dos AGs e os registros históricos operacionais, considerados como previsão perfeita das demandas, e foi aplicado a uma alça do Sistema Adutor Metropolitano de São Paulo denominada SAM Leste.

O SAM Leste possui 10 reservatórios, 75,66 quilômetros de adutoras, 1 estação elevatória, 3 boosters, 9 válvulas de controle de vazão e 6 válvulas redutoras de pressão.

Foram otimizados 33 cenários com variações dos níveis iniciais de operação dos reservatórios, parâmetros dos AGs e pesos das penalidades, chegando aos seguintes resultados:

- O melhor cenário indicou redução nos custos com energia elétrica da ordem de $22 \%$, R \$ 25.000,00, com relação à operação usualmente feita pela SABESP na época;

- Baixas taxas de recombinação (30\%) produziram melhores resultados na otimização do que taxas elevadas $(80 \%)$;

- O tempo computacional demandado foi de 3 horas e 20 minutos para simular 24 horas de operação, computador Pentium 4 com 2.2GHz de velocidade (excessivamente longo para aplicações em Tempo Real). 
Apesar de esse trabalho propor a avaliação dos AGs na otimização da operação de sistemas de abastecimento de água em tempo real, não foi aplicada a Operação em Tempo Real, com intervalos de atualização dos dados do sistema pelo SCADA horários, e sim o Planejamento Operacional em Nível Estratégico das bombas para o horizonte de planejamento de 24 horas, assim como o trabalho desenvolvido por Vicente (2005).

O projeto POWADIMA - POtable WAter DIstribution MAnagement - foi instituído pela Comissão Européia, durante o V Framework em Energia, Meio-Ambiente e Desenvolvimento Sustentável, com objetivos de: (1) auxiliar a indústria da água na redução dos custos operacionais e das perdas e beneficiar os usuários em termos de vazões; (2) aumentar a qualidade dos serviços prestados em termos de adequação das pressões, qualidade da água e continuidade no abastecimento; (3) contribuir para um futuro sustentável através da redução das demandas dos recursos hídricos e promoção da eficiência energética; (4) e, fornecimento de experiência técnica tanto para as companhias particulares e instituições acadêmicas diretamente implicadas (http://www.ncl.ac.uk/powadima).

O desenvolvimento desse projeto envolveu a elaboração de um software genérico de otimização da operação de sistemas de abastecimento de água em tempo real, para dar suporte aos operadores na seleção das melhores estratégias operacionais visando à redução dos custos operacionais e à promoção de um abastecimento confiável e operações mais seguras.

As técnicas utilizadas para o desenvolvimento desse software e os resultados obtidos foram publicados na edição especial do Journal of Hydroinformatics. São seis artigos (Jamieson et al., 2007; Rao e Alvarruiz, 2007; Rao e Salomons, 2007; Alvisi et al., 2007; Salomons et al. 2007; e, Martínez et al., 2007), detalhados a seguir.

Posteriormente, em 2008, Shamir e Salamons publicaram um artigo sobre a utilização desse software a um modelo reduzido de sistema de distribuição de água. 
Jamieson et al. (2007) apresentaram um artigo introdutório sobre os trabalhos produzidos ao longo do desenvolvimento do projeto POWADIMA, que culminaram no software de otimização. Este foi desenvolvido sobre a premissa de que para avaliar as estratégias operacionais otimizadas de bombas e válvulas é necessário calcular não apenas o conjunto de comandos atuais mas aqueles ao longo do horizonte de operação, buscando selecionar a estratégia de menor custo. Todavia, apenas o conjunto de controles ótimos para o passo atual deve ser implementado. Após a atualização dos dados do sistema (níveis dos reservatórios) é realizada a previsão de demandas antes do processo ser repetido e uma nova estratégia de operação ser gerada. Assim, o processo de controle operacional otimizado é realizado ao longo do tempo, adaptando a operação de acordo com o comportamento do sistema durante o processo.

O modelo proposto utiliza uma aproximação ao substituir o simulador hidráulico convencional pelo uso das redes neurais artificiais (RNA). As RNA após serem "treinadas" para usar valores de entrada e prever valores de saída podem ser utilizadas em substituição ao simulador hidráulico. O simulador hidráulico é utilizado apenas para produzir resultados para treinamento da RNA. Após treinada e testada, a RNA é embutida num processo de otimização cuja função é selecionar a melhor combinação de controles de bombas e válvulas para satisfazer as demandas atuais e futuras para o horizonte de operação com custos mínimos de energia e obedecendo as restrições operacionais. O processo de otimização selecionado é baseado em algoritmos genéticos (AGs).

Rao e Alvarruiz (2007) escreveram o segundo artigo, tratando especificamente da utilização das Redes Neurais Artificiais em substituição aos simuladores hidráulicos convencionais. Segundo os autores, o modelo selecionado para prever as conseqüências de 
diferentes conjuntos de controles (operação de componentes tais como válvulas e bombas dos sistemas) com vistas à otimização da operação em tempo real deve ser computacionalmente eficiente, acurado e numericamente robusto. Os simuladores hidráulicos atendem aos requisitos de acurácia e robustez, mas podem ser impraticáveis para a operação em tempo-real de grandes sistemas de distribuição de água, devido ao tempo computacional necessário. Modelos hidráulicos simplificados são computacionalmente eficientes, mas a acurácia e robustez dos mesmos é questionável. As RNAs são computacionalmente eficientes e robustas, mas requerem uma grande quantidade de padrões (entrada-saída) para treinamento e teste. Portanto, o projeto POWADIMA utilizou dados produzidos simulador hidráulico convencional para os propósitos de treinamento e teste das RNAs.

Para teste desta proposição foi escolhido o sistema 'Any Town', amplamente estudado na literatura. No entanto, visando tornar a otimização uma tarefa mais desafiadora, mudanças foram introduzidas nesse sistema, tais como a adição de um reservatório e tubos na porção noroeste da rede original. O sistema resultante foi chamado de 'Any Town (Modified)' ou $\mathrm{AT}(\mathrm{M})$. A rede $\mathrm{AT}(\mathrm{M})$ possui 41 tubos e 19 nós, com 3 bombas de velocidade fixa e 3 reservatórios.

O sistema AT(M) foi modelado utilizando o pacote de simulação hidráulica EPANET. O tempo entre um passo e outro adotado foi de uma hora. Foi proposto um modelo de RNA de uma camada oculta, sendo a camada de entrada dotada de 5 neurônios (valores de entrada: o primeiro representando o número de bombas em uso; o segundo a demanda agregada para os 19 nós consumidores e os 3 níveis iniciais de água, um para cada reservatório) e a camada de saída de 7 neurônios (valores de saída: a potência total consumida pelas bombas, as pressões nos 3 nós representativos da rede (170, 90 e 55) e os níveis resultantes em cada qual dos 3 reservatórios). Através do método de tentativa e erro, uma boa representação do modelo do EPANET foi encontrada com 20 neurônios na camada oculta (intermediária), resultando 
numa estrutura final de $\operatorname{RNA}(5,20,7)$. A vantagem computacional deste método é uma redução média de 10 vezes o tempo necessário para prever as conseqüências de diferentes conjuntos de controles em comparação com o simulador hidráulico convencional. Os desvios entre os resultados do EPANET e da RNA foram inferiores a 0,06 metros, para níveis dos reservatórios, e 0,40 metros para pressão.

O artigo desenvolvido por Rao e Salomons (2007) foca a seleção da melhor combinação de conjuntos de controles não apenas para o a situação presente, mas também as condições esperadas durante o horizonte de operação no sentido de minimizar os custos com bombeamento. A tecnologia dos AGs foi utilizada para otimização do controle operacional.

A inicialização do conjunto de controles (variáveis de decisão) é aleatória. Portanto, o conjunto de controles é usado como entrada para a RNA, que estima as pressões e vazões resultantes, assim como os níveis nos reservatórios e potências necessárias, a cada passo no horizonte de operação. O valor da aptidão de cada solução de AG é avaliado com base nos custos operacionais, ao qual são adicionados custos de penalidade para qualquer violação das restrições. Após a geração aleatória da população inicial do $A G$, e a avaliação de cada solução, então engaja-se no AG, quando parentes são selecionados e acontecem croos-over e mutação, produzindo nova combinações de conjuntos de controle. Este novo conjunto de controles é utilizado como entrada na RNA e todo o processo é repetido até que se atinja o número máximo de gerações do AG. A melhor combinação de controles encontrada ao fim do processo de busca é referida como a solução quase ótima.

Antes da re-inicialização do conjunto de controles para o próximo passo no tempo, a previsão é realizada com base nos dados de demanda atualizados com as informações observadas uma hora atrás. Tal previsão é então utilizada como entrada para a RNA e o AG no próximo passo. Tendo computado a nova estratégia operacional, o conjunto de controles 
para o tempo corrente são implementados via SCADA, enquanto a porção restante espera pela re-inicialização das variáveis de controle com a nova atualização dos dados atuais do sistema pelo SCADA. Todo este sistema de controle dinâmico foi chamado de DRAGA-ANN (Dynamic Real-time Adaptive Genetic Algorithm - Artificial Neural Network).

Alvisi et al. (2007) desenvolveram o modelo previsor de demanda para tempo real consistente com as necessidades do otimizador DRAGA-ANN. Segundo os autores, o modelo reproduz as periodicidades observadas nos níveis anuais, semanais e diários para estimar os valores das demandas futuras.

A cidade escolhida para estudo das flutuações de demanda em curto prazo foi a cidade italiana de Castelfranco Emilia. A análise das demandas de água horárias e diárias revelou a existência de padrões em que é possível identificar periodicidades sazonal e semanal das demandas de água bem como periodicidades diárias nas demandas horárias.

O modelo previsor proposto é baseado nos padrões implícitos nas séries temporais de dados de demanda de água e por esta razão, é referido como modelo previsor de demanda de água baseado em padrões. No primeiro dos dois módulos a sazonalidade e padrões semanais são levados em conta, junto com a persistência de médio prazo. No segundo módulo, estas configurações diárias são combinadas com os padrões de demandas diárias e a persitência de curto prazo gera as previsões horárias sobre o correspondente período de 24 horas.

Uma análise dos resultados obtidos mostra que o modelo é capaz de gerar uma previsão robusta e acurada das futuras demandas de água na base horária.

Salomons et al. (2007) escreveram sobre o primeiro estudo de caso do projeto POWADIMA. Foi realizado para Haifa, Israel, na parte A do sistema de distribuição de água da cidade que compreende cerca de $20 \%$ do sistema, servindo uma população de 60 mil 
habitantes. O modelo simulador hidráulico é composto por 126 tubulações, 112 nós, 9 reservatórios, 1 válvula redutora de pressão e 17 bombas em 5 diferentes estações de bombeamento.

A RNA escolhida tem 29 valores de entrada (neurônios de entrada), 80 neurônios na camada intermediária e 15 valores de saída (neurônios de saída). Os valores de entrada compreendem 13 variáveis representativas do status de funcionamento das bombas (on/off), 9 níveis de reservatórios em cada instante (t) representativo do início do passo de tempo em estudo, 6 demandas correntes (uma para cada zona de pressão) e 1 controle de válvula (10 $50 \mathrm{~m}$ de pressão). Os valores de saída são 5 potências consumidas de bombas (uma para cada estação de bombeamento), 9 níveis de reservatório no instante $(\mathrm{t}+1)$, representativos do final do passo de tempo considerado, e 1 pressão no nó crítico do sistema. A RNA foi treinada com 12.000 pares de vetores entrada/saída e testada com mais 5.000 pares. Os desvios em termos da raiz quadrada média (RMSEs) dos dados normalizados foi 0.449 e $0.481 \%$ para os conjuntos de treinamento e teste, respectivamente.

Cada solução de AG é representada por uma cadeia de 408 bits, com 1 bit para cada bomba e 4 bits para a válvula redutora de pressão, em cada intervalo do horizonte de operação de 24 horas. O AG operou com uma população de tamanho 50, probabilidade de cross-over de 0,76 e de mutação de 0,002 . O tamanho do torneio selecionado foi 4 e o número de gerações foi 1000 .

Este pacote de otimização foi aplicado ao sistema A de Haifa para todo o ano de 2000. Como não estavam disponíveis os dados de demanda deste sistema, foram utilizados dados de demanda de uma cidade com características urbanas similares e mesma área. Os dados horários dos custos com energia elétrica também não estavam disponíveis, portanto foi adotada uma tarifa elétrica qualquer. 
O EPANET simulou o comportamento do sistema, considerando a prática operacional corrente para o ano 2000, com as mesmas demandas e tarifa energética utilizada na versão otimizada. Como resultado, a economia potencial de energia elétrica com a otimização foi estimada em 25,4\%. A avaliação também mostrou a melhora na performance em termos dos serviços aos consumidores, no que se refere aos níveis de pressão e vazão.

Apenas o conjunto de controles do passo atual determinados pela otimização é implementado, assim uma nova estratégia de operação é gerada com a nova atualização pelo sistema SCADA. No entanto, são geradas estratégias operacionais otimizadas para todas as 24 horas. O conjunto de operações para as 24 horas do dia, a cada hora durante o ano, foi avaliado pelo EPANET, usando o mesmo conjunto de controles que foi implementado no processo AG-RNA. Nestas condições foi encontrado que em 1.234 de 8.784 otimizações horárias para um ano (14\%), os níveis d'água no final do período de 24 horas do período de operação excede a faixa de tolerância para pelo menos um reservatório do sistema, como resultado da acumulação de erros. Segundo os autores, AG-EPANET pode ser utilizado em substituição ao AG-RNA em situações em que não haja restrições do tempo computacional demandado, eliminando assim uma possível fonte de erro.

O AG-RNA mostrou-se aproximadamente 25 vezes mais rápido do que AG-EPANET para o sistema de 112 nós investigado, o que não significa que o AG-RNA seja 25 vezes mais rápido que o AG-EPANET, uma vez que parte substancial deste tempo é demandado pelo AG.

O segundo dos dois estudos de caso do projeto POWADIMA, desenvolvido por Martínez (2007), foi realizado para o sistema de distribuição de água da cidade de Valência, Espanha, que abastece uma população de aproximadamente 1,2 milhões de habitantes e é abastecido por água superficial via duas estações de tratamento que possuem diferença 
significante de custos de tratamento. Os reservatórios disponíveis estão localizados na saída das estações de tratamento, sendo que cada qual possui sua estação de bombeamento. O gerenciamento do sistema é uma complexa operação envolvendo 4 zonas de pressão e 49 válvulas operadas, das quais 10 ajustadas rotineiramente. A estrutura de tarifa de energia varia com a hora do dia e o mês do ano. Um modelo de simulação foi criado no EPANET com 725 nós, 10 válvulas operacionais, 2 reservatórios e 17 bombas reunidas em 2 estações de bombeamento. O sistema de controle foi implementado compreendendo um modelo de rede neural artificial em substituição ao EPANET e um algoritmo genético dinâmico para otimizar o controle do conjunto de bombas e válvulas durante o horizonte de 24 horas.

A RNA definida tem 24 neurônios na camada de entrada, 100 na camada intermediária e 15 na camada de saída. Os valores de entrada compreendem o status operacional de 6 grupos de bombas (on/off), o conjunto de 10 válvulas de controle remoto, as demandas das 6 zonas de pressão e o nível inicial dos dois reservatórios. Os valores de saída são a potência consumida nos 6 grupos de bombas, a pressão nos 4 nós críticos, a vazão em 3 pontos críticos e os níveis de água resultantes nos 2 reservatórios. O número de vetores usados para o estágio de treinamento foi de cerca de 2.500 e foram gerados aleatoriamente usando o EPANET. Mais 800 vetores foram utilizados para o processo de teste. O RMSE dos dados normalizados foi de 1,20 e $1,30 \%$ para os conjuntos de treinamento e teste, respectivamente.

Cada cadeia representativa da solução do AG consistia em 1368 bits, com 1 bit para cada uma das 17 bombas e 4 bits para cada uma das 10 válvulas operacionais, para cada passo durante o horizonte operacional. Baseado em centenas de testes, uma combinação robusta de parâmetros de AG foi encontrada: população inicial de tamanho 50; probabilidade de crossover e de mutação de 0,765 e 0,002 , respectivamente; tamanho do torneio de 4 ; e 2.000 gerações. 
O DRAGA-ANN foi aplicado ao sistema de Valência, considerando os dados de demanda para todo o ano de 2001. A economia potencial estimada para custos operacionais do período do modelo otimizado varia de acordo com o mês do ano, de 13,4\% em agosto a $19,75 \%$ em maio, sendo em média de $17,6 \%$.

O estudo aplicado ao sistema de Valência demonstrou a completa capacidade do DRAGA-ANN em operar sistemas complexos e de grande porte. O ganho computacional usando a RNA em substituição ao EPANET foi ainda maior do que no sistema Haifa-A. Para o sistema de Valência de 725 nós a AG-RNA é 94 vezes mais rápida que o AG-EPANET.

Sem dúvida este projeto representa um referencial na área de otimização da operação de sistemas de abastecimento de água em tempo real. Os resultados apresentados demonstram que o modelo utilizado é bastante eficiente.

Salomons et al. (2008) aplicaram o software desenvolvido durante o projeto POWADIMA na parte B do sistema de distribuição de água de Haifa, Israel. Eles substituíram a utilização das redes neurais por um modelo reduzido (esqueletizado) do sistema.

O algoritmo desenvolvido por Ulanici et al. (1996) foi utilizado para criar o modelo reduzido do sistema Haifa-B. O algoritmo procede em uma eliminação passo-a-passo de nós e tubos, alocando as demandas dos nós eliminados para os nós vizinhos. Obviamente todas as bombas, válvulas e reservatórios permanecem no modelo reduzido.

O sistema completo de distribuição de água de Haifa-B possui 867 nós, 987 tubos, 9 reservatórios, 17 bombas em 5 estações elevatórias, 8 válvulas redutoras de pressão e seis áreas de demandas. Já o sistema reduzido possui 77 nós e 92 tubos, uma redução de aproximadamente 10 vezes, e tempo computacional de simulação 15 vezes inferior.

Os autores "rodaram" os primeiros 15 dias de janeiro de 2004 com o sistema completo, conectado ao AG, e compararam aos custos com a operação usualmente feita no sistema. A 
economia foi de aproximadamente $12 \%$ para esses 15 dias. Esse experimento demandou extensivo tempo computacional, sendo impraticável para otimização em tempo real.

O modelo reduzido conectado ao AG foi simulado para dois meses do ano de 2004, Janeiro (baixa demanda) e Julho (alta demanda), obtendo-se economia em relação a operação usualmente feita no sistema da ordem de 11 e $8 \%$, respectivamente. O tempo computacional demandado para simular um mês é de aproximadamente 8 horas em um computador Pentium4, 2 GHz IBM com 1.5 GB RAM.

Moreira (2008) apresentou uma alternativa para a resolução do problema de otimização operacional de sistemas de abastecimento de água, propondo e testando um procedimento de minimização do consumo de energia elétrica em tempo real, via algoritmo genético, em dois níveis (nível estratégico e nível operacional), e uso de modelo de previsão de demandas.

O modelo desenvolvido foi testado em parte do sistema de distribuição de água da cidade de São Carlos - SP, abrangendo o setor comercial 11 e uma pequena parcela do setor 10, constituído por quatro reservatórios: Parque Fehr, Jardim Ipanema, São Carlos III e Santa Felícia, que abastecem cerca de $25 \%$ da cidade.

Uma das primeiras fases da pesquisa constituiu no cadastramento digital da rede de abastecimento de água utilizada e lançamento da topologia no EPANET - Figura 2.1. Posteriormente foi realizada a filtragem dos dados de vazão obtidos junto ao SAAE-São Carlos (Superintendência Municipal de Água e Esgoto de São Carlos), para os reservatórios que possuíam medidores on-line na saída (Parque Fehr e São Carlos III), e a construção de curvas típicas de demanda para 24 horas. Uma vez que a variação dos perfis observados para todos os dias da semana foi muito pequena, foi adotada a curva média dos 07 dias como representativa da curva de padrão de demanda de cada sistema de reservação. 


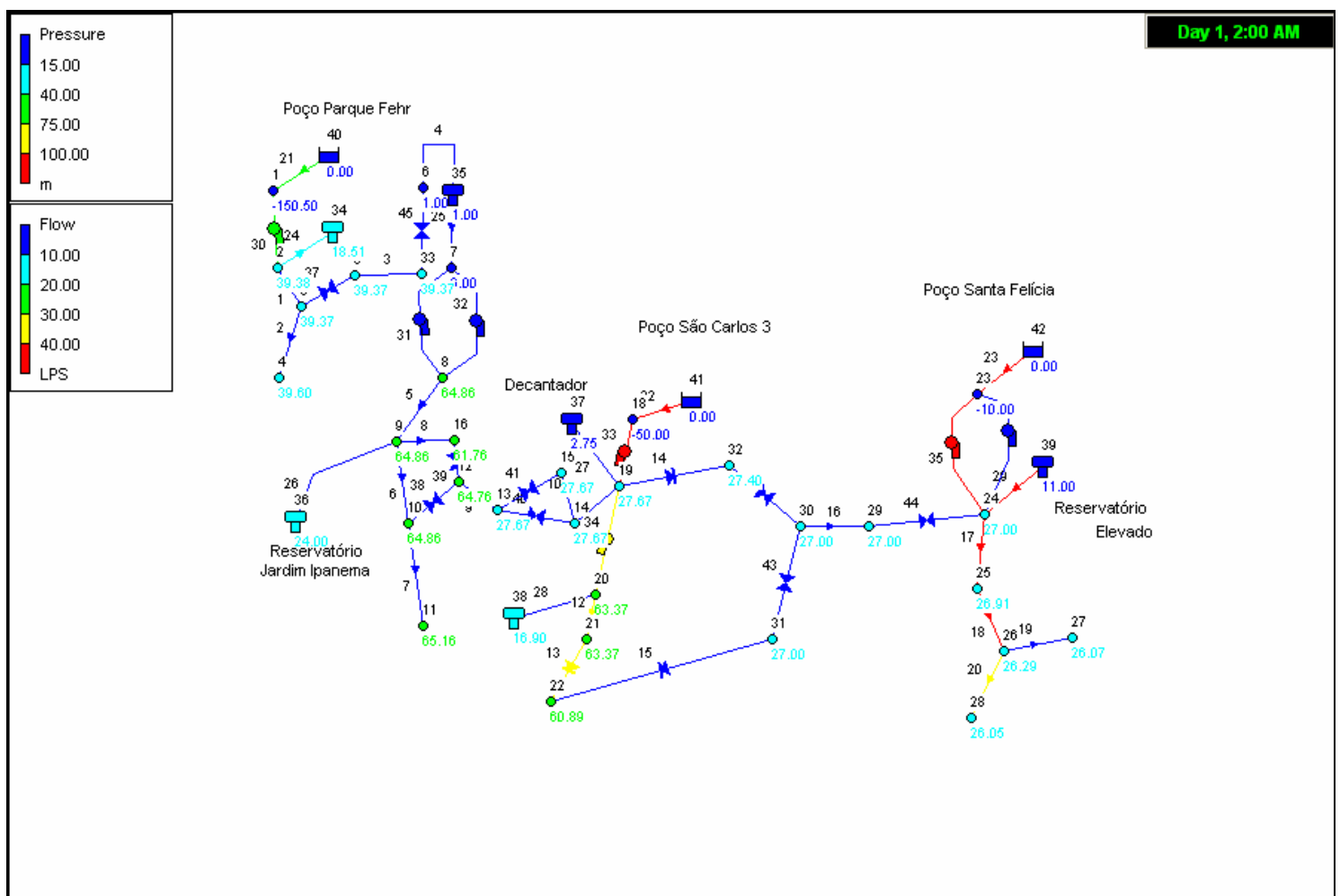

Figura 2.1 - Representação no EPANET do sistema estudado por Moreira (2008).

Para a minimização dos custos de energia foi proposta uma otimização com objetivo único, considerando restrições hidráulicas do tipo: pressões mínimas de abastecimento não inferiores a $10 \mathrm{mH} 2 \mathrm{O}$ e o desnível entre os níveis inicial e final de cada reservatório do sistema. O algoritmo genético busca soluções que satisfaçam a função objetivo e o EPANET testa se tais soluções violam as restrições impostas. O resultado dessa otimização foi uma trajetória para os níveis dos reservatórios, denominados níveis meta, a serem perseguidos pelo planejamento da fase operacional.

O planejamento operacional foi então iniciado a partir da aplicação do modelo previsor de demandas baseado na série de Fourier móvel, considerando o horizonte de previsão de 24 horas à frente. Estabeleceu a cada passo (hora) a estratégia operacional ótima para as próximas 24 horas, sendo que somente a solução obtida para a primeira hora seria efetivamente implementada. Atualizaram-se os dados de demanda e relativos ao estado do sistema e nova otimização foi realizada, e, assim, sucessivamente. 
Com relação à eficiência energética, os resultados obtidos pelo programa foram comparados com os dados do SAAE, considerando o Planejamento em nível Estratégico e Operacional, para o mês de referência de outubro de 2006. Foram obtidos os regimes de operação de bombas, válvulas e variação de nível dos reservatórios junto ao SAAE para que pudesse ser realizado este estudo comparativo.

O planejamento em nível operacional atualizado (tempo real) obteve os resultados mais expressivos de economia de energia elétrica quando comparados aos resultados do SAAE, algo em torno de $27 \%$ e que o planejamento em nível estratégico sugere uma economia de 16,4\% - Tabela 2.1. O Planejamento em nível operacional indicou ganhos também quando comparado ao Nível Estratégico, 12,4\%.

Tabela 2.1 - Custos mensais de energia elétrica e comparativo entre o Planejamento da operação do SAAE, Estratégico e Operacional atualizado, Moreira (2008).

\begin{tabular}{|c|c|c|c|c|c|c|}
\hline \multirow{2}{*}{ Estaçäo de Bombeamento } & \multicolumn{2}{|c|}{ Planejamento SAAE } & \multicolumn{2}{|c|}{ Planejamento estratégico } & \multicolumn{2}{|c|}{ Planejamento Operacional } \\
\hline & Kwatt & Custo Mensal (R\$) & Kwatt & Custo Mensal (R\$) & Kwatt & Custo Mensal (R\$) \\
\hline Parque Fehr & 4.38 & 7390.20 & 2.56 & 4630.65 & 6.13 & 9072.96 \\
\hline Jardim Ipanema-01 & 9.60 & 376.80 & 5.82 & 320.70 & 5.59 & 281.40 \\
\hline Jardim Ipanema-02 & 12.11 & 363.30 & 10.66 & 324.30 & 29.44 & 624.30 \\
\hline Sẫo Carlos III-01 & 36.04 & 4529.40 & 58.17 & 12668.40 & 32.22 & 5753.70 \\
\hline São Carlos III-02 & 78.95 & 18010.20 & 42.32 & 7388.40 & 32.25 & 5888.70 \\
\hline Santa Felícia-01 & 65.65 & 17346.60 & 52.34 & 15082.20 & 39.33 & 12326.10 \\
\hline Santa Felícia-02 & 66.28 & 17743.50 & 31.47 & 14531.40 & 29.76 & 14167.50 \\
\hline Média (Kwatts)/Custo Total & 39.00 & 65760.00 & 29.05 & 54946.05 & 24.96 & 48114.66 \\
\hline Eficiência & Estratégico/S & $16.4 \%$ & acional/ & $26.8 \%$ & ional/Estr & $12.4 \%$ \\
\hline
\end{tabular}

Esse modelo apresentado por Moreira (2008) é considerado um pseudo-modelo, uma vez que, foi necessário estabelecer correlações para obtenção de dados inexistentes.

Além dos estudos citados anteriormente, a literatura especializada reporta pesquisas visando o desenvolvimento de softwares que resolvessem a problemática da otimização da operação de sistemas de abastecimento de água em tempo real, com caráter comercial, cujo cliente principal seria a indústria da água. O principal atrativo para essas companhias de água é a possibilidade de reduzir, com a utilização de tais softwares, os custos operacionais, através do melhor gerenciamento das pressões no sistema e redução das despesas com energia elétrica. Dentre esses programas destacam-se o FINESSE e o ENCOMS, descritos a seguir. 
Cabe ressaltar que as bases técnicas de desenvolvimento desses programas não foram explicitadas, o que dificulta a obtenção de detalhes que permitam melhor entendimento e conhecimento das técnicas utilizadas. Acredita-se que essa dificuldade se deva principalmente ao caráter comercial destes softwares.

\section{FINESSE}

Como continuidade dos trabalhos desenvolvidos por Coulbeck (1987) foi desenvolvido o projeto WaterCIME (WSS - 2004), que envolveu um consórcio entre oito entidades de cinco países europeus. As pesquisas da WSS tiveram como foco principal o desenvolvimento de tecnologias de otimização para solucionar problemas de controle operacional e de pressão em sistemas de abastecimento, que resultou no modelo de suporte à decisão FINESSE.

FINESSE é um pacote para modelação de sistemas de abastecimento e distribuição de água e de sistemas de drenagem. Compreende cinco módulos principais, cujas funções são: simulador hidráulico; previsor de demanda; otimizador operacional, simplificador de modelos; e modelo de calibração.

O simulador hidráulico realiza simulações dinâmicas e estáticas e tem como base técnica o software GINAS, desenvolvido por Coulbeck. Possui também uma função especial para simulações em tempo real, baseadas nas mais recentes medidas de estado do sistema como condições iniciais. O simulador é configurado para automaticamente receber dados de entrada que incluem os níveis dos reservatórios, vazões e pressões.

O modelo previsor de demanda requer seis semanas de dados históricos para funcionar, é baseado em um algoritmo de alisamento do tipo exponencial triplo.

Já o otimizador operacional calcula rotinas de bombeamento para minimização dos custos operacionais. O cálculo é baseado nos softwares GAMS e CONOPT, que utilizam programação não-linear e são usados em problemas de otimização diversos. 
O calibrador ajusta a resistência dos tubos e demandas nos nós para minimizar as diferenças entre os valores observados e simulados pelo modelo. Os valores observados podem ser obtidos on-line a partir do SCADA. O algoritmo é relativamente robusto, necessitando de trabalhos futuros para generalizar a sua aplicação on-line.

Segundo o Manual Técnico do FINESSE (http://www.eng.dmu.ac.uk/wssys/), esse está sendo testado: (1) pela Société du Canal de Provence para otimização da operação on-line de um sistema de irrigação; e, (2) Société Wallonne des Distributions d'Eau, para otimização da operação em tempo real do sistema de distribuição de água da cidade de Verviers, na Bélgica.

\section{$\underline{\text { ENCONS }}$}

ENCOMS (Energy Cost Minimisation System) é o nome comercial dado ao software inicialmente desenvolvido pelo projeto POWADIMA, e aprimorado pela empresa Halcrow Group Ltd, com vistas à sua comercialização.

Rao, Wicks \& West (2007), colaboradores da Halcrow Group, apresentam as formas gerais de funcionamento do ENCOMS e resumem as ferramentas utilizadas no seu desenvolvimento.

\subsection{Técnicas de Otimização Aplicáveis a Sistemas de Abastecimento de Água}

Conforme pode ser verificado no item anterior, ao longo da descrição dos trabalhos existentes sobre otimização da operação de sistemas de abastecimento de água, diferentes métodos de otimização têm sido aplicados.

Tradicionalmente os problemas de otimização na década de 60 eram resolvidos usando métodos consagrados como programação linear, não-linear e dinâmica. Esses métodos 
determinísticos normalmente fazem uso do cálculo de derivadas da função objetivo para a determinação da direção de busca do ponto ótimo. Segundo Wu e Simpson (2001) as principais desvantagens dos algoritmos determinísticos são: a necessidade de cálculo de derivadas; dificuldade de adaptação a projetos com variáveis discretas, e complexidade de implementação nos trabalhos práticos de engenharia. Por outro lado, alguns desses métodos possuem grande rapidez e precisão na procura do ponto solução.

Na década de 70, as heurísticas passam a despertar mais interesse. Segundo Barr et. al. (1995) apud Ribeiro (2005), os métodos heurísticos são um conjunto de passos bem definidos para identificar rapidamente uma solução de alta qualidade para um problema, cuja solução é um conjunto de valores desconhecidos para o problema e a qualidade é definida por um critério ou uma avaliação métrica padrão.

Já nos últimos 15 anos a atenção dos pesquisadores das áreas de hidráulica e hidrologia se voltou para a utilização de técnicas meta-heurísticas, como por exemplo Redes Neurais, Lógica Fuzzy, Algoritmos Evolucionários, Árvores de Decisão, Ant Colony Optimization Algorithms, Simulated Annealing, etc.

Dentre as meta-heurísticas mais consagradas estão os Algoritmos Evolucionários (Programação Evolutiva, Programação Genética, Classificadores Genéticos e Algoritmos Genéticos), que são sistemas computacionais de solução de problemas baseados nas técnicas de evolução.

Os Algoritmos Genéticos (AGs) são os mais populares dos Algoritmos Evolucionários, uma vez que permitem o tratamento de problemas com alto coeficiente de complexidade, propriedades e comportamento não-lineares, mostrando-se robustos e eficientes.

Em recursos hídricos os AGs têm sido largamente utilizados, apresentando resultados significativos, sendo possível encontrar dezenas de trabalhos na literatura especializada. 
Carrijo (2004), Ribeiro (2005), Pedrosa (2006) e Sousa (2007) descrevem as inúmeras aplicações dos AGs para resolução de problemas relacionados a recursos hídricos.

A seguir consta uma breve descrição dos AGs, por se tratar da técnica utilizada no desenvolvimento desse trabalho, e da biblioteca utilizada para implementação do mesmo.

\subsubsection{Algoritmos Genéticos}

Os AGs foram criados por Holland na década de 60 na Universidade de Michigan e posteriormente popularizados por um de seus alunos, David Goldberg.

Em contraste com outras técnicas evolutivas, a grande idéia de Holland foi de estudar o fenômeno de adaptação como ele ocorre na natureza e desenvolver caminhos através dos quais os mecanismos de adaptação natural pudessem ser importados para os sistemas computacionais (Goldberg, 1989).

O primeiro trabalho publicado sobre AG foi em 1975, nos Estados Unidos, com o título: Adaptation in Natural and Artificial Systems de autoria de John Holland. Este livro foi o marco para o desenvolvimento e aplicação dos AGs na resolução de vários problemas na área de engenharia (Carrijo, 2004).

Os AGs são métodos de otimização por busca inspirados nos mecanismos de evolução de populações de seres vivos. Estes algoritmos seguem o princípio da seleção natural e sobrevivência dos mais aptos, declarado em 1859, pelo naturalista e fisiologista inglês Charles Darwin.

Devido a essa origem os AGs possuem muitos termos provenientes da biologia. Para melhor entendimento dessa técnica, apresenta-se a seguir uma lista com os principais termos encontrados sobre o assunto na literatura: 
- Cromossomo e Genoma: os dois representam a estrutura de dados que codifica uma solução para um problema, ou seja, um cromossomo ou genoma representa um simples ponto no espaço de busca;

- Gene: é um parâmetro codificado no cromossomo, ou seja, a representação de um elemento do vetor solução (cromossomo);

- Alelo: representa os valores que um gene pode assumir;

- Indivíduo: é um simples membro da população de cromossomos ao qual corresponde um valor de aptidão (ajuste ou adaptação);

- Genótipo: representa a informação contida no cromossomo ou genoma (composição genética contida no genoma);

- Fenótipo: representa o objeto, estrutura ou organismo construído a partir das informações do genótipo. É o cromossomo decodificado;

- Epistasia: interação entre genes do cromossomo, isto é, quando um valor de um gene influencia o valor de outro gene.

- Elitismo: é uma estratégia comum nos AGs tradicionais e baseia-se na transferência de melhores cromossomos de uma geração para outra sem alterações, já que os melhores cromossomos podem ser perdidos devido à aplicação dos operadores de recombinação e de mutação. Proposto por DeJong ((1975) apud Lacerda \& Carvalho, 1999), o AG com elitismo encontra a solução mais rapidamente que o AG sem elitismo, ressaltando que o AG ocasionalmente encontra máximos locais.

De acordo com essa terminologia dos AGs, cada cromossomo, também referido como string, representa uma possível solução para o problema e uma população de cromossomos representa um conjunto de possíveis soluções. 
O primeiro passo de um AG é a geração de uma população inicial de soluções. Durante o processo de otimização, a população é avaliada e cada solução recebe um valor, denominado de aptidão (fitness).

Para criar uma nova população, cromossomos chamados descendentes são formados pela união de dois cromossomos pais da geração atual, através do operador de recombinação (crossover) e em seguida modificados, através do operador mutação. Assim, novas populações são formadas sucessivamente, mantendo as soluções (cromossomos) mais aptas e descartando as menos qualificadas, para que seja mantido o tamanho da população inicial, até a convergência para uma solução "ótima”.

A recombinação promove a troca parcial de segmentos correspondentes entre dois cromossomos pais, gerando dois cromossomos filhos. E a mutação é uma degeneração casual dos valores permitindo a introdução de novas características genéticas às populações. A Figura 2.2 ilustra os passos de um algoritmo genético.

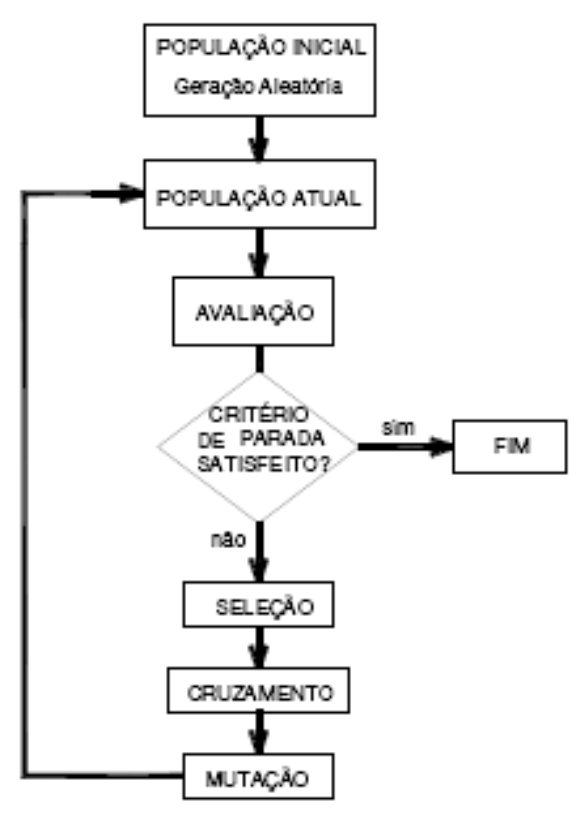

Figura 2.2 - Ciclo Básico de um AG. 


\section{$\underline{\text { Representação das soluções }}$}

Cada solução (cromossomo) para o problema em estudo é representada através de uma cadeia (string) de características necessárias à sua completa definição e que constituem as variáveis de decisão do problema. Tais características ou códigos podem ser valores binários ou reais.

A representação binária é a tradicional, sendo fácil de utilizar e manipular, além de simples de analisar teoricamente. No entanto, se um problema tem parâmetros contínuos e deseja-se trabalhar com uma boa precisão, haverá a necessidade do armazenamento de cromossomos longos na memória, os quais precisam ser decodificados para avaliação da função de aptidão. Este aspecto pode fazer com que o algoritmo tenha uma convergência vagarosa.

Contudo, a representação real (com ponto flutuante), além de gerar cromossomos menores, possui uma maior facilidade na criação de novos operadores.

\section{Operadores Genético}

Seleção

Num Algoritmo Genético torna-se muito importante definir a forma como será realizada a seleção dos indivíduos que irão constituir a nova geração. O mecanismo de seleção deve possibilitar que os indivíduos mais aptos (com índice de aptidão mais elevado) se reproduzam mais vezes para que, desta forma, a população vá melhorando ao longo das gerações. No entanto, o coeficiente de exigência deste mecanismo deve ser moderado, uma vez que uma seleção muito exigente faz com que a população seja dominada muito rapidamente pelos melhores indivíduos o que pode levar à estagnação num extremo local e, ao contrário, uma seleção pouco exigente pode tornar o processo de evolução muito lento. 
Os tipos de seleção mais usuais são Ordenamento, Roda da Roleta, Torneio, Uniforme, Amostragem Determinística e Stochastic Remainder Sampling (SRS).

De acordo com algoritmo do Ordenamento dos cromossomos na população, definindo uma aptidão arbitrária máxima para o primeiro cromossomo da população e uma aptidão mínima, também arbitrária (geralmente zero), para o último cromossomo, as demais aptidões são calculadas interpolando os dois extremos por uma reta.

Outra forma de seleção é a Roda da Roleta, onde são calculadas as probabilidades de seleção para cada cromossomo de acordo com a razão para sua aptidão e da aptidão da população acumulada. Em seguida, um número aleatório é gerado no intervalo de zero até o valor da aptidão acumulada e, então, a solução selecionada sofre a ação dos operadores recombinação e mutação.

$\mathrm{Na}$ seleção por torneio são escolhidos, aleatoriamente e com probabilidades iguais, $\mathrm{n}$ cromossomos da população e comparados os respectivos valores de aptidão entre si, sendo o melhor selecionado.

Com a mesma probabilidade de seleção para todos os cromossomos da população, a seleção Uniforme "escolhe" aleatoriamente os cromossomos a serem recombinados e mutados.

Na seleção por Amostragem Determinística as probabilidades de seleção são calculadas como na Roda da Roleta. Em seguida, cada probabilidade é multiplicada pelo número de cromossomos da população e, então, cada cromossomo é selecionado de acordo com a parte inteira do valor calculado e a população ordenada de acordo com a parte decimal deste mesmo valor. A seguir, selecionam-se uniformemente os cromossomos que sofrerão a ação dos operadores genéticos.

No Stochastic Remainder Sampling (SRS) o processo começa como na Amostragem Determinística e difere no tratamento das partes fracionárias, que são consideradas 
probabilidades. Por exemplo, um cromossomo com aptidão 1,5 terá uma cópia idêntica na população intermediaria e uma probabilidade de $50 \%$ de ter outra cópia.

\section{Recombinação}

A recombinação (ou cruzamento) é o mecanismo de criação de indivíduos (novas soluções) filhos através da recombinação de indivíduos pais (soluções atuais). Geralmente este processo é realizado através de simples permuta ou da combinação de características correspondentes entre soluções pais. A recombinação pode ser realizada de diferentes formas, chamadas operadores convencionais de um ponto, Uniforme, de Um Ponto, de Dois Pontos, Aritmética e Blend (BLX- $\alpha)$.

A recombinação uniforme opera nos genes individuais dos cromossomos selecionados ao invés de atuar nos blocos de material genético e cada gene é considerado um por um (não blocos) tanto na recombinação quanto na troca.

Na recombinação em um ou dois pontos, cada um dos cromossomos pais tem sua cadeia “cortada" em uma (Um Ponto) ou duas posições (Dois Pontos) aleatórias. As partes são recombinadas, gerando dois novos cromossomos filhos. A recombinação é aplicada com uma dada probabilidade.

A recombinação aritmética realiza uma combinação linear entre os cromossomos pais, produzindo dois cromossomos filhos da seguinte forma:

$$
\begin{aligned}
& \text { Filho }_{1}=b * \mathrm{Pai}_{1}+(1-b)^{* \mathrm{Pai}_{2}} \\
& \text { Filho }_{2}=(1-b) * \mathrm{Pai}_{1}+b * \mathrm{Pai}_{2}
\end{aligned}
$$

onde o valor de $b$ varia de 0 a 1 .

A recombinação BLX- $\alpha$ produz um novo cromossomo a partir de dois cromossomos através da seguinte recombinação:

$$
\text { Filho }=\mathrm{Pai}_{1}+b^{*}\left(\mathrm{Pai}_{2}-\mathrm{Pai}_{1}\right)
$$


onde o valor de $b$ pertence ao intervalo $(-\alpha, 1+\alpha)$, podendo variar o valos de $b$ para cada par de genes.

\section{Mutação}

A mutação é um processo que possibilita a introdução de características genéticas novas às soluções existentes, através da eventual substituição de genes dos indivíduos. Geralmente é realizada bit a bit (representação binária) ou variável por variável (representação real) possibilitando que cada bit ou gene seja alterado com uma pequena taxa de mutação (Pm) entre 0,001 e 0,1.

\section{$\underline{\text { Critérios de Parada }}$}

Após a aplicação dos operadores de recombinação e mutação, são implementadas as avaliações pertinentes ao processo, até que o critério de parada seja satisfeito. A literatura descreve vários critérios de parada para os AGs, dos quais podem-se destacar: a realização de um número de gerações (avaliações) pré-determinado; iterar até que não ocorra melhoramento significativo no cromossomo de maior aptidão por um determinado número de gerações ou até que a variabilidade dos valores de aptidão relativos às soluções da população possa ser considerado desprezível.

\subsection{Aspectos Críticos do Problema}

\section{NÍVEL INICIAL DOS RESERVATÓRIOS}

A solução ótima do problema de otimização da operação de sistemas de abastecimento de água depende do nível inicial de operação dos reservatórios. 
Algumas investigações científicas pesquisam a influência desses níveis nos gastos energéticos dos sistemas. Com esse enfoque, Almeida e Barbosa (2002) pesquisaram a influência de percentuais iniciais de reservação no consumo de energia de uma bomba, tipo booster, de rotação variável, instalada numa rede de distribuição alimentada por dois reservatórios de montante. Na busca da melhor configuração operacional trataram o problema como de otimização determinística restrita. Chegaram à conclusão de que, para o estudo de caso explorado, as condições iniciais dos níveis de água podem conduzir a economias da ordem de $35,4 \%$ a 36\% com relação a potência de eixo de um dia normal de operação.

Para solucionar esse problema e aferir o nível de água inicial para posteriores simulações diversos autores realizaram análise de sensibilidade, dentre eles Lansey \& Awumah (1994), Ribeiro (2005) e Sousa (2007).

A análise de sensibilidade efetuada por Ribeiro (2005) indicou que os melhores resultados são fornecidos para nível inicial (06:00 horas) dos reservatórios igual a 90\% da carga máxima.

Carrijo (2004) optou por impor que os níveis de água nos reservatórios, no final do período de análise, sejam idênticos aos considerados no início da simulação. Com relação aos níveis iniciais o autor afirma que uma situação desejável, em termos de operação de sistemas de distribuição de água, é manter níveis de água próximos dos máximos nos reservatórios no final da noite, mas que essa nem sempre é uma solução possível, além de implicar em vazamentos noturnos.

O autor realizou a otimização multi-objetivo da operação de parte do sistema de abastecimento de água de Goiânia considerando a minimização dos custos com energia elétrica e a maximização dos benefícios hidráulicos. Foram gerados resultados considerando os níveis iniciais dos reservatórios iguais aos níveis máximos e aos níveis médios. As 
soluções que consideram níveis iniciais máximos apresentaram maiores valores do benefício hidráulico com, praticamente, os mesmos valores dos custos de energia elétrica.

Pedrosa (2006), ao testar um modelo de otimização energética da operação de sistemas de abastecimento de água baseado em Algoritmos Genéticos no sistema adutor Marés (João Pessoa - Paraíba), considerou o estado inicial dos reservatórios (24:00 horas) como estando com $80 \%$ da sua lâmina útil.

Sousa (2007) efetuou análise de sensibilidade em que foram analisados quatro cenários distintos, correspondentes aos níveis iniciais 1,35 (nível considerado no modelo de simulação), 1,80, 2,30 e 2,80 m. Para cada um dos cenários foi determinada a solução de custo mínimo e quantificada a confiabilidade hidráulica associada, em termos de capacidade de reserva disponível no sistema.

\section{$\underline{\text { PENALIDADES }}$}

Os AGs não tratam diretamente os problemas de otimização que contenham funções restritivas. Normalmente esse impedimento nos modelos de otimização pode ser contornado empregando-se o Método de Penalidades, através do qual as restrições do problema podem ser adicionadas à função objetivo em termos de penalidades, convertendo o problema inicialmente restrito em um problema irrestrito.

Segundo Deb (2000), a maior dificuldade na utilização de funções de penalidade é encontrar parâmetros de penalidade mais adequados para guiar a busca dos AGs até a combinação ótima.

Wu e Simpson (2002) comentam que se o fator de penalidade é muito baixo, muitas soluções não-factíveis dominam a população do algoritmo genético. Se o fator de penalidade é muito alto, boas soluções serão eliminadas do processo de busca do AG. Portanto, esse fator 
direciona o Algoritmo Genético para determinada região do espaço de busca influindo na performance do processo e no resultado da solução final.

Diversas técnicas utilizando Algoritmos Genéticos têm sido foco de pesquisas para encontrar soluções ótimas a partir de coeficientes de penalidades bem equilibrados. Entretanto, para chegar a resultados satisfatórios os tratamentos matemáticos empregados concebem alteração nos operadores genéticos naturais (Schoenauer e Michalewicz, 1996) ou encampam os coeficientes de penalidades como sendo variáveis de decisão, modificando o número de cromossomos inicialmente previstos para a população inicial, (Wu e Simpson, 2002).

Nenhum desses métodos estudados se enquadra na proposta deste trabalho que é de investigar a viabilidade de se conseguir encontrar resultados factíveis para o problema proposto empregando os Algoritmos Genéticos na sua forma primitiva, sem a necessidade de aperfeiçoá-lo para acelerar o tempo de processamento computacional ou apresentar melhorias na qualidade das soluções resultantes, embora essas qualidades sejam importantes para o sucesso do modelo empregado, mas que poderá ser foco de outros estudos sobre o mesmo tema.

Ribeiro (2005) normalizou os valores das violações das restrições e o valor dos custos de energia elétrica a ser minimizado de forma que variassem de 0 a 1 e, para a determinação dos pesos aplicados a cada penalidade, adotou análise de sensibilidade.

Pedrosa (2006) optou por empregar uma análise de sensibilidade para estimar os melhores valores dos parâmetros de penalidade devido às dificuldades operacionais de aplicação das metodologias existentes e a baixa quantidade de coeficientes de penalidade a determinar.

Rao e Salomons (2007) utilizaram o Método das Penalidades Multiplicativas (descrito em detalhes por Hilton \& Culver (2000)) para incorporar as restrições ao AG. De acordo com 
esse método a função objetivo é multiplicada por um fator proporcional ao total de violações, $\mu(\mathrm{x})$, pela função linear:

$$
\mu(\mathrm{x})=1,0+\sum \omega_{\mathrm{m}} \mathrm{v}_{\mathrm{m}}, \mathrm{m}=1, \ldots, \mathrm{M}
$$

em que $\omega_{\mathrm{m}}$ são os pesos das restrições e $v_{\mathrm{m}}$ os valores das violações das restrições. Dessa maneira, se uma solução não resulta em violações de nenhuma das restrições então a função de aptidão permanece igual a função objetivo original.

Apesar dos autores afirmarem que os pesos das restrições $\left(\omega_{\mathrm{m}}\right)$ podem ser constantes ou variáveis ao longo das gerações de AG e também podem ser iguais ou diferentes para todas as restrições M, em nenhum dos artigos publicados sobre o projeto POWADIMA é explicitada a metodologia para determinação desses pesos ou maneira como as restrições foram tratadas.

\section{OTIMIZAÇÃO COM OBJETIVO ÚNICO}

Segundo Walski (2001), no Editorial denominado "The wrong paradigm - Why water distribution optimization doesn't work", a principal falha dos modelos de otimização da operação de sistemas de abastecimento de água, que impedem que estes sejam utilizados no dia-a-dia da operação de sistemas de abastecimento, é a otimização com objetivo único.

Para Neufville ${ }^{1}$ (1971 apud Walski, 2001) a relativa simplicidade das funções objetivo (por exemplo, a minimização dos custos com energia elétrica sujeita às restrições) nos modelos de otimização existentes não reflete os vários critérios pelos quais os sistemas de abastecimento de água são usualmente avaliados. Para realizar análises computacionais mais significativas é necessário definir aceitáveis indicadores de desempenho para todos os objetivos importantes da operação de um sistema de abastecimento de água.

Ainda segundo Walski (2001) os modelos de otimização deveriam se basear no conceito de que o objetivo mais importante do planejamento de sistemas de abastecimento de água é a

\footnotetext{
${ }^{1}$ Neufiville, R. (1971) "System analysis of water distribution networks." Journal of Sanitary Engineering, ASCE, 825.
} 
maximização dos benefícios líquidos, que é a diferença entre custos e benefícios (confiabilidade do sistema, capacidade de reservação, atendimento das demandas, etc.). No entanto, na operação de sistemas de abastecimento de água tais benefícios são subjetivos, de difícil identificação e mensuração e variam de acordo com o sistema em estudo.

O referido autor cita que, na opinião dele, os modelos de otimização são tão obcecados em reduzir os custos com energia elétrica que para cada $\$ 1.000,00$ de redução de custos, os benefícios são reduzidos em $\$ 2.000,00$. E que até que os modelos de otimização se tornem capazes de considerar adequadamente tais benefícios, eles não serão capazes de gerar soluções tão boas quanto um engenheiro munido de um simulador hidráulico (com o sistema em estudo devidamente modelado), bom senso e conhecimento, muitas vezes subjetivo, do funcionamento e operação do sistema. 


\section{Modelo Otimizador}

\subsection{Estrutura}

O propósito deste trabalho é estudar a otimização energética da operação de sistemas de abastecimento de água em tempo real. Um procedimento de minimização do custo relativo ao consumo de energia elétrica em tempo real é proposto e testado para o sistema descrito no Capítulo 4. O referido procedimento se apóia na execução de três módulos computacionais:

- Módulo de Previsão de Demandas: (1) os dados de demanda são submetidos a um processo de filtragem e determinadas as curvas de demanda típica; e (2) os dados de demanda filtrados são modelados com base na metodologia proposta por Zahed (1990), dando origem à previsão de demanda;

- Módulo de Simulação Hidráulica: representado pelo programa EPANET, através das funções presentes na Toolkit, responsável pela avaliação do comportamento hidráulico das soluções geradas pelo Módulo Otimizador; 
- Módulo de Otimização: realiza a otimização da operação, utilizando a tecnologia dos AGs de maneira integrada ao Módulo de Simulação Hidráulica. Para tanto, o problema de otimização correspondente é posto de forma a tratar o estado de funcionamento das bombas e válvulas em intervalos de tempo pré-determinados como variáveis de decisão, cujos valores resultem num custo mínimo de bombeamento para padrões de demanda conhecidos.

Os módulos de simulação hidráulica e otimização trabalham conjuntamente, de forma que o simulador hidráulico é repetidamente solicitado para avaliar possíveis soluções, gerada pelo AG, na busca de alternativas de melhor performance, ou seja, custos energéticos mínimos.

Conforme explicitado no item 2.2, a otimização da operação de sistemas de distribuição de água pode ser abordada sob os enfoques do Planejamento Estratégico e da Operação em Tempo Real. Apesar deste trabalho ser voltado para a Otimização da Operação em Tempo Real, optou-se pela sua realização em duas etapas.

Na primeira etapa é realizada a otimização em Nível Estratégico, a partir das Curvas Típicas de Demanda para cada nó de demanda do macro-sistema considerado. Determinase o conjunto de controles que minimizam os custos de energia elétrica, respeitando as restrições hidráulicas do sistema, aqui denominado de estratégia operacional.

Para cada conjunto de controles otimizados têm-se os níveis que os reservatórios irão atingir ao final de cada hora durante o horizonte de planejamento considerado, denominados Níveis Metas. Tais níveis servem de guia para a segunda etapa de otimização, a Operação em Tempo Real.

A Operação em Tempo Real se inicia com o recebimento dos dados sobre as condições atuais do sistema: níveis dos reservatórios e demandas da última hora. A partir 
das demandas informadas, o Módulo de Previsão de Demandas gera todas as demandas para o horizonte de planejamento. Alimenta-se então o Otimizador em Tempo Real com os níveis atuais dos reservatórios, os níveis metas e a previsão de demandas, obtêm-se o conjunto de regras operacionais ótimas para o horizonte de planejamento, sendo que são implementadas apenas as regras para a hora atual. Na próxima hora há o recebimento dos dados do sistema, nova previsão de demandas é gerada, o Otimizador em Tempo Real recebe os novos dados de entrada e um novo conjunto de controles otimizados é gerado, sendo implementados apenas os referentes a hora em curso, e assim por diante. Ou seja, a Otimização em Tempo Real é refeita a cada hora, permitindo que possíveis erros inerentes ao processo possam ser corrigidos e não se acumulem ao longo do horizonte, tal como seria na aplicação apenas do Planejamento Estratégico.

Cabe ressaltar que a Otimização em Nivel Estratégico não é necessariamente realizada antes de cada Otimização em Tempo Real e nem ao final de cada horizonte de previsão. O que determina a execução da Otimização em Nível Estratégico são as Curvas Típicas de Demanda.

As mudanças nas Curvas Típicas de Demanda variam de sistema para sistema e costumam ocorrer entre dias de semana e finais de semana e de acordo com a estação do ano, além da variação gradual devida ao aumento da demanda do sistema.

O diagrama de fluxo do modelo para a otimização da operação em tempo real proposto é apresentado na Figura 3.1 e nos itens 3.2 a 3.5, a metodologia utilizada para a construção de cada um dos módulos. 


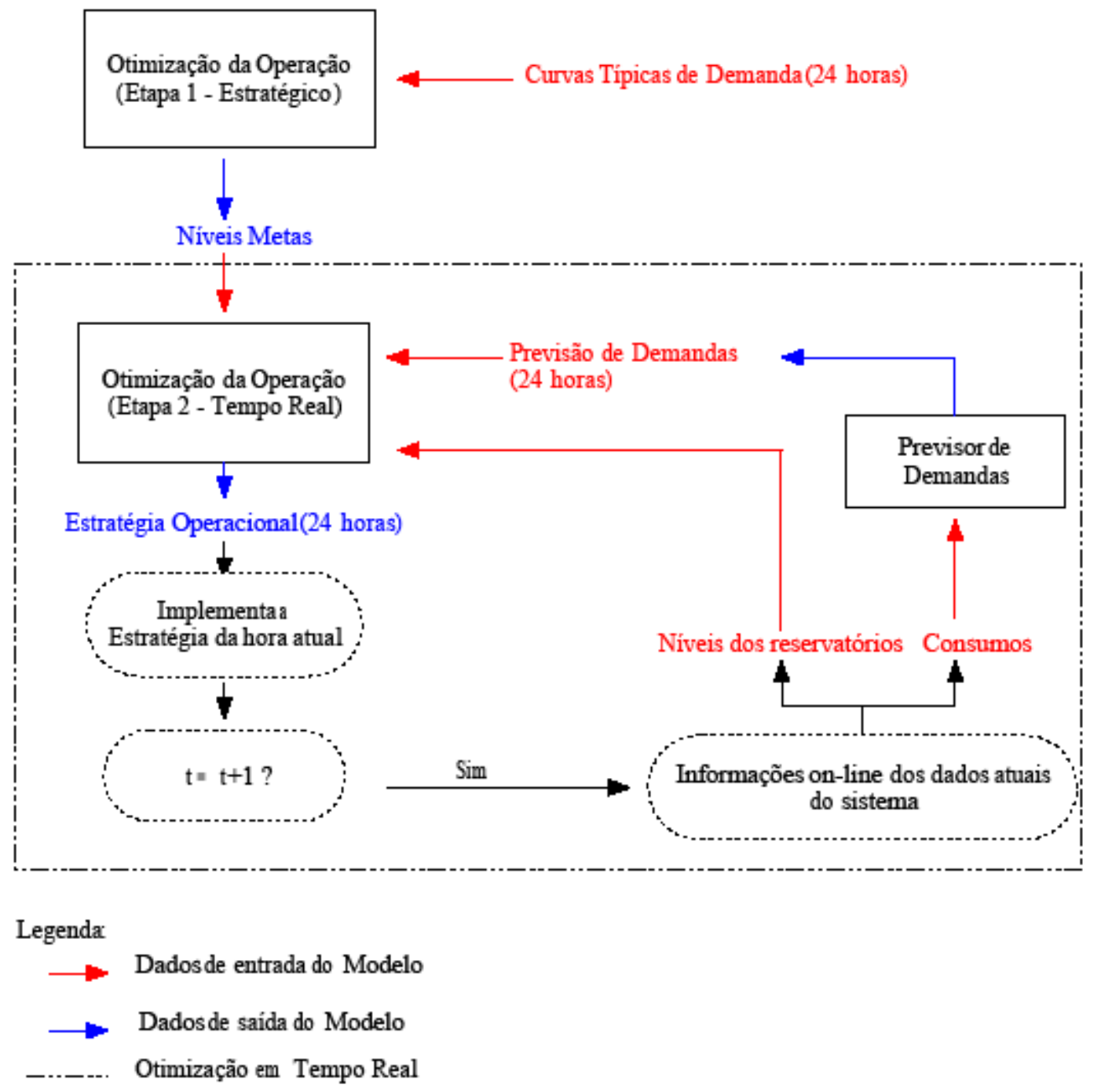

Figura 3.1 - Fluxograma do Modelo de Operação Otimizada em Tempo Real Proposto.

\subsection{Módulo de Previsão de Demandas}

A previsão de demandas é a estimativa de valores de demanda para um ou mais intervalos de tempo específicos do futuro. O intervalo de tempo no futuro, que define a antecedência das previsões, recebe o nome de horizonte de previsão. Tipicamente, a previsão de demanda pode ser realizada a curto ou longo prazo. A previsão de curto prazo é realizada com antecedência de minutos ou uma hora, enquanto que a previsão de longo prazo é realizada com antecedência de horas ou um dia. 
Por sua vez, a freqüência de previsão define o período de tempo no qual são produzidos novos dados de previsão. Assim, por exemplo, uma previsão de demanda que se estende por 3 dias e que é repetida a cada dia tem uma freqüência diária e um horizonte de 3 dias. Neste trabalho será utilizada previsão com horizonte de 24 horas e freqüência horária.

\subsubsection{Previsor de demanda}

O previsor de demandas empregado no presente trabalho, desenvolvido por Odan (2008), basea-se no modelo desenvolvido por Zahed (1990), o qual utiliza a Série de Fourier para prever a demanda de água, já que esta possui comportamento periódico.

Basicamente, por meio de dados observados, ajusta-se a equação harmônica que possui a seguinte forma (Zahed,1990):

$$
f\left(x_{j}\right)=a_{0}+\sum_{k=1}^{n p}\left(a_{k} \cdot \cos \left(\frac{k 2 \pi j}{2 N}\right)+b_{k} \cdot \sin \left(\frac{k 2 \pi j}{2 N}\right)\right) \quad n p<N
$$

em que: $a_{0}$ é o valor médio da função no intervalo utilizado; $a_{k}, b_{k}$ são coeficientes ajustados; $2 \mathrm{~N}$ é o número de pontos eqüidistantes equivalente ao período $2 \pi$; $\mathrm{j}$ é número de ordem de $\mathrm{f}(\mathrm{x}) ; \mathrm{n}_{\mathrm{p}}$ é o número de harmônicos, adotado $\mathrm{n}_{\mathrm{p}}=21 ; \mathrm{x}_{\mathrm{j}}=\mathrm{j} \cdot(2 \pi / 2 \mathrm{~N})$; e, $\mathrm{t}$ é a variável tempo.

O ajuste dos coeficientes é realizado por meio do método dos mínimos quadrados:

$$
\begin{array}{ll}
a_{0}=\frac{1}{2 N} \sum_{j=1}^{2 N} \operatorname{Cons}\left(x_{j}\right) & \\
a_{k}=\frac{1}{N} \sum_{j=1}^{2 N} \operatorname{Cons}\left(x_{j}\right) \cdot \cos \left(\frac{k \pi j}{N}\right) & 1 \leq k \leq N \\
b_{k}=\frac{1}{N} \sum_{j=1}^{2 N} \operatorname{Cons}\left(x_{j}\right) \cdot \sin \left(\frac{k \pi j}{N}\right) & 1 \leq k \leq N
\end{array}
$$

Em que: Cons $\left(\mathrm{x}_{\mathrm{j}}\right)$ é o consumo observado. 
O ciclo adotado é semanal, discretizado a nível horário $(2 \mathrm{~N}=24 \times 7=168$ horas $)$, ou seja, necessita-se de no mínimo 1 semana de dados observados para a utilização do modelo, sendo a atualização dos coeficientes horária.

No modelo, para cada avanço de uma hora na série de dados observada, realiza-se a previsão de $24 \mathrm{~h}$ à frente.

Ainda segundo Zahed (1990), a fim de incorporar à previsão as informações intrínsecas nos dados de consumo, aplica-se um coeficiente de correção alfa, que corresponde à relação média entre os valores observados e os valores obtidos pelos harmônicos para as últimas $\mathrm{n}_{\mathrm{b}}$ horas do conjunto de 168 horas (adotado $\mathrm{n}_{\mathrm{b}}=6$ horas).

Neste modelo, durante a previsão de $24 \mathrm{~h}$, à medida que o período de previsão avança, inevitavelmente o consumo previsto se afasta dos valores observados, por isso, caso a diferença entre a previsão e a média dos valores observados para determinada hora das semanas anteriores (no caso, foi adotado 3 semanas anteriores) seja maior que um determinado desvio (adotado 20\%), substitui-se o valor previsto pela média observada.

No entanto, antes de utilizar a série de dados observada para realizar a previsão, foi necessário tratar os dados, pois verificam-se falhas na medição, erros na transmissão de dados, etc. Para tanto, completam-se os dados faltosos por meio de interpolações e realizase, também, tratamento estatístico dos dados. 


\subsection{Módulo de Simulação Hidráulica}

O termo simulação geralmente se refere à reprodução do comportamento de um sistema físico de interesse. No caso específico dos sistemas de abastecimento de água, modelos de simulação são ferramentas que permitem, com uma determinada exatidão estimável, analisar e prever o comportamento hidráulico e de parâmetros de qualidade da água de sistemas hidráulicos sob pressão com base nas características físicas dos seus componentes, do seu modo de operação e das solicitações de demanda.

Permitem, assim, a partir de um conjunto de dados descritivos das características físicas dos sistemas, das solicitações a que são sujeitos e das suas condições operacionais, reproduzir o seu comportamento hidráulico por intermédio de algoritmos de resolução de equações não lineares representativas às leis físicas que regem o escoamento sob pressão.

Atualmente, os modelos de simulação são ferramentas disponíveis para suporte ao diagnóstico e análise dos sistemas de abastecimento de água.

Existem no mercado diversos modelos e softwares de modelagem matemática para desenvolvimento de análises hidráulicas e de qualidade da água em redes. Dentre eles: H2ONET - H2OMap - Montgomery Watson Inc.; SynerGEE - Stoner Workstation Service; EPANET - Environmental Protection Agency; WaterCAD - Bentley's Haestad Methods; Pipe2000 - KYPipe; FINESSE - Water Software Systens; etc. O modelo simulador hidráulico utilizado no presente trabalho se baseia no código original do EPANET (ROSSMAN, 2000), que pode ser apontado como o software de domínio público mais utilizado no mundo todo, acoplado a um código computacional na linguagem $\mathrm{C}++$ (Borland Builder $C++5.0$ ). 


\section{EPANET}

O EPANET é um programa de computador, criado pela U.S. Environmental Protection Agency (USEPA), dos Estados Unidos da América, que permite executar simulações estáticas e dinâmicas do comportamento hidráulico e de qualidade da água de sistemas de distribuição de água para abastecimento.

O pacote computacional é distribuído gratuitamente sob duas formas: executável e código fonte (Toolkit Library). A forma executável é aplicável a estudos que envolvem apenas as simulações hidráulicas. A forma de código fonte é recomendável para estudos que envolvem o acoplamento de outros modelos (calibração, vazamentos, demandas variáveis, entre outros) com o EPANET.

Para a resolução do conjunto de equações não lineares que caracterizam os escoamentos sob pressão, designadamente as equações da continuidade e da conservação de energia, e as leis de resistência ao escoamento, o modelo EPANET utiliza o Método do Gradiente Modificado, que se baseia numa aproximação híbrida nó-malha para a resolução destas equações.

As principais vantagens desse simulador são: dimensão da rede a analisar ilimitada; cálculo da perda de carga utilizando as fórmulas alternativas de Hazen-Williams, DarcyWeisbach ou Chezy-Manning; possibilidade de consideração das perdas de carga singulares em curvas, alargamentos, estreitamentos, etc; modelação de bombas de velocidade constante ou variável; cálculo da energia de bombeamento e do respectivo custo; modelação dos principais tipos de válvulas, incluindo válvulas de seccionamento, de retenção, reguladoras de pressão e de vazão; e, conexão com códigos computacionais de diversas linguagens $(\mathrm{C}++$, BASIC, etc) através da toolkit.

A toolkit é uma biblioteca de vínculo dinâmico (DLL) a qual contém funções que permitem aos programadores o desenvolvimento de aplicações específicas. Além disso, 
essa biblioteca permite abrir e fechar um arquivo que descreve a rede (.inp), bem como ler e modificar os vários parâmetros de projeto e operação, simular períodos extensivos acessando resultados a cada passo e escrever os resultados das simulações nos arquivos de saída (.rpt).

A versão executável do EPANET para Windows pode ser obtida gratuitamente na Internet na versão portuguesa (http://www.dha.lnec.pt/nes/epanet e www.lenhs.ct.ufpb.br) e na versão original (http://www.epa.gov/nrmrl/wswrd/epanet), juntamente com o manual de utilização, exemplos de aplicação e a toolkit de programação.

Para simulação do comportamento hidráulico de um sistema de distribuição de água utilizando um software de simulação hidráulica é necessário o fornecimento dos dados que representem as características físicas do sistema e suas condições de contorno. Portanto, foi representada no EPANET a topologia do sistema em estudo utilizando-se os dados cadastrais, contendo o posicionamento da rede, válvulas, reservatórios e demais acessórios, comprimentos e diâmetros dos tubos, bem como cotas do terreno, curvas de bombas, etc.

Posteriormente atribui-se: (1) a demanda base para os determinados nós e padrões de demanda para o horizonte de planejamento; (2) as tarifas de energia elétrica; e, (3) os níveis iniciais de cada reservatório.

Vale salientar que a distribuição espacial das demandas nos diferentes nós é uma potencial fonte de erro do modelo. No entanto, como o sistema em estudo corresponde basicamente à macro-adução, optou-se por alocar as demandas apenas na saída de cada Centro de Reservação (CR).

Outro fator de extrema importância, conforme mencionado no Item 2.5 - Aspectos Críticos do Problema, são os níveis iniciais dos reservatórios. Obviamente percebe-se que a solução ótima para o Nível Estratégico depende dos níveis iniciais de operação do reservatório, que não foi incorporado como variável de decisão do problema. Portanto 
optou-se por realizar uma análise de sensibilidade de forma a verificar quais níveis iniciais adotar.

Com o sistema devidamente caracterizado no simulador hidráulico, exporta-se, através do próprio EPANET, o arquivo texto (extensão .inp) que será utilizado pelo otimizador.

\subsection{Módulo Otimizador}

Os modelos de simulação hidráulica disponíveis permitem reproduzir o comportamento hidráulico de um sistema de abastecimento de água sob determinadas condições de operação. Estes modelos não possibilitam, no entanto, a determinação das condições de funcionamento ótimo dos sistemas, sendo para tal necessário recorrer à utilização de modelos computacionais baseados em métodos de otimização.

Assim, criaram-se duas rotinas otimizadoras (em Nível Estratégico e de Tempo Real) que compõe o módulo otimizador, ambas desenvolvidas em linguagem $\mathrm{C}++$ com o uso do compilador da Borland, Builder C++5.0 e, também, do código fonte do EPANET Toolkit Library, contido no arquivo Epanet2.dll.

A implementação do AG foi feita com o uso da Galib, que é a biblioteca de objetos de AGs criada pelo MIT - Massachusetts Institute of Technology (http://lancet.mit.edu/galib-2.4/).

\subsubsection{Rotina 1 - Otimização em Nível Estratégico}

O procedimento geral da rotina de Otimização em Nível Estratégico pode ser representado pelo fluxograma da Figura 3.2. 


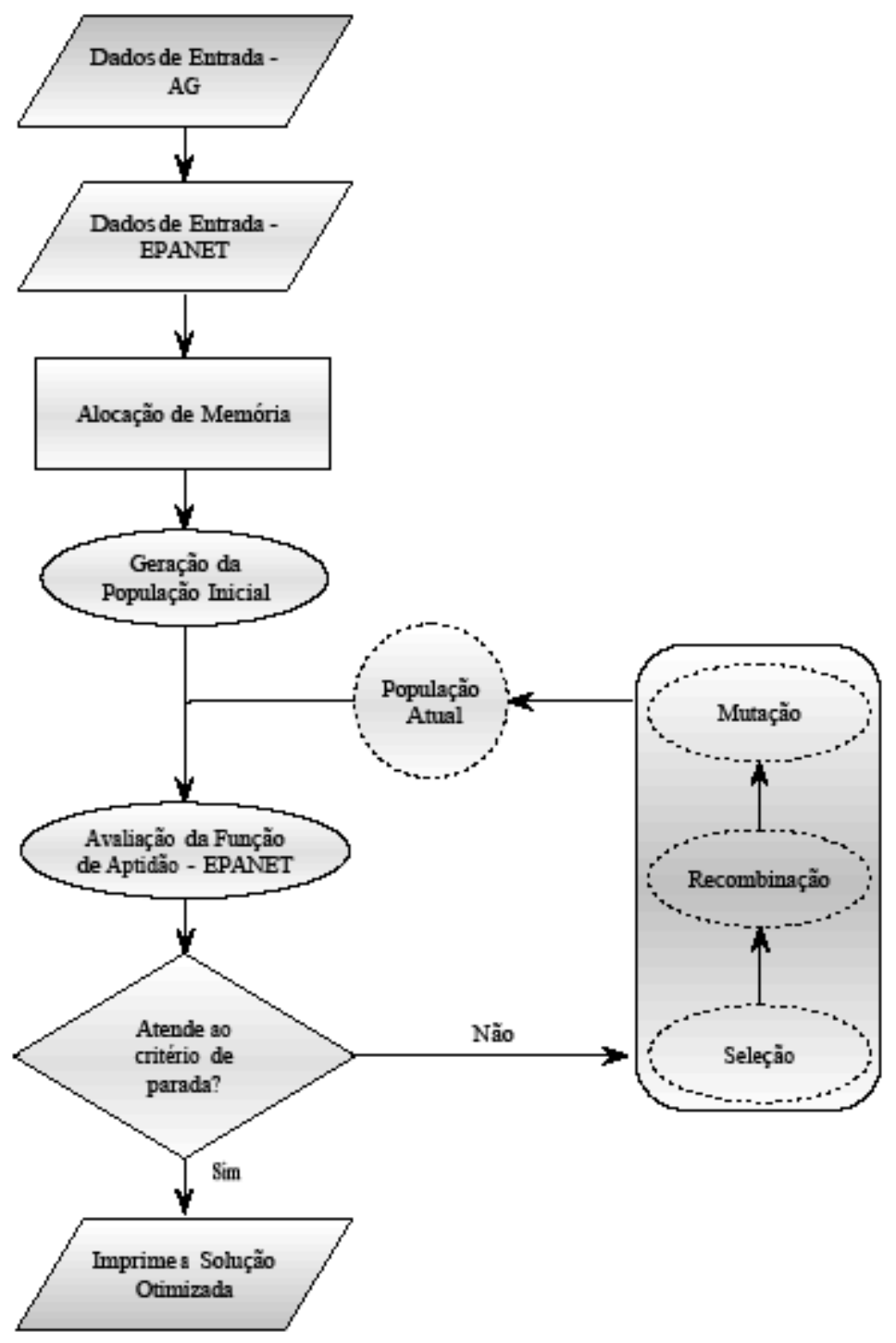

Figura 3.2 - Diagrama de Fluxo da Otimização em Nível Estratégico.

\section{ETAPA 1 - LEITURA E ARMAZENAMENTO DOS DADOS DE ENTRADA DO AG}

Cria-se um arquivo texto, denominado gal.in, com os dados de entrada relativos aos operadores e parâmetros genéticos, número de bombas e válvulas e respectivos trechos, horizonte de planejamento e pressão mínima admissível na rede e uma rotina, Figura 3.3, para ler estes dados e armazenar nas devidas variáveis.

No Item 3.4.2, adiante, é apresentado um estudo sobre a adoção dos valores dos operadores e parâmetros genéticos utilizados. 


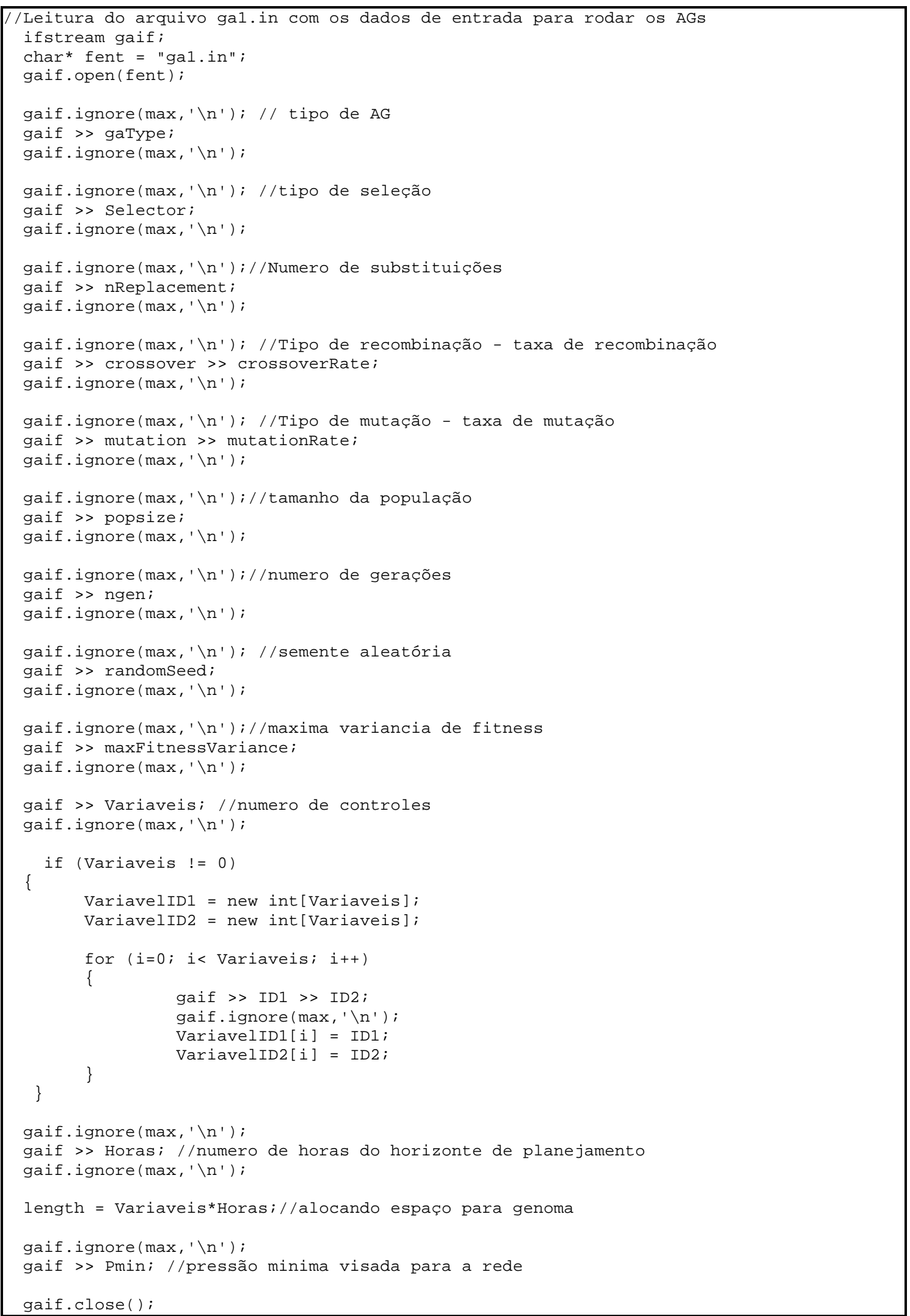

Figura 3.3 - Sub-rotina leitura do arquivo ga1.in para Otimização em Nível Estratégico. 


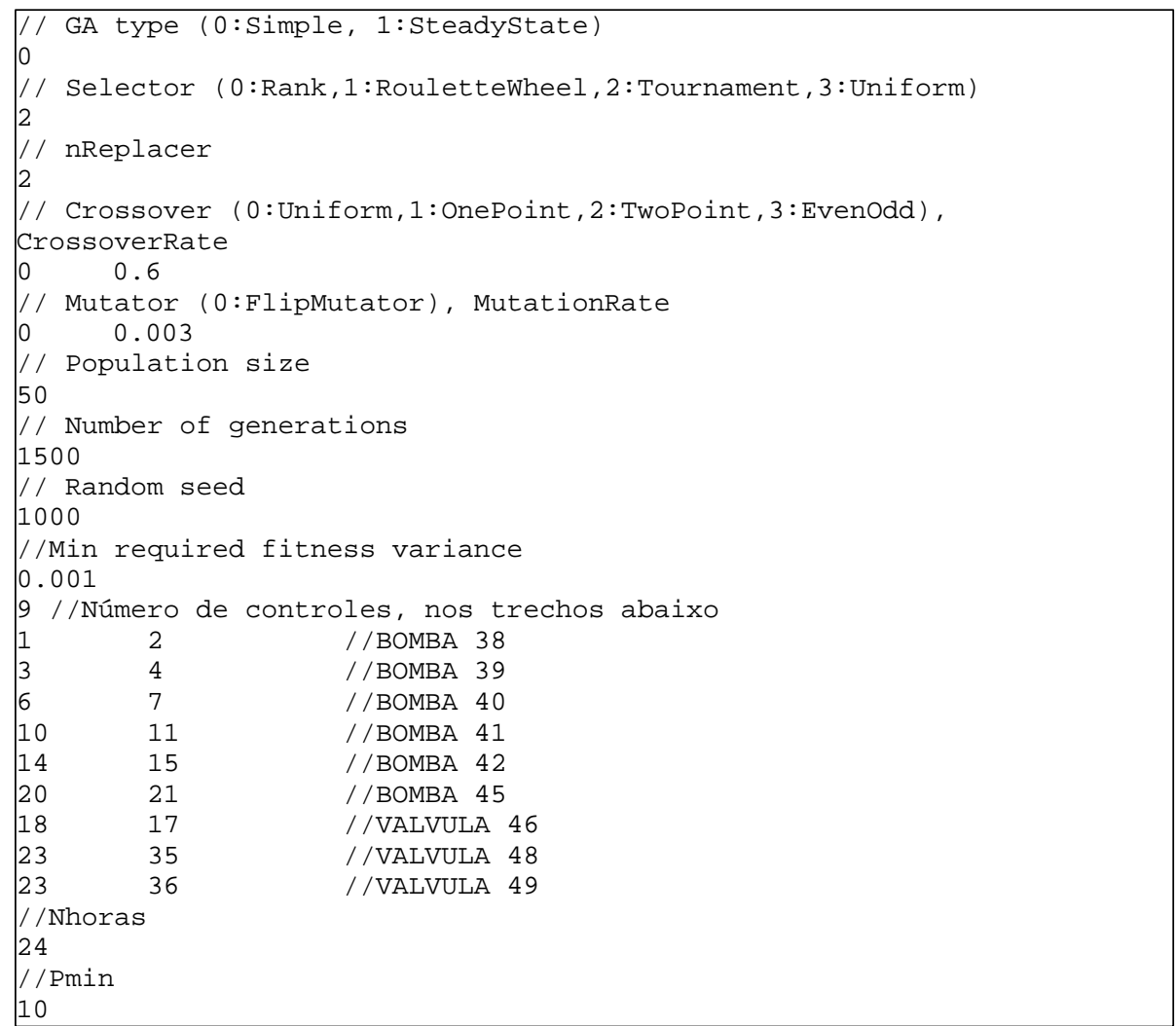

Figura 3.4 - Arquivo ga1.in para Otimização em Nível Estratégico.

\section{ETAPA 2 - LEITURA E ARMAZENAMENTO DOS DADOS PRINCIPAIS DO SISTEMA}

O otimizador, através da função ENopen, abre o arquivo de texto da rede (extensão .inp), conta (ENgetcount) o número de links e nós do sistema e armazena nas respectivas variáveis (NumLinks e NumNodes) - Figura 3.5.

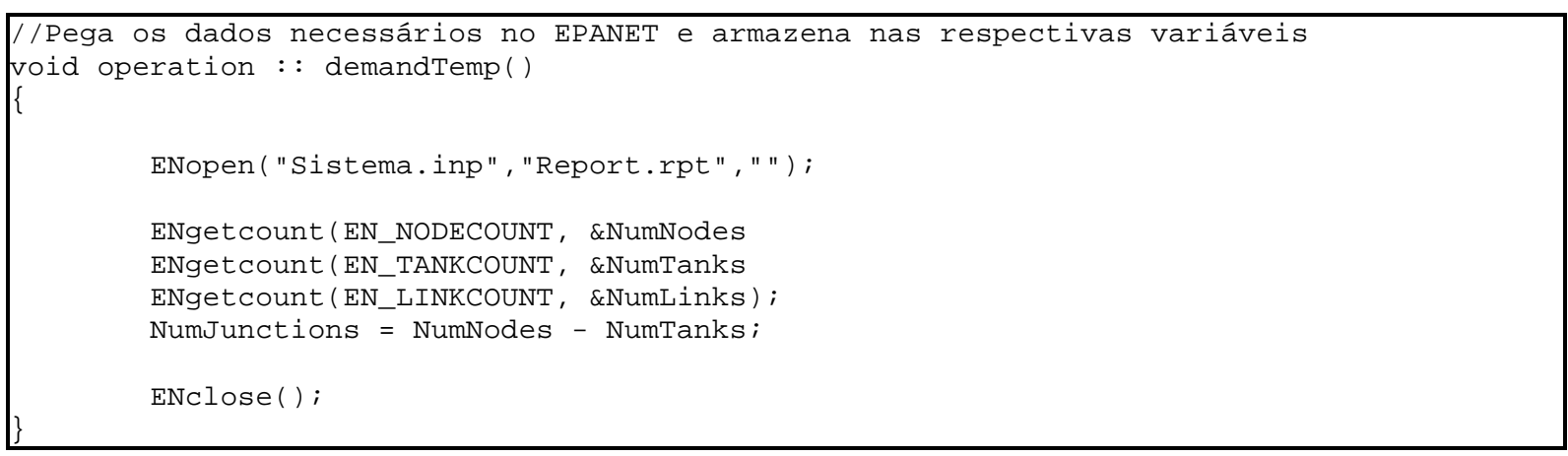

Figura 3.5 - Sub-rotina de leitura dos dados do Sistema.

Observa-se que a função ENopen deve ser seguida de um parênteses dentro do qual especifica-se o nome do arquivo texto de entrada do EPANET e o nome com que é salvo o report file (relatório onde são armazenados todas as mensagens geradas durante a simulação hidráulica e os resultados hidráulicos para nós e trechos). 


\section{ETAPA 3 - ALOCAÇÃO DE MEMÓRIA}

Sub-rotina implementada para alocar memória para as matrizes e vetores utilizados durante a otimização - Figura 3.6.

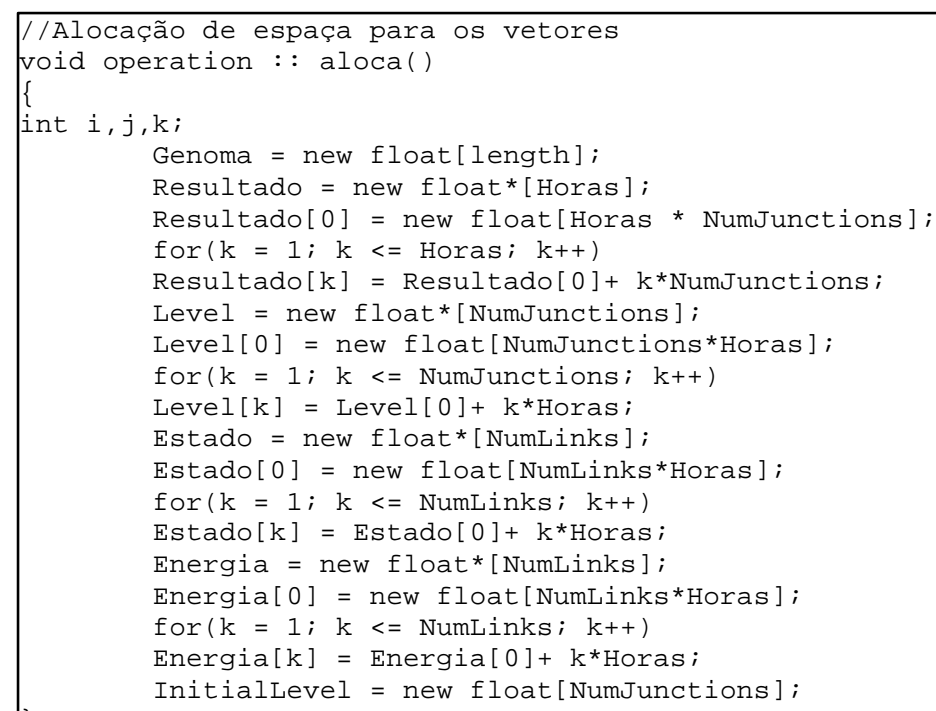

Figura 3.6 - Sub-rotina para alocação de memória.

\section{ETAPA 4 - GERAÇÃO DA POPULAÇÃO INICIAL}

Através da sub-rotina Initializer - Figura 3.7, são gerados aleatoriamente os cromossomos que formam a população inicial de solução. Define-se também o tipo de genoma a ser utilizado, no caso em estudo, vetor de binários com uma dimensão (GA1DBinaryStringGenome), conforme explicado a seguir no item 3.4.3.

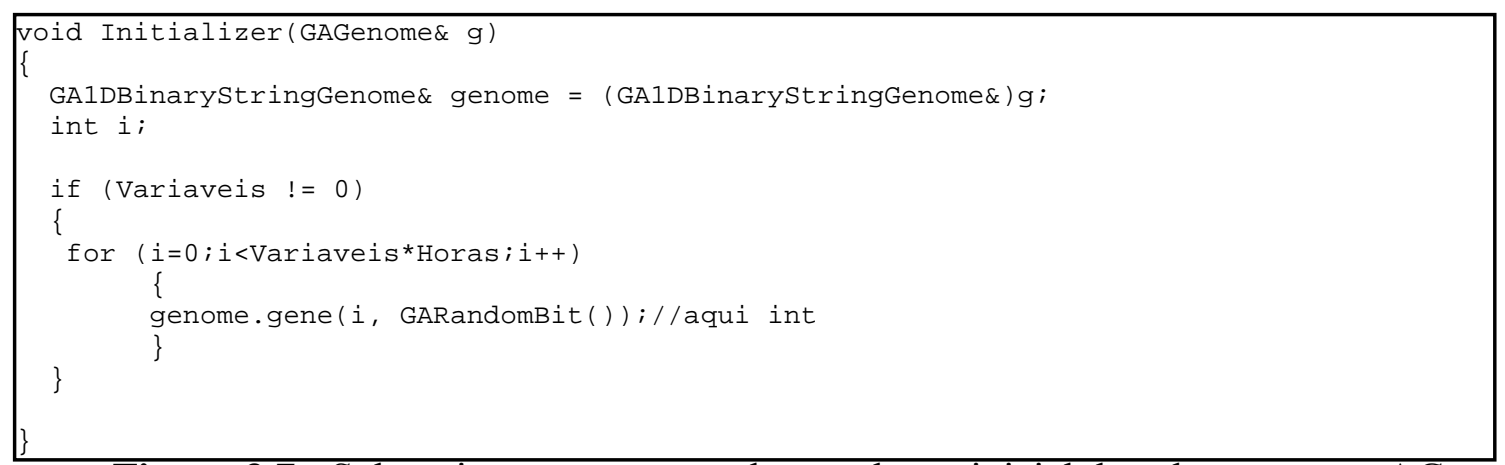

Figura 3.7 - Sub-rotina para geração da população inicial de solução para o AG. 


\section{ETAPA 5 - AVALIAČ̃̃̃ DA FUNÇ̃̃O DE APTIDÃO}

Nesta etapa, o Otimizador solicita o EPANET para simular o sistema proposto hidraulicamente em tempo estendido ( 24 horas) considerando os estados de funcionamento de bombas e válvulas designados pelo genoma corrente, obtendo o valor da Função de Aptidão - Figura 3.8.

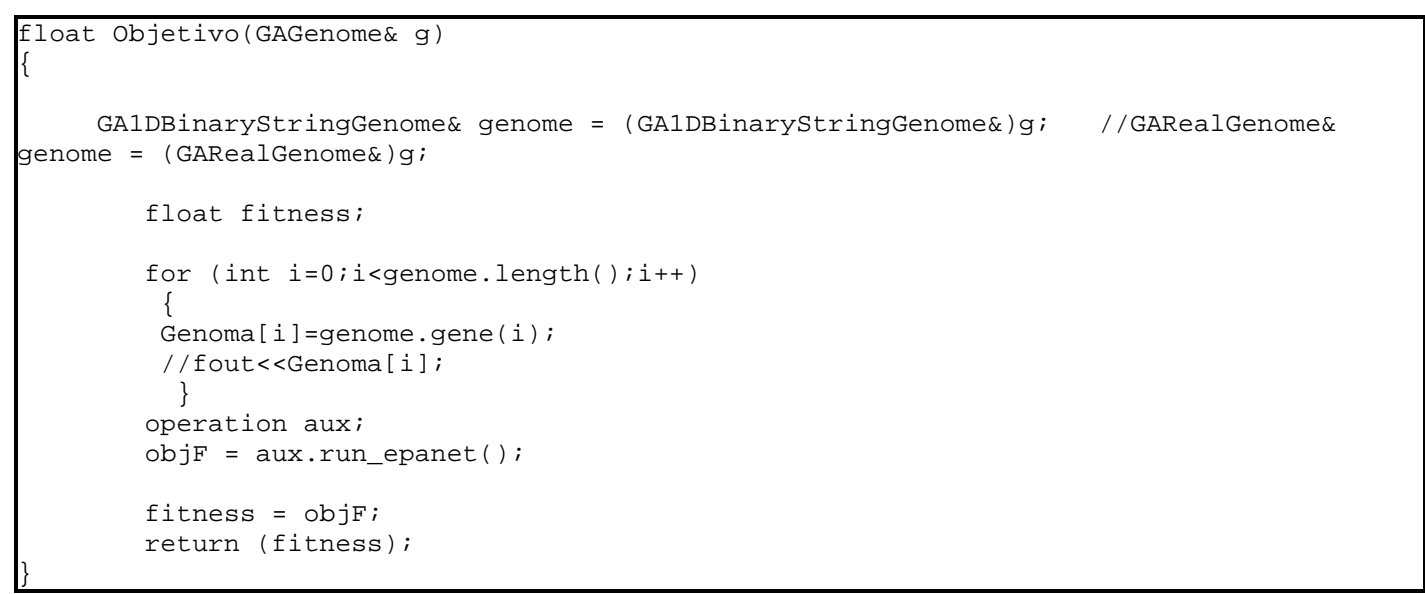

Figura 3.8 - Sub-rotina para obtenção do valor da função de aptidão.

\section{ETAPA 6 - AVALIAÇÃO DO CRITÉRIO DE PARADA}

Se a quantidade de gerações atende o critério de parada pré-definido do algoritmo, então o processo é interrompido, caso contrário, continua-se a avaliação em busca de melhores solução.

Cabe aqui uma ressalva de que as melhores soluções encontradas não correspondem necessariamente às respectivas soluções ótimas, uma vez que a aplicação dos AGs não garante a convergência para o ótimo. Portanto, nesse trabalho, a melhor solução encontrada após um número determinado de gerações é referida como solução otimizada e não como solução ótima.

\section{ETAPA 7 - APLICAČ̃̃O DOS OPERADORES GENÉTICOS}

Caso ainda não se tenha atingido o critério de parada, a população corrente é submetida aos operadores genéticos de Seleção, Cruzamento e Mutação. 


\section{ETAPA 8 - IMPRIME A SOLUÇÃO OTIMIZADA}

Quando o processo chega ao fim, a solução otimizada é novamente simulada no EPANET, através da sub-rotina results(), e o EPANET gera o report file desta simulação. Através deste report file é possível observar os níveis dos reservatórios, atendimento das demandas, pressões nos nós, vazões nos trechos, entre outros, avaliando-se hidraulicamente a solução gerada pelo otimizador.

As sub-rotinas results() e run_epanet(), ao contrário das demais, não são aqui apresentadas por serem muito longas. No entanto, são utilizadas também na Otimização em Tempo Real, cuja rotina completa é apresentada no Apêndice A.

\section{AVALIAÇ̃̃o HIDRÁULICA - EPANET}

Durante a Etapa 5, o Otimizador abre o EPANET, solicita que este simule hidraulicamente a solução corrente através da sub-rotina run_epanet(), retornando o valor da Função Objetivo (objF), e fecha novamente o EPANET.

Essa sub-rotina compreende os seguintes passos:

Passo 1 - $\quad$ Abre a análise hidráulica do sistema através da Função ENopenH;

Passo 2 - Inicializa níveis dos reservatórios, estados dos trechos, bombas, válvulas, e tempo da simulação (ENinitH);

Passo 3 - Simula, através da utilização em conjunto das funções do - ENrunH(\&t) ENnextH(\&tstep) - while(tstep $>0)$, todo o horizonte de planejamento considerado. Essa simulação é divida em períodos de análise hidráulica, com tempo corrente de simulação t (em segundos). Em cada período são informados os estados das bombas e válvulas, correspondentes ao genoma da população corrente, através da função ENsetlinkvalue. Como o tempo de simulação corrente não é necessariamente igual a uma hora, e sim o tempo 
transcorrido até que o próximo evento hidráulico ocorra, optou-se por utilizar um contador (tt) que só irá permitir que os valores do genoma sejam atribuídos aos seus respectivos controles (bomba ou válvula) de hora em hora. Já que o genoma foi concebido como sendo o estado de cada controle para cada hora ao longo do horizonte de planejamento.

Passo 4 - $\quad$ Repete-se toda a simulação do Passo 3, agora com os estados dos controles já definidos, resgatando do EPANET os valores de energia de cada bomba, as pressões em cada nó, os níveis dos reservatórios e a quantidade de acionamentos de cada bomba. Da mesma forma que no passo 3, foi criado um contador (zz) para que esses valores só fossem tomados a cada hora e não a cada tempo corrente de simulação $(\mathrm{t})$.

Passo 5 - $\quad$ A partir dos valores tomados no passo anterior, calcula-se a Função de Aptidão para a solução corrente, retornando seu valor (objF).

Consta do item 3.4.3 o detalhamento do cálculo da Função de Aptidão e suas considerações.

\subsubsection{Rotina 2 - Otimização em Tempo Real}

As sub-rotinas implementadas na Otimização em Tempo Real são basicamente as mesmas da Otimização em Nível Estratégico, descritas no item anterior, com a diferença de que são constantemente repetidas. O diagrama de fluxo desta sub-rotina é apresentado na Figura 3.9, na página seguinte.

As Etapas 1 e 2 são as únicas realizadas apenas uma vez. Em cada novo passo de tempo há a alocação do espaço dos vetores, geração da população inicial, avaliação da função da aptidão da população atual, verificação do critério de parada e aplicação dos 
operadores genéticos. Ao final de cada ciclo de otimização a solução obtida é novamente simulada no EPANET, através da sub-rotina results(), o EPANET gera o report file da otimização corrente, desaloca-se todos os vetores utilizados e implementa-se a solução otimizada. Na próxima hora, obtêm-se os dados atuais do sistema, realiza-se nova previsão de demandas e todo o processo é repetido a partir da Etapa 3.

Conforme citado anteriormente, a rotina completa para a Otimização em Tempo Real encontra-se apresentada no Apêndice A.

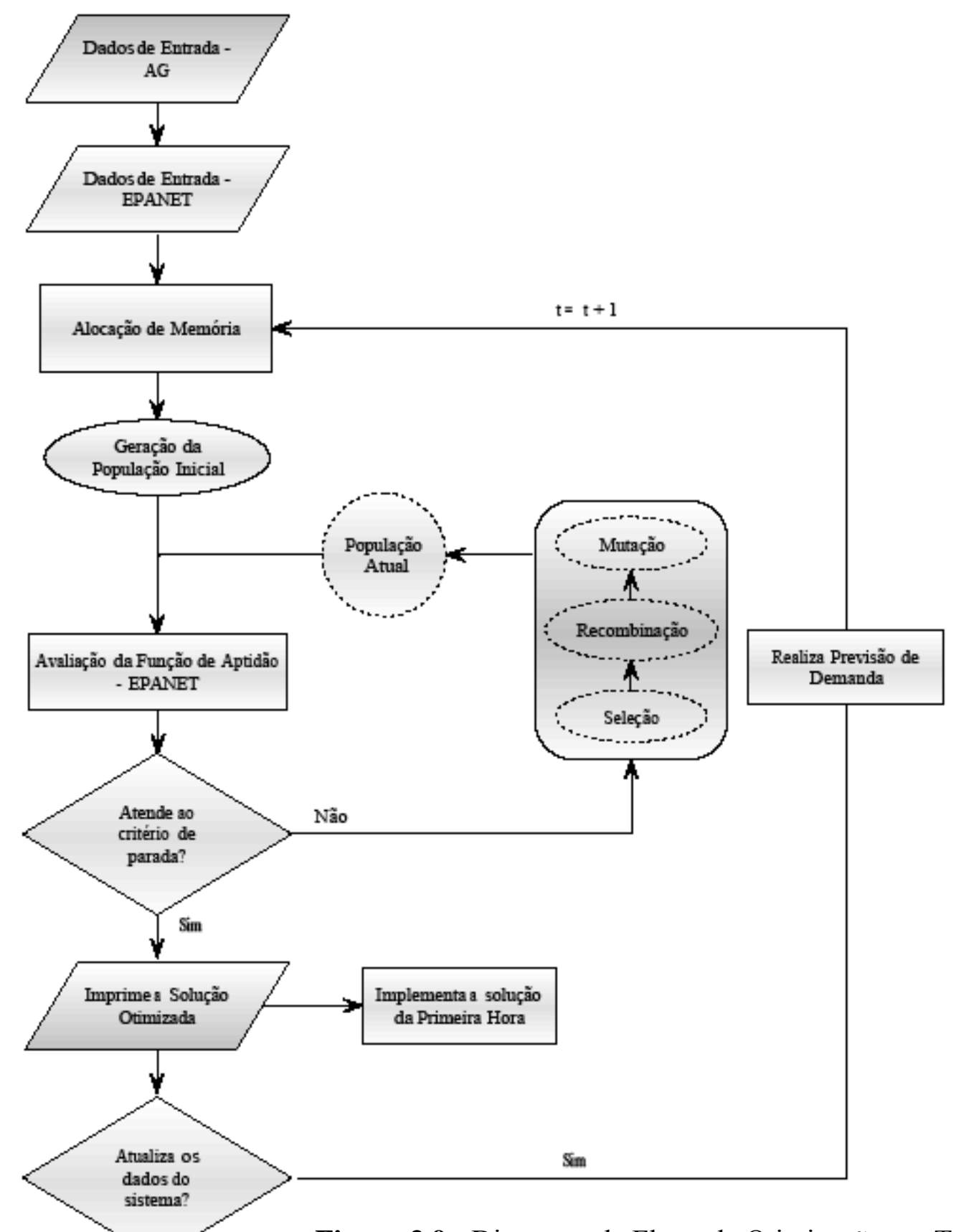

Figura 3.9 - Diagrama de Fluxo da Otimização em Tempo Real. 


\subsubsection{Função de Aptidão}

\section{$\underline{\text { Variáveis de Decisão }}$}

No problema tratado, a função objetivo expressa a minimização dos custos de energia elétrica relativa ao bombeamento de um sistema de adução de água. Assim, a solução ótima investigada significa encontrar a melhor combinação, operacionalmente factível, do estado das bombas e válvulas, a cada intervalo de tempo, ao longo de um horizonte de planejamento, de forma a resultar num custo energético mínimo.

Portanto as variáveis de decisão são os conjuntos de controles das bombas $x_{t}=\left(x_{1 t}\right.$, $\left.x_{2 t}, \ldots, x_{B t}\right)$ e das válvulas $y_{t}=\left(y_{1 t}, y_{2 t}, \ldots, y_{V t}\right), t=1, \ldots, T$, para todos os intervalos de tempo $t$ ao longo do horizonte de planejamento T, onde $B$ é o número de bombas, $V$ é o número de válvulas e $T$ é o número de intervalos de tempo que totalizam o horizonte de planejamento (24).

Para bombas de vazão fixa, as variáveis de decisão são restritas ao estado da bomba que pode ser ligado ou desligado. Todavia, para bombas de velocidade variável essas variáveis de decisão englobam também as taxas de vazão da mesma naquele intervalo de tempo. As válvulas controladoras de vazão são similares às bombas de velocidade variável, as variáveis de decisão englobam o coeficiente de abertura da mesma e não somente seu estado (aberta/fechada).

Nesse trabalho não foram consideradas bombas de velocidade variável e nem o coeficiente de abertura das válvulas controladoras de vazão. E admitiu-se a codificação binária das variáveis, onde cada gene assume o valor 0 ou 1 . Assim sendo, as variáveis de decisão limitam-se aos valores 1 ou 0 , ou seja, ligada / desligada e aberta / fechada, para as bombas e válvulas, respectivamente. 
Cada solução (indivíduo) é representada por um vetor (cromossomo) de dimensão $(B+V)^{*} T$, descrevendo as diferentes combinações de estado das bombas e válvulas ao longo do horizonte de planejamento. A Figura 3.10 mostra um simples exemplo de um vetor solução (cromossomo) para duas bombas e duas válvulas, assumindo um horizonte de planejamento $T$.

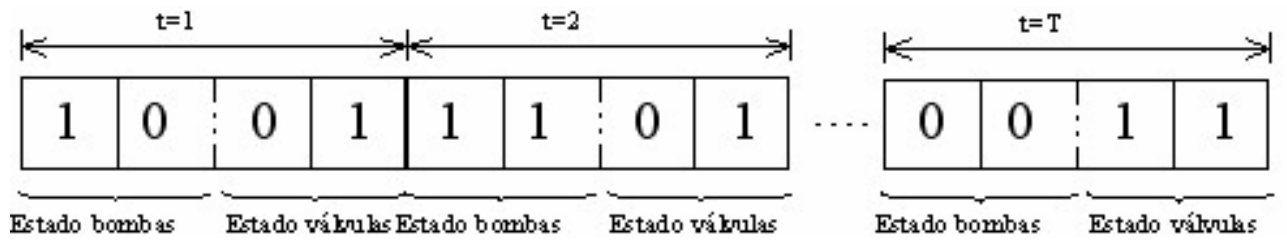

Figura 3.10 - Vetor solução de duas bombas e duas válvulas, horizonte de planejamento $T$.

\section{Função Objetivo}

Como os custos associados ao consumo de energia representam grande parcela dos custos totais de exploração dos sistemas de abastecimento de água, a função objetivo a minimizar $(\mathrm{Cb})$ do problema pode ser definida pelo somatório dos custos associados ao consumo de energia elétrica no bombeamento de água no sistema.

Se $B$ é o número de bombas no sistema de adução, e $E$ é o número de elevatórias, então o custo energético de bombeamento $(\mathrm{Cb})$ em $T$ períodos de tempo, é representado genericamente por:

$$
C b=\sum_{b=1}^{B} \sum_{t=1}^{T}[\text { custoconsumo }(b, t)]+\sum_{e=1}^{E} \text { custodemanda }(e)
$$

Considerando que a cada elevatória (unidade consumidora) possa estar associada uma estrutura tarifária própria com tarifas diferenciadas de energia em $D$ períodos distintos, a função objetivo pode ser expressa pela equação abaixo. 


$$
C b=\sum_{b=1}^{B} \sum_{t=1}^{T}\left[\frac{9,81 \times Q(b, t) \times H m(b, t) \times T C(b, t) \times \Delta t}{\eta(b, t)}\right]+\sum_{e=1}^{E} \sum_{d=1}^{D}\left\{T D(e, d) \times \max _{-} \text {dem }(e, d)\right\}
$$

em que, $\mathrm{Cb}=$ custo energético total $(\mathrm{R} \$) ; \mathrm{Q}(\mathrm{b}, \mathrm{t})=$ vazão bombeada $\left(\mathrm{m}^{3} / \mathrm{h}\right) ; \operatorname{Hm}(\mathrm{b}, \mathrm{t})=$ altura manométrica total da bomba $(\mathrm{m}) ; \mathrm{TC}(\mathrm{t})=$ tarifa de consumo $(\mathrm{R} \$ \mathrm{kWh}) ; \mathrm{TD}(\mathrm{e}, \mathrm{d})=$ tarifa de demanda $(\mathrm{R} \$ / \mathrm{kW}) ;$ max_dem $(\mathrm{e}, \mathrm{d})=$ demanda máxima $(\mathrm{kW}) ; \eta(\mathrm{b}, \mathrm{t})=$ rendimento do conjunto elevatório. $\mathrm{O}$ termo $t$ corresponde a hora do dia, $b$ se refere a uma bomba particular, $e$ está associado à respectiva estação elevatória, e $d$ é o período do dia (horário ponta/fora de ponta).

\section{$\underline{\text { Restrições }}$}

A otimização da operação de sistemas de abastecimento tem sido formulada como um problema de otimização sujeito a restrições implícitas e explícitas.

As restrições implícitas são as restrições de igualdade definindo o equilíbrio estático do sistema, que correspondem à conservação da massa em cada nó e à conservação da energia no sistema, representadas por um conjunto de equações implicitamente resolvidas internamente ao simulador hidráulico.

Já as restrições explícitas compreendem as restrições de ordem física e operacional. As restrições físicas englobam capacidade dos reservatórios, capacidade dos mananciais, configuração das bombas, etc. As restrições operacionais podem assumir as mais diferentes considerações, sendo através dessas restrições que se associa a noção de confiabilidade do sistema à otimização de objetivo único (minimização dos custos com energia elétrica), garantindo que a solução encontrada seja viável operacionalmente. O produto resultante da otimização não será necessariamente a solução de menor custo e sim uma solução factível de ser implementada na prática, com os padrões de confiabilidade desejados. 
Optou-se por incorporar à Otimização em Nível Estratégico as restrições relativas às ocorrências de pressões inferiores à mínima, diferença entre os níveis inicial e final nos reservatórios e quantidade de acionamentos das bombas. Na Otimização em Tempo Real a restrição quanto à diferença de níveis inicial e final nos reservatórios é substituída pela diferença entre os níveis atingidos pelos reservatórios e os níveis meta, ou seja, obtidos na otimização estratégica.

Matematicamente, o problema original de minimização da função objetivo (FO), com restrições é do tipo,

Minimize: $F O(X)$,

sujeito a: $P_{r}(X) \geq 0, r=1,2, \ldots, n_{r}$

em que: $\mathrm{X}$ é o vetor de variáveis de decisão $\left\{\mathrm{x}_{1}, \mathrm{x}_{2}, \ldots, \mathrm{x}_{\mathrm{n}}\right\} ; \mathrm{n}$ é o número total de variáveis de decisão; e, $\mathrm{n}_{\mathrm{r}}$ é o número de restrições.

Como o Algoritmo Genético não trata diretamente de problemas de otimização que contenham funções restritivas, esse impedimento nos modelos de minimização pode ser contornado empregando-se o Método de Penalidades, segundo o qual as restrições são adicionadas à função objetivo em termos de penalidades, convertendo o problema inicialmente restrito em um problema irrestrito. Portanto, a formulação inicial do problema é transformada em:

$$
\text { Minimize }: \operatorname{obj} F(X, r)=F O(X)+\sum_{r=1}^{n_{r}} \lambda_{r} P_{r}
$$

em que, $\mathrm{P}_{\mathrm{r}}$ é calculada usando funções de penalidades que representam as violações; FO é a função objetivo original; $\lambda_{\mathrm{r}}$ é o coeficiente de penalidade aplicado a restrição; e objF(X, r) é a função objetivo transformada (função de aptidão). 


\section{$\underline{\text { Penalidades }}$}

\section{Penalidade 1 - Pressões inferiores à mínima}

Restrição quanto à ocorrência de pressões inferiores à mínima, garantindo assim o atendimento das demandas com pressões adequadas e, obviamente, que não haja pressões inferiores à atmosférica, assegurando a continuidade no abastecimento. É calculada pela seguinte expressão:

$$
P_{1}=\lambda_{1} \sum_{t=1}^{T=24}\left(P_{\min }-P_{i t}\right), \text { sendo } P_{i t}<P_{\min }
$$

em que: $\lambda_{1}$ é o coeficiente de penalidade a ser aplicada à função de restrição; $\mathrm{P}_{\mathrm{it}}$ é a pressão no nó $i$ (desde que haja demanda nesse nó) na hora $t$; e, $\mathrm{P}_{\min }$ é igual a $10 \mathrm{mH} 2 \mathrm{O}$ (conforme preconiza a NBR 12218).

Essa penalidade é aplicada apenas aos nós onde há demanda, uma vez que determinados nós, tais como sucção de bombas e saídas de reservatórios apoiados ou enterrados, sempre terão pressões inferiores à mínima.

\section{Penalidade 2 - Diferença entre os níveis inicial e final nos reservatórios}

Impõe-se que o nível final de água nos reservatórios seja pelo menos igual ao nível de água no instante inicial. Essa restrição é estabelecida para que no final do horizonte de planejamento operacional o sistema apresente as mesmas condições hidráulicas iniciais, visando garantir a continuidade da operação em períodos subseqüentes.

Para atender essa condicionante foi desenvolvida uma função de custo (Equações 3.11 e 3.12) para penalizar a função de aptidão caso os níveis de água nos reservatórios não atinjam seus valores iniciais, forçando com que o sistema tente recuperar o déficit.

$$
\begin{array}{lr}
P_{2}=\lambda_{2} \sum_{r=1}^{R}\left(N_{\text {inicial }, r}-N_{\text {final }, r}\right), & \text { sendo } N_{\text {inicial }, r}>N_{\text {final }, r} \\
P_{2}=0, & \text { para } N_{\text {inicial }, r} \leq N_{\text {final }, r}
\end{array}
$$


em que: $\lambda_{2}$ é o coeficiente de penalidade a ser aplicado à restrição; $N_{\text {inicial, },}$ e $N_{\text {final, },}=$ níveis de água no reservatório $r$ para os instantes inicial e final $(t=0$ e $t=24)$.

\section{Penalidade 3 - Quantidade de acionamentos}

Um conjunto de controles em que as bombas e válvulas são ligadas e desligadas ou manobradas com freqüência pode até reduzir o consumo de energia. Entretanto, isso pode acarretar acréscimo nos custos de manutenção, visto que quanto mais vezes uma bomba for acionada, ou uma válvula operada, durante um ciclo de operação, maior será seu desgaste.

Baseando-se no trabalho desenvolvido por Lansey \&Awumah (1994), adotou-se que cada bomba/válvula poderia ser acionada/manobrada quatro vezes por dia sem haver acréscimo de penalidades na função de aptidão. A partir do quinto acionamento a restrição é considerada violada, sendo então aplicada essa penalidade, segundo a função:

$$
P_{3}=\lambda_{3}\left(\sum_{b=1}^{B} N A_{b}+\sum_{v=1}^{V} N A_{v}\right), \quad \text { sendo } \quad N A>4
$$

em que: $\lambda_{3}$ é o coeficiente penalidade a ser aplicada à função de restrição; NA é o número de acionamento da bomba $b$ ou da válvula $v$ para o horizonte de planejamento considerado.

Penalidade 4-Diferença entre os níveis dos reservatórios e níveis meta

Para a Otimização em Tempo Real a Penalidade 2 é substituída pela Penalidade 4. Impõe-se que o nível de cada reservatório em cada período de tempo, ao longo do horizonte de planejamento, seja igual ou superior ao Nível Meta para aquele período e aquele reservatório. Ou seja, ao final de cada hora o nível do reservatório deverá se aproximar o máximo possível do Nível Meta definido pela Otimização em Nível Estratégico. 
A inclusão dessa penalidade tem por objetivo fazer com que os Níveis Metas sirvam de guia para a Otimização em Tempo Real.

$$
P_{4}=\lambda_{4} \sum_{r=1}^{R} \sum_{t=1}^{T} \text { Nmeta }_{r t}-N_{r t}, \quad \text { sendo } \quad \text { Nmeta } a_{r t}>N_{r t}
$$

em que: $\lambda_{4}$ é o coeficiente penalidade a ser aplicada à função de restrição; Nmeta $a_{r, t}$ é o nível meta do reservatório $r$ no instante $t$; e, $N_{r t}$ é o nível do reservatório $r$ no instante $t$, determinado pela Otimização em Tempo Real.

\section{Penalidade 5 - Continuidade do Abastecimento}

Deseja-se que o abastecimento dos nós de demanda seja contínuo, ou seja, durante as simulações não pode haver pressões inferiores à pressão atmosférica e os nós devem estar sempre conectados às fontes de suprimento.

A verificação dessa situação é efetuada com auxílio da função $E N r u n H$, disponível no Toolkit do EPANET. Essa função retorna, ao final do processo, um código de alerta (warning code) se alguma condição operacional foi violada. A Figura 3.11, retirada da Toolkit (Rossman, 2000), mostra os códigos e as correspondentes mensagens.

Figura 3.11 - Códigos de Alerta e respectivas mensagens. Fonte: Toolkit (Rossman, 2000).

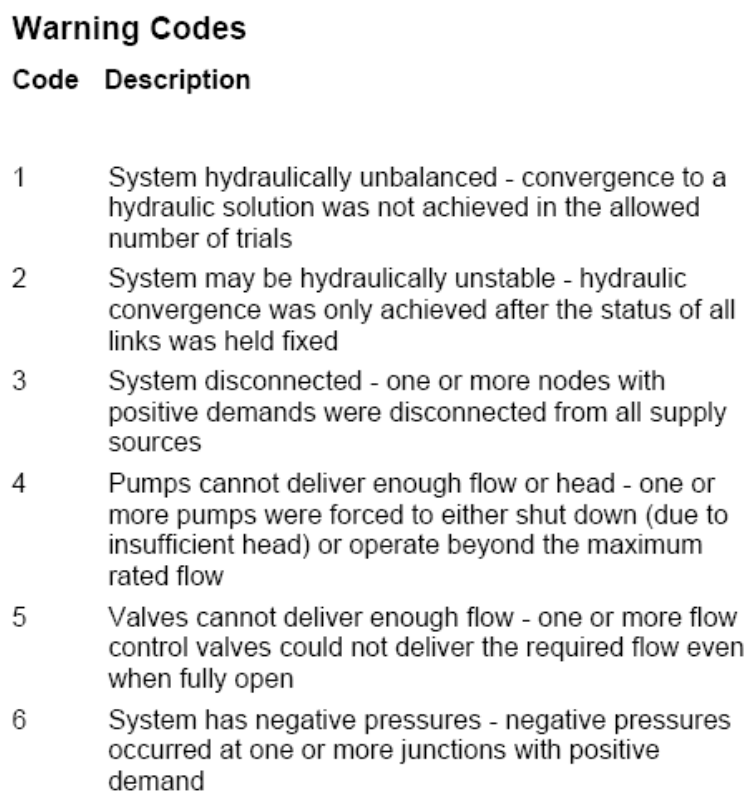

2 System may be hydraulically unstable - hydraulic convergence was only achieved after the status of all links was held fixed

3 System disconnected - one or more nodes with positive demands were disconnected from all supply sources

$4 \quad$ Pumps cannot deliver enough flow or head - one or more pumps were forced to either shut down (due to insufficient head) or operate beyond the maximum rated flow

$5 \quad$ Valves cannot deliver enough flow - one or more flow control valves could not deliver the required flow even when fully open

6 System has negative pressures - negative pressures occurred at one or more junctions with positive demand 
Se ENrunH retorna o valor 3 ou 6 em algum instante da simulação, o que representa a ocorrência de pressão negativa em algum dos nós alimentados pelos reservatórios de distribuição ou a desconexão de algum nó com demanda positiva de sua fonte de suprimento, há a penalização.

$$
P_{5}=\lambda_{5} \sum_{t=1}^{T} \text { warningcode, se warningcode }=3 \text { ou } 6
$$

em que: $\lambda_{5}$ é o coeficiente penalidade a ser aplicada à função de restrição; warningcode é código de alerta gerado pela função ENrunH.

A seleção dos valores apropriados dos coeficientes de penalidades $\left(\lambda_{1}, \lambda_{2}, \lambda_{3}, \lambda_{4}\right.$ e $\left.\lambda_{5}\right)$ para avaliar o custo de cada restrição violada é fator crucial para utilização do Método de Penalidades. Conforme visto no Item 2.4, existem algumas metodologias para obtenção destes valores. No entanto, pelas dificuldades operacionais de aplicação das metodologias existentes e pela baixa quantidade de coeficientes de penalidade a determinar, optou-se por empregar a análise de sensibilidade para estimar seus melhores valores.

\section{Função de Aptidão}

A função objetivo transformada (função de aptidão) a minimizar passa a ser definida pela soma dos termos de penalidade à função objetivo original:

Otimização em Nível Estratégico:

$$
o b j F=\sum C b+P_{1}+P_{2}+P_{3}+P_{5}
$$

Otimização em Tempo Real:

$$
o b j F=\sum C b+P_{1}+P_{4}+P_{3}+P_{5}
$$


em que: objF é a função de aptidão; $\mathrm{Cb}$ é o custo de bombeamento ( $\mathrm{R} \$ /$ dia); $\mathrm{P}_{1}$ é Penalidade 1 - Pressões inferiores à mínima; $\mathrm{P}_{2}$ é Penalidade 2 - Diferença entre os níveis inicial e final nos reservatórios; $\mathrm{P}_{3}$ é Penalidade 3 - Quantidade de acionamentos das bombas e válvulas; $\mathrm{P}_{4}$ é Penalidade 4 - Diferença entre os níveis dos reservatórios e níveis meta; e, $\mathrm{P}_{5}$ é Penalidade 5 - Continuidade do abastecimento.

\subsubsection{Algoritmos Genéticos - Operadores e Parâmetros}

Para a aplicação dos AGs devem ser definidos os operadores e parâmetros genéticos - Etapa 2, do procedimentos de otimização.

Os tipos de operadores genéticos em questão são aqueles disponíveis na GAlib, que é o conjunto de objetos de algoritmos genéticos em $\mathrm{C}++$ utilizados para implementação do referido método.

Os operadores e parâmetros genéticos são sensíveis às funções objetivo, à quantidade de variáveis de decisão e aos indicadores de desempenho e a melhor implementação destes não é tão óbvia. Conseqüentemente, diferentes estudos resultam em diferentes conclusões sobre valores ótimos dos parâmetros, requerendo investigações por parte do usuário.

Dentre as técnicas citadas pela literatura especializada para determinação dos parâmetros genéticos destacam-se: as análises de sensibilidade, aplicadas por diversos pesquisadores, tais como Pedrosa (2006), Carrijo (2005) e Sousa (2007), em problemas de otimização da operação de sistemas de abastecimento de água; e, a aplicação do Swarm Particle Optimization - SPO, (Zeferino et al., 2007 e Moraes, 2008).

Como a aplicação do SPO requer a realização de diversas iterações e em cada uma delas é necessário "rodar" o modelo otimizador para avaliação da solução gerada pelo SPO, demandando tempo excessivamente longo, optou-se pela realização de análise de 
sensibilidade para aferir os operadores genéticos e os valores dos parâmetros a adotar, buscando assim que um bom desempenho seja atingido. 
“Experiência não é o que aconteceu com você, mas o que você fez com o que lhe aconteceu."

\section{Sistema Objeto de Estudo}

Um dos principais entraves ao desenvolvimento deste trabalho foi a indisponibilidade de dados de um sistema de abastecimento de água real necessários à otimização, a saber: topologia do sistema (cotas topográficas, diâmetros e comprimentos das tubulações, arranjo hidráulico e interligações, curvas das bombas e rendimento, etc.), dados de pressão e vazão para calibração e demandas horárias na saída dos reservatórios.

Atribui-se essa ausência de dados principalmente à falta real de macromedição e armazenamento dos dados históricos de vazão dos sistemas de abastecimento de água, que ainda ocorre na maioria das companhias de saneamento no Brasil.

Após algumas tentativas frustradas em diferentes companhias de saneamento, optouse por adotar o sistema estudado por Pedrosa (2006) que abastece parte da cidade de João Pessoa/PB e dispõe de todos os dados de topologia necessários já calibrados pelo autor. E sintetizar uma série de demandas horárias para os nós de saída dos reservatórios utilizando o histórico de demandas horárias da cidade de São Carlos/SP.

Assim, o sistema aqui estudado corresponde àquele sistema apresentado por Pedrosa (2006), no que se refere às cotas topográficas, diâmetros e comprimentos das tubulações, arranjo hidráulico e interligações, curvas das bombas e rendimento, demandas base dos nós, etc., todos retirados da tese do autor. No entanto, o histórico de demandas foi sintetizado, não correspondendo às demandas reais observadas em tal sistema. 


\subsection{Descrição do Sistema Objeto de Estudo}

O sistema objeto de estudo, representado na Figura 4.1, possui 2 fontes de suprimento de água (1ETA e 1 poço profundo), 5 reservatórios, 3 estações elevatórias (aqui denominadas EEAT, $\mathrm{CR}_{1}$ e $\mathrm{CR}_{2}$ ), 4 válvulas controladoras de vazão e aproximadamente $9,5 \mathrm{~km}$ de adutoras.

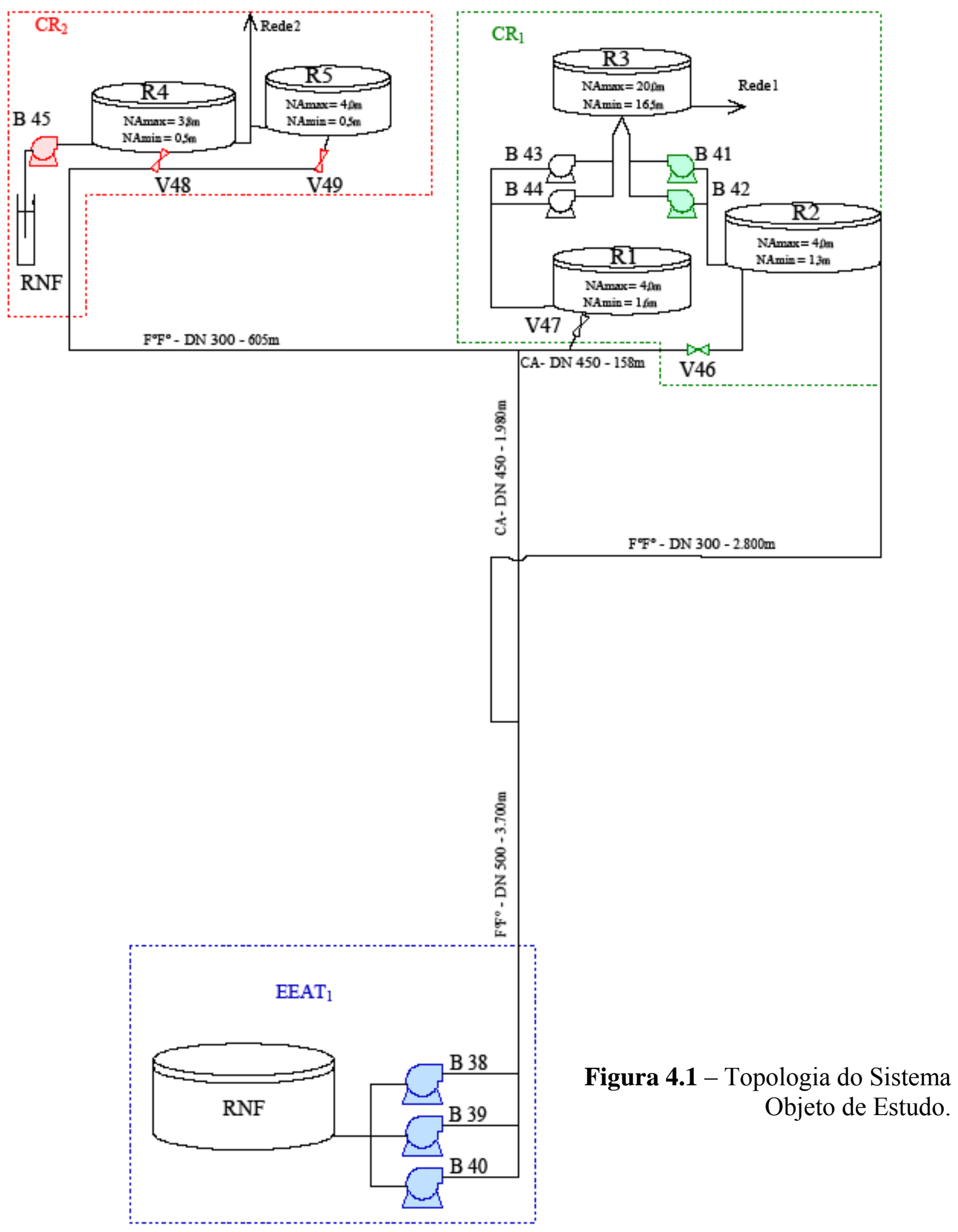




\subsubsection{Estação Elevatória de Água Tratada - EEAT}

A EEAT é responsável pelo recalque da água tratada da ETA até os Centros de Reservação 1 e 2. Nesta elevatória existem três bombas, duas Worthington 8-LN-21, motor $500 \mathrm{cv}, 1.765 \mathrm{rpm}$, podendo trabalhar associadas em paralelo, e uma de reserva Worthington 12-LN-26, motor $750 \mathrm{cv}$ de $1.175 \mathrm{rpm}$.

A linha de recalque principal é constituída por dois trechos contínuos interligados. O primeiro trecho é formado por $3.700 \mathrm{~m}$ de tubos de ferro fundido, DN 500, e o segundo com $2.300 \mathrm{~m}$ de extensão, constituído por tubos de cimento-amianto, DN $450 \mathrm{~mm}$, totalizando 6.000 metros de linha adutora, até sua chegada ao $\mathrm{CR}_{1}$. Cerca de 25 metros antes da chegada no $\mathrm{CR}_{1}$ há duas válvulas de gaveta, V46 e V47, que controlam a admissão da água ao Centro.

$\mathrm{Na}$ interligação entre os dois trechos da linha de recalque principal inicia-se uma linha "em paralelo" à esta linha principal, com 2.800 m de tubos de ferro fundido, DN 300, $\mathrm{m}$ até o reservatório $\mathrm{R} 1$ do $\mathrm{CR}_{1}$.

Quase no final da linha tronco tem início uma sub-adutora de $605 \mathrm{~m}$ de comprimento formada por tubos de ferro fundido, DN 300, responsável principal pelo abastecimento de água do $\mathrm{CR}_{2}$.

\subsubsection{Centro de Reservação 1 - CR1}

O Centro de Reservação $1\left(\mathrm{CR}_{1}\right)$ é formado por dois reservatórios semi-enterrados (R1 e R2) totalizando um volume de $5.000 \mathrm{~m}^{3}$, duas elevatórias com duas bombas cada 
(Tabela 4.1), e um reservatório elevado (R3) com capacidade para armazenar $2.000 \mathrm{~m}^{3} \mathrm{de}$ água.

Tabela 4.1 - Dados dos conjuntos moto bombas do CR1. Fonte: Pedrosa (2006).

\begin{tabular}{|l|c|c|c|c|}
\hline \multirow{2}{*}{ ID } & \multicolumn{2}{|c|}{ Bomba } & \multicolumn{2}{c|}{ Motor } \\
\cline { 2 - 5 } & Fabricante & Modelo & Potência (cv) & Rotação (rpm) \\
\hline B41 & Worthington & 6 CNE-104 & 60 & 1.750 \\
\hline B42 & Worthington & 6 CNE-104 & 75 & 1.750 \\
\hline B43 & Worthington & 6 CNE-104 & 60 & 1.750 \\
\hline B44 & Worthington & 6 CNE-104 & 75 & 1.750 \\
\hline
\end{tabular}

A água chega no reservatório R2 de onde é recalcada por duas bombas em paralelo para o reservatório elevado, $\mathrm{R} 3$, através de uma curta adutora de $43 \mathrm{~m}$ de extensão em ferro fundido, DN 500, e desnível geométrico de cerca de 20 metros.

O reservatório R1 é utilizado como reserva técnica, seu funcionamento se dá apenas nos meses de maior solicitação, quando essa unidade passa a operar normalmente, contando com a ajuda das bombas B43 ou B44 para recalcar água até o reservatório elevado R3.

Como essas duas bombas não fazem parte da operação normal diária do sistema na maioria dos meses do ano, sua operação não foi incluída no conjunto de variáveis de decisão do problema operacional aqui tratado.

Por problema de estanqueidade na válvula V47 (Figura 4.1), que controla o fluxo de água para o reservatório R1, uma vazão estimada de $10 \mathrm{~L} / \mathrm{s}$ aflui a essa unidade mesmo a válvula estando totalmente fechada. Para evitar o transbordamento desse reservatório uma das bombas conectadas a ele é acionada uma hora por dia para fazer cair o nível de água no seu interior. 


\subsubsection{Centro de Reservação 2 - CR2}

O Centro de Reservação $2\left(\mathrm{CR}_{2}\right)$ é formado por dois reservatórios semi-enterrados (R4 e R5) totalizando o volume de $4.000 \mathrm{~m}^{3}$ e um poço artesiano, capacidade de produção de $11,9 \mathrm{~L} / \mathrm{s}$, com $176 \mathrm{~m}$ de profundidade (DN $150 \mathrm{~mm}$ ).

Os dois reservatórios semi-enterrados podem abastecer simultaneamente a rede de distribuição a jusante. No entanto, eles estão assentados em cotas topográficas diferentes, o que faz com que o reservatório R5, de maior cota piezométrica, tenha capacidade de abastecer, tanto a rede, como o reservatório R4.

O modelo hidráulico construído no EPANET admite uma válvula de retenção na saída do reservatório R4, como forma de direcionar o fluxo de água apenas para a rede de distribuição, simplificando o processo.

Há, também, duas válvulas tipo gaveta (V48 e V49) que controlam o fluxo de entrada aos dois reservatórios.

\subsection{Energia Elétrica}

O custo unitário da energia, em unidades monetárias por $\mathrm{kWh}$, foi estabelecido em conformidade com as tarifas cobradas pelas empresas concessionárias de energia elétrica. As tarifas cobradas dos consumidores finais estruturam-se tanto por nível de tensão (alta, média e baixa), como por classe de consumo (residencial, industrial, comercial, rural, serviços públicos, poderes públicos e iluminação pública). Os consumidores ligados em alta e média tensão têm a possibilidade de escolher tarifas diferenciadas por horário de consumo (ponta e fora de ponta) e por época do ano (período úmido e período seco). Os consumidores de média e alta tensão são classificados no Grupo A, cuja tensão de 
alimentação é superior a $2,3 \mathrm{kV}$ e os de baixa no Grupo $\mathrm{B}$, com tensão de alimentação menor ou igual a $2,3 \mathrm{kV}$.

A operação da rede pública de abastecimento de água se enquadra na categoria de Serviço Público, normalmente ligada em alta e média tensão.

As faturas de energia elétrica dos consumidores do Grupo A, no qual se enquadram as concessionárias de água, são compostas por dois tipos de tarifas: de consumo e de demanda. A tarifa de consumo corresponde àquela cobrada pela energia efetivamente consumida pela estação de bombeamento; e a tarifa de demanda corresponde a um valor cobrado mensalmente pela potência instalada, demandada pela estação de bombeamento. Essas faturas de tarifa podem ainda ser efetivadas segundo duas modalidades: a convencional e a horo-sazonal, esta última divida em azul e verde.

A horo-sazonal azul possui quatro valores diferenciados para a tarifa de consumo: para os horários ponta em período úmido e seco e fora de ponta em período úmido e seco, e dois valores de demandas.

A tarifa horo-sazonal verde é cobrada com uma tarifa de demanda única, independente do horário e período de operação. Para a tarifa de consumo existem 4 valores diferenciados segundo os horários de ponta e fora de ponta e para os períodos seco e úmido.

Dentro da estrutura tarifária acima explicitada a unidade consumidora EEAT $_{1}$ está sujeita ao regime tarifário horo-sazonal Azul, a unidade consumidora $\mathrm{CR}_{1}$ é enquadrada no regime Convencional e o $\mathrm{CR}_{2}$ operando com apenas uma bomba submersa, é submetido à tarifação Convencional do Sub-Grupo B3 (baixa tensão).

Neste estudo de caso, todas as tarifas unitárias envolvidas no processo de otimização estão apresentadas na Figura 4.2, correspondentes ao período de janeiro a abril de 2004, obtidas em Pedrosa (2006). 


\begin{tabular}{|c|c|c|c|c|}
\hline \multicolumn{3}{|c|}{ Tarifa horo-sazonal azul } & \multirow{2}{*}{\multicolumn{2}{|c|}{$\begin{array}{c}\text { Tarifa horo-sazonal verde } \\
\text { Consumo }(\mathrm{R} \$ \mathrm{kWh})\end{array}$}} \\
\hline \multirow{10}{*}{$\begin{array}{l}\text { Sub-Grupo A4 } \\
(2,3 \text { a } 25 \mathrm{kV})\end{array}$} & \multicolumn{2}{|c|}{ Consumo (R\$/kWh) } & & \\
\hline & \multicolumn{2}{|c|}{ Fora de Ponta } & \multicolumn{2}{|c|}{ Fora de Ponta } \\
\hline & Seca & Úmida & Seca & Úmida \\
\hline & 0,11160 & 0,09586 & 0,10299 & 0,0910 \\
\hline & \multicolumn{2}{|c|}{ Ponta } & \multicolumn{2}{|c|}{ Ponta } \\
\hline & Seca & Úmida & Seca & Úmida \\
\hline & 0,21799 & 0,19768 & 0,87986 & 0,86542 \\
\hline & \multicolumn{2}{|c|}{ Demanda $(\mathrm{R} \$ / \mathrm{kW})$} & \multicolumn{2}{|c|}{ Demanda $(\mathrm{R} \$ / \mathrm{kW})$} \\
\hline & Fora de Ponta & Ponta & \multirow{2}{*}{\multicolumn{2}{|c|}{11,5456}} \\
\hline & 9,77000 & 29,76000 & & \\
\hline
\end{tabular}

\begin{tabular}{|c|c|}
\hline \multicolumn{2}{|c|}{ Tarifa convencional } \\
\hline Sub-Grupo A4 & Consumo $(\mathrm{R} \$ / \mathrm{kWh})$ \\
\cline { 2 - 2 }$(2,3 \mathrm{a} 25 \mathrm{kV})$ & 0,16176 \\
\cline { 2 - 2 } & Demanda $(\mathrm{R} \$ / \mathrm{kW})$ \\
\cline { 2 - 2 } & 13,120 \\
\hline
\end{tabular}

\begin{tabular}{|c|c|}
\hline \multicolumn{2}{|c|}{ Tarifa convencional } \\
\hline $\begin{array}{c}\text { Sub-Grupo B3 } \\
\text { (<600 V) }\end{array}$ & Consumo (R\$/kWh) \\
\cline { 2 - 2 } & 0,29263 \\
\hline
\end{tabular}

- Horánio de Ponta 3 horas consecutivas entre 17 h e $22 \mathrm{~h}$

- Horário Fora de Ponta as demais horas e sábados, domingos e feriados

- Período Seco: de maio até novembro

- Período Úmido: de dezembro até abril

Figura 4.2 - Tarifa horo-sazonal verde e azul para o Sub-Grupo A4, convencional para o Sub-Grupo A4 e convencional para o Sub-Grupo A3. Fonte: Pedrosa (2006).

O horário de ponta foi estabelecido para o período entre $17 \mathrm{~h}: 30 \mathrm{~min}$ e 20h:30 min. Como neste trabalho a discretização do horizonte de planejamento é horária, adotou-se a simplificação de que o horário de ponta ocorre entre 18h:00 min e 21h:00 min.

\subsection{Demandas}

Como não se dispõe de histórico de demandas horárias na saída dos centros de reservação - nós Rede1 e Rede2 (Figura 4.1), optou-se por adimensionalizar os dados de demanda horária disponíveis para os reservatórios Parque Fehr e São Carlos III na cidade de São Carlos/SP (Moreira, 2007), e multiplicá-los pela demanda base dos nós Redel e 
Rede2, apresentadas por Pedrosa (2006), de 234,7 L/s e 75,0 L/s, respectivamente, obtendo-se, assim, uma série sintética de dados de demanda.

Uma vez que para a otimização em tempo real utilizam-se como base os valores adimensionalizados de Moreira (2007), também definiu-se a utilização das curvas médias de demanda do sistema apresentado pelo referido autor.

Para obter as curvas médias de demanda, Moreira (2007) submeteu o histórico de demandas medidas, referente aos dias 27/05/2005 à 17/08/2005, a um processo de preenchimento de falhas e filtragem, baseado na metodologia proposta por Zahed (1990), agrupou estes dados de acordo com o dia de semana e, posteriormente, para cada dia de semana avaliou a média construindo a curva de vazão ao longo do dia para todos os dias da semana.

Com o objetivo de obter um padrão diário de demanda, adimensionalisou-se as curvas apresentadas por Moreira (2007), dividindo-se as vazões da curva pela vazão média do dia a que se referem. Os resultados obtidos estão apresentados no gráfico da Figura 4.3.

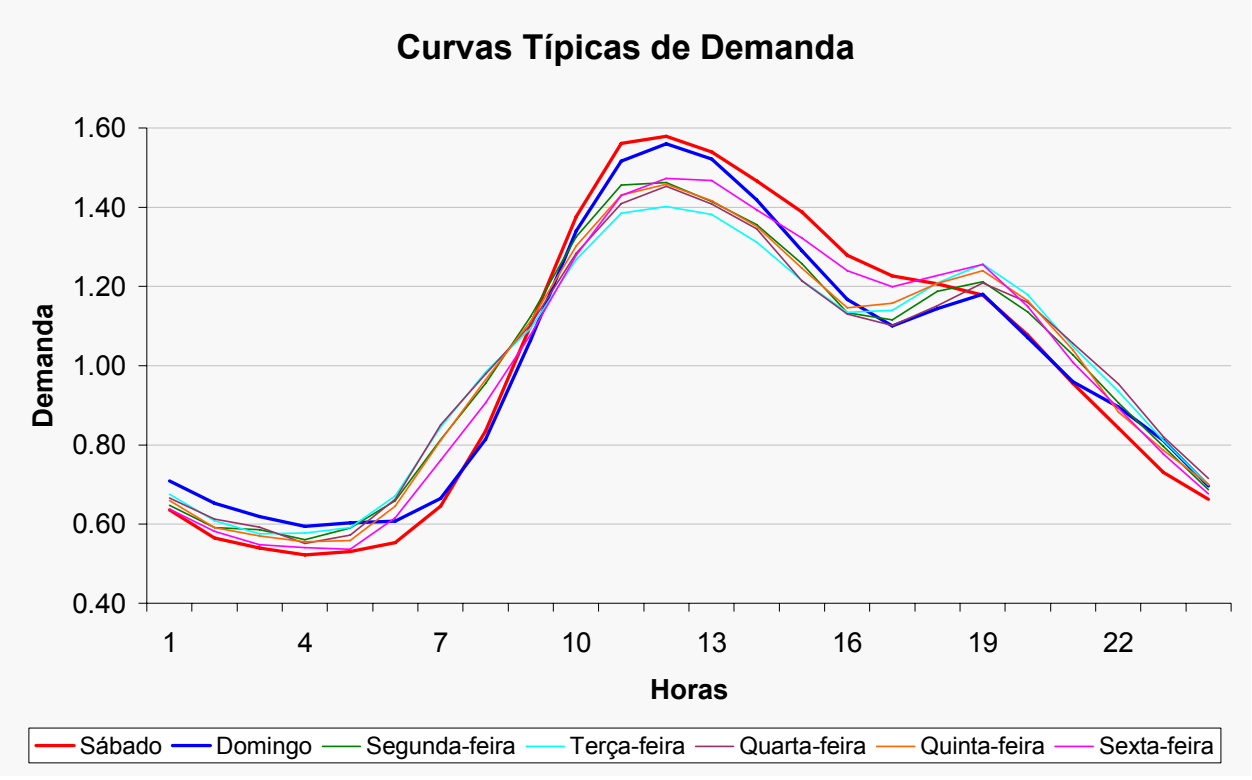

Figura 4.3 - Curvas Típicas de Demanda para todos os dias da semana. 


\subsection{Variáveis de Decisão}

O sistema estudado possui 12 elementos passíveis de terem seu estado de funcionamento alterado durante a operação, sendo 8 bombas e 4 válvulas. No entanto, as bombas B43 e B44 e a válvula V47 não são normalmente operadas uma vez que o reservatório R2 é considerado reserva técnica.

Assim, nove são as variáveis de decisão para cada hora do período de planejamento, totalizando 216 elementos $(9 \times 24$ horas $)$. 
"Você tem de refletir sobre as grandes coisas enquanto está fazendo as pequenas coisas, para que todas as pequenas coisas sigam a direção correta."

Alvin Toffler

\section{Aplicação do Modelo Desenvolvido}

O desenvolvimento do modelo de otimização construído compreendeu cinco fases distintas, conforme o fluxograma apresentado na Figura 5.1.
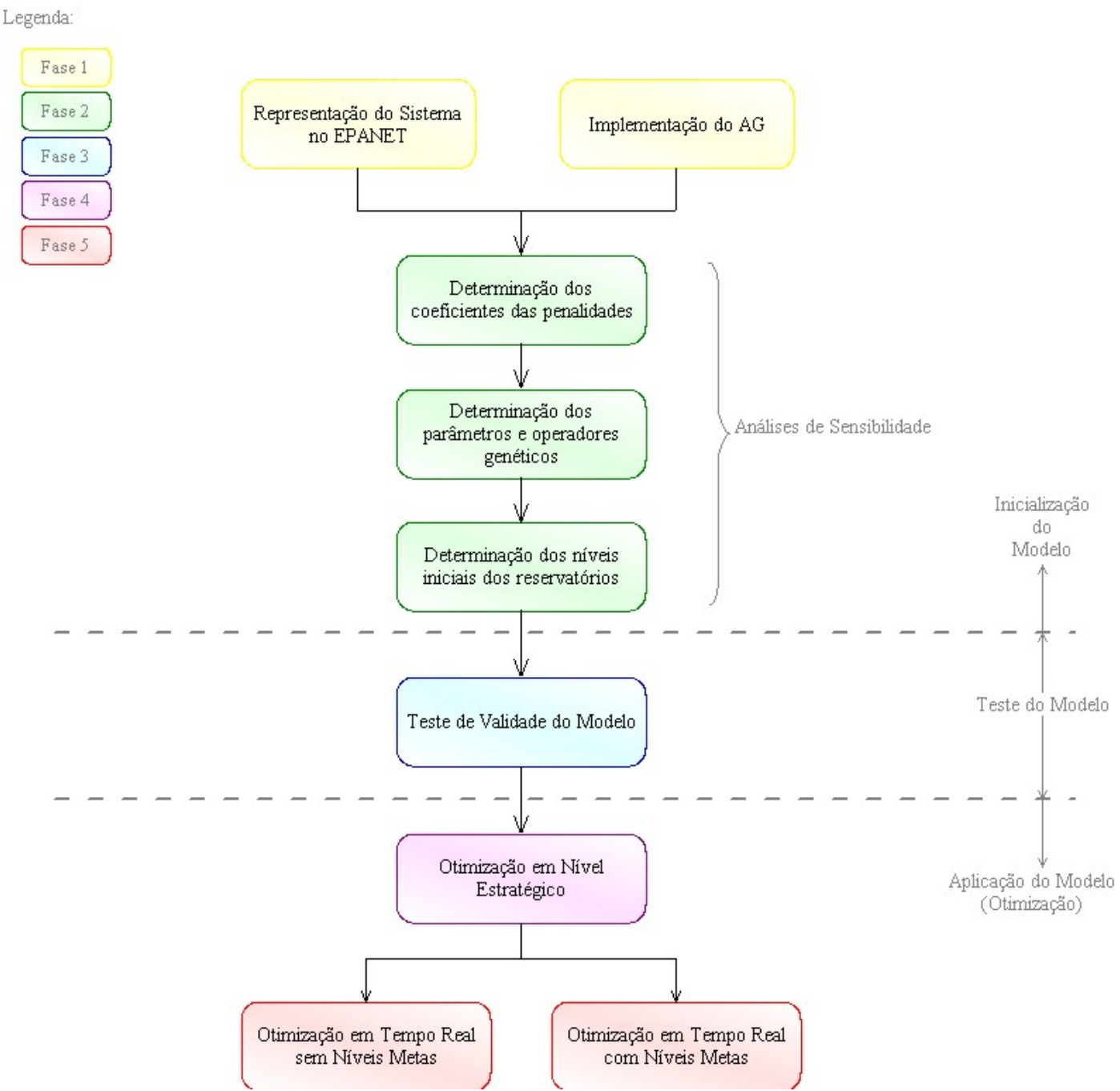

Figura 5.1 - Organização da Aplicação do Modelo Desenvolvido. 
Nas Fases 1 e 2 foram realizadas a representação do sistema estudado no modelo desenvolvido (representação no EPANET e a implementação do AG) e as análises de sensibilidade para determinação dos coeficientes de penalidade $(\lambda 1, \lambda 2, \lambda 3, \lambda 5)$, dos operadores e parâmetros genéticos (tamanho da população, tipo de seleção, tipo e probabilidade de cruzamento e probabilidade de mutação) e dos níveis iniciais dos reservatórios.

A Fase 3 correspondeu ao teste de validade do modelo desenvolvido. Adotando-se as curvas de demandas citadas por Pedrosa (2006) e os mesmos níveis iniciais utilizados pelo autor, realizou-se a otimização em Nível Estratégico, verificando-se assim a capacidade do modelo desenvolvido em produzir bons resultados.

Já na Fase 4 realizou-se a otimização propriamente dita. Foram determinados os Níveis Metas a serem utilizados na Otimização em Tempo Real com base nas curvas de demanda de São Carlos para dias úteis, sábados e domingos. Na Fase 5 realizou-se análise de sensibilidade para determinação do coeficiente de penalidade para os níveis metas $\left(\lambda_{4}\right)$ e, posteriormente, a Otimização em Tempo Real propriamente dita considerando duas hipóteses: com os Níveis Metas; e, sem os Níveis Metas (elimina-se a Penalidade 4 e inclui a 2). Nesta última fase também foram comparados os resultados da Otimização em Tempo Real utilizando as demandas previstas pelo Módulo de Previsão de Demandas e utilizando as demandas reais observadas, de forma a analisar a influência da qualidade da previsão de demandas sobre os resultados da Otimização. 


\subsection{Estrutura do Modelo Desenvolvido}

O modelo computacional desenvolvido é constituído por três módulos: módulo de simulação hidráulica; módulo de previsão de demandas; e, módulo de otimização.

Os módulos de simulação hidráulica e de previsão de demandas podem ser aplicados individualmente e independentemente dos restantes desde que o objetivos da sua utilização seja o cálculo das variáveis hidráulicas do sistema, no caso no simulador hidráulico, e o cálculo das demandas previstas, para o módulo de previsão. No entanto, a aplicação do módulo de otimização não é independente, na medida em que a aplicação deste módulo tem por base os resultados obtidos na execução do módulo de simulação hidráulica e necessita, como dado de entrada, das demandas previstas. Por outro lado, a aplicação do módulo de otimização gera novos dados de entrada para o módulo de simulação hidráulica, novas estratégias operacionais (estado de funcionamento das bombas e válvulas) e variáveis de estado (níveis de operação dos reservatórios).

A dinâmica entre módulos é um processo iterativo que se repete consecutivamente até que o critério de parada estabelecido no módulo de otimização seja verificado.

\subsection{Simulador Hidráulico - EPANET}

A aplicação do modelo de otimização desenvolvido pressupõe a disponibilidade de um módulo de simulação que represente de forma fidedigna o comportamento do sistema em estudo.

De uma maneira geral as redes hidráulicas são representadas por uma rede de fluxo formada por um conjunto de trechos (links) conectados a nós (nodes) nas suas extremidades. 
O sistema em estudo (Figura 5.2) foi modelado no EPANET considerando os seguintes componentes físicos:

- 36 Nós: representativos das singularidades do sistema (mudança de material, mudança de diâmetro, confluência de condutos) e de pontos aos quais está associado um padrão temporal de demanda;

- 49 Trechos: que além das tubulações, representam os conjuntos moto bombas instalados nas estações elevatórias (5) e as válvulas de controle hidráulico existentes (4).

- 2 Reservatórios de Nível Fixo (RNF): representam um volume de capacidade ilimitada e carga hidráulica constante. No sistema em questão tanto o poço profundo é considerado como um RNF, cujo nível de água é igual à cota piezométrica do aqüífero, como o poço de sucção da $\mathrm{EEAT}_{1}$, a jusante da ETA.

- 5 reservatórios de nível variável (RNV): caracterizam-se por apresentar volume definido, podendo ocorrer variação do nível de água no seu interior ao longo de uma simulação de período estendido. O Sistema possui 5 RNVs: os reservatórios semienterrados R1, R2, R4 e R5 e o reservatório elevado R3.

A válvula de gaveta, V46, foi modelada no EPANET como TCV (throttle control valve). Ela controla o fluxo para o reservatório $\mathrm{R} 1$ trabalhando totalmente aberta, exceto quando há a necessidade de aumentar a oferta de água ao CR2, ocasião em que ela é manobrada manualmente para que a gaveta (cunha) ocupe uma posição correspondente a uma abertura de aproximadamente $20 \%$ da seção plena.

A válvula, V47, também do tipo gaveta, controla o fluxo para o reservatório R2. Este dispositivo sempre permanece fechado, uma vez que o volume do reservatório é considerado reserva técnica. No entanto, sua estanqueidade está comprometida, permitindo continuamente a passagem de uma vazão aproximada de $10 \mathrm{~L} / \mathrm{s}$ para o interior do 
compartimento, fato que força o acionamento de uma das bombas durante uma hora por dia para abaixar o nível de água e evitar o transbordamento do R2. A modelação dessa válvula, com essas características, foi possível considerando-a uma Válvula Controladora de Fluxo (FCV).

Para os conjuntos moto bombas adotaram-se as curvas características e de rendimento apresentadas por Pedrosa (2006). 


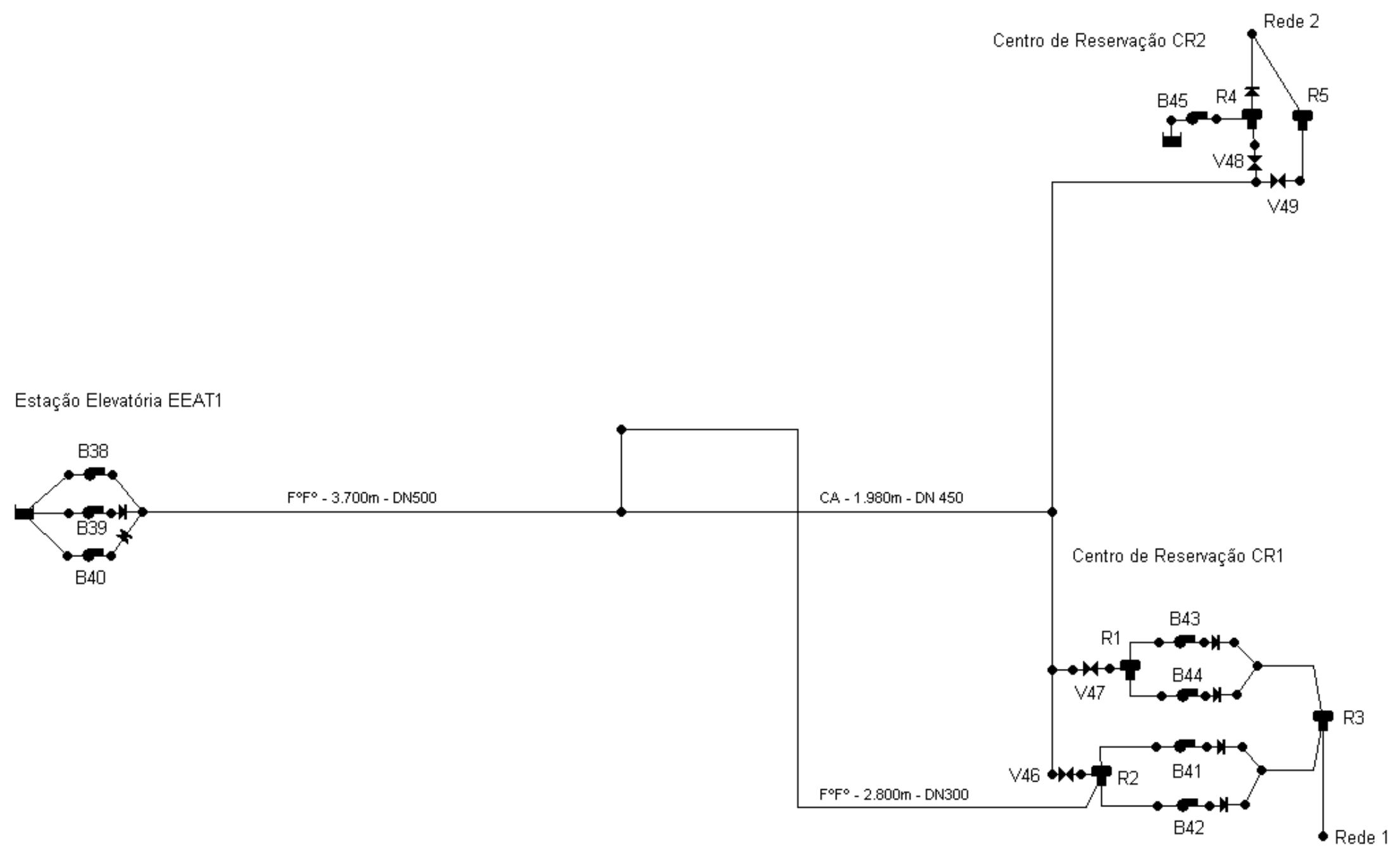

Figura 5.2 - Representação no EPANET do Sistema Estudado. 


\subsection{Módulo Otimizador}

O Capítulo 3 desta dissertação estabeleceu a metodologia utilizada para implementação dos AGs, bem como as funções da GAlib utilizadas. Mostra-se aqui apenas um pequeno resumo da implementação do AG considerando as características do sistema estudado.

Cabe ressaltar que as funções da GAlib variam de acordo com o tipo de genoma utilizado, conforme explicado anteriormente. Portanto, todas as funções implementadas levavam em consideração as características do sistema estudado para utilização da representação binária das soluções (genoma binário).

\subsubsection{Implementação do Algoritmo Genético}

\section{Função Objetivo}

Considerando que o sistema objeto de estudo possui 6 bombas $(B 38, B 39, B 40, B 41$, $B 42$ e B45) e 3 estações elevatórias (apenas 2 possuem custo de demanda, $E E A T_{l}$ e $C R_{l}$ ) a equação para o cálculo do custo de bombeamento $(\mathrm{Cb})$ pode ser representada por:

$$
C b=\sum_{b=1}^{6} \sum_{t=1}^{T=24}[\text { custoconsumo }(b, t)]+\sum_{e=1}^{2} \text { custodemanda }(e)
$$

\section{$\underline{\text { Penalidade } 1 \text { - Pressões inferiores à mínima }}$}

Como apenas os nós Rede 1 e Rede 2 possuem demanda, a Penalidade 1 é representada por: 


$$
P_{1}=\lambda_{1}\left[\sum_{t=1}^{T=24}\left(10-P_{\operatorname{Re} d e l t}\right)+\sum_{t=1}^{T=24}\left(10-P_{\operatorname{Re} d e 2 t}\right)\right], \quad \text { sendo }\left(P_{\operatorname{Re} d e 1 t}, P_{\operatorname{Re} d e 2 t}\right)<10
$$

em que: $\lambda_{1}$ é o coeficiente de penalidade a ser aplicado à restrição $\mathrm{P}_{1} ; \mathrm{P}_{\mathrm{t}}$ é a pressão nos nós Rede 1 e Rede 2 (Figura 4.1) na hora $t$; e, $\mathrm{P}_{\min }$ é igual a $10 \mathrm{mH} 2 \mathrm{O}$ (conforme preconiza a NBR 12218).

$\underline{\text { Penalidade } 2 \text { - Diferença entre os níveis inicial e final nos reservatórios }}$

$$
\begin{array}{lr}
P_{2}=\lambda_{2} \sum_{r=1}^{R=5}\left(N_{\text {inicial }, r}-N_{\text {final }, r}\right), & \text { sendo } \\
P_{2}=0, & N_{\text {inicial }, r}>N_{\text {final }, r} \\
& \text { para } N_{\text {inicial }, r}<N_{\text {final }, r}
\end{array}
$$

em que: $\lambda_{2}$ é o coeficiente de penalidade a ser aplicado à restrição $\mathrm{P}_{2} ; N_{\text {inicial }, r}$ e $N_{\text {final }, r}=$ níveis de água nos reservatórios $R 1, R 2, R 3 R 4$ e $R 5$ para os instantes inicial e final $(t=0$ e $t=24$, respectivamente)

$\underline{\text { Penalidade } 3 \text { - Quantidade de acionamentos das bombas }}$

A partir do quinto acionamento a restrição é considerada violada, sendo então aplicada a seguinte função penalidade:

$$
P_{3}=\lambda_{3}\left(\sum_{b=1}^{B=6} N A_{b}+\sum_{v=1}^{V=3} N A_{v}\right), \quad \text { sendo } \quad N A>4
$$

em que: $\lambda_{3}$ é o coeficiente de penalidade a ser aplicado à restrição $\mathrm{P}_{3} ; \mathrm{NA}_{\mathrm{b}}$ é o número de acionamento de cada bomba $(B 38, B 39, B 40, B 41, B 42$ e B45) para o horizonte de planejamento considerado; e, $\mathrm{NA}_{\mathrm{v}}$ é o número de manobra de cada válvula (V46, V48 e V49) para o horizonte de planejamento considerado. 
Penalidade 4 - Diferença entre os níveis dos reservatórios e níveis meta

Essa penalidade faz com que os Níveis Meta sirvam de guia para a Otimização em Tempo Real.

$$
P_{4}=\lambda_{4} \sum_{r=1}^{R=5} \sum_{t=1}^{T=24} N m e t a_{r t}-N_{r t}, \quad \text { sendo } \quad N m e t a_{r t}>N_{r t}
$$

em que: $\lambda_{4}$ é o coeficiente de penalidade a ser aplicado à restrição $\mathrm{P}_{4} ; N$ Neta ${ }_{r, t}$ é o nível meta do reservatório $r$ no instante $t$; e, $N_{r t}$ é o nível dos reservatórios $(R 1, R 2, R 3, R 4$ ou $R 5$ ) no instante $t$, determinado pela Otimização em Tempo Real.

$\underline{\text { Penalidade } 5 \text { - Continuidade do Abastecimento }}$

$$
P_{5}=\lambda_{5} \sum_{t=1}^{T=24} \text { warningcode, se warningcode }=3 \text { ou } 6
$$

em que: $\lambda_{5}$ é o coeficiente de penalidade a ser aplicado à restrição $\mathrm{P}_{5}$; warningcode é código de alerta gerado pela função $E N r u n H$.

\section{$\underline{\text { Representação da Solução }}$}

A cadeia de valores para as variáveis que representam completamente uma solução para o problema em estudo representa o estado de cada componente operacional do sistema: ligado ou desligado para os bombas, e aberto ou fechado para as válvulas. $\mathrm{Na}$ Figura 5.3 é exemplificado o vetor solução, com 216 elementos, sendo 6 bombas e 3 válvulas.

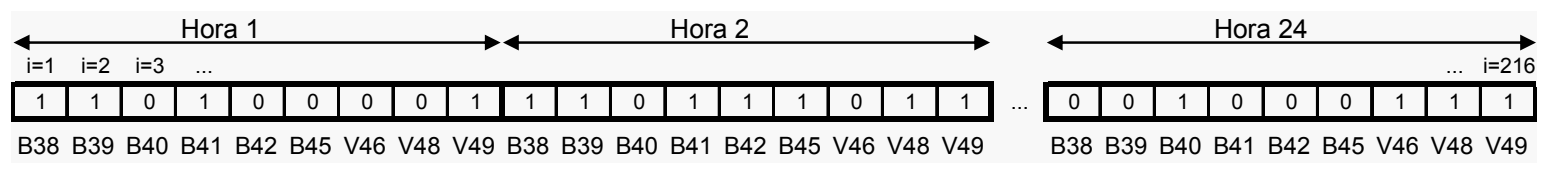

Figura 5.3 - Representação esquemática do vetor solução. 


\subsubsection{Análises de Sensibilidade}

Conforme citado no Capítulo 3 - Modelo Otimizador, existem diferentes variáveis que afetam o processo de otimização, tais como coeficientes das penalidades, operadores e parâmetros genéticos e níveis iniciais dos reservatórios, cuja definição constitui tarefa para quem emprega a técnica dos algoritmos genéticos como ferramenta de otimização.

Neste trabalho optou-se por testar os parâmetros que afetam o processo de otimização, com critério de parada de 1.500 gerações, e realizar análises de sensibilidade dos resultados obtidos para determinação das diferentes variáveis. A seguir são apresentados os resultados de tais analises.

\subsubsection{Operadores e Parâmetros Genéticos}

A técnica otimização adotada inicia-se com a criação da população inicial de soluções. Para que o AG inicie sempre com a mesma população, podendo chegar ao mesmo valor otimizado a cada aplicação do programa computacional, é necessário informar a "semente"geradora da regra pseudo aleatória a ser utilizada pela GAlib.

Semente (Random seed) nada mais é que um número utilizado como ponto de partida para o gerador aleatório, fazendo com que este inicie em um determinado ponto da seqüência pseudo-randômica. Se a mesma semente é utilizada, a seqüência dos aleatórios gerada será a mesma.

O caráter estocástico do algoritmo genético permite encontrar, para cada semente utilizada, uma solução diferente para o problema, com um custo energético próximo do ótimo global. Portanto, para as análises de sensibilidade dos operadores e parâmetros 
genéticos efetuaram-se as otimizações com seis diferentes valores de semente, ou seja, a partir de 6 populações iniciais de soluções distintas.

Os coeficientes das penalidades utilizados são os definidos no item anterior e o nível inicial dos reservatórios foi fixado em $80 \%$ do nível máximo de cada reservatório - Tabela 5.1.

Tabela 5.1 - Valores adotados nas análises de sensibilidade dos operadores e parâmetros do AG.

\begin{tabular}{|l|c|}
\hline \multicolumn{1}{|c|}{ Variáveis } & Default \\
\hline Sementes utilizadas & $800 ; 1.000 ; 1.500 ; 2.000 ; 2.500 ;$ e 3.000 \\
\hline Critério de Parada & 1.500 gerações \\
\hline Níveis Iniciais & $80 \%$ do máximo \\
\hline$\lambda_{1}, \lambda_{2}, \lambda_{3}$ e $\lambda_{5}$ & $1.000 ; 1.000 ; 50 ; 1.000$ \\
\hline
\end{tabular}

Tamanho da População

O tamanho da população depende do problema e da sua formulação. Populações de pequenas dimensões causam convergência prematura do AG para um mínimo local porque a pesquisa ocorre em um espaço de busca de poucas possibilidades. Por outro lado, populações grandes identificam boas soluções após um número grande de geração de AG, consumindo tempo computacional elevado.

Para determinar o tamanho de população a adotar foram avaliadas populações com 20, 50, 100 e 150 indivíduos, para as diferentes sementes, considerando para cada alternativa os mesmos operadores e parâmetros genéticos. Os resultados assim obtidos são apresentados na Figura 5.4. 
(a)

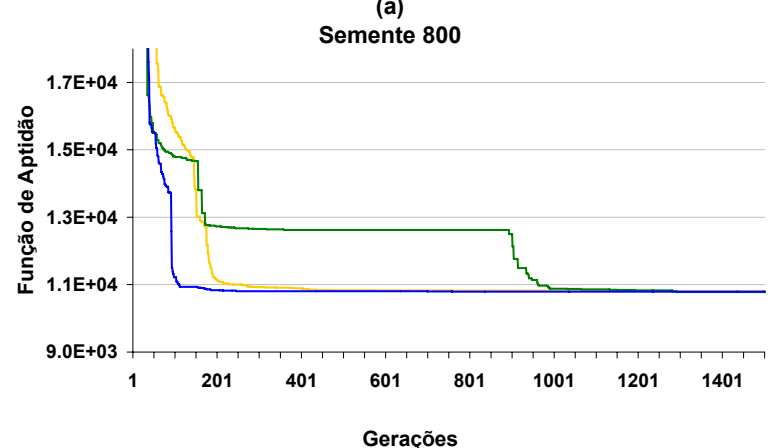

(c)

Semente 1.500

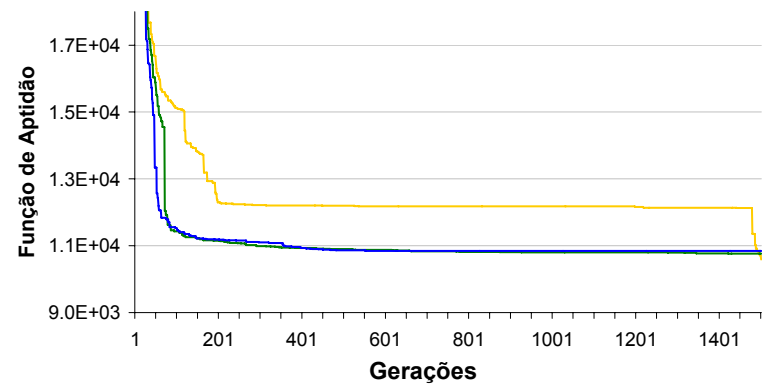

(e)

Semente 2.500

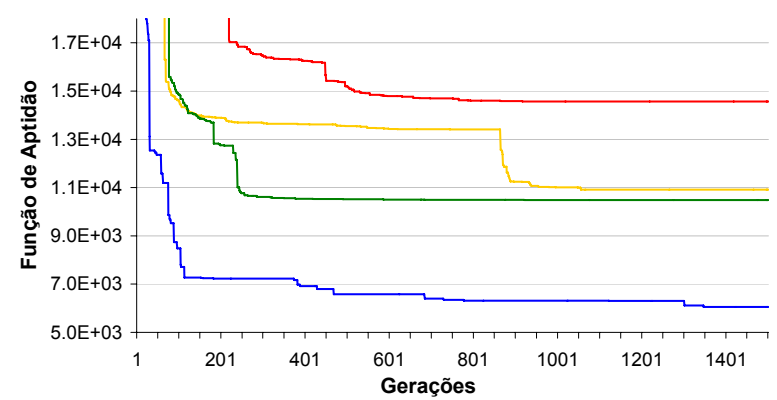

(b)

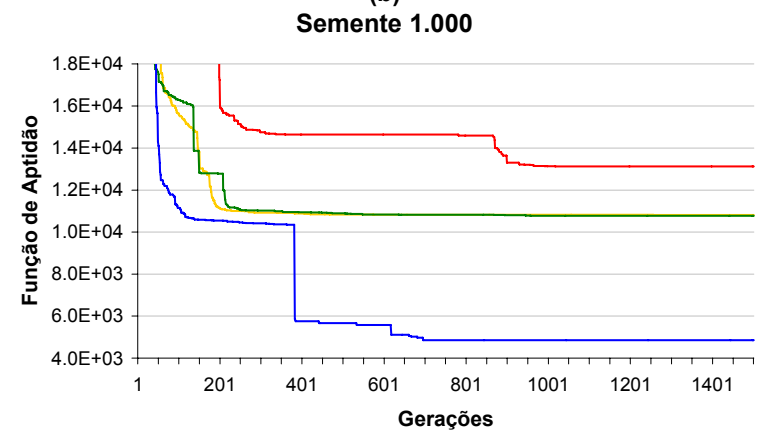

(d)

Semente 2.000

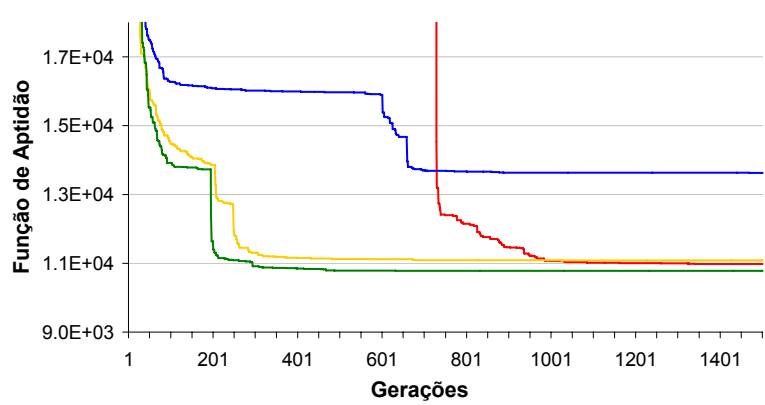

(f)

Semente 3.000

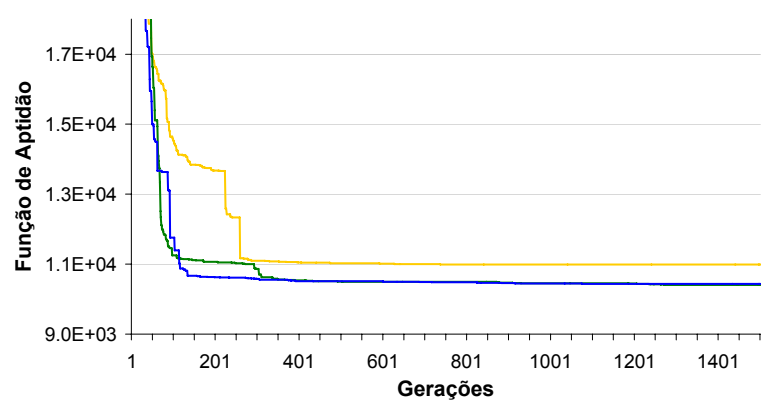

-POPsize20 - POPsize50 - POPsize100 - POPsize150

Figura 5.4 - Evolução do valor da função de aptidão para diferentes tamanhos de população.

Verificou-se que para a semente 800 , populações de 20 indivíduos nem sempre atingem bons resultados.

Populações com 150 indivíduos produzem os melhores resultados (menores valores da Função de Aptidão) para quase todas as sementes testadas. No entanto, esta dimensão de população demanda tempo computacional excessivamente elevado, de 90 a 150 minutos, o que é um fator limitante para a otimização em tempo real.

Assim sendo, optou-se por adotar populações de 50 indivíduos, que geram boas soluções e dentro da faixa de tempo aceitável para a Otimização em Tempo Real. 


\section{$\underline{\text { Seleção }}$}

Com relação aos tipos de seleção, para todas as sementes utilizadas, a seleção por torneio produz os melhores resultados entre todos os operadores de seleção testados, a saber, rank, roleta, torneio de 4 elementos e uniforme, conforme indicado na Figura 5.5. O torneio aparentemente promove uma pressão seletiva maior sobre as soluções inviáveis, direcionando a busca dos AGs para a região viável, consistindo, a opção de seleção adotada.
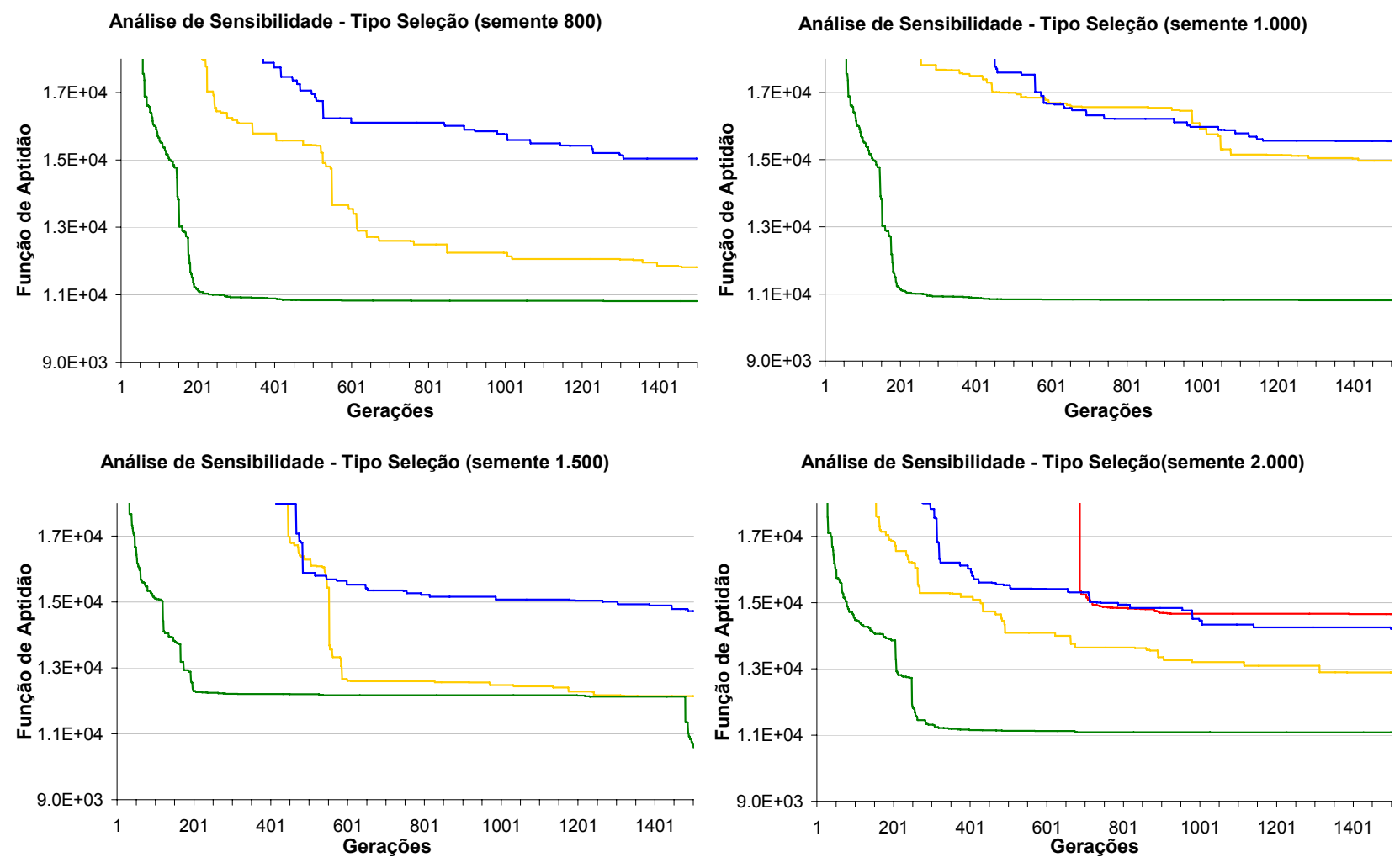

Análise de Sensibilidade - Tipo Seleção (semente 2.500)

Análise de Sensibilidade - Tipo Seleção (semente 3.000)
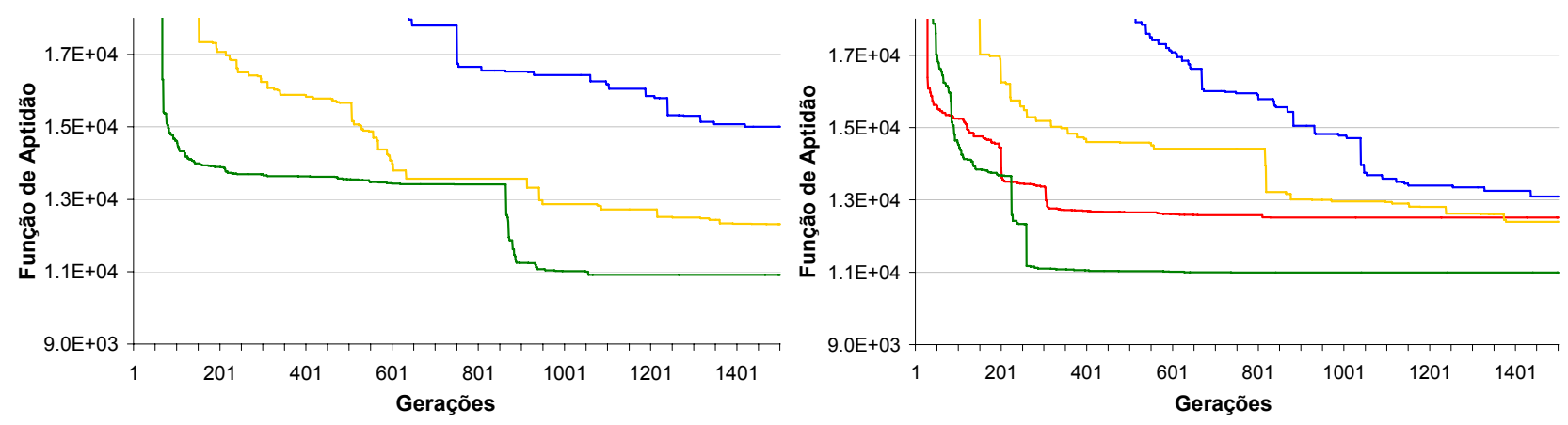

\section{— rank — roleta — torneio - uniforme}

Figura 5.5 - Evolução da função de aptidão para os diferentes operadores de seleção. 


\section{Cruzamento}

Considerando a população de 50 indivíduos e seleção por torneio, investigaram-se os cruzamentos do tipo Uniforme, de Um ponto, Dois pontos e Par-ímpar. Os resultados são apresentados na Figura 5.6.

Observa-se que, para a maioria das sementes, ao final das 1.500 gerações, os valores das funções de aptidão entre os diferentes tipos investigados são praticamente os mesmos. Apenas a estratégia Uniforme produz baixos valores de aptidão para praticamente todas as investigações, sendo escolhida para fazer parte do processo de otimização.
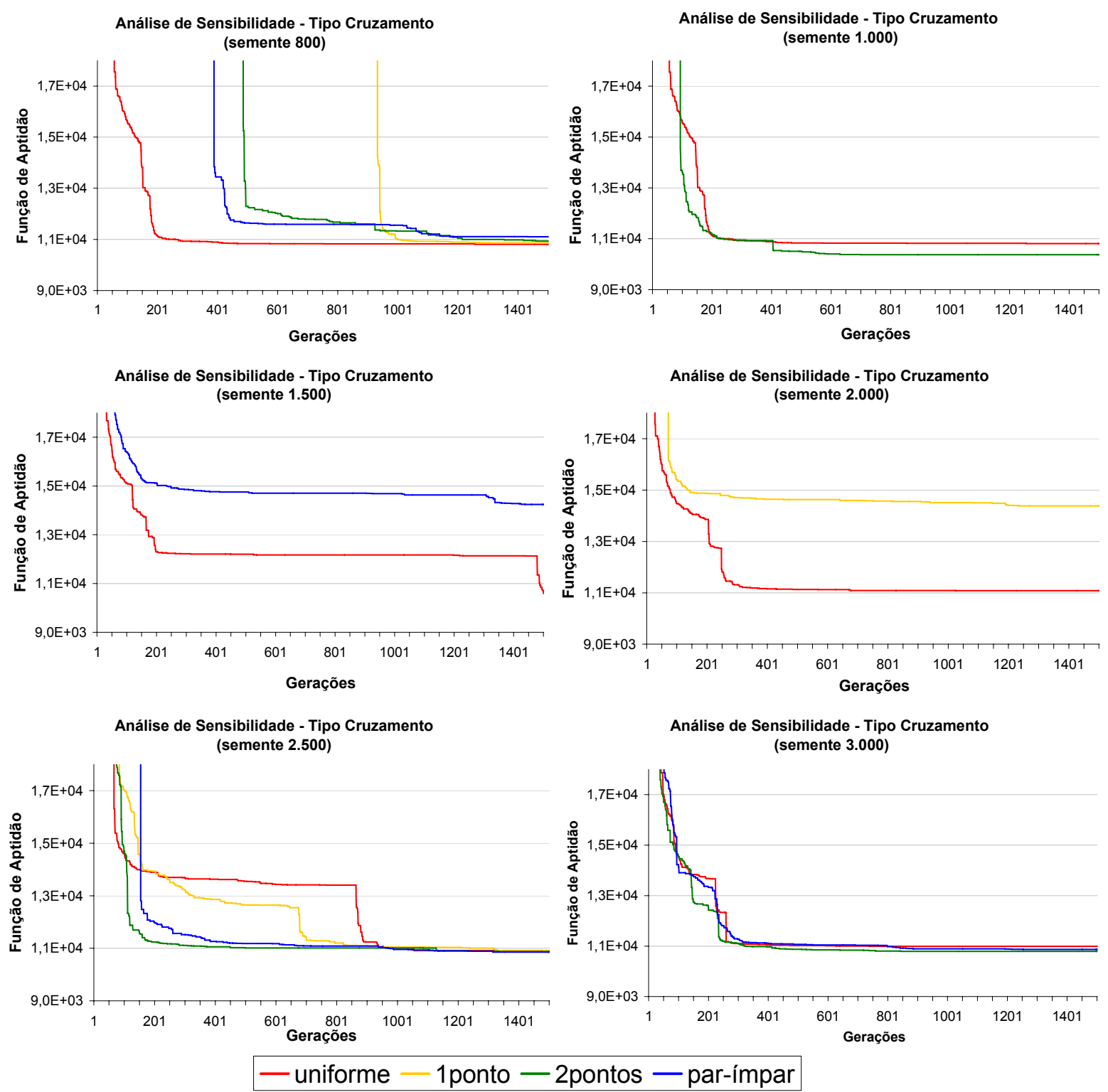

Figura 5.6 - Evolução da função de aptidão para os diferentes operadores de cruzamento. 
Já considerando a estratégia de cruzamento Uniforme, foram investigadas as probabilidades de cruzamento, $p_{c}$, de $0,6,0,7,0,8$ e 0,9 .

Os resultados, apresentados na Figura 5.7, demonstram que para as seis sementes utilizadas a probabilidade de 0,9 gera o melhor resultado para uma delas, 0,8 gera o melhor resultado para duas e 0,7 para três. Logo, adotou-se $p_{c}$ igual a 0,7 .

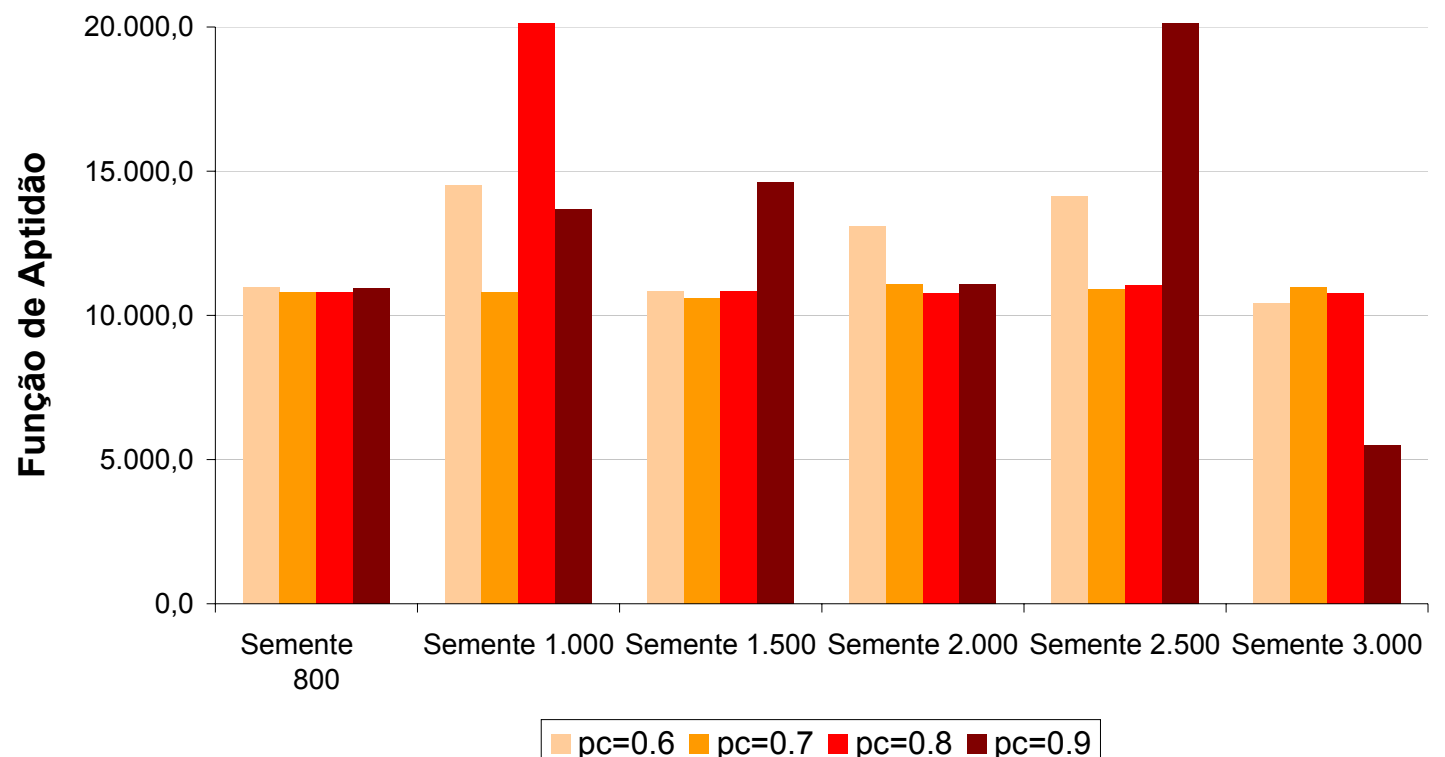

Figura 5.7 - Funções de aptidão para diferentes probabilidades de cruzamento.

\section{$\underline{\text { Mutação }}$}

Para aferir a probabilidade de mutação, $p_{m}$, utilizou-se uma população de 50 indivíduos, seleção por torneio, cruzamento uniforme com probabilidade de 0,7 e mutação simples, segundo a qual se substitui o bit ( 0 por 1 ou 1 por 0$)$. As probabilidades de mutação investigadas foram $0,001,0,003,0,005,0,009$ e 0,01 .

Ao observar a Figura 5.8 é possível perceber que as probabilidades de 0,005 e 0,009 sempre produzem os mesmos resultados. Outro fato que chama a atenção é que apesar de a probabilidade de mutação de 0,01 não gerar bons resultados para todas as simulações, para duas delas identifica valores da função de aptidão extremamente baixos. 
Visando obter valores de aptidão tão baixos, a probabilidade de 0,01, apesar de sabidamente ser uma probabilidade alta em termos de mutação, podendo tornar a busca aleatória, foi adotada como a probabilidade a ser utilizada.

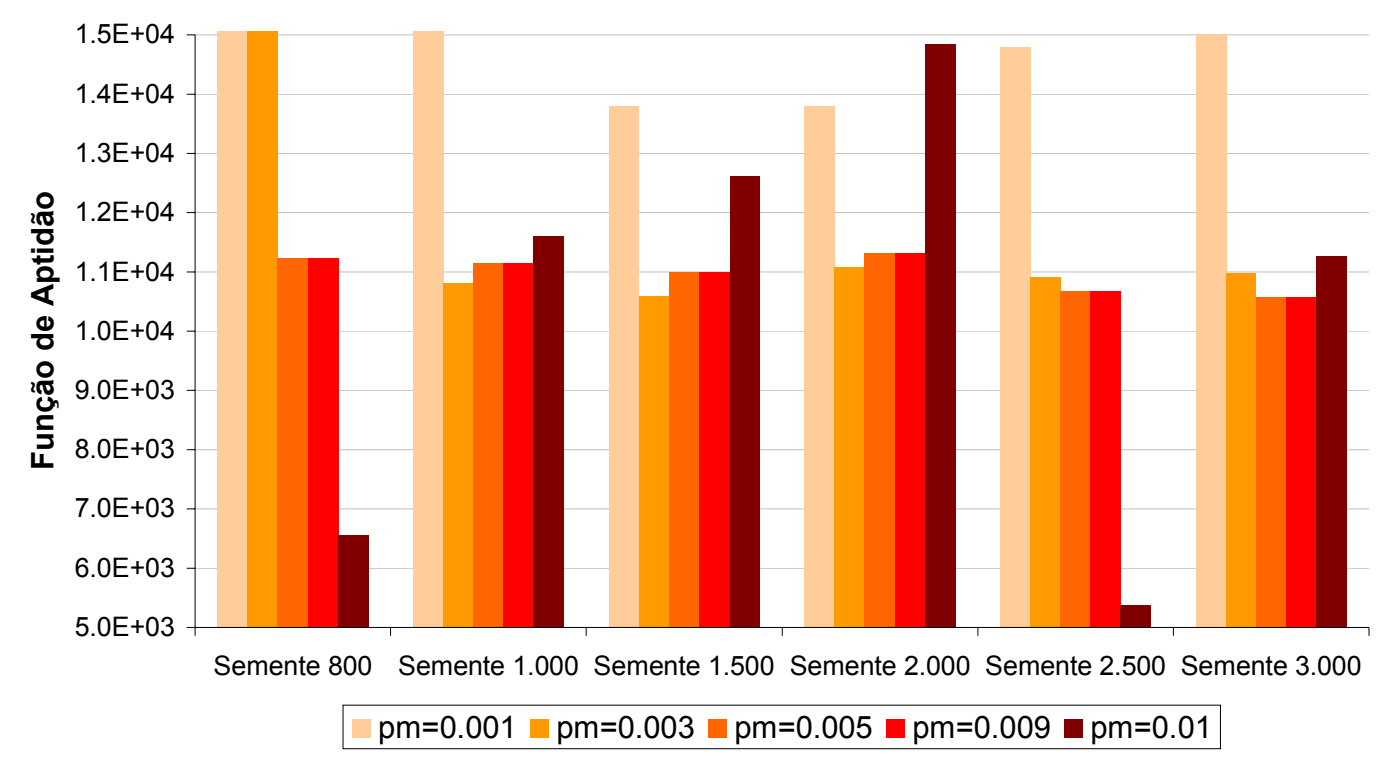

Figura 5.8 - Funções de aptidão para diferentes probabilidades de mutação.

\section{$\underline{\text { Conclusão }}$}

Como era esperado, a análise de sensibilidade realizada indicou que a utilização de diferentes operadores genéticos e valores para os parâmetros dos AG introduzem alterações no comportamento da função objetivo ao nível de convergência e de qualidade da solução ótima, pelas diferentes formas de exploração do espaço de soluções.

Foram testadas várias combinações de operadores e parâmetros dos AG de forma a avaliar a sua eficiência e rapidez na obtenção de soluções ótimas. As melhores soluções encontradas para 1.500 gerações foram: população de 50 indivíduos, seleção por torneio, cruzamento do tipo uniforme com probabilidade de 0.7 e mutação simples com probabilidade de 0,01 , sintetizados na Tabela 5.2. 
Tabela 5.2 - Operadores e parâmetros genéticos adotados.

\begin{tabular}{|l|l|}
\hline Operadores Genéticos & Parâmetros de Otimização \\
\hline Seleção: Torneio & Dimensão da população: 50 \\
Cruzamento: Uniforme & Número de Gerações: 1.500 \\
Mutação: Simples & Probabilidade de cruzamento (Pc): 0,7 \\
& Probabilidade de Mutação (Pm): 0,01 \\
\hline
\end{tabular}

\subsubsection{Nível Inicial}

A solução ótima do problema de otimização em estudo depende do nível inicial de operação do reservatório a jusante do sistema elevatório, que não foi incorporado como variável de decisão no problema. Portanto, para melhor definir o nível inicial de operação dos reservatórios para posteriores simulações foram ensaiados os valores de 50, 70, 80 e 90\% do nível máximo dos reservatórios às 06:00 horas.

Ao longo das otimizações percebeu-se que o reservatório R3 normalmente estava com nível próximo do máximo antes das 06:00 horas. Logo, para o reservatório R3, considerou-se o nível inicial sempre igual a 90\% do nível máximo.

Na Figura 5.9 apresentam-se, para os diferentes níveis iniciais, as soluções ótimas encontradas em termos da função de aptidão. Uma análise visual desta permite concluir que os melhores resultados são obtidos considerando o nível inicial dos reservatórios igual a 70\% do nível máximo. Portanto os níveis iniciais utilizados na otimização são 4,50 m para o reservatório $R_{3}, 2,80$ m para os reservatórios $R_{1}, R_{2}$ e $R_{5}$ e 2,65 m para o $R_{4}$. 


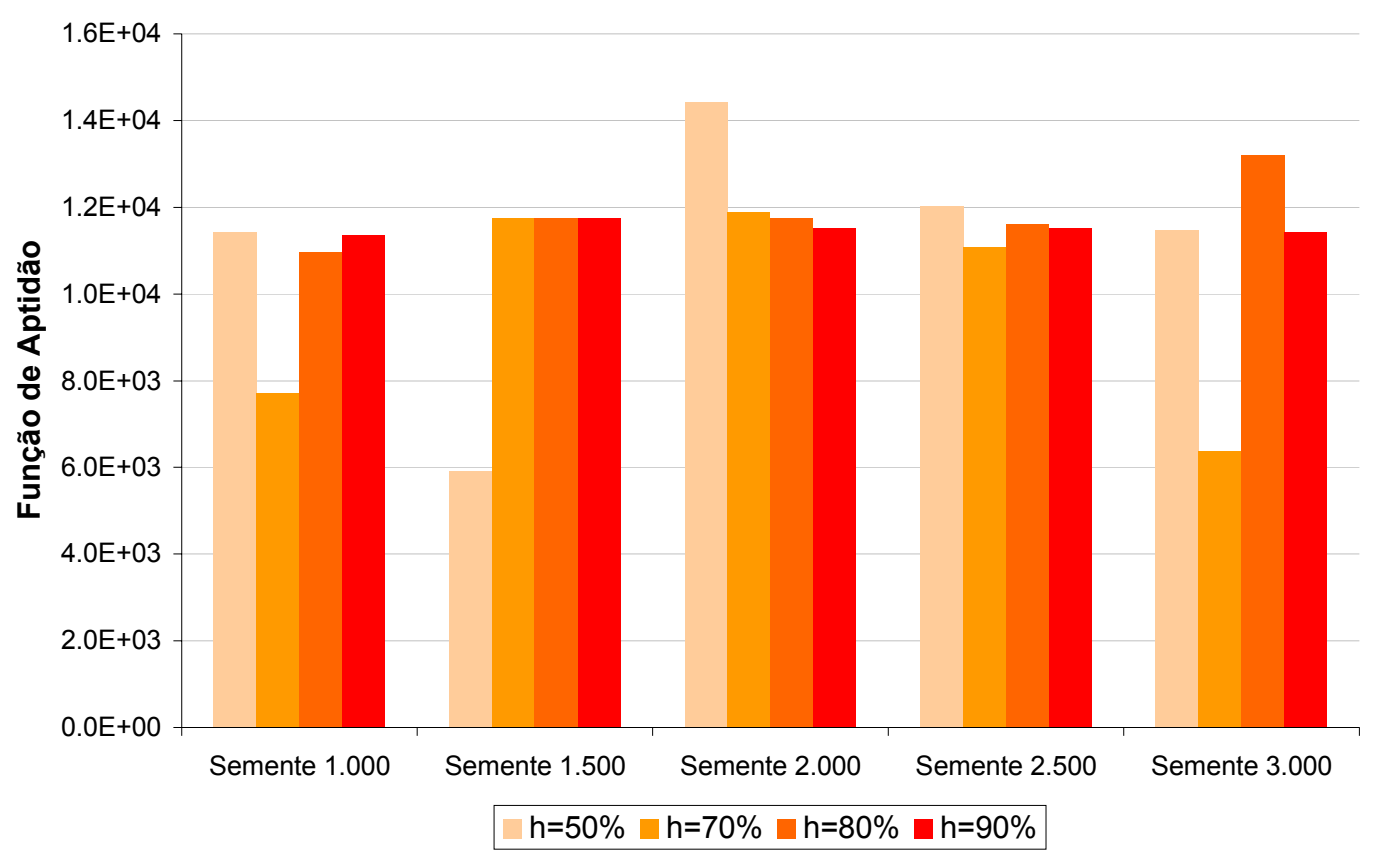

Figura 5.9 - Evolução da função de aptidão para diferentes níveis iniciais nos reservatório.

\subsubsection{Coeficientes das Penalidades $(\lambda 1, \lambda 2, \lambda 3, \lambda 5)$}

Como AG é um método de busca irrestrito, adotou-se o Método das Penalidades para contemplar as restrições do problema em questão. As restrições existentes são adicionadas à função objetivo em termos de penalidades, conforme Equações 3.16 e 3.17.

Cada penalidade é multiplicada por um termo positivo $\left(\lambda_{\mathrm{r}}\right)$ que determina o rigor com que a respectiva restrição deve ser atendida, dependendo da gravidade de sua violação. Assim, restrições graves devem ter sua violação severamente penalizada através de valores elevados de $\lambda_{\mathrm{r}}$.

Para a otimização em nível estratégico foram adotadas penalidades quanto: à ocorrência de pressões inferiores à mínima (Penalidade 1); à diferença entre os níveis inicial e final nos reservatórios (Penalidade 2); à elevada quantidade de acionamentos de 
bombas e/ou manobras de válvulas (Penalidade 3); e, à descontinuidade do abastecimento (Penalidade 5).

O não cumprimento das penalidades 1 e 5 significa encontrar soluções inviáveis de serem aplicadas a um sistema real, ou seja, uma regra de operação que provocaria pressões inferiores àquela preconizada pela norma (NBR 12218) ou intermitência no abastecimento de água. Para assegurar a não ocorrência dessas soluções inviáveis, foi adotado valor elevado para os coeficientes $\lambda_{1}$ e $\lambda_{5}(1.000)$.

O não cumprimento da Penalidade 2 também foi admitido como uma solução inviável, uma vez que a otimização de uma rede de abastecimento ao longo de um período estabelecido não tem significado se não se leva em conta a periodicidade na operação. Portanto, adotou-se o mesmo valor dos coeficientes das penalidades 1 e $5\left(\lambda_{1}=\lambda_{5}=\lambda_{2}=\right.$ 1.000). Cabe lembrar que esse excessivo rigor aqui adotado é revisto quando da Otimização em Tempo Real, quando já não faz sentido pensar em diferença de nível inicial e final dos reservatórios já que o horizonte de planejamento é móvel e os níveis dos reservatórios são guiados pelos Níveis Meta.

Restou, então, a Penalidade 3, cujo coeficiente de penalidade foi determinado pela Análise de Sensibilidade.

$\mathrm{Na}$ análise de sensibilidade foram otimizados 12 cenários, variando o valor do coeficiente de penalidade $3\left(\lambda_{3}\right)$ de 1.000 a 10 , observando os efeitos desta variação tanto na função de aptidão quanto nas penalidades. Os coeficientes das demais penalidades $\left(\lambda_{1}\right.$, $\lambda_{2}$ e $\lambda_{5}$,) foram mantidos fixos e igual a 1.000. Na Tabela 5.3 estão sintetizados os resultados obtidos. 
Tabela 5.3 - Análise de sensibilidade do coeficiente de penalidade $3\left(\lambda_{3}\right)$.

\begin{tabular}{|c|c|c|c|c|c|c|c|c|}
\hline \multirow[b]{2}{*}{ Cenário } & \multirow[b]{2}{*}{$\lambda 3$} & \multicolumn{4}{|c|}{ Resultados Penalidades } & \multicolumn{3}{|c|}{ Avaliação (Resultados/ $\lambda$ ) } \\
\hline & & P1 & P2 & P3 & P5 & $\begin{array}{c}\text { Custo de } \\
\text { bombeamento } \\
\text { (R\$/dia) }\end{array}$ & $\begin{array}{c}N_{\text {final- }} \\
N_{\text {inicial }} \\
(\mathrm{m})\end{array}$ & $\begin{array}{c}\mathbf{N}^{\circ} \text { de } \\
\begin{array}{c}\text { Acionamentos } \\
\text { (unid.) }\end{array}\end{array}$ \\
\hline 1 & 1,000 & 0.00 & $1,105.14$ & 0.00 & 0.00 & $9,571.78$ & 1.11 & 0.00 \\
\hline 2 & 500 & 0.00 & 90.40 & 0.00 & 0.00 & $10,379.90$ & 0.09 & 0.00 \\
\hline 3 & 250 & 0.00 & $1,106.44$ & 500.00 & 0.00 & $9,872.31$ & 1.11 & 2.00 \\
\hline 4 & 100 & 0.00 & 173.95 & 0.00 & 0.00 & $9,745.77$ & 0.17 & 0.00 \\
\hline 5 & 90 & 0.00 & 0.00 & 0.00 & 0.00 & $9,831.03$ & 0.00 & 0.00 \\
\hline 6 & 80 & 0.00 & 0.00 & 160.00 & 0.00 & $9,668.19$ & 0.00 & 2.00 \\
\hline 7 & 70 & 0.00 & 0.00 & 70.00 & 0.00 & $9,840.87$ & 0.00 & 1.00 \\
\hline 8 & 60 & 0.00 & 0.00 & 120.00 & 0.00 & $9,574.17$ & 0.00 & 2.00 \\
\hline 9 & 50 & 0.00 & 0.00 & 50.00 & 0.00 & $9,565.50$ & 0.00 & 1.00 \\
\hline 10 & 30 & 0.00 & 169.49 & 330.00 & 0.00 & $9,678.63$ & 0.17 & 11.00 \\
\hline 11 & 20 & 0.00 & 156.71 & 320.00 & 0.00 & $9,751.48$ & 0.16 & 16.00 \\
\hline 12 & 10 & 0.00 & 929.83 & 270.00 & 0.00 & $9,844.56$ & 0.93 & 27.00 \\
\hline
\end{tabular}

Observa-se que valores de $\lambda_{3}$ acima de 100 ou abaixo de 50 , destacados em verde, influenciam a Penalidade 2, gerando diferenças entre os níveis iniciais e finais dos reservatórios, o que é indesejável. Na faixa de valores de $\lambda_{3}$ entre 90 e 50 , o cenário $5\left(\lambda_{3}=\right.$ 90), apesar de impor menor quantidade de acionamentos, tem custo de energia elétrica superior aos demais, com exceção do cenário 7.

Portanto, adotou-se o cenário que possui menor custo com energia elétrica na faixa de valores que não afetam a Penalidade 2 , ou seja, $\lambda_{3}=50$.

\subsubsection{Coeficiente de Penalidade $(\lambda 4)$}

Para a Otimização em Tempo Real Com Níveis Meta são adotadas penalidades quanto: à ocorrência de pressões inferiores à mínima (Penalidade 1); à elevada quantidade de acionamento de bombas e/ou manobras de válvulas (Penalidade 3); à descontinuidade do abastecimento (Penalidade 5); e, à diferença entre os níveis dos reservatórios e níveis 
meta (Penalidade 4). Já para a Otimização em Tempo Real Sem Níveis Meta são adotadas apenas as penalidades $1,2,3$ e 5 .

Assim como os demais coeficientes das penalidades, apresentados no item anterior, o coeficiente para a Penalidade 4, referente aos Níveis Metas, foi determinado através de análise de sensibilidade. Para tanto foram testados os valores de $\lambda_{4}$ de 1, 10, 20, 30, 40, 50 e 100 .

Como era esperado, verificou-se a tendência de maiores valores do coeficiente de penalidade $\lambda_{4}$ produzirem menores somatórios das diferenças entre os níveis obtidos com a otimização em tempo real e os Níveis Metas - Figura 5.10.

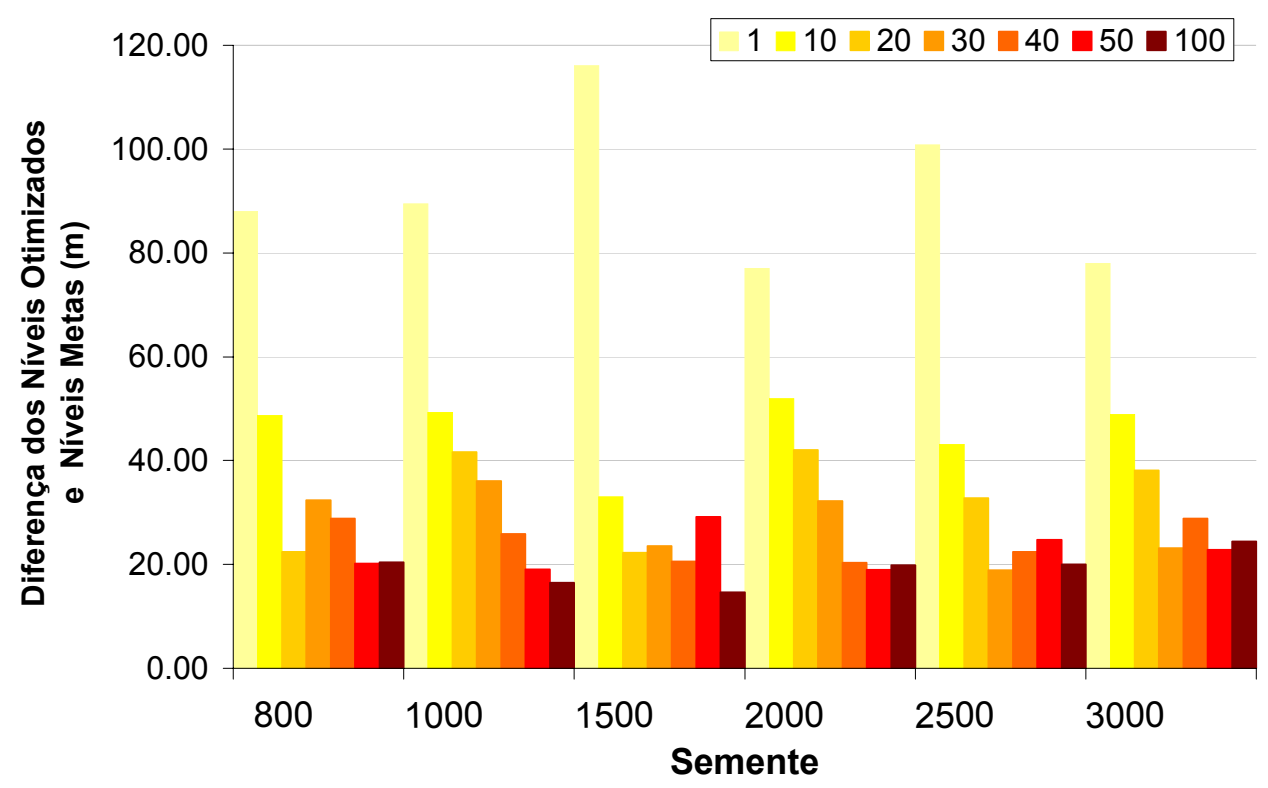

Figura 5.10 - Diferença entre níveis dos reservatórios e níveis meta para diferentes $\lambda_{4}$.

Já com relação aos custos de energia elétrica, a relação entre estes e $\lambda_{4}$ não é tão evidente. $\mathrm{O}$ mesmo valor de $\lambda_{4}$ produziu tanto baixos valores de energia elétrica quanto altos, dependendo da solução inicial adotada. Observou-se uma leve tendência dos valores intermediários $\left(\lambda_{4}=30\right.$ e $\left.\lambda_{4}=40\right)$ em produzirem menores custos de bombeamento Figura 5.11. 


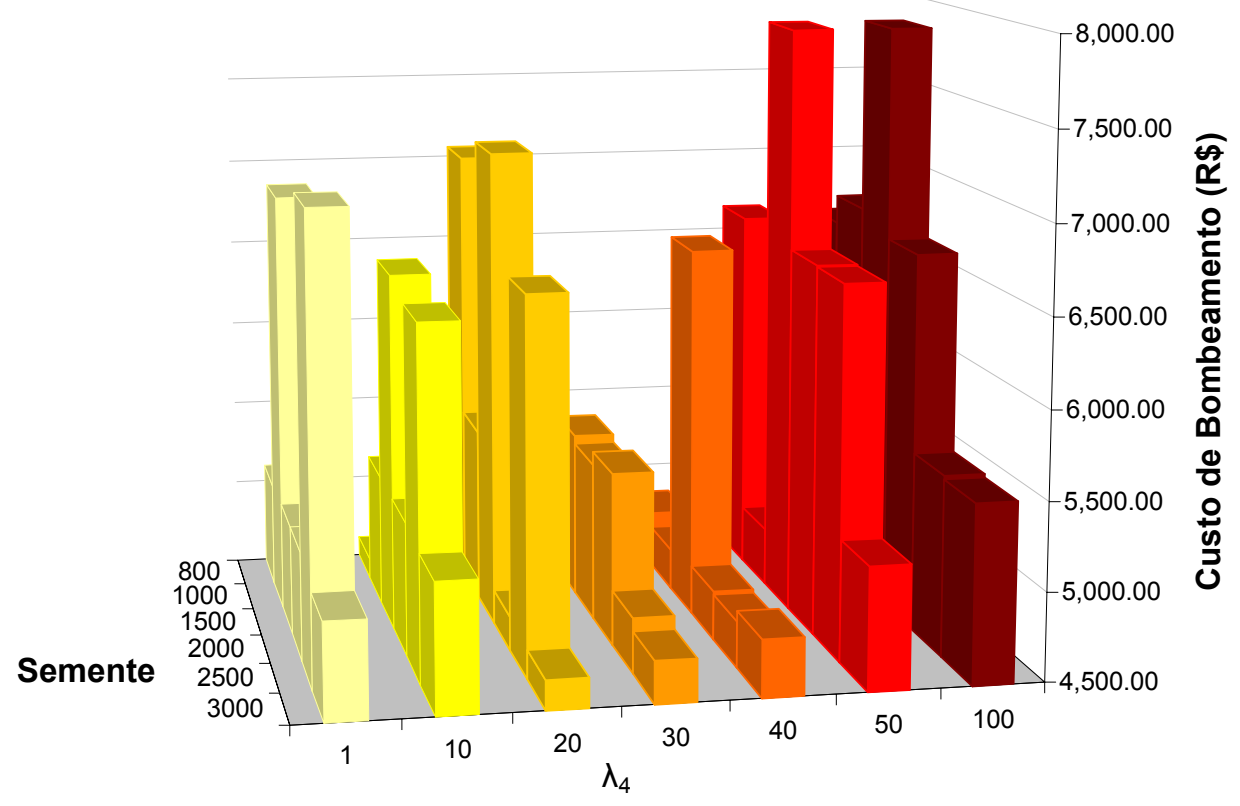

Figura 5.11 - Custo com energia elétrica $(\mathrm{R} \$)$ para diferentes valores de $\lambda_{4}$.

Portanto, adotou-se $\lambda_{4}=30$ que possui menor média de custos com energia elétrica para as diferentes soluções iniciais.

\subsection{Previsão de Demandas}

Para a realização da otimização em tempo real com previsão de demandas utilizou-se o Módulo de Previsão de Demandas desenvolvido por Odan (2008).

Odan (2008) realizou a previsão de demandas com base nos dados históricos da cidade de São Carlos apresentados por Moreira (2007), para os meses de fevereiro e junho de 2004, obtendo para cada hora do dia 24 horas a frente de previsão de demanda.

Para poder aplicar tais dados ao sistema aqui estudado, as previsões de demanda obtidas por Odan (2008) foram adimensionalizadas, dividindo o valor da demanda de cada hora pela média das 24 horas à frente, e posteriormente multiplicando-se este valor pela demanda base dos nós. 
Para os valores observados de demanda utilizou-se a mesma metodologia, dividindo o valor de demanda para cada hora pela média do dia correspondente e multiplicando o valor obtido pela demanda base de cada nó.

As previsões de demanda e as demandas reais utilizadas na otimização constam do Apêndice B.

\subsection{Teste de Validade do Modelo}

Para a verificação da aplicabilidade do modelo desenvolvido foram obtidos dois conjuntos de regras operacionais para o horizonte de previsão de 24 horas. $\mathrm{O}$ primeiro conjunto foi obtido considerando o enquadramento tarifário atual do sistema estudado $\left(\right.$ EEAT $_{1}$-Verde; $\mathrm{CR}_{1}$ - Convencional; e, $\mathrm{CR}_{2}$ - Convencional B3) e o segundo considerando a alteração do enquadramento tarifário proposto por Pedrosa (2006). Em ambos os casos consideraram-se os parâmetros genéticos ótimos encontrados no item 5.2 deste trabalho.

Como o objetivo deste teste é comparar os resultados obtidos pelo modelo otimizador desenvolvido com os apresentados por Pedrosa (2006), adotou-se, apenas neste teste, os padrões temporais de demanda apresentados pelo autor (Figura 5.12) e o estado inicial dos reservatórios $80 \%$ do nível máximo, condição adotada pelo autor. Cabe destacar que para as demais aplicações do modelo foram utilizados as demandas da cidade de São Carlos (explicitadas no item 5.4) e os níveis iniciais dos reservatórios determinados pela análise de sensibilidade. 
(a)

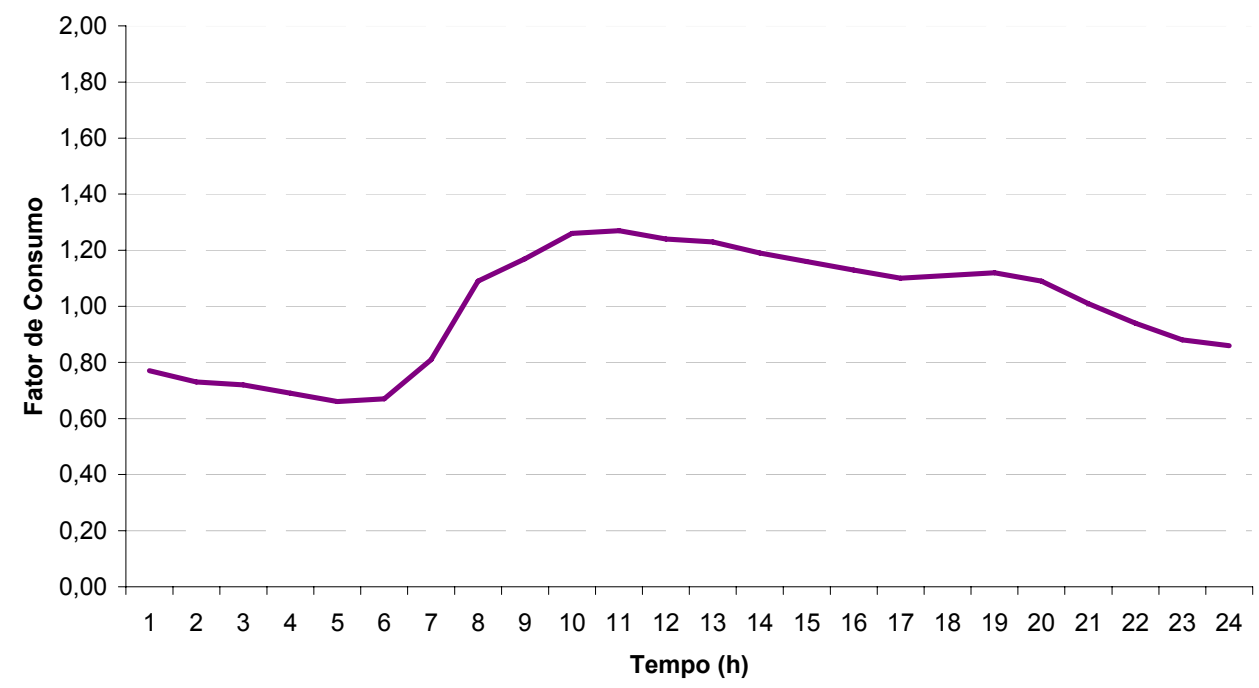

(b)

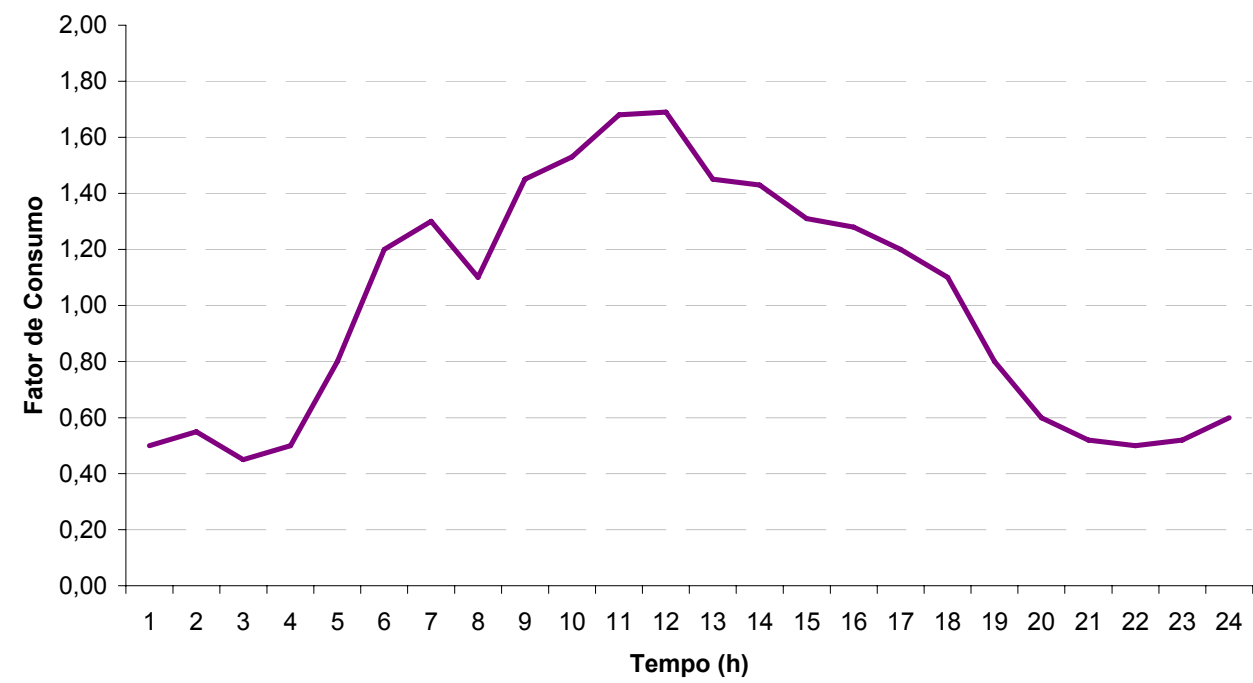

Figura 5.12 - Padrão adimensional de demanda associado ao nó de consumo a jusante (a) do CR1 e (b) do CR2. Fonte: Pedrosa (2006).

Uma análise inicial das regras operacionais obtidas mostra que o AG possibilita encontrar várias soluções viáveis de serem praticadas no campo da engenharia. As restrições de não ocorrência de pressão negativa ou inferior à $10 \mathrm{mH} 2 \mathrm{O}$ na rede é satisfeita nas simulações (Figura 5.13), garantindo a continuidade do abastecimento ao longo de todo alcance de operação, e os níveis operacionais para os reservatórios encontram-se dentro dos limites praticáveis. 
(a)

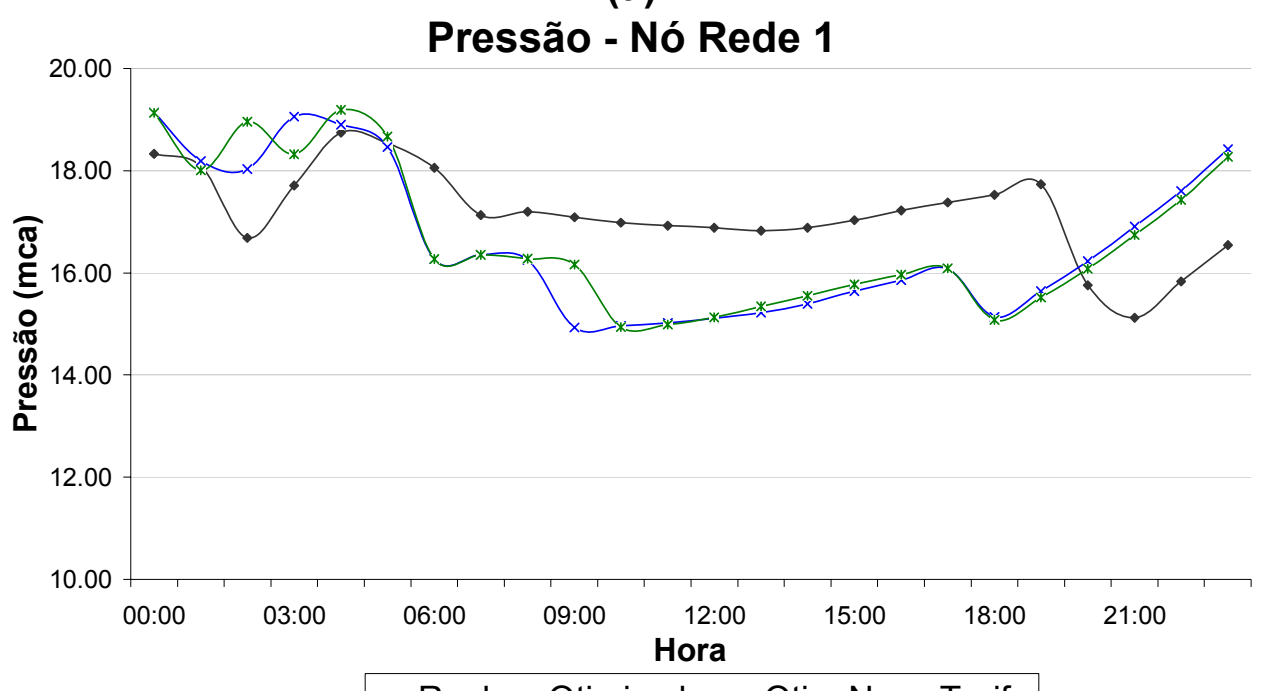

- Real -x-Otimizado - - Otim Nova Tarifa

(b)

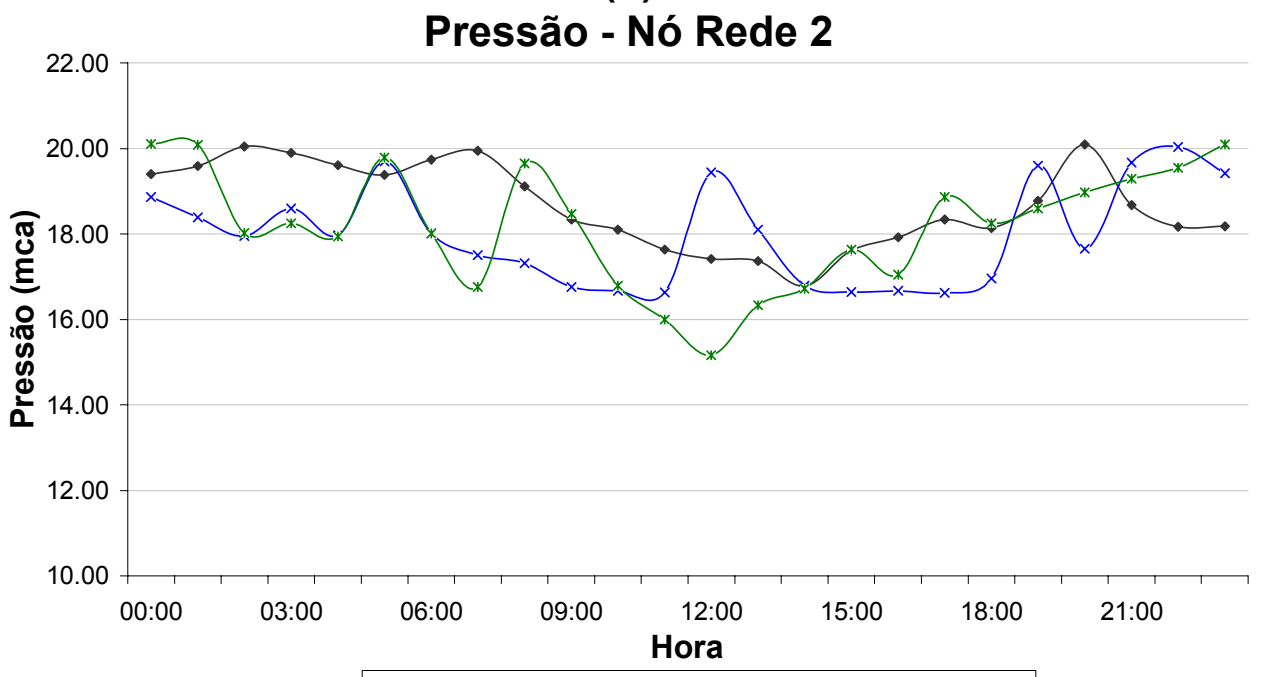

- Real -x-Otimizado $-*$-Otim Nova Tarifa

Figura 5.13 - Distribuição temporal das pressões nos nós (a) Rede 1 e (b) Rede 2.

O comportamento dos níveis de água entre os limites operacionais dos cinco reservatórios que compõem o sistema adutor pode ser visto nas Figuras 5.14 e 5.15. A forma mais acidentada que se verifica no perfil corresponde à regra de operação otimizada, que reflete a reação do sistema a maior quantidade de manobras de bombas e/ou válvulas, definida pelo algoritmo, necessárias para se aproximar da solução de custo mínimo, procurando satisfazer restrições de ordem física e operacional impostas ao modelo. $\mathrm{Na}$ 
prática tradicional a quantidade de manobras desses equipamentos é comparativamente bem menor (Pedrosa, 2006).

\section{Reservatório R2}

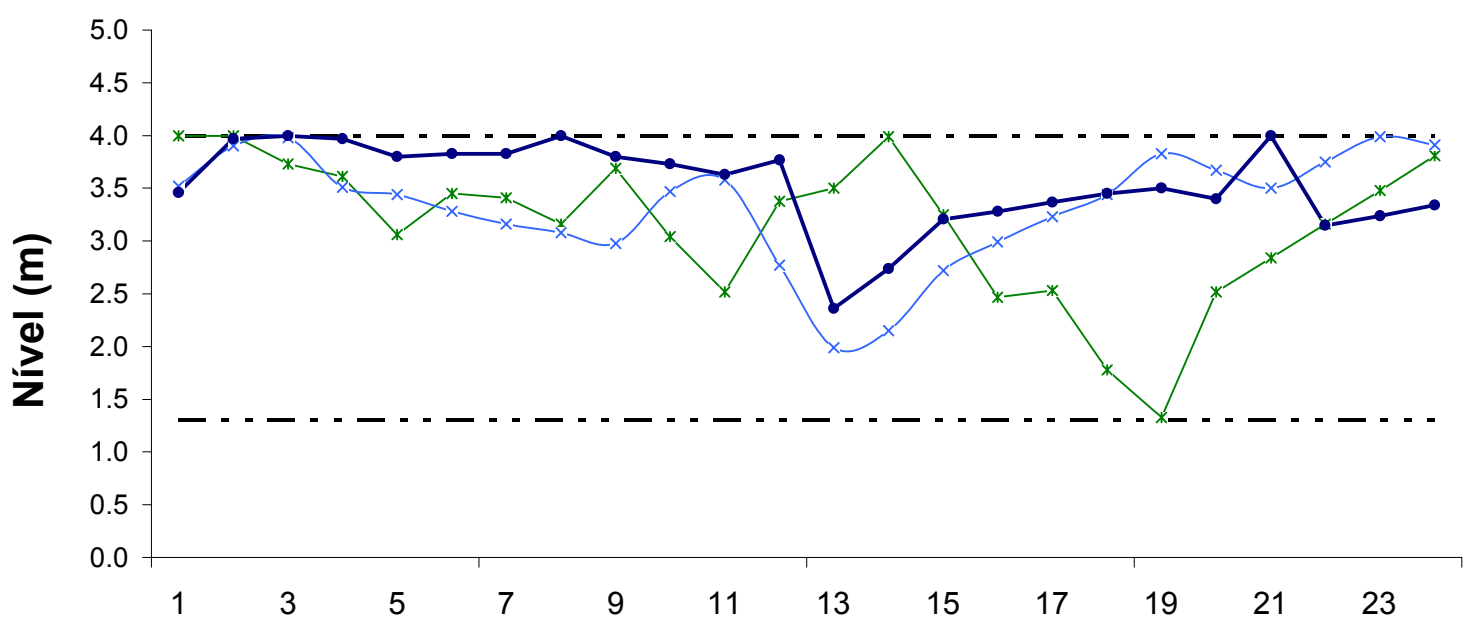

Hora

\section{Reservatório R3}

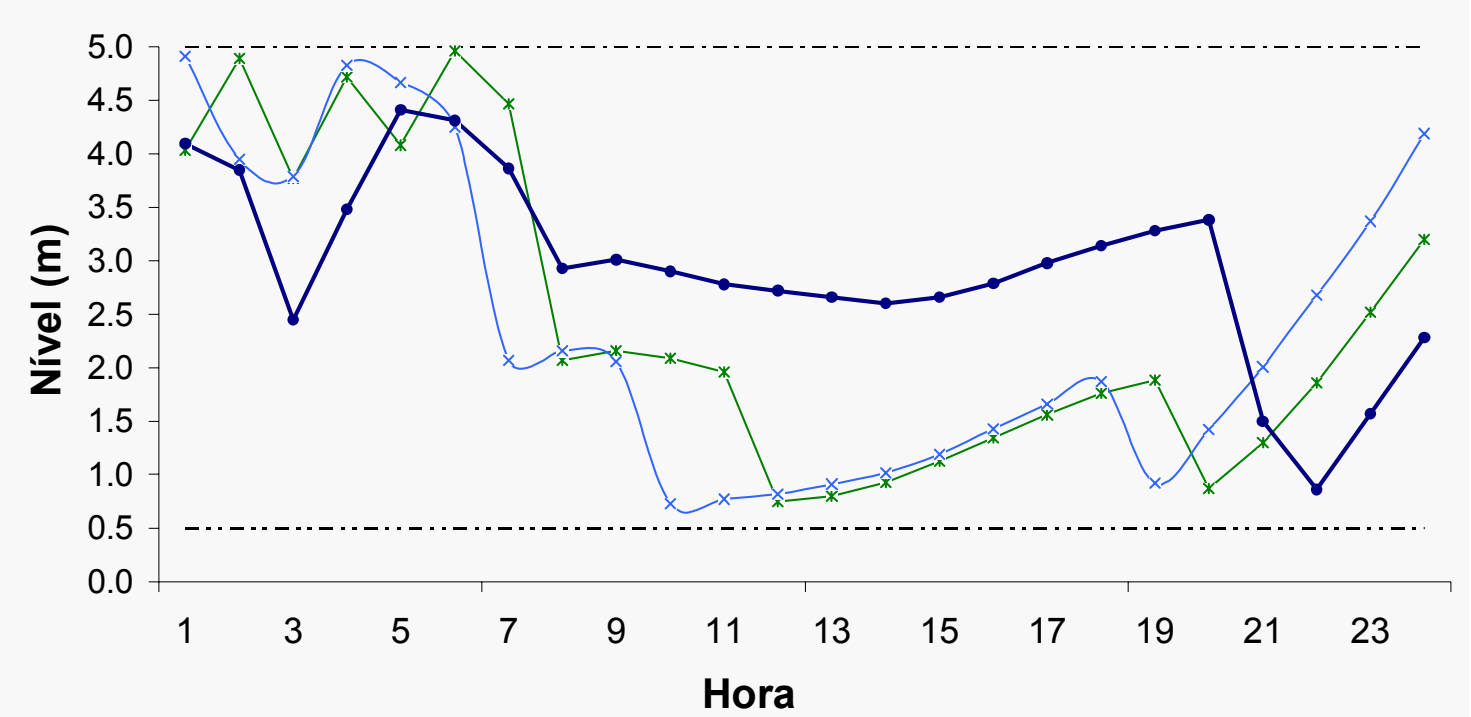

-.- NA max -.- NA min $-*-$ NAotim nova tarf $-x-$ NAotim $\rightarrow$ NA Operacional

Figura 5.14 - Distribuição temporal dos níveis dos reservatórios para otimização considerando o enquadramento tarifário atual (NAotim), a alteração do enquadramento tarifário (NAotim nova tarf) e (NAoperacional) - Reservatórios R1 e R3. 


\section{Reservatório R4}

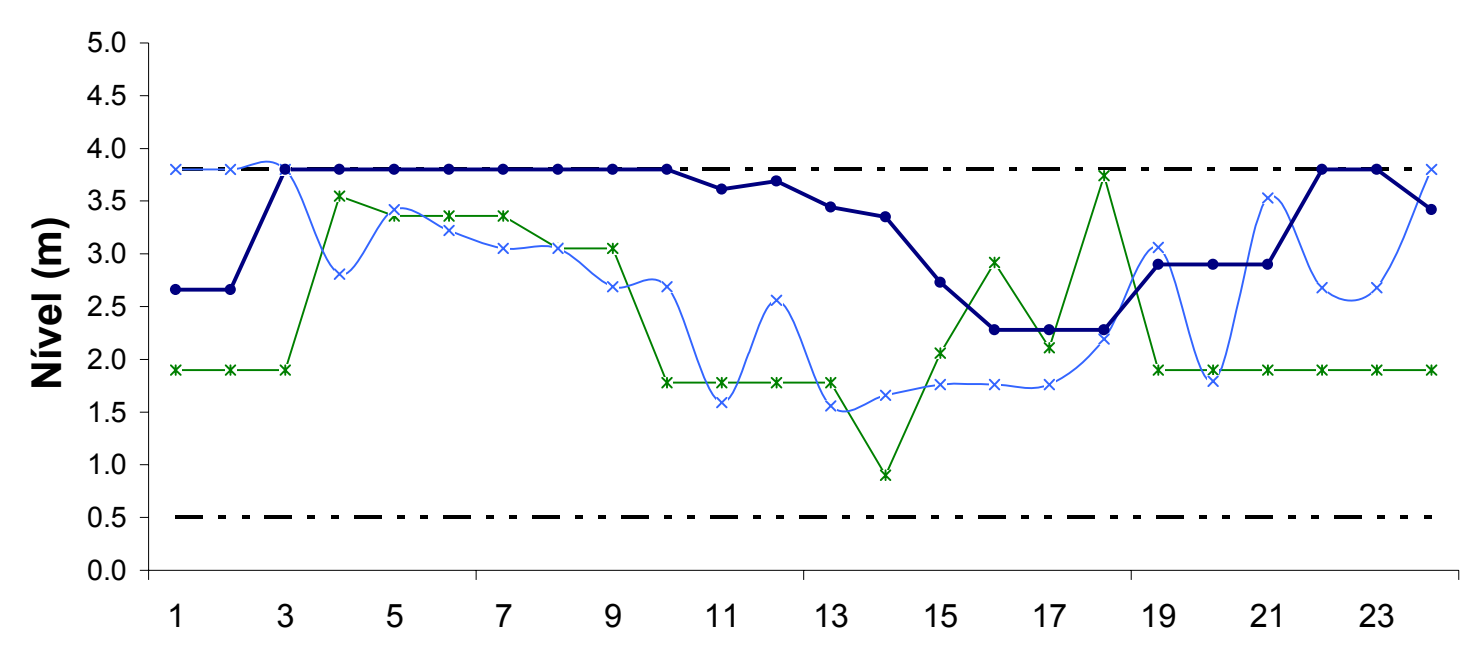

Hora

Reservatório R5

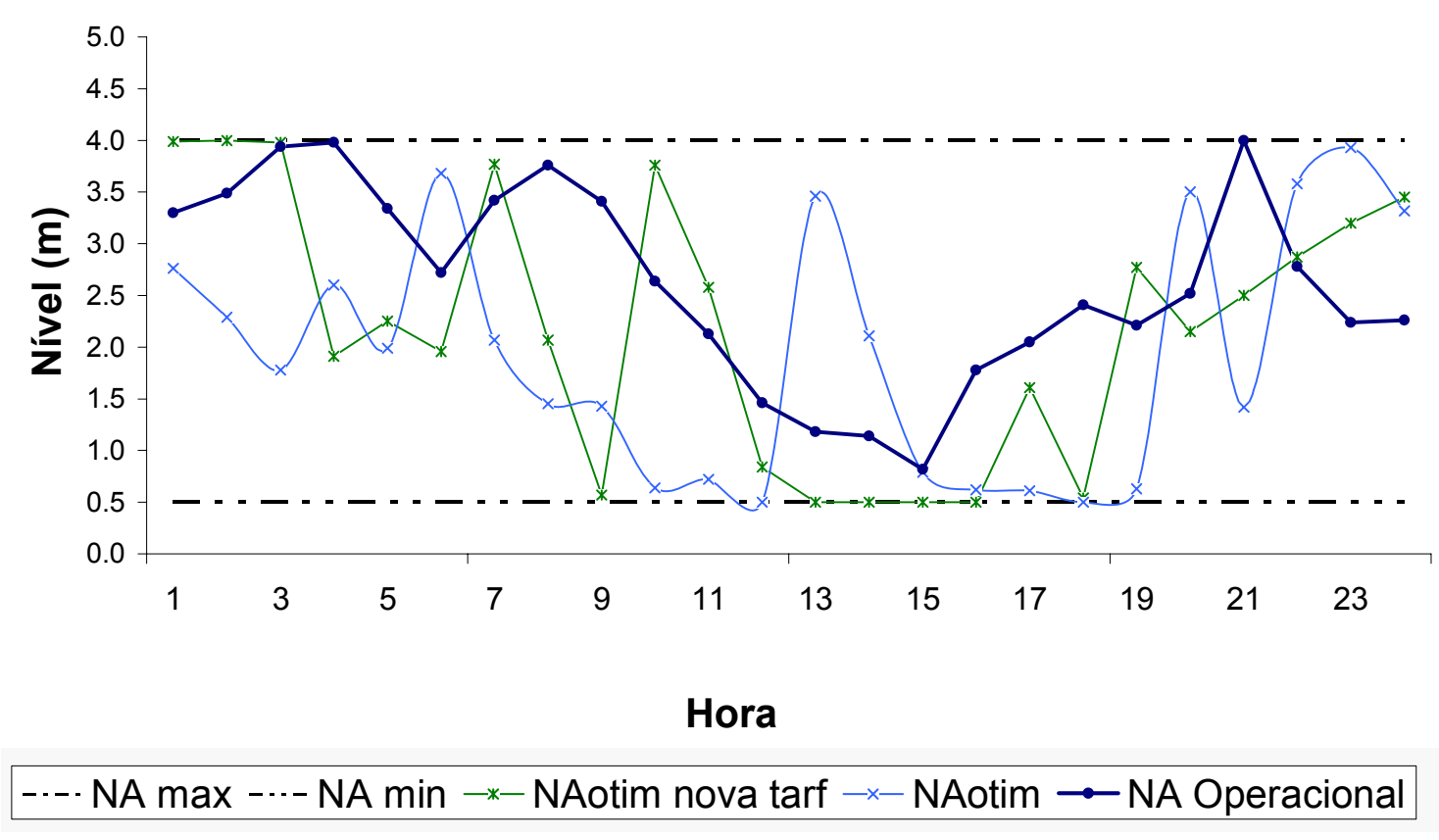

Figura 5.15 - Distribuição temporal dos níveis dos reservatórios para otimização considerando o enquadramento tarifário atual (NAotim), a alteração do enquadramento tarifário (NAotim nova tarf) e (NAoperacional) - Reservatórios R4 e R5.

Segundo Pedrosa (2006), as estimativas dos consumos de energia elétrica diários reais da $\mathrm{EEAT}_{1}, \mathrm{CR}_{1}$ e $\mathrm{CR}_{2}$ são de 9.911.50, 2.076,63 e 305,64 kWh, respectivamente. 
Com a otimização é possível alcançar economia média 8,5\% em relação a estes valores reais. A comparação destes valores com os resultados obtidos via otimização, é possível analisando a Tabela 5.4.

Tabela 5.4 - Consumo médio diário por unidade, real e otimizado.

\begin{tabular}{|l|l|l|l|c|}
\hline Unidade & EEAT $_{\mathbf{1}}$ & $\mathbf{C R}_{\mathbf{1}}$ & $\mathbf{C R}_{\mathbf{2}}$ & Total \\
\hline $\begin{array}{l}\text { Consumo médio diário praticado (kWh/dia) } \\
\text { (Fonte: Pedrosa) }\end{array}$ & $9,911.50$ & $2,076.63$ & 305.64 & $12,293.77$ \\
\hline Consumo diário otimizado $(\mathrm{kWh} / \mathrm{dia})$ & $9,492.15$ & $1,541.65$ & 300.89 & $11,334.69$ \\
\hline Redução & $\mathbf{4 . 4 \%}$ & $\mathbf{3 4 . 7 \%}$ & $\mathbf{1 . 6} \%$ & $\mathbf{8 . 5 \%}$ \\
\hline
\end{tabular}

Pedrosa (2006) sugere a alteração do enquadramento na tarifação das unidades consumidoras EEAT1 e CR1 para a classe tarifária horo-sazonal Verde, mantendo o poço profundo da unidade consumidora CR2 na classe Convencional de baixa tensão B3, com vistas à redução dos custos com energia elétrica. Segundo o autor, as regras operacionais determinadas resultaram em significativa melhora no custo de bombeamento, totalizando custo diário para as três unidades de $\mathrm{R} \$ 7.336,27$.

Considerando esta alteração tarifária, determinaram-se as regras operacionais para o sistema em estudo, obtendo um ganho em relação aos custos apontados por Pedrosa (2006) da ordem de $10 \%(\mathrm{R} \$ 6.608,10)$. No entanto, tal estratégia operacional impôs 6 acionamentos a mais do que o número considerado, 2 da bomba B38 e 4 da bomba B39.

Cabe destacar que o objetivo desta análise não é comparar a otimização aqui realizada com a de Pedrosa (2006) e sim demonstrar que o modelo desenvolvido pode produzir estratégias operacionais viáveis de serem praticadas para o sistema em estudo, reduzindo o custo relativo à energia elétrica consumida. Em outras palavras, o objetivo aqui perseguido é demonstrar a eficiência do modelo computacional construído.

Para sistemas de maior complexidade, estudos devem ser realizados para verificação da adequação do modelo, principalmente no que diz respeito ao tempo computacional. 


\subsection{Otimização em Nível Estratégico}

Após a realização dos testes do modelo e definição dos operadores e parâmetros genéticos envolvidos no processo de otimização pode-se proceder a Otimização da Operação.

A Otimização da Operação em Tempo Real é dividida em duas etapas: Otimização em Nível Estratégico, cujos resultados são apresentados neste item 5.6; e, Otimização em Tempo Real propriamente dita, apresentada no item 5.7.

Cabe salientar que, face ao elevado tempo computacional necessário aos ensaios computacionais de otimização, para ambas as etapas de otimização foi utilizada uma única semente (semente $=2000)$. Apesar desta simplificação não comprometer o trabalho e os resultados aqui obtidos, sabe-se que os níveis meta e as estratégias operacionais otimizadas gerados não podem ser considerados ótimos. Observa-se que o caráter estocástico do algoritmo genético permite encontrar, para cada semente utilizada, uma solução diferente para o problema, com um custo energético próximo do ótimo global.

O objetivo da Otimização em Nível Estratégico é definir Níveis Metas que serão utilizados como guias para a otimização em tempo real. Para tanto determina-se o conjunto de controle otimizados para o horizonte de planejamento considerado ( 24 horas) com base nas curvas médias de demanda do sistema, definidas como Curvas de Demanda Típicas.

\subsubsection{Curvas de Demanda Típica}

Observando-se as curvas típicas de demandas para os diferentes dias da semana, apresentadas e discutidas no Capítulo 4 - Figura 4.3, foi possível perceber que os dias úteis 
possuem comportamento muito parecido, diferenciando-se dos sábados e domingos. Portanto adotou-se, como Curvas de Demanda Típicas, as curvas para Dias Úteis, Sábados e Domingos, que se apresentam na Figura 5.16.

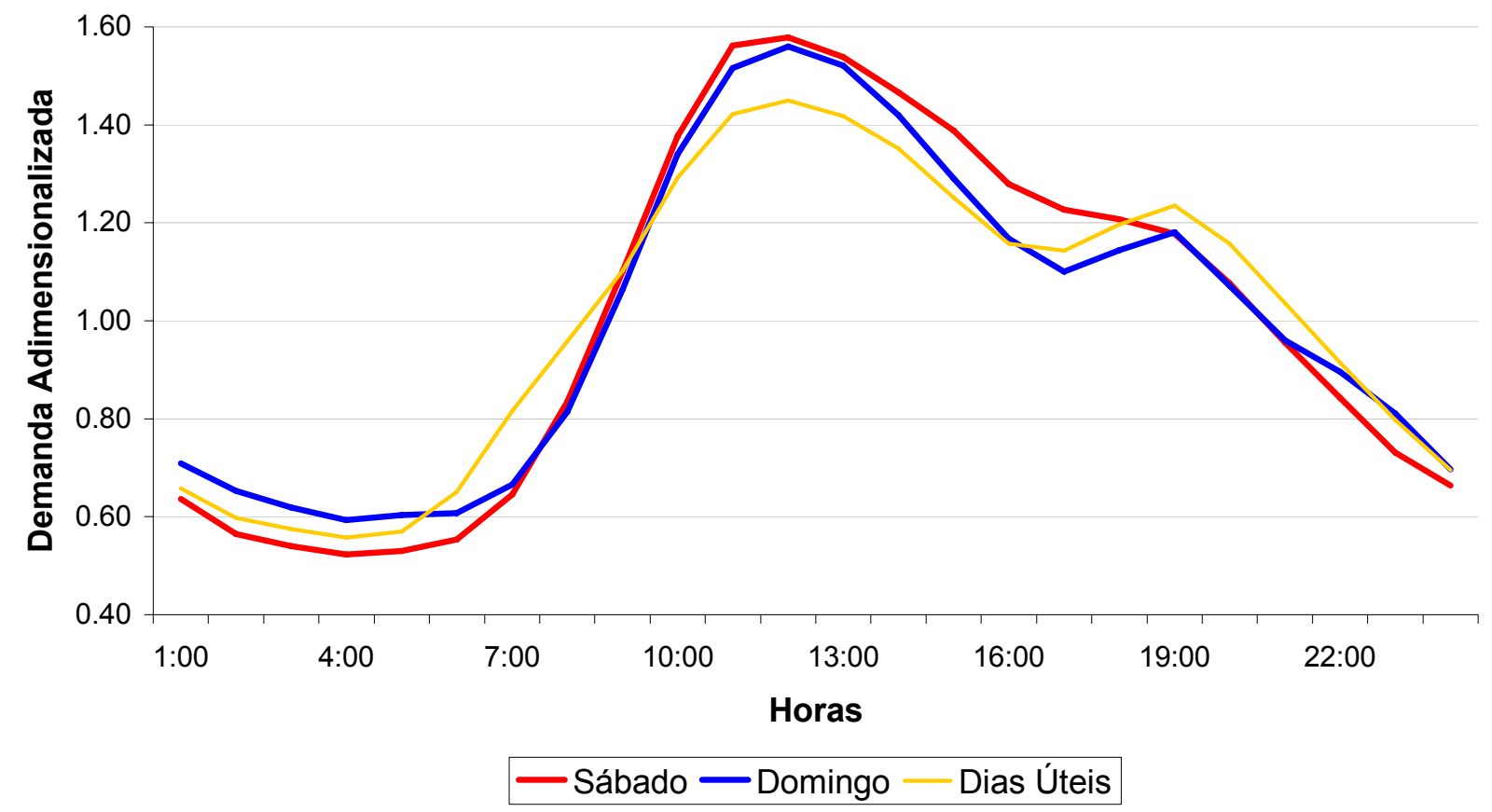

Figura 5.16 - - Curvas de Demanda Típica dos Dias úteis, Sábados e Domingos.

\subsubsection{Resultados da Otimização em Nível Estratégico}

Para cada Curva de Demanda Típica definida (dias úteis, sábados e domingos) realizou-se uma otimização em nível estratégico, utilizando-se os parâmetros apontados no item 5.3.2 -Análises de Sensibilidades. Na Tabela 5.5 estão sintetizados os resultados obtidos em termos de custo diário de energia elétrica, penalidades e tempo computacional gasto. 
Tabela 5.5 - Resultados da otimização para as diferentes Curvas de Demanda Típica.

\begin{tabular}{|c|c|c|c|c|}
\hline Otimização & $\begin{array}{c}\text { Tempo } \\
\text { Computacional } \\
\text { (min) }\end{array}$ & $\begin{array}{c}\text { Custo diário } \\
\text { energia elétrica } \\
(\mathbf{R} \$ \mathbf{)}\end{array}$ & $\begin{array}{c}\text { Penalidade 2 }- \\
\mathbf{P 2}=\sum \mathbf{N}_{\text {final- }} \mathbf{N}_{\text {inicial }}(\mathbf{m})\end{array}$ & $\begin{array}{c}\text { Penalidade 3 - } \\
\mathbf{P} \text { 3 }=\sum \text { Acionamentos, se } \\
\text { for maior que 4 (unid) }\end{array}$ \\
\hline Dias úteis & 49 & $8.474,71$ & 0,00 & 0 \\
\hline Sábados & 57 & $7.346,50$ & 0,00 & 7 \\
\hline Domingos & 47 & $6.666,02$ & 0,00 & 2 \\
\hline
\end{tabular}

\section{Função Objetivo}

A estratégia gerada pela otimização em Nível Estratégico para os dias úteis implica em consumo de $10.638,3 \mathrm{~kW}(88,6 \%$ do total), $1.449,7 \mathrm{~kW}(11,8 \%)$ e $200,7(1,6 \%) \mathrm{kW}$, nas unidades $\mathrm{EEAT}_{1}, \mathrm{CR}_{1}$ e $\mathrm{CR}_{2}$, respectivamente. Sendo a potência total consumida de $12.288,7 \mathrm{~kW} /$ dia e o custo correspondente de $\mathrm{R} \$ 8.474,7$ / dia.

Para a $\mathrm{EEAT}_{1}$, em que há diferenciação da tarifa nos horários de ponta e fora de ponta nos dias úteis, registrou-se consumo de $1.782,9 \mathrm{~kW}$ no horário de ponta e $8.855,4 \mathrm{~kW}$ fora de ponta. A proporção de consumo é de 1:5 ente os horários fora de ponta de ponta.

Com relação aos domingos, dia que apresenta esquema operacional com menor quantidade de bombas em funcionamento, conforme observado na Figura 5.17, são consumidos $13.127,5 \mathrm{~kW}$, distribuidos em: $11.643 \mathrm{~kW}(88,7 \%)$ pela $\mathrm{EEAT}_{1}, 1.451 \mathrm{~kW}$ (11,0\%) pelo $\mathrm{CR}_{1}$ e $33,5 \mathrm{~kW}(0,3 \%)$ pelo $\mathrm{CR}_{2}$. Esses consumos implicam em gastos de $\mathrm{R} \$ 5.659,59$ (média de 0,49reais/ $\mathrm{kW}), \mathrm{R} \$ 996,63$ (média de 0,68 reais/ $\mathrm{kW}) \mathrm{R} \$ 9,80(0,29$ reais/ $\mathrm{kW})$, nas respectivas unidades.

A Figura 5.17 mostra o número de conjuntos moto-bombas em operação nos dias úteis, sábados e domingos ao longo do horizonte de planejamento, considerando o total de 5 equipamentos no sistema estudado. A operação das bombas B43 e B44, por não constituírem variáveis de decisão do problema de otimização em análise, assim elas encontram-se sempre desligadas. 


\section{Sábados}
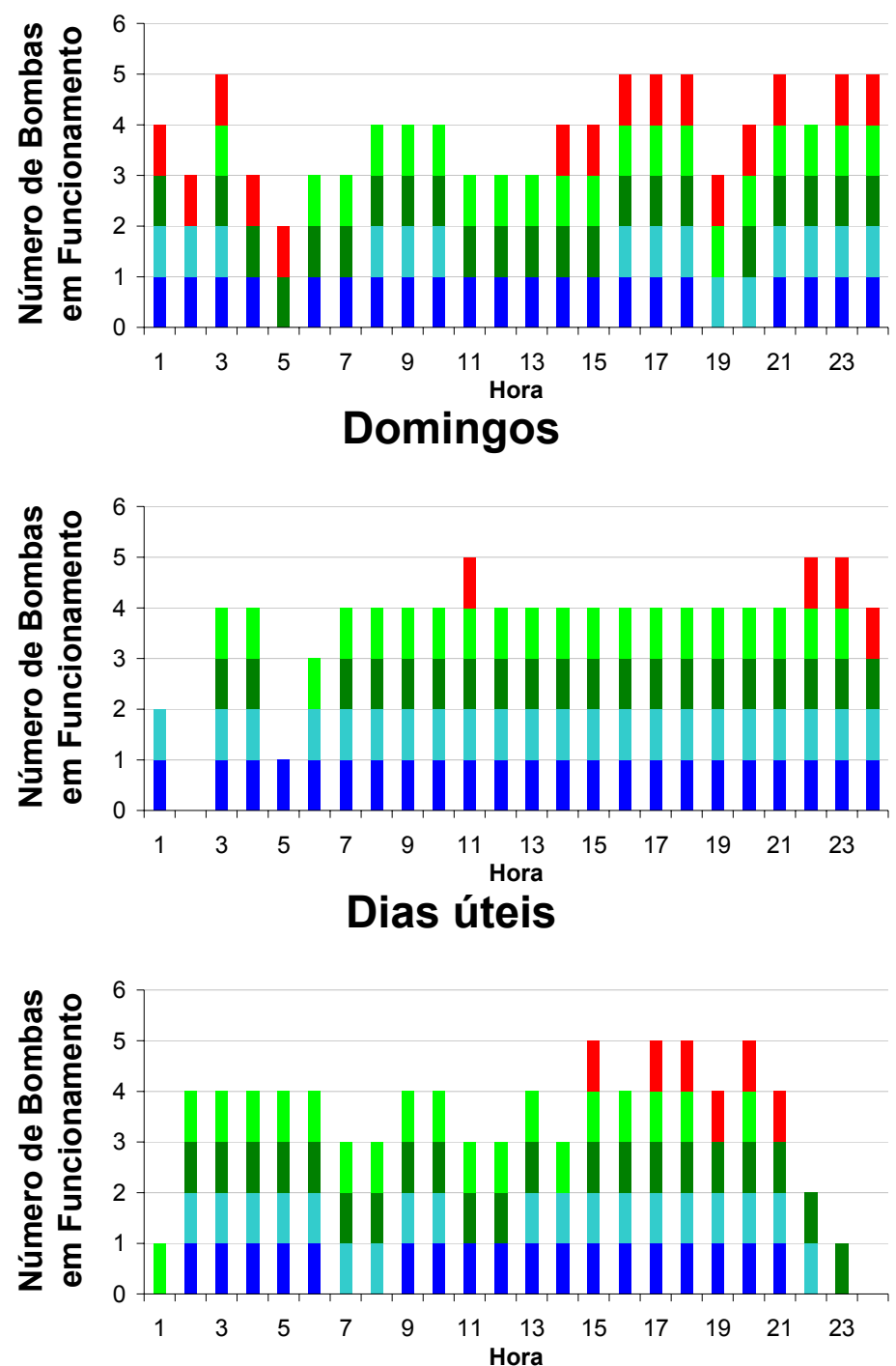

Figura 5.17 - Número de bombas em funcionamento nas otimizações estratégicas.

Visando facilitar a compreensão, optou-se por sempre adotar o seguinte esquema de representação: as bombas da elevatória EEAT1 (B39, B40 e B41) representadas em tons de azul; as do CR1 (B41 e B42) de verde; e, a do CR2 em vermelho.

\section{$\underline{\text { Penalidades }}$}

As penalidades 1 e 5 sempre resultaram em valor zero, ou seja, as restrições impostas ao problema de não ocorrência de pressão negativa na rede e de pressão inferior a 10 mH2O são satisfeitas nas três simulações realizadas, o que garante a continuidade do 
abastecimento ao longo de todo o horizonte de operação, não havendo custos de penalidades a serem considerados. Na Figura 5.18 podem ser visualizadas as pressões nos nós com demanda ao longo do horizonte de planejamento para os três ensaios de otimização.

(a)

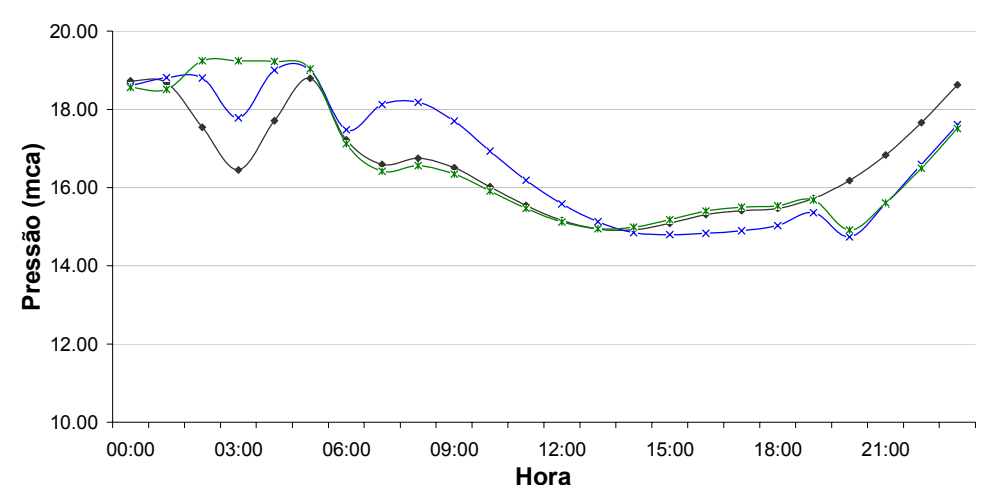

(b)

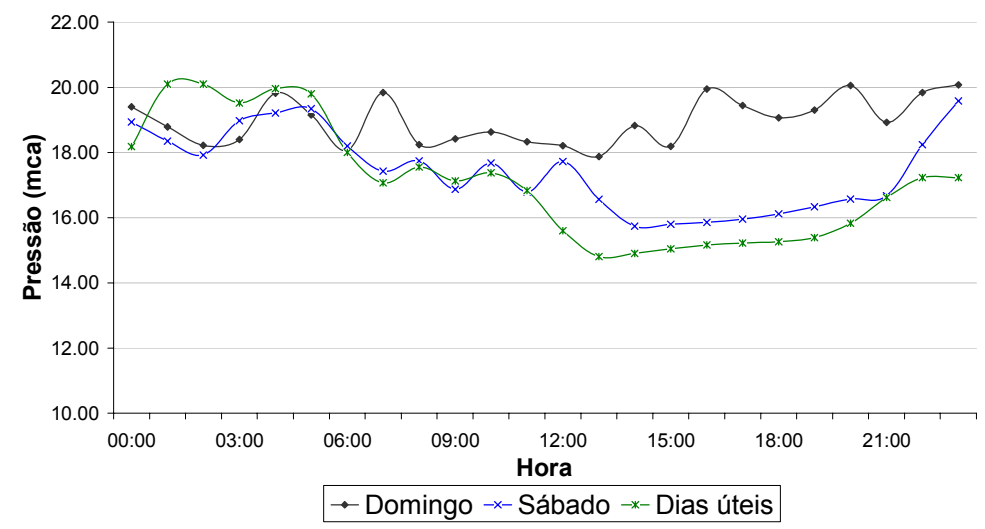

Figura 5.18 - Distribuição temporal das pressões nos nós (a) Rede 1 e (b) Rede 2, com a otimização em nível estratégico.

Nos testes de otimização realizados, conforme ensejado pela adoção do alto valor do coeficiente de penalidade $2(\lambda 2=1.000)$, os reservatórios sempre conseguem recuperar seu estado inicial, finalizando a otimização com níveis superiores a 70\% do nível máximo (e 90\% para o reservatório R3).

Observando a Tabela 5.6 e considerando o valor limite imposto no modelo de 4 acionamentos por elemento é possível perceber as violações da Penalidade 3. Para a otimização considerando a curva típica de demanda dos domingos houve 2 penalizações (B40 e V46). Para os sábados, houve penalidades ainda maiores. 
Tabela 5.6 - Quantidade de acionamentos nas otimizações em nível estratégico.

\begin{tabular}{|c|c|c|c|c|c|c|c|c|c|}
\hline \multirow{2}{*}{ Curva Típica } & \multicolumn{8}{|c|}{ Número de Acionamentos por controle } \\
\cline { 2 - 10 } & $\begin{array}{c}\text { Bomba } \\
\mathbf{3 8}\end{array}$ & $\begin{array}{c}\text { Bomba } \\
\mathbf{3 9}\end{array}$ & $\begin{array}{c}\text { Bomba } \\
\mathbf{4 0}\end{array}$ & $\begin{array}{c}\text { Bomba } \\
\mathbf{4 1}\end{array}$ & $\begin{array}{c}\text { Bomba } \\
\mathbf{4 2}\end{array}$ & $\begin{array}{c}\text { Bomba } \\
\mathbf{4 5}\end{array}$ & $\begin{array}{c}\text { Válvula } \\
\mathbf{4 6}\end{array}$ & $\begin{array}{c}\text { Válvula } \\
\mathbf{4 8}\end{array}$ & $\begin{array}{c}\text { Válvula } \\
\mathbf{4 9}\end{array}$ \\
\hline DOMINGO & 0 & 3 & $\mathbf{5}$ & 3 & 4 & 3 & $\mathbf{5}$ & 3 & 4 \\
\hline SÁBADO & 0 & $\mathbf{5}$ & $\mathbf{5}$ & $\mathbf{5}$ & 3 & 4 & 2 & 4 & $\mathbf{8}$ \\
\hline DIAS ÚTEIS & 0 & $\mathbf{4}$ & $\mathbf{4}$ & $\mathbf{4}$ & 3 & 4 & 3 & 4 & 4 \\
\hline
\end{tabular}

Destaca-se que as violações da Penalidade 3 não comprometem a boa qualidade dos resultados apresentados pelo modelo. Entretanto, estudos mais aprofundados devem ser realizados para que se possa realmente quantificar tais ocorrências. Na prática sabe-se que partidas de bombas demandam quantidade de energia elétrica significativa, não computada pelo modelo aqui apresentado, e que os custos de manutenção tanto das bombas quanto das válvulas são diretamente proporcionais à quantidade de acionamentos e/ou manobras nos mesmos.

Esquemas Otimizados de Operação das Bombas

Nos gráficos da Figura 5.19 estão apresentadas as regras operacionais otimizadas, para as 5 bombas do sistema, propostas pelas otimizações em Nível Estratégico para dias úteis, sábados e domingos.

Observando-se as regras de operação das bombas otimizadas em Nível Estratégico é fácil perceber que:

- a bomba 38, de maior potência e que por isso não pode ser acionada em paralelo com as bombas B39 e/ou B40, permanece desligada ao longo do horizonte de operação nos três ensaios de otimizações realizados;

- na otimização de dias úteis o otimizador não consegue desligar todas as bombas da $\operatorname{EEAT}_{1}(\mathrm{~B} 38, \mathrm{~B} 39$ e B40) no horário de ponta, mesmo sendo a tarifa no horário de ponta o dobro da fora de ponta e a demanda o triplo ; 
- a bomba B45 permanece ligada apenas 6 horas em dias úteis, 4 horas aos domingos e 15 horas aos sábado, mais tempo do que nos outros dias face à maior demanda registrada aos sábados.

Caso os resultados deste estudo fossem aplicados na prática, dever-se-iam considerar os custos de produção das águas provenientes de poços e ETA, já que a água aduzida pela $\mathrm{EEAT}_{1}$ possui custo de produção superior à do poço, uma vez que provém de uma ETA com custos de operação e manutenção significativos. Tal consideração poderia alterar consideravelmente o esquema operacional da bomba B45.

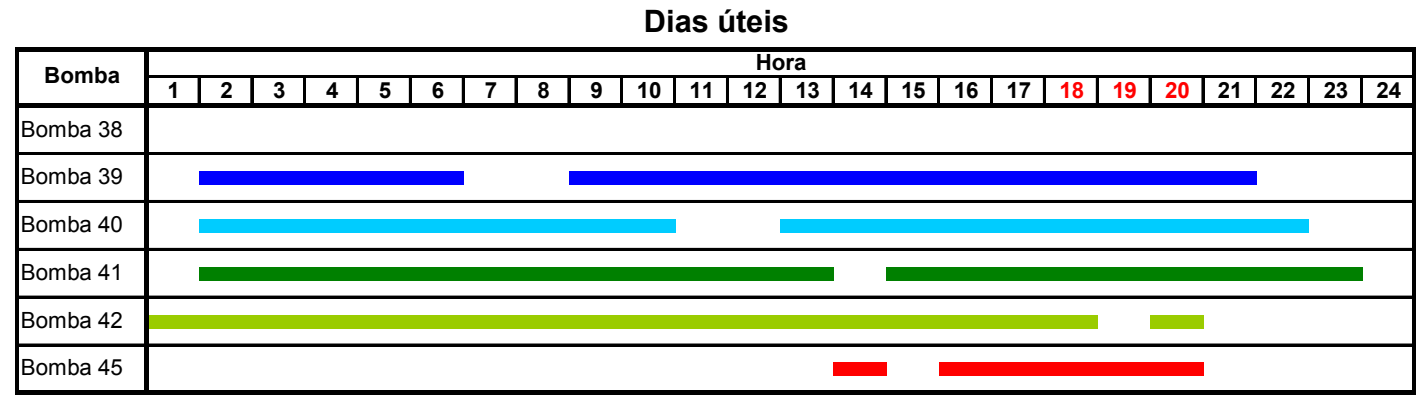

Sábados

\begin{tabular}{|c|c|c|c|c|c|c|c|c|c|c|c|c|c|c|c|c|c|c|c|c|c|c|c|c|}
\hline \multirow{2}{*}{ Bomba } & \multicolumn{24}{|c|}{ Hora } \\
\hline & 1 & 2 & 3 & 4 & 5 & 6 & 7 & 8 & 9 & 10 & 11 & 12 & 13 & 14 & 15 & 16 & 17 & 18 & 19 & 20 & 21 & 22 & 23 & 24 \\
\hline \multicolumn{25}{|l|}{ Bomba 38} \\
\hline \multicolumn{25}{|l|}{ Bomba 39} \\
\hline \multicolumn{25}{|l|}{ Bomba 40} \\
\hline \multicolumn{25}{|l|}{ Bomba 41} \\
\hline \multicolumn{25}{|l|}{ Bomba 42} \\
\hline Bomba 45 & & & & & & & & & & & & & & & & & & & & & & & & \\
\hline
\end{tabular}

Domingos

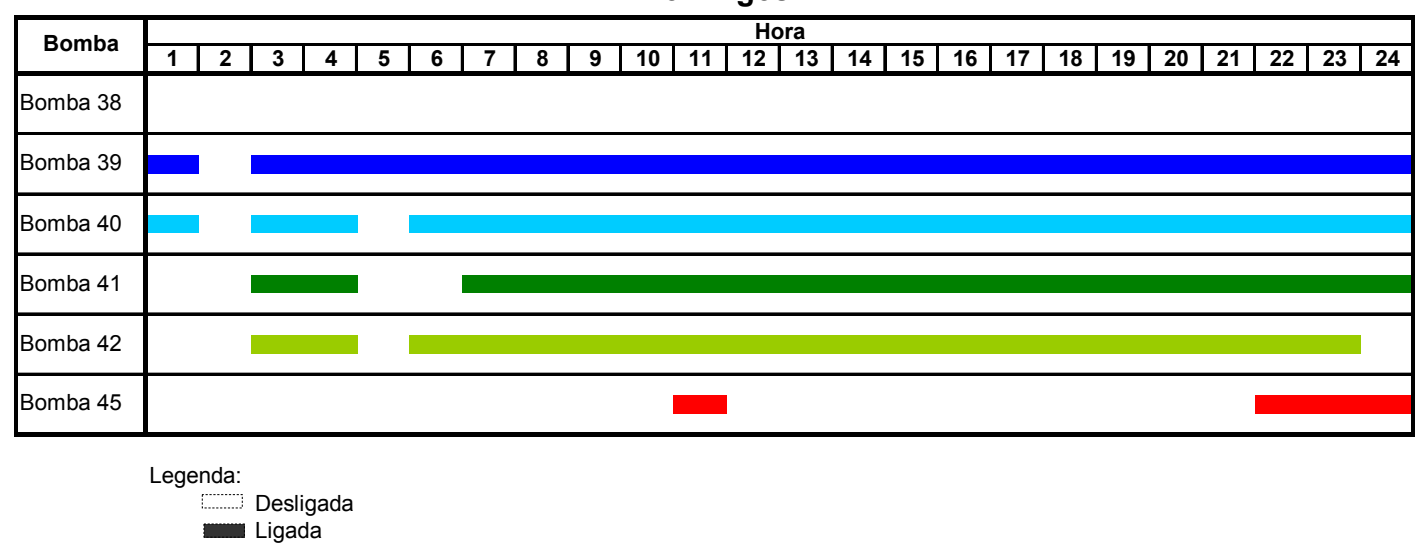

Figura 5.19 - Regras de operação das bombas resultantes da otimização estratégica. 
Esquemas Otimizados de Operação das Válvulas

O sistema aqui estudado possui 4 válvulas: V47, localizada na entrada do reservatório R1, cuja operação não constitui variável de decisão do problema, uma vez que permanece sempre fechada, apesar de permitir a passagem de vazão de $10 \mathrm{~L} / \mathrm{s}$ devido a problemas de estanqueidade; V46, localizada na entrada do reservatório R2, que regula a admissão de água para o mesmo, priorizando ou não a adução de água para o CR2; V48, que regula o fluxo de água para o R4; e, V49, que controla a entrada e saída de água do reservatório $\mathrm{R} 5$.

As estratégias operacionais otimizadas para as diferentes curvas típicas de demanda são apresentadas na Figura 5.20.

Dias úteis

\begin{tabular}{|c|c|c|c|c|c|c|c|c|c|c|c|c|c|c|c|c|c|c|c|c|c|c|c|c|}
\hline \multirow{2}{*}{ Válvula } & \multicolumn{24}{|c|}{ Hora } \\
\hline & 1 & 2 & 3 & 4 & 5 & 6 & 7 & 8 & 9 & 10 & 11 & 12 & 13 & 14 & 15 & 16 & 17 & 18 & 19 & 20 & 21 & 22 & 23 & 24 \\
\hline Válvula 46 & & & & & & & & & & & & & & & & & & & & & & & & \\
\hline Válvula 49 & & & & & & & & & & & & & & & & & & & & & & & & \\
\hline
\end{tabular}

Sábados

\begin{tabular}{|c|c|c|c|c|c|c|c|c|c|c|c|c|c|c|c|c|c|c|c|c|c|c|c|c|}
\hline \multirow{2}{*}{ Válvula } & \multicolumn{24}{|c|}{ Hora } \\
\hline & 1 & 2 & 3 & 4 & 5 & 6 & 7 & 8 & 9 & 10 & 11 & 12 & 13 & 14 & 15 & 16 & 17 & 18 & 19 & 20 & 21 & 22 & 23 & 24 \\
\hline \multicolumn{25}{|l|}{ Válvula 46} \\
\hline Válvula 49 & & & & & 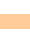 & & & & & & 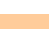 & & & & 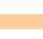 & & & & & & & 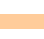 & & \\
\hline
\end{tabular}

Domingos

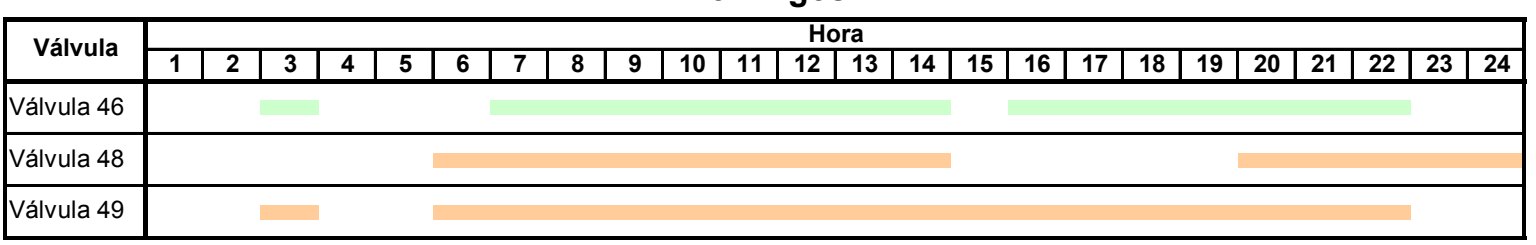

Figura 5.20 - Regras de operação das válvulas resultantes da otimização estratégica.

\section{Esquemas Otimizados de Operação dos Reservatórios}

As estratégias operacionais para bombas e válvulas, obtidas da otimização em Nível Estratégico, foram implementadas no simulador hidráulico para a produção dos níveis 
operacionais dos reservatórios e posterior avaliação do comportamento do sistema nos diferentes dias da semana.

Nos gráficos na Figura 5.21 estão apresentas as curvas de variação dos níveis de água nos reservatórios $\mathrm{R} 2$ e $\mathrm{R} 3$.
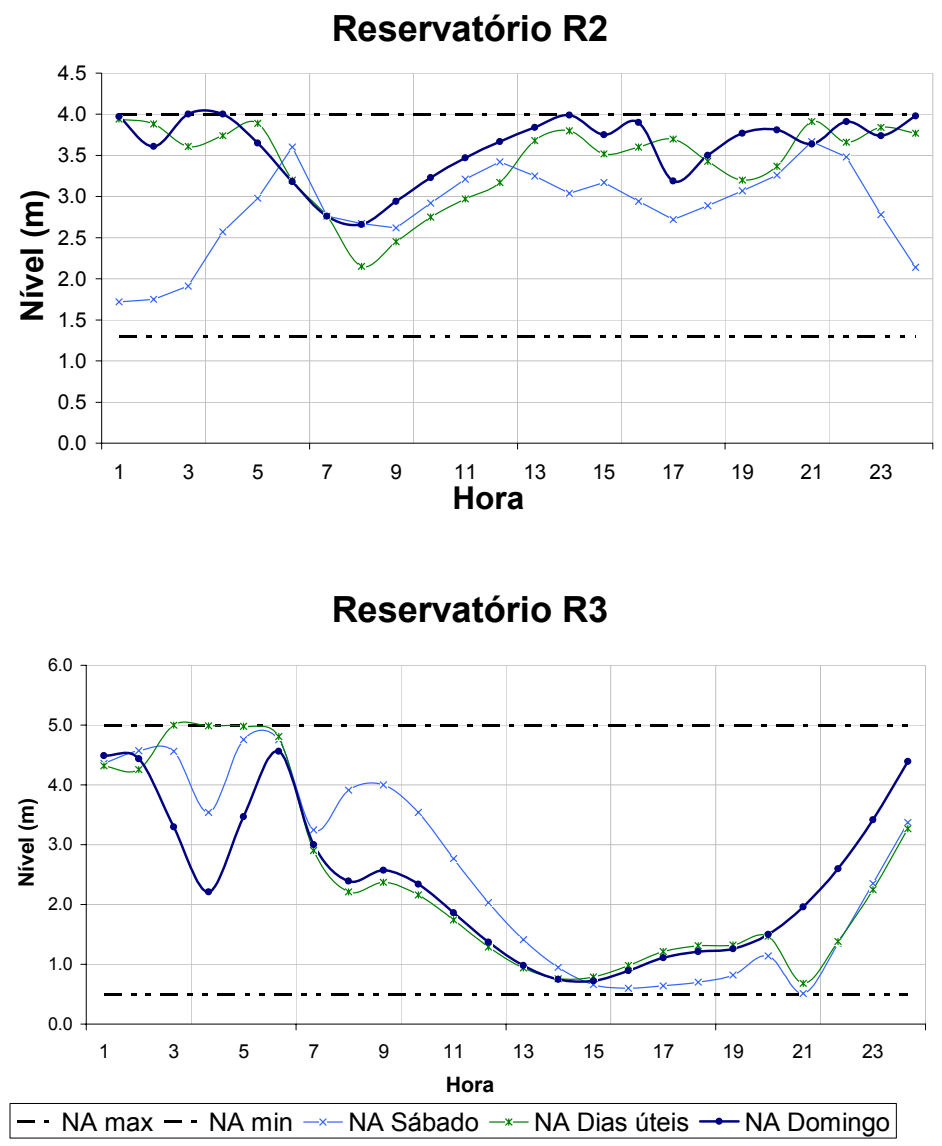

Figura 5.21 - Operação Otimizada em Nível Estratégico dos reservatórios R2 e R3.

Os gráficos mostram que as estratégias de operação dos reservatórios R2 e R3 propostas pelo otimizador encontram-se dentro dos limites operacionais estabelecidos para todas as curvas típicas de demanda (dias úteis, sábados e domingos).

Observa-se que no reservatório R3 há o aproveitamento quase que total do volume disponível durante o período estudado. Já para o reservatório R2 esse aproveitamento acontece apenas aos sábados.

Para ambos os reservatórios, e todas as otimizações realizadas, é possível perceber a tendência em recuperar o estado inicial dos reservatórios. O nível dos reservatórios 
mostra-se crescente durante a madrugada, de forma que as 06:00 esteja superior a 70\% do nível máximo no R2 e 90\% no R3.

No reservatório R3 há um brusco rebaixamento do nível durante a madrugada, evidenciado principalmente aos sábados e domingos às 04:00, resultante do desligamento da bomba B42, que volta a funcionar apenas às 06:00.

Na Figura 5.22 estão apresentados os gráficos com as curvas de variação dos níveis de água nos reservatórios R4 e R5.

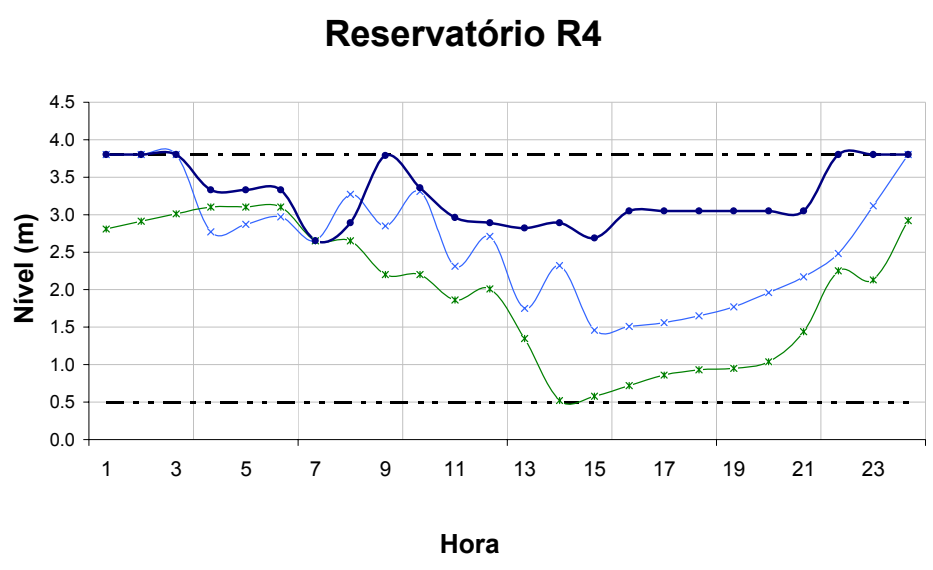

Reservatório R5

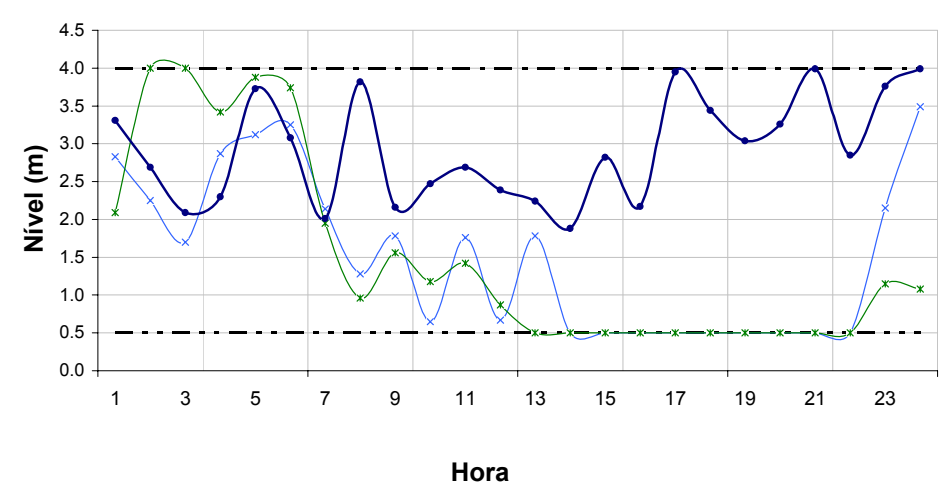

Figura 5.22 - Operação Otimizada em Nível Estratégico dos reservatórios R4 e R5.

Ao observar o gráfico da Figura 5.22 relativo ao reservatório R5 é possível perceber a oscilação do nível de água do mesmo, principalmente aos sábados e domingos. Isto se deve à elevada quantidade de manobras no sistema que a otimização determina, visando melhores estratégias operacionais. 
Observa-se que o R5 tanto pode ser abastecido por gravidade pelos reservatórios R4 e R2 quanto por recalque da EEAT1. Quando as bombas da EEAT1 são desligadas, diminuindo a pressão nas linhas de adução, ocorre o retorno de água por gravidade do reservatório R2 para o CR2, conforme ilustrado na Figura 5.23.

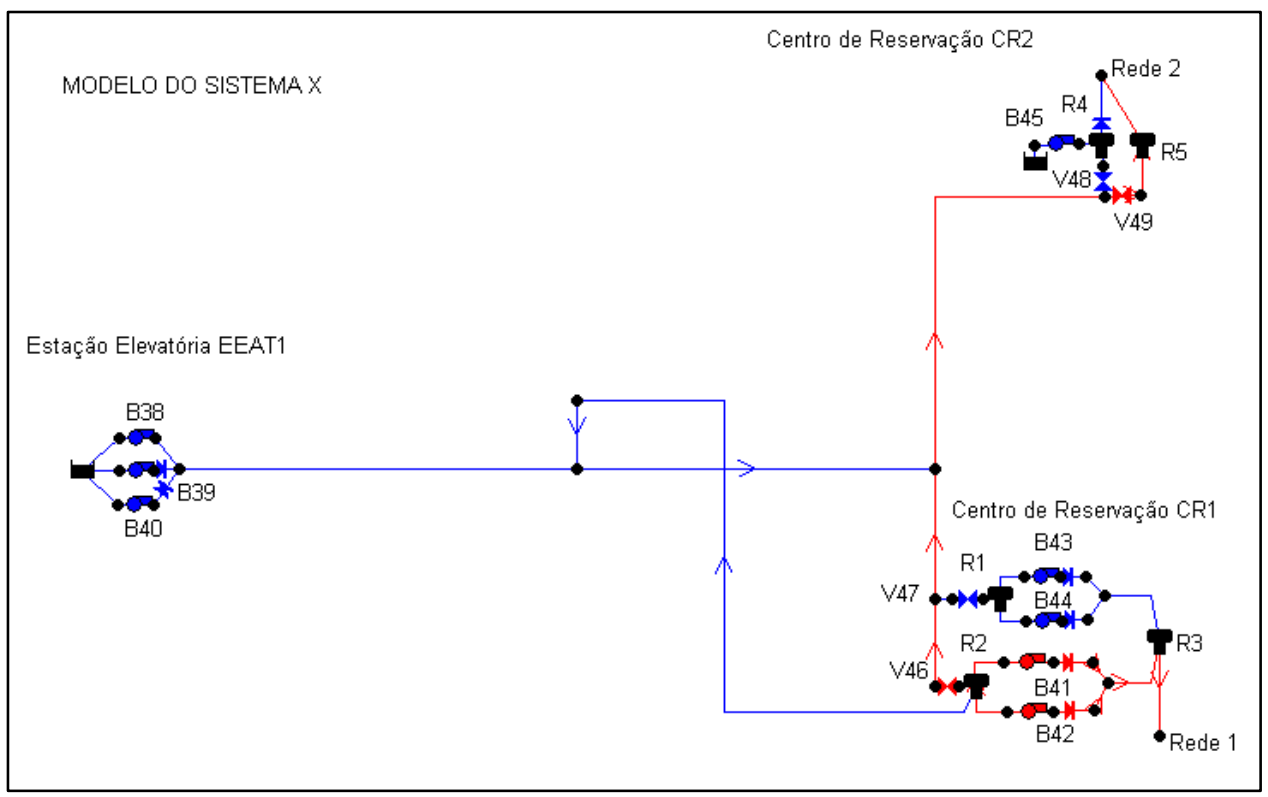

Figura 5.23 - Sentido de escoamento.

R5 ainda possui a característica de poder abastecer, além do nó Rede 2, o reservatório R4. Na Figura 5.24 estão ilustrados os sentidos de fluxo de água que podem ocorrer no CR2.

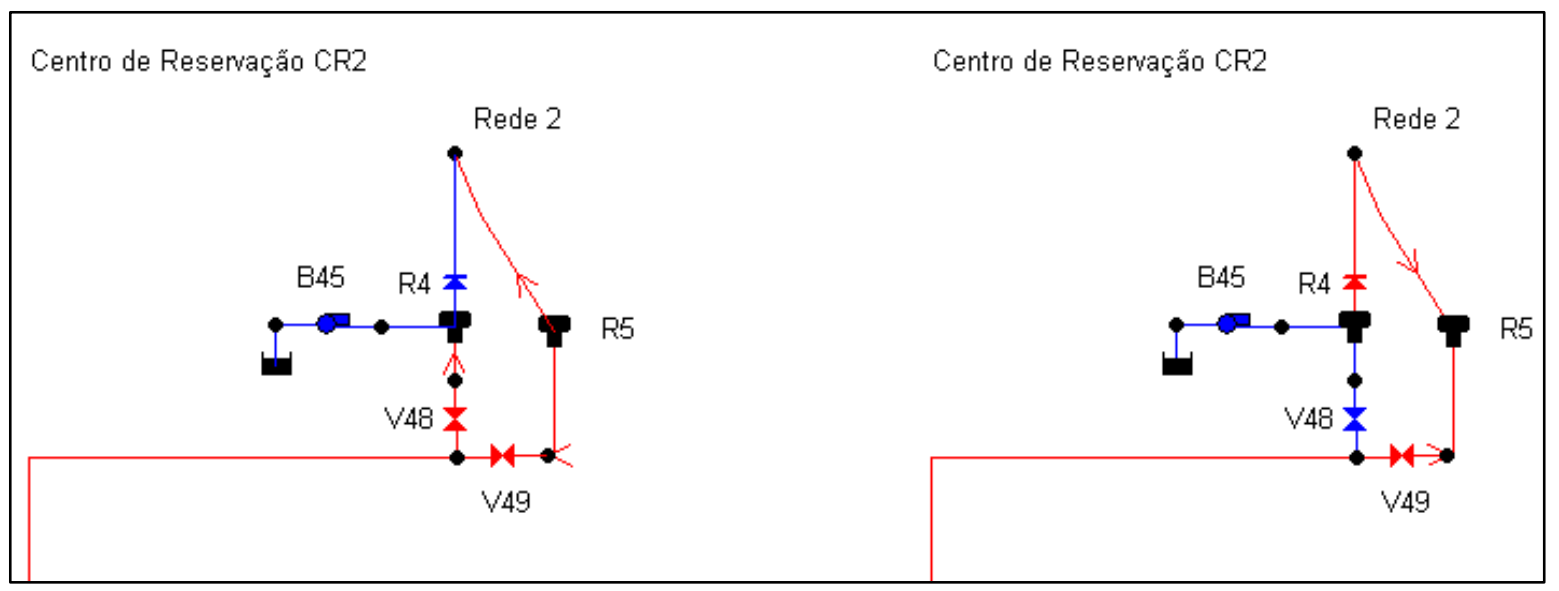

Figura 5.24 - Sentidos de fluxo no CR2. 
Outro fato marcante é que o reservatório R5 permanece com nível mínimo de água durante longos períodos, o que não é desejável operacionalmente, mostrando claramente a deficiência da otimização de objetivo único (com vistas apenas à minimização dos custos com energia elétrica), discutida por Walski (2001) e citada no Capítulo 2 desta dissertação. Apesar das soluções otimizadas em nível estratégico terem reduzido os custos relativos ao consumo de energia elétrica, o sistema perdeu consideravelmente parte da sua “confiabilidade", uma vez que os reservatórios não acumulam água suficiente, em grande parte do dia, para suprir eventuais problemas operacionais.

\subsubsection{Níveis Meta}

Os níveis dos reservatórios obtidos com a otimização em Nível Estratégico para dias úteis, sábados e domingo, apresentados anteriormente nas Figura 5.21 e Figura 5.22, foram adotados como Níveis Metas para a otimização em Tempo Real.

Cabe relembrar que, conforme explicitado no item '4.3 - Demandas' desta dissertação, a otimização em nível estratégico, e, consequentemente, os níveis metas, foram gerados com base no histórico de demandas referente aos meses de Maio, Junho, Julho e Agosto. Portanto, os níveis meta gerados são referentes apenas ao período de seca.

\subsection{Otimização em Tempo Real}

Realizou-se a otimização em Tempo Real da operação do sistema estudado para o período de uma semana em dois meses distintos: um no período de seca (de 05 de junho a 11 de junho) e outro no período chuvoso (de 07 a 13 de fevereiro). 
Com o objetivo de avaliar a influência dos Níveis Metas realizou-se também a otimização em Tempo Real sem considerar tais níveis.

Já com o objetivo de avaliar a influência da Previsão de Demandas nos resultados da Otimização em Tempo Real realizou-se também a otimização em Tempo Real considerando o histórico de demandas disponível.

Portanto, foram realizadas otimizações em tempo real com dados previstos de demandas e dados históricos de demandas, com níveis metas e sem níveis, para os meses de fevereiro e junho - conforme apresentado na Figura 5.25.

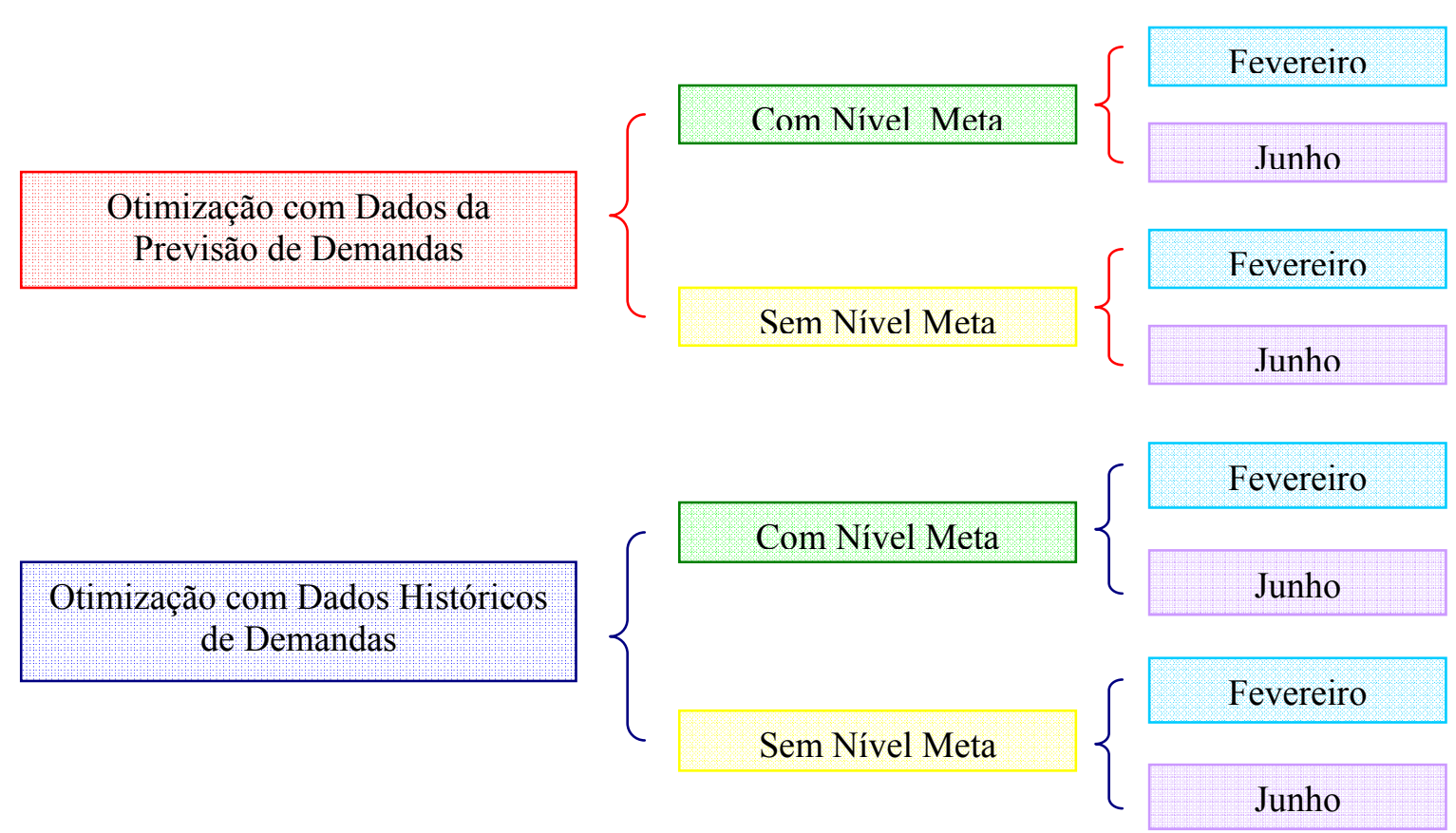

Figura 5.25 - Fluxograma das Otimizações em Tempo Real realizadas.

Para a Otimização em Tempo Real Com Níveis Meta foram adotadas penalidades quanto: à ocorrência de pressões inferiores à mínima (Penalidade 1); à elevada quantidade de acionamento de bombas e/ou manobras de válvulas (Penalidade 3); à descontinuidade do abastecimento (Penalidade 5); e, à diferença entre os níveis dos reservatórios e níveis meta (Penalidade 4). Já para a Otimização em Tempo Real Sem Níveis Meta foram adotadas apenas as penalidades 1, 2, 3 e 5 . 
5.7.1 Resultados da Otimização em Tempo Real com Previsão de Demandas

Aplicando os módulos relativos ao simulador hidráulico e ao otimizador em tempo real e utilizando os parâmetros descritos nos itens 5.3.2 e a previsão de demandas, no sistema objeto de estudo, obteve-se os custos de bombeamento das estratégias operacionais otimizadas em tempo real apresentados na Tabela 5.7.

Tabela 5.7 - Custo de Bombeamento Tempo Real - Com Dados de Demandas Previstos.

\begin{tabular}{|l|c|c|c|c|c|}
\hline \multirow{3}{*}{ Dia } & \multicolumn{4}{|c|}{ Custo de bombeamento (R\$/dia) } & \multirow{3}{*}{ Otimização Tempo Real } \\
\cline { 2 - 5 } & \multicolumn{3}{|c|}{ Estratégico } \\
\cline { 2 - 5 } & \multicolumn{2}{|c|}{ Com Nível Meta } & \multicolumn{2}{c|}{ Sem Nível Meta } & \\
\cline { 2 - 5 } & Fevereiro & Junho & Fevereiro & Junho & \\
\hline Sábado & $8.281,58$ & $8.424,45$ & $8.127,05$ & $7.989,05$ & 7.346 .50 \\
\hline Domingo & $5.636,59$ & $5.667,67$ & $5.596,76$ & $5.518,17$ & 6.666 .02 \\
\hline Dias úteis* & $9.124,88$ & $9.104,00$ & $9.274,69$ & $9.038,97$ & 8.474 .71 \\
\hline
\end{tabular}

* Média do custo diário de bombeamento para os cinco dias úteis otimizados.

Observa-se que a otimização em Tempo Real produz custos superiores ao da otimização em Nível Estratégico já que a estratégia operacional do Tempo Real não é uma estratégia resultante de um processo de otimização global do período e sim o somatório da primeira hora das 24 estratégias resultantes da otimização realizada para horizontes de 24 horas defasadas de 1 hora.

É de se esperar que a otimização estratégica produza menores custos de bombeamento do que a otimização em tempo real. Essa expectativa se confirmou para os dias úteis e sábados. Entretanto tal comportamento não se verificou para o domingo. Uma explicação para o fato talvez seja de que, como a aplicação dos AGs não garante a convergência para o ótimo, as soluções encontradas em nível estratégico para o domingo podem não corresponder às respectivas soluções ótimas. 


\section{$\underline{\text { DIAS ÚTEIS }}$}

O custo de bombeamento obtido com as regras operacionais geradas pela otimização em tempo real para os dias úteis, conforme pode ser observado na Figura 5.26, são muito próximos entre si. O desvio padrão é de $\mathrm{R} \$ 401,50$, o que corresponde a menos de $5 \%$ do custo médio diário de bombeamento.

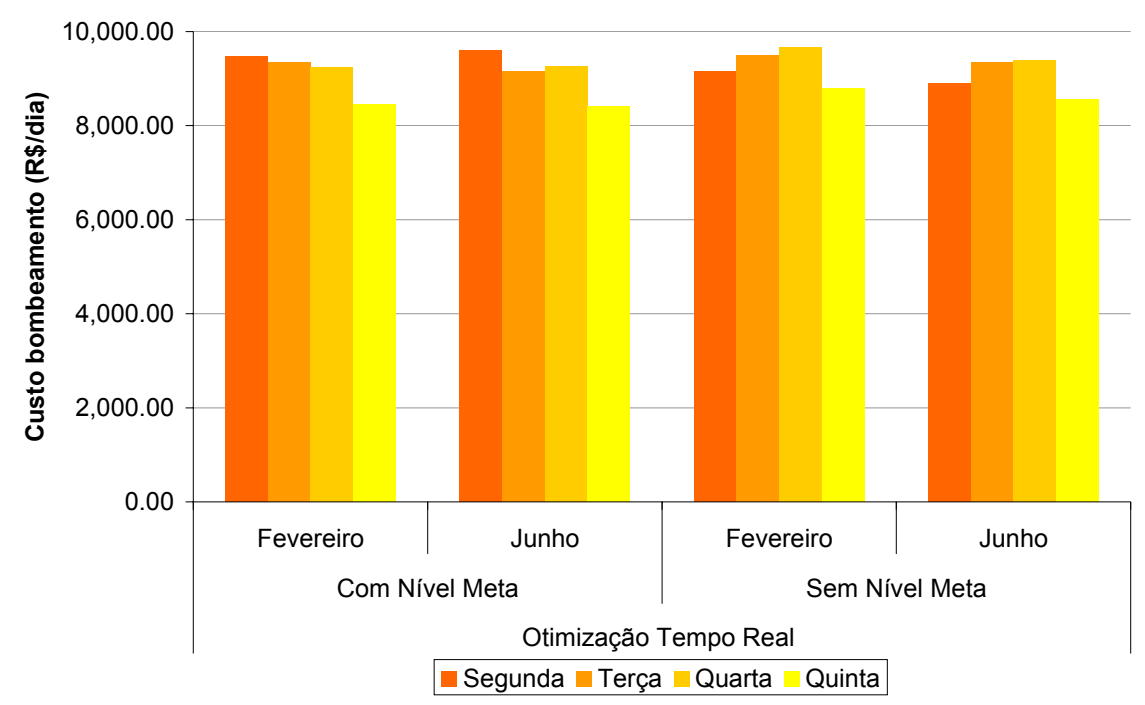

Figura 5.26 - Custo diário de bombeamento otimizado em tempo real - Dias Úteis.

\section{PENALIDADES}

Conforme definido na análise de sensibilidade, os valores para os coeficientes de penalidades $\lambda_{2}, \lambda_{3}$ e $\lambda_{4}$ adotados foram de $1.000,50$ e 30 , respectivamente.

As penalidades 1 e 5 sempre foram iguais a zero, comprovando a aplicabilidade das estratégias operacionais geradas pelo modelo. As pressões nos nós com demanda ao longo do horizonte de planejamento para as otimizações em tempo real dos sábados, domingos e dias úteis sempre foram superiores a $10 \mathrm{mH}_{2} \mathrm{O}$.

A seguir, na Tabela 5.8 e na Figura 5.27, são apresentados os valores das penalidades 2, 3 e 4 para as otimizações em tempo real dos sábados, domingos e dias úteis. 
Tabela 5.8 - Resultados das Penalidades- Com Dados de Demandas Previstos..

\begin{tabular}{|c|c|c|c|c|c|c|c|c|}
\hline \multirow{3}{*}{ Dia } & \multicolumn{4}{|c|}{ Fevereiro } & \multicolumn{4}{|c|}{ Junho } \\
\hline & \multicolumn{2}{|c|}{ Com Nível Meta } & \multicolumn{2}{|c|}{ Sem Nível Meta } & \multicolumn{2}{|c|}{ Com Nível Meta } & \multicolumn{2}{|c|}{ Sem Nível Meta } \\
\hline & $\begin{array}{c}\text { Penalidade } \\
3\end{array}$ & \begin{tabular}{|c|} 
Penalidade \\
4
\end{tabular} & \begin{tabular}{|c|} 
Penalidade \\
2
\end{tabular} & \begin{tabular}{|c|} 
Penalidade \\
3
\end{tabular} & \begin{tabular}{|c|} 
Penalidade \\
3
\end{tabular} & \begin{tabular}{|c|} 
Penalidade \\
4
\end{tabular} & \begin{tabular}{|c|} 
Penalidade \\
2
\end{tabular} & \begin{tabular}{|c|} 
Penalidade \\
3
\end{tabular} \\
\hline Sábado & 100,00 & 99,65 & 660,15 & 150,00 & 100,00 & 122,35 & 200,27 & 150,00 \\
\hline Domingo & 100,00 & 107,67 & 3,90 & 150,00 & 150,00 & 138,25 & 234,95 & 100,00 \\
\hline Dias úteis & 150,00 & 124,42 & 3,67 & 250,00 & 100,00 & 90,16 & 0,00 & 150,00 \\
\hline
\end{tabular}

Os valores obtidos para as Penalidades 2,3 e 4, apresentados na tabela acima divididos pelos respectivos coeficientes de penalidade produzem os valores mostrados na Figura 5.27.

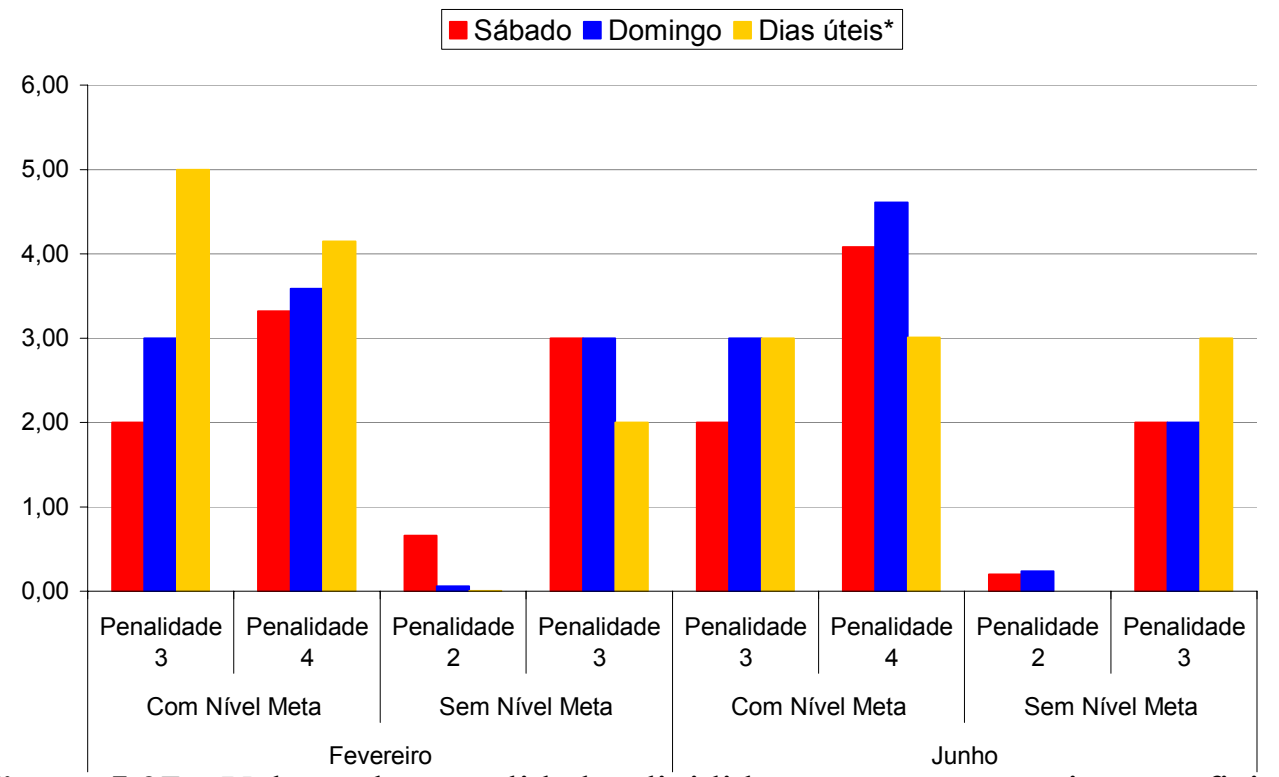

Figura 5.27 - Valores das penalidades divididos por seus respectivos coeficientes.

Com base em tais valores é possível concluir-se que:

- Conforme ensejado pela adoção do alto valor do coeficiente de penalidade 2 $(\lambda 2=1.000)$, os reservatórios sempre conseguem recuperar seu estado inicial, finalizando a otimização com níveis superiores a 70\% do nível máximo (e 90\% para o reservatório $\mathrm{R} 3$ ) - penalidade 2 praticamente nula.

- Assim como na otimização em nível estratégico, ocorreram violações da Penalidade 3, com números de acionamentos das bombas e válvulas chegando a 7 por elemento. Ressalta-se que esta penalidade é aplicada apenas a partir do quarto acionamento; 
portanto, os acionamentos em quantidade inferior a 4 por elemento não estão mostrados na Figura 5.27.

- Nas otimizações com os níveis metas houve maior quantidade de acionamento das bombas e/ou manobra das válvulas (Penalidade 3) para que fosse possível atingir níveis nos reservatórios superiores aos níveis metas, minimizando a Penalidade 4.

\section{ESQUEMAS OTIMIZADOS DE OPERAÇÃO DAS BOMBAS}

As estratégias operacionais otimizadas em tempo real para as bombas dos sábados, domingos e dias úteis são apresentadas nas Figura 5.28, Figura 5.29 e Figura 5.30,

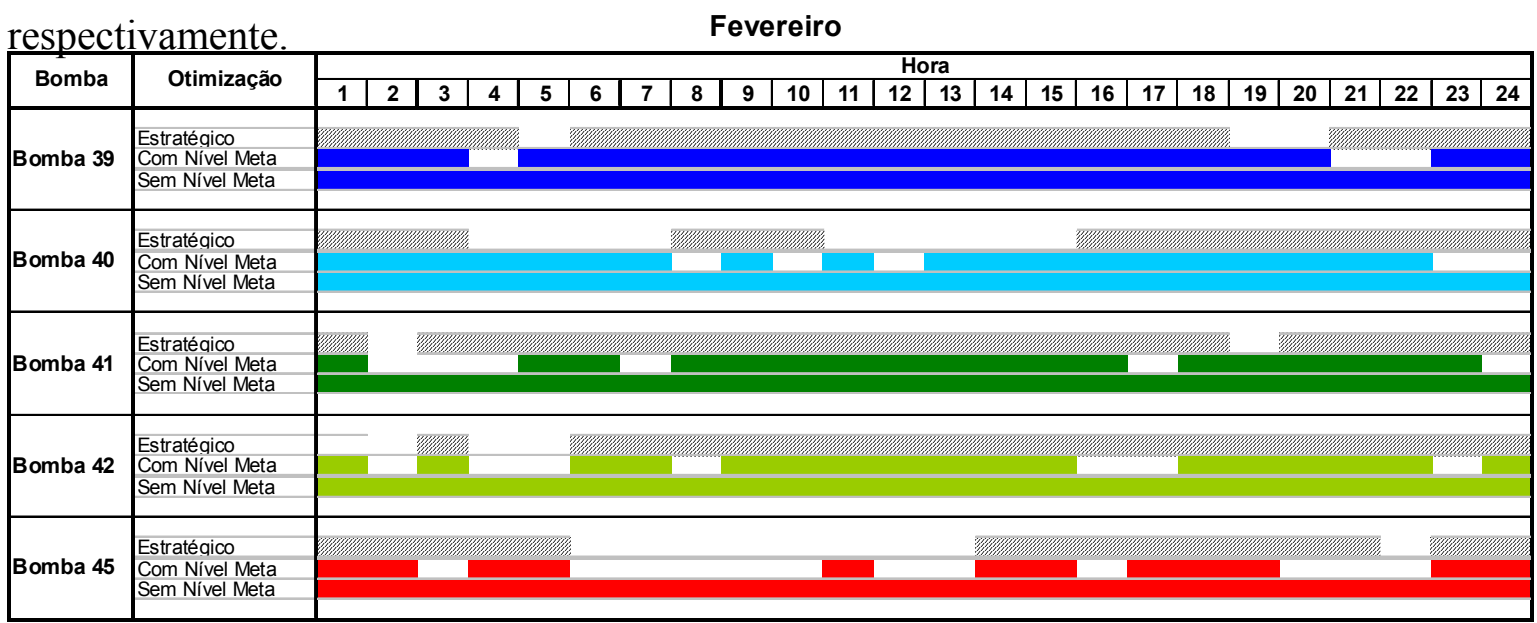

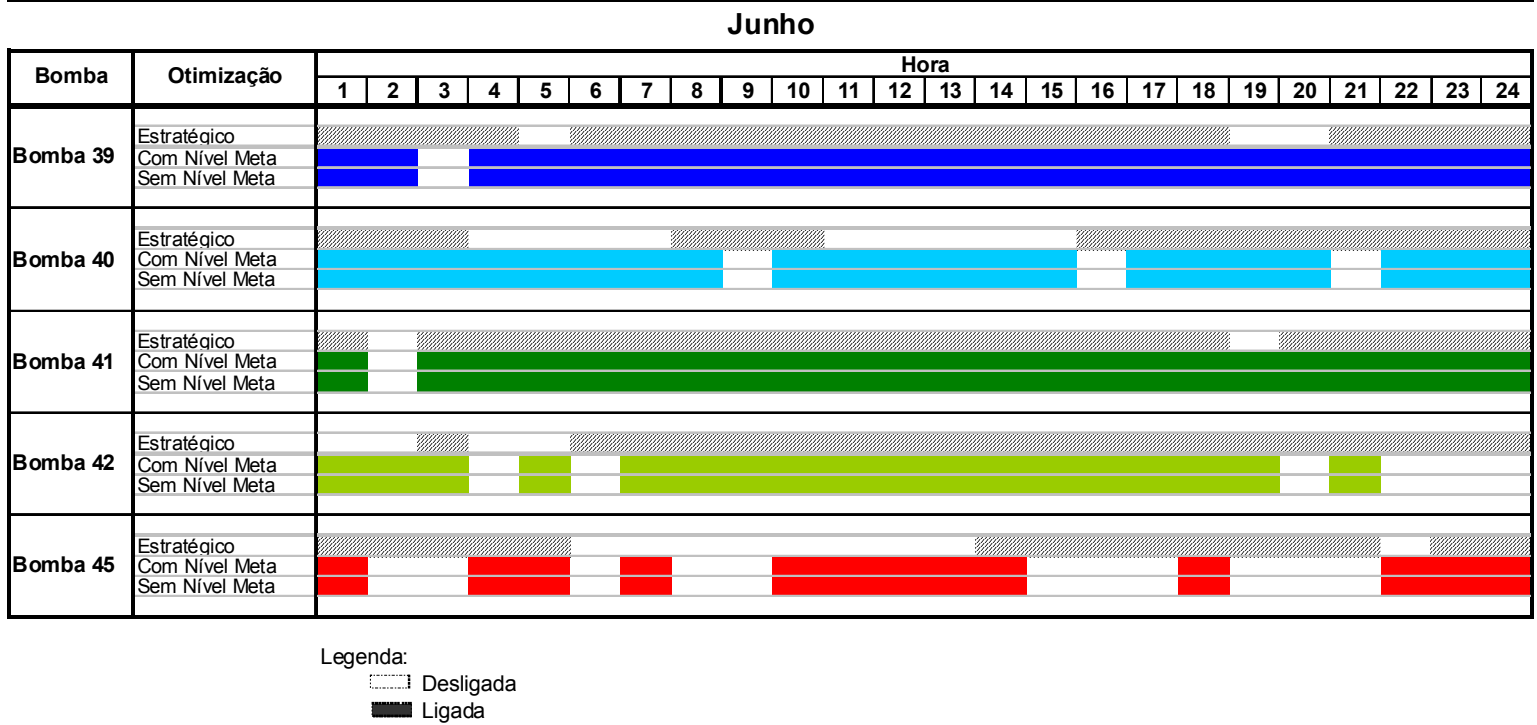

Figura 5.28 - Regras de operação otimizadas - Sábado. 


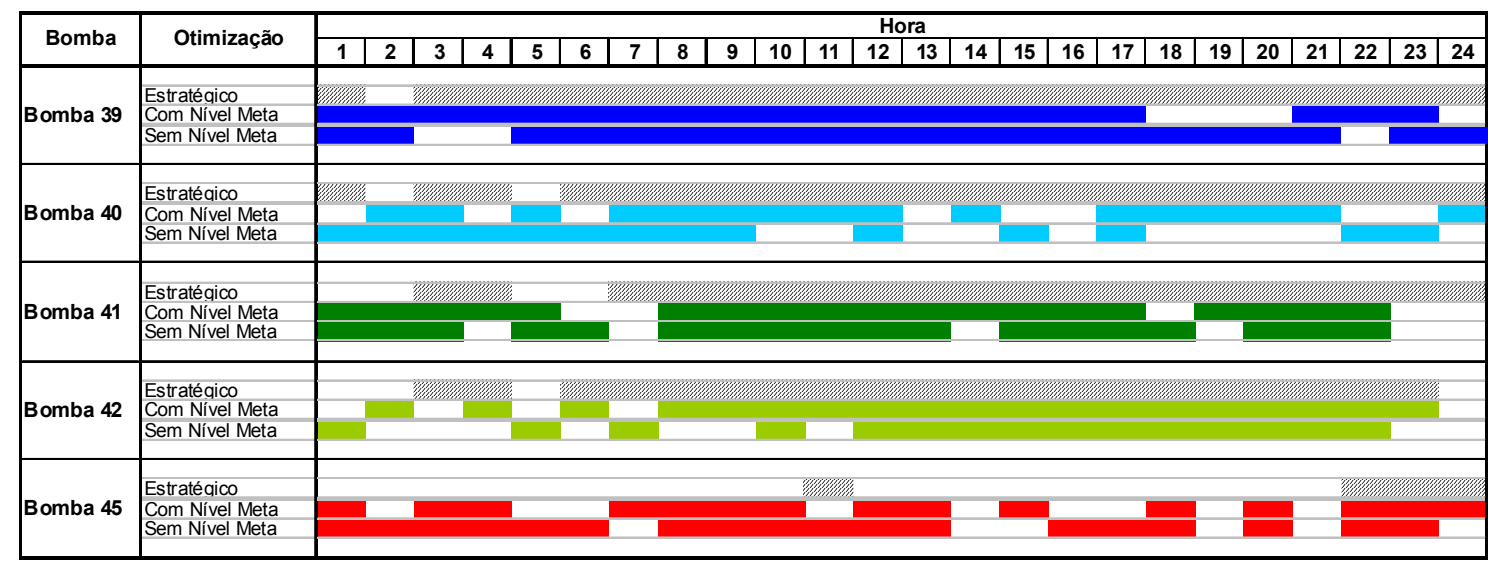

\section{Junho}

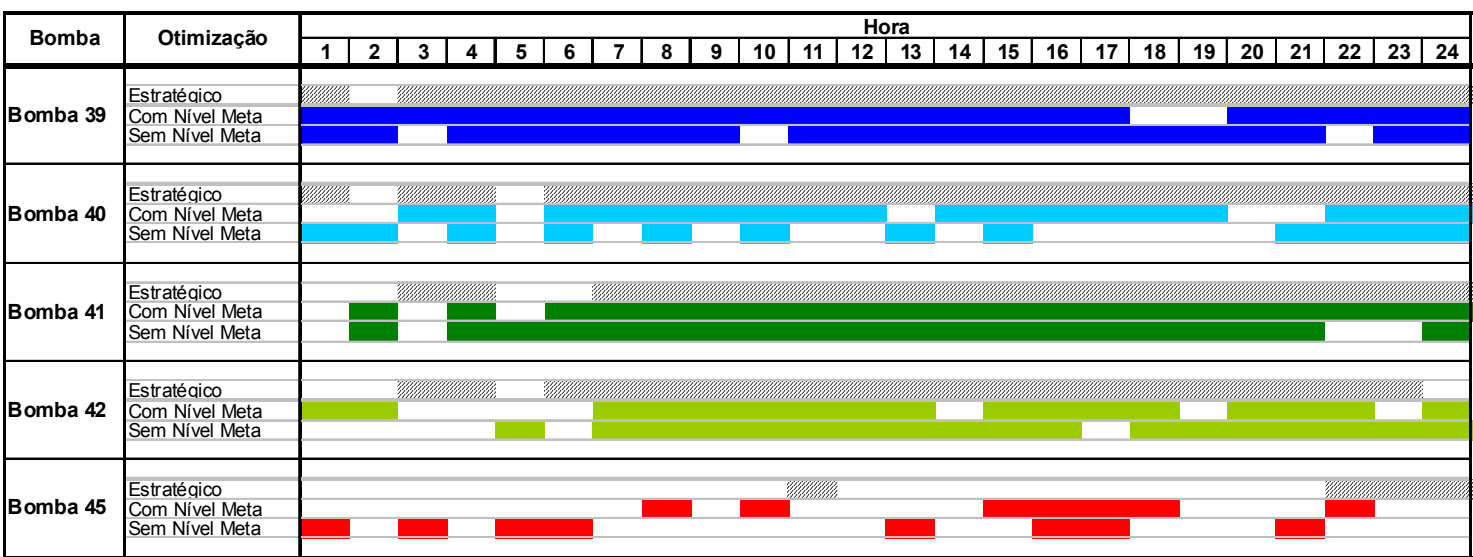

Figura 5.29 - Regras de operação otimizadas - Domingo.

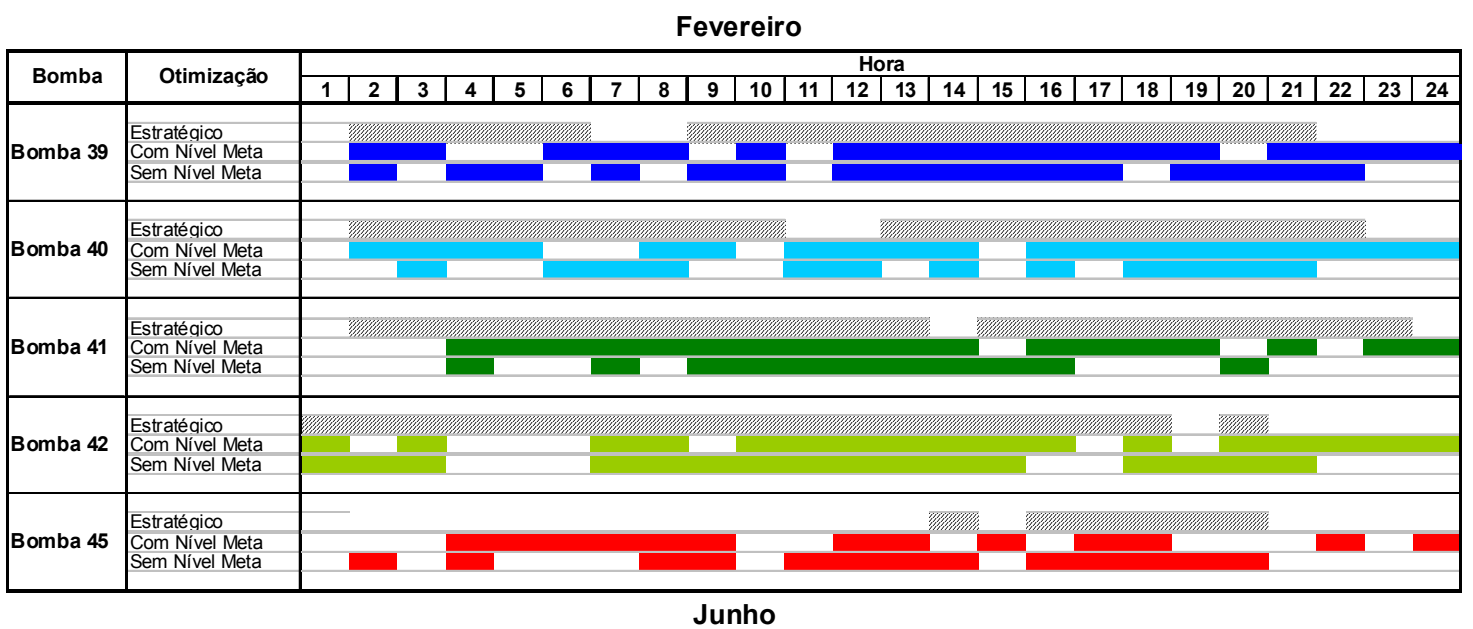

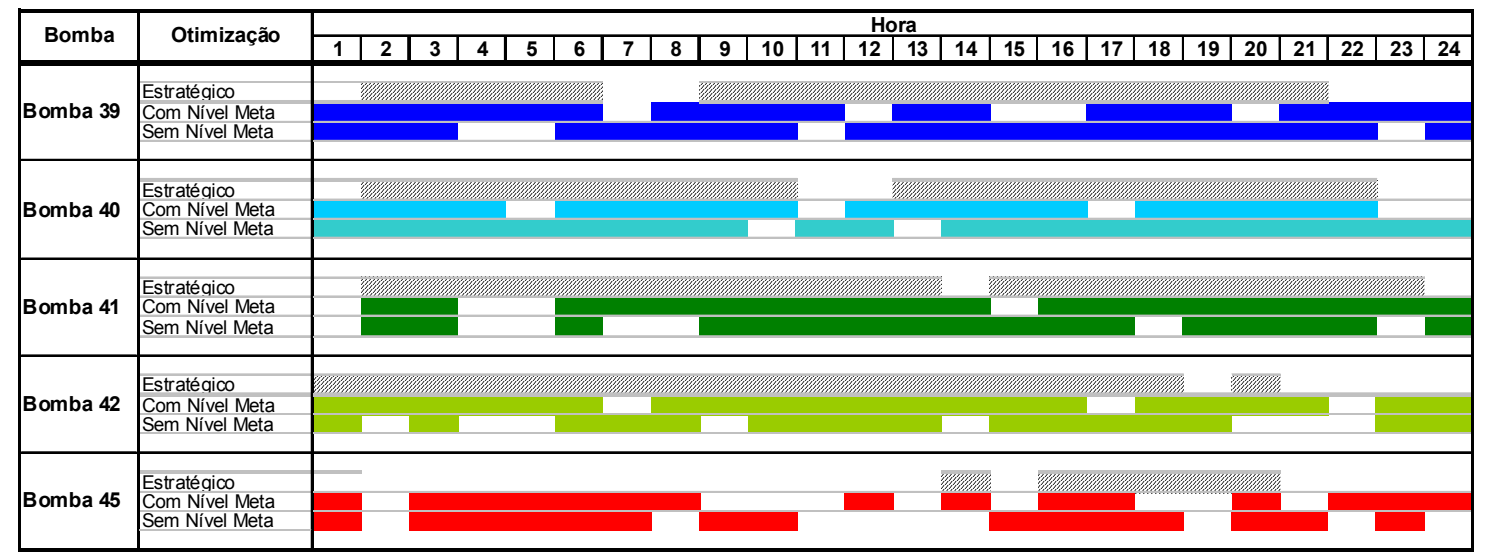

Figura 5.30 - Regras de operação otimizadas - Segunda-feira. 
Uma restrição que não foi colocada no modelo e que pôde ser claramente visualizada nas Figura 5.28 a Figura 5.30 foi com relação ao funcionamento das bombas em paralelo. Muitas vezes o modelo desliga uma bomba e liga outra da mesma elevatória, aumentando a quantidade de acionamentos e o desgaste das bombas sem necessidade.

Destaca-se também a maior quantidade de acionamentos das bombas na otimização em tempo real do que na otimização em nível estratégico. Isto porque a otimização em tempo real é formada pela união das estratégias operacionais otimizadas da primeira hora de 24 otimizações realizadas (uma em cada hora do dia). E, apesar do número de acionamentos ser limitado ao longo de cada otimização, pela penalidade 3 , a união das primeiras horas das 24 otimizações não tem necessariamente a quantidade de acionamentos limitados.

\section{ESQUEMAS OTIMIZADOS DE OPERAÇÃO DOS RESERVATÓRIOS}

Os níveis dos reservatórios ao longo das 24 horas do sábado, domingo e segunda, para as diferentes otimizações, são apresentados nas Figura 5.31 aFigura 5.32, respectivamente.

Observou-se que: (i) os níveis obtidos encontram-se dentro dos limites operacionais dos reservatórios, demonstrando a viabilidade das estratégias operacionais geradas pelo modelo proposto; (ii) as otimizações considerando os níveis metas apresentaram a tendência de manter os níveis mais elevados, já que as soluções com nível inferior ao nível meta são penalizadas, obviamente que se o valor de $\lambda 4$ fosse maior essa tendência também seria maior; e, (iii) com a otimização em tempo real houve um menor aproveitamento do volume útil dos reservatórios, sendo que estes permaneceram a maior parte do dia com mais de $50 \%$ da sua capacidade. 

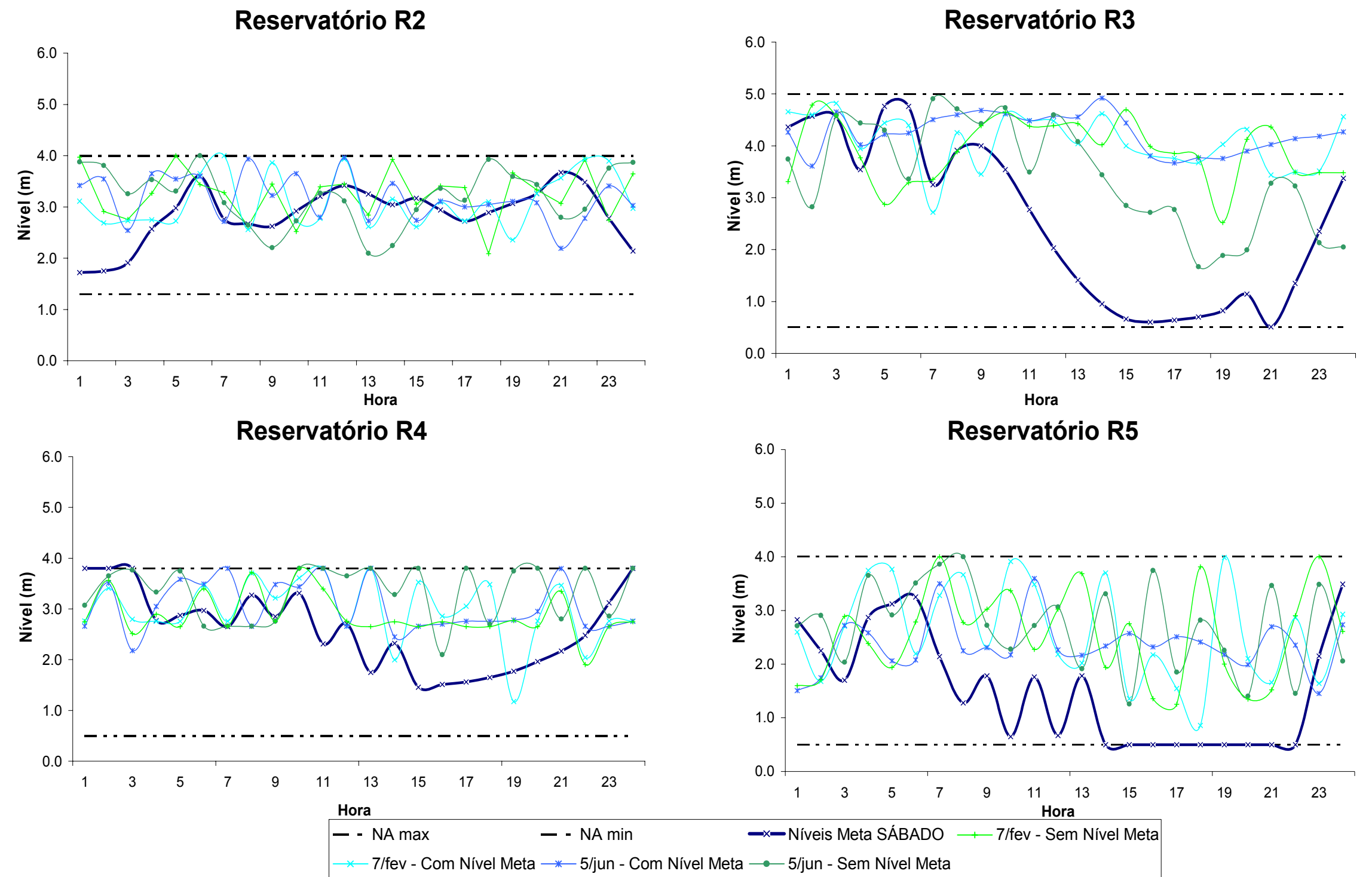

Figura 5.31 - Níveis dos reservatórios - estratégias operacionais otimizadas sábados. 

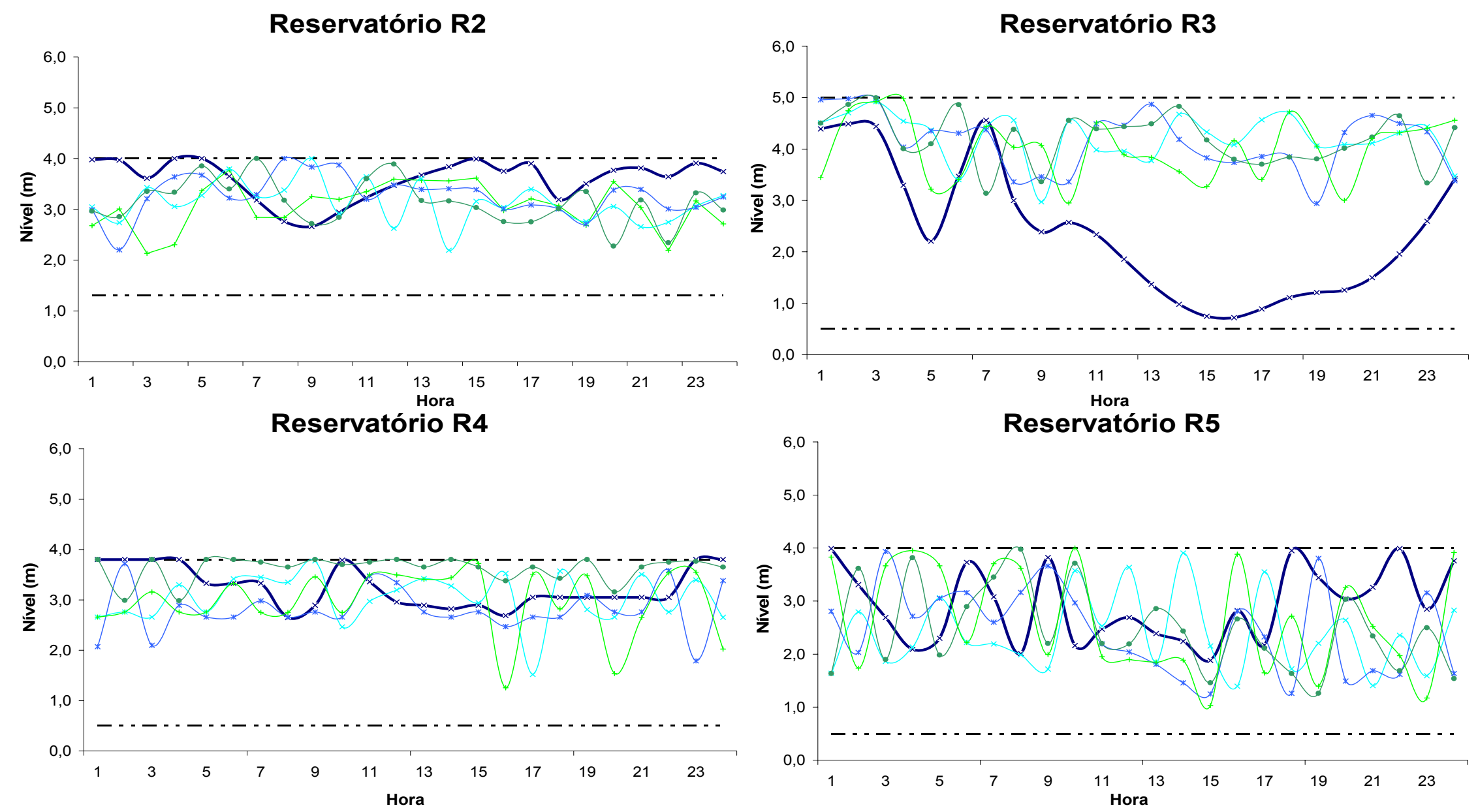

\begin{tabular}{|c|c|c|}
\hline $\begin{array}{l}- \text { - NA max } \\
-\times 8 / \mathrm{fev} \text { - Com Nível Meta } \\
-\quad 8 / \mathrm{fev} \text { - Sem Nível Meta }\end{array}$ & $\begin{array}{l}- \text { - NA min } \\
-6 / j u n-\text { Com Nível Meta }\end{array}$ & $\begin{array}{l}-x-\text { Níveis Meta Domingo } \\
-6 / \text { jun - Sem Nível Meta }\end{array}$ \\
\hline
\end{tabular}

Figura 5.32 - Níveis dos reservatórios - estratégias operacionais otimizadas domingos. 

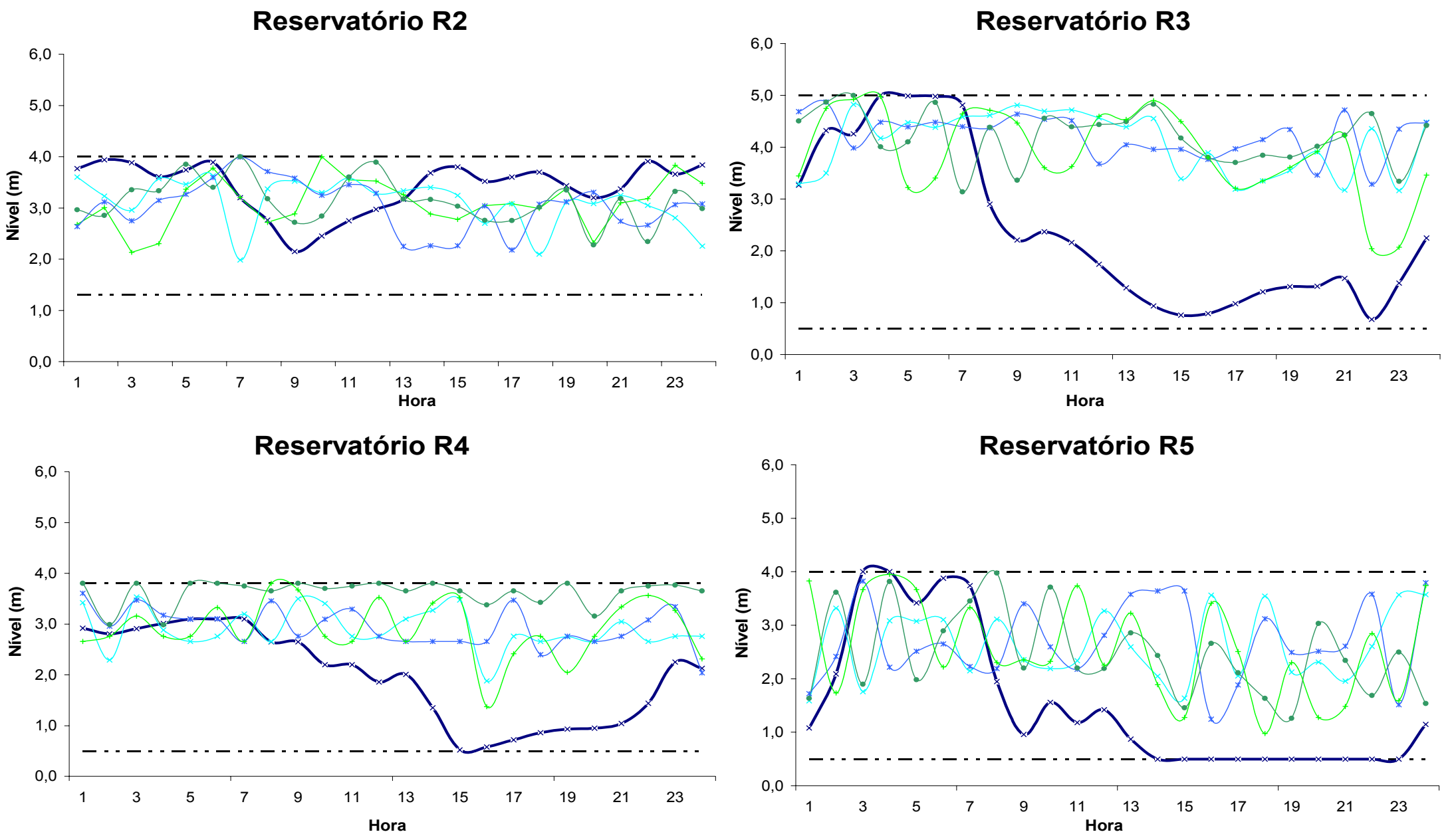

$$
\begin{array}{lll}
\text { NA max } & -- \text { NA min } & -\times- \text { Níveis Meta DIAS ÚTEIS } \\
\text { 9/fev - Com Nível Meta } & *-7 / \text { jun - Com Nível Meta } & \rightarrow-7 / \text { jun - Sem Nível Meta } \\
\text { 9/fev - Sem Nível Meta } & &
\end{array}
$$

Figura 5.33 - Níveis dos reservatórios - estratégias operacionais otimizadas segundas-feiras. 


\section{$\underline{\text { TEMPO COMPUTACIONAL }}$}

Na prática, para a otimização em Tempo Real tem-se apenas uma hora para receber as informações do sistema através do SCADA, realizar a previsão de demandas e a otimização e implementar a regra operacional gerada. Portanto, o tempo computacional gasto pelo modelo constitui um fator limitante à aplicação do modelo.

Os tempos computacionais demandados para realizar as 24 otimizações correspondentes ao período de um dia, para as diferentes alternativas aqui avaliadas, são apresentados na Figura 5.34.

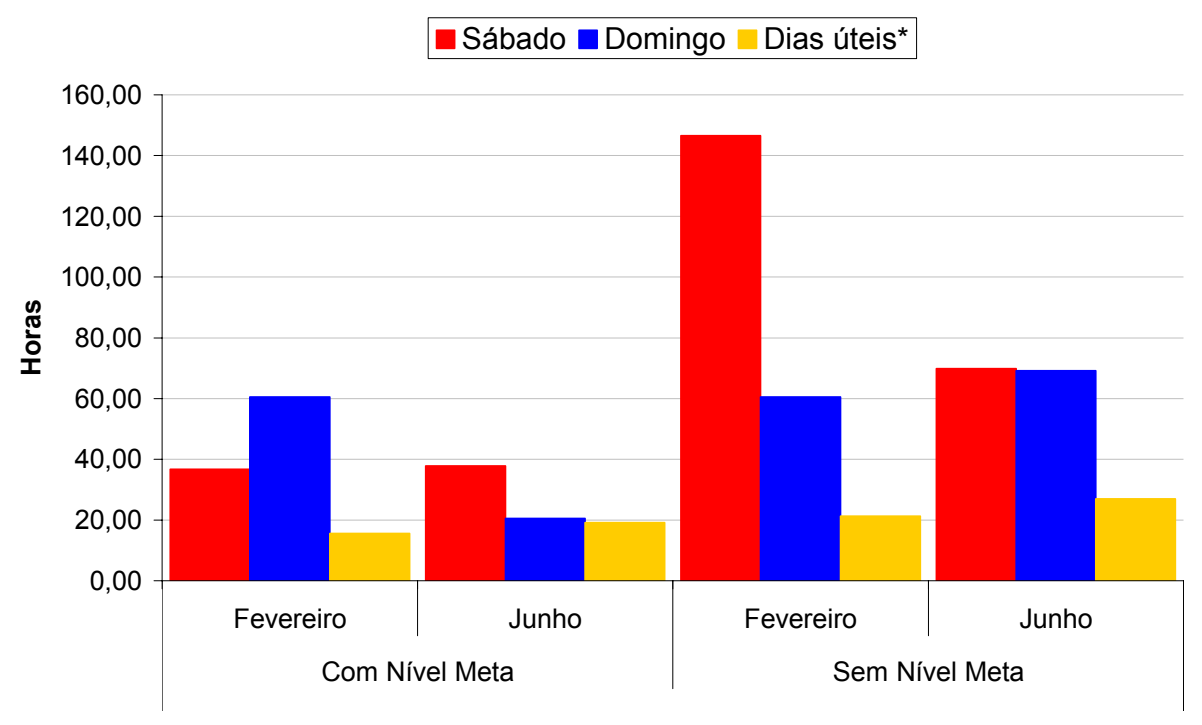

Figura 5.34 - Tempo computacional gasto com as otimizações em tempo real.

Teoricamente, para que o modelo realmente fosse implantado para a otimização em tempo real de um sistema de abastecimento de água, com freqüência de realização da otimização horária, o tempo computacional gasto para realizar as 24 otimizações deveria ser inferior a 24 horas. O que ocorreu apenas em 25\% dos ensaios de otimização realizados. 


\section{CUSTOS DE BOMBEAMENTO PARA CADA UMA DAS 24 OTIMIZAÇÕES REALIZADAS}

A otimização em tempo real nada mais é do que a realização de uma otimização, com período de 24 horas, em cada hora do dia. Para se ter a otimização em tempo real de um dia junta-se a primeira hora das 24 otimizações realizadas e as demais horas são descartadas.

A seguir, nas Figura 5.35 a Figura 5.37, são apresentados os custos de bombeamento para cada uma das 24 otimizações realizadas aos sábados, domingos e segunda-feira.

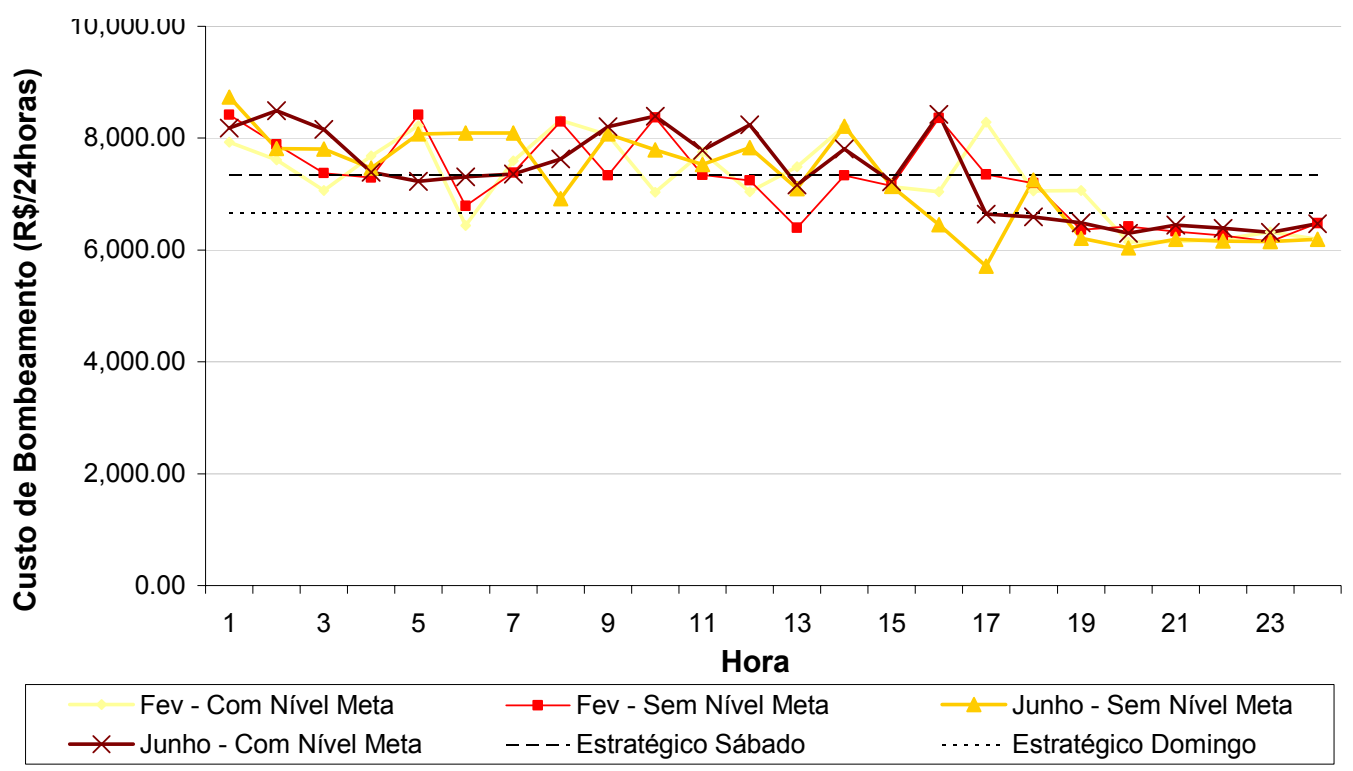

Figura 5.35 - Custo de bombeamento para as otimizações em tempo real dos sábados.

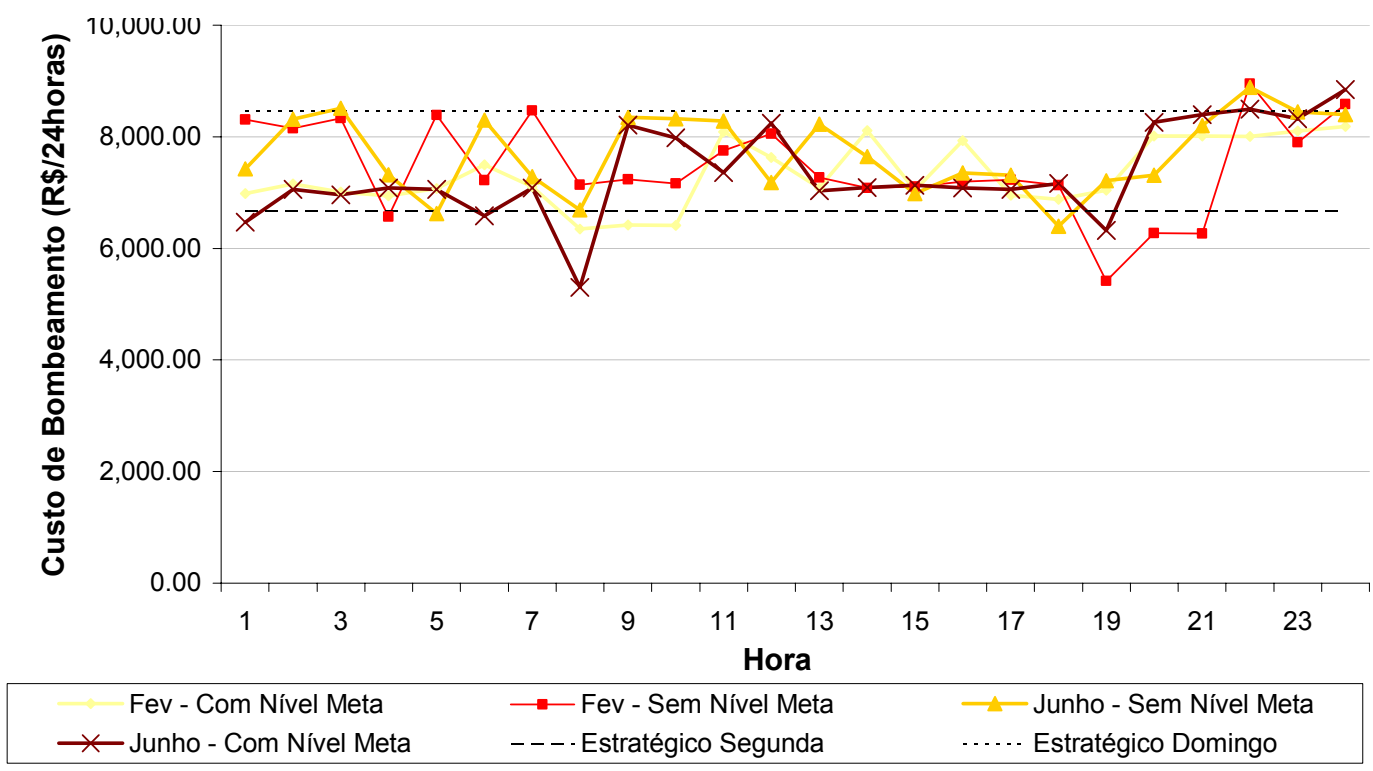

Figura 5.36 - Custo de bombeamento para as otimizações em tempo real dos domingos. 


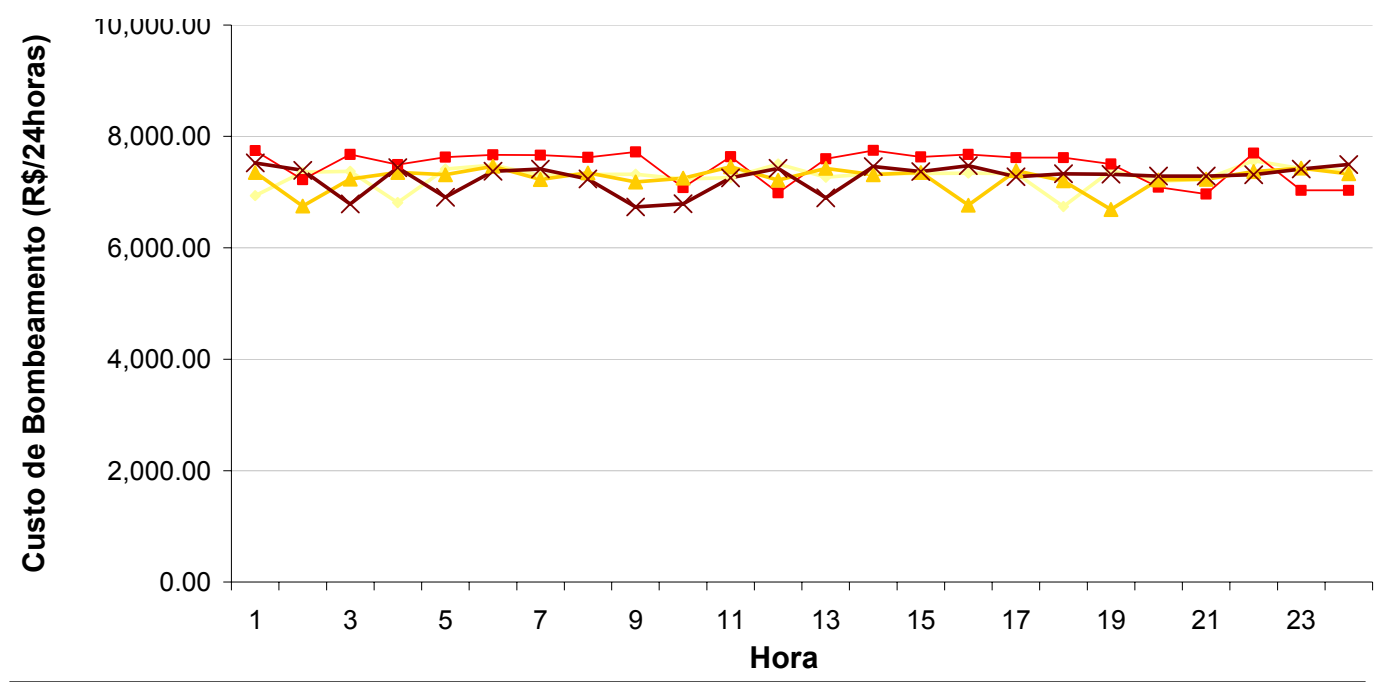

Fev - Com Nível Meta $\rightarrow-$ Fev - Sem Nível Meta $\rightarrow-$ Junho - Sem Nível Meta $\nleftarrow$ Junho - Com Nível Meta

Figura 5.37 - Custo de bombeamento para as otimizações em tempo real - Segunda-feira.

Um fator que chamou a atenção foi a redução dos custos de bombeamento ao longo das 24 horas no sábado e o aumento destes custos ao longo das 24 horas no domingo.

Isto ocorreu porque as demandas aos domingos são menores e, como a otimização foi feita para 24 horas à frente, nas últimas horas de sábado tem-se uma maior quantidade de horas otimizadas no domingo do que no próprio sábado. Na hora 22, por exemplo-se, otimizou-se das 22:00 hs de sábado às 22:00 hs de domingo, ou seja, quase todo o período otimizado corresponde ao domingo e consequentemente possui menores demandas.

Já as últimas 6 horas de otimização do domingo apresentaram maiores custos de bombeamento, pois englobam os horários de ponta da segunda-feira cuja tarifa é quase três vezes superior à do horário fora de ponta.

\subsubsection{Avaliação da Influência da Previsão no Resultado da Otimização}

Para avaliar a influência da qualidade da previsão de demandas nos resultados da otimização da operação em tempo real, realizou-se a otimização no período de três dias 
(sábado, domingo e segunda-feira) dos dois meses distintos: um no período de seca (de 05 de junho a 07 de junho) e outro no período chuvoso (de 07 a 09 de fevereiro) considerando também o histórico de demandas. Ou seja, foram realizadas as mesmas simulações apresentadas no item 5.7.1 só que com os dados reais de demanda e não a partir dos resultantes da previsão de demandas.

Antes de tratar da influência da previsão de demandas nos resultados da otimização avaliou-se a qualidade da previsão realizada.

\section{AVALIAÇÃO DAS DEMANDAS GERADAS PELO MÓDULO OTIMIZADOR}

Na Figura 5.38, a seguir, estão apresentadas as demandas previstas e reais para diferentes horas do dia 07 de Fevereiro. Cabe lembrar que para cada hora é realizada a previsão de demandas para as próximas 24 horas, por isso as curvas com 24 horas para cada hora representada.

Observa-se que existe uma diferença significativa entre as demandas previstas e reais.
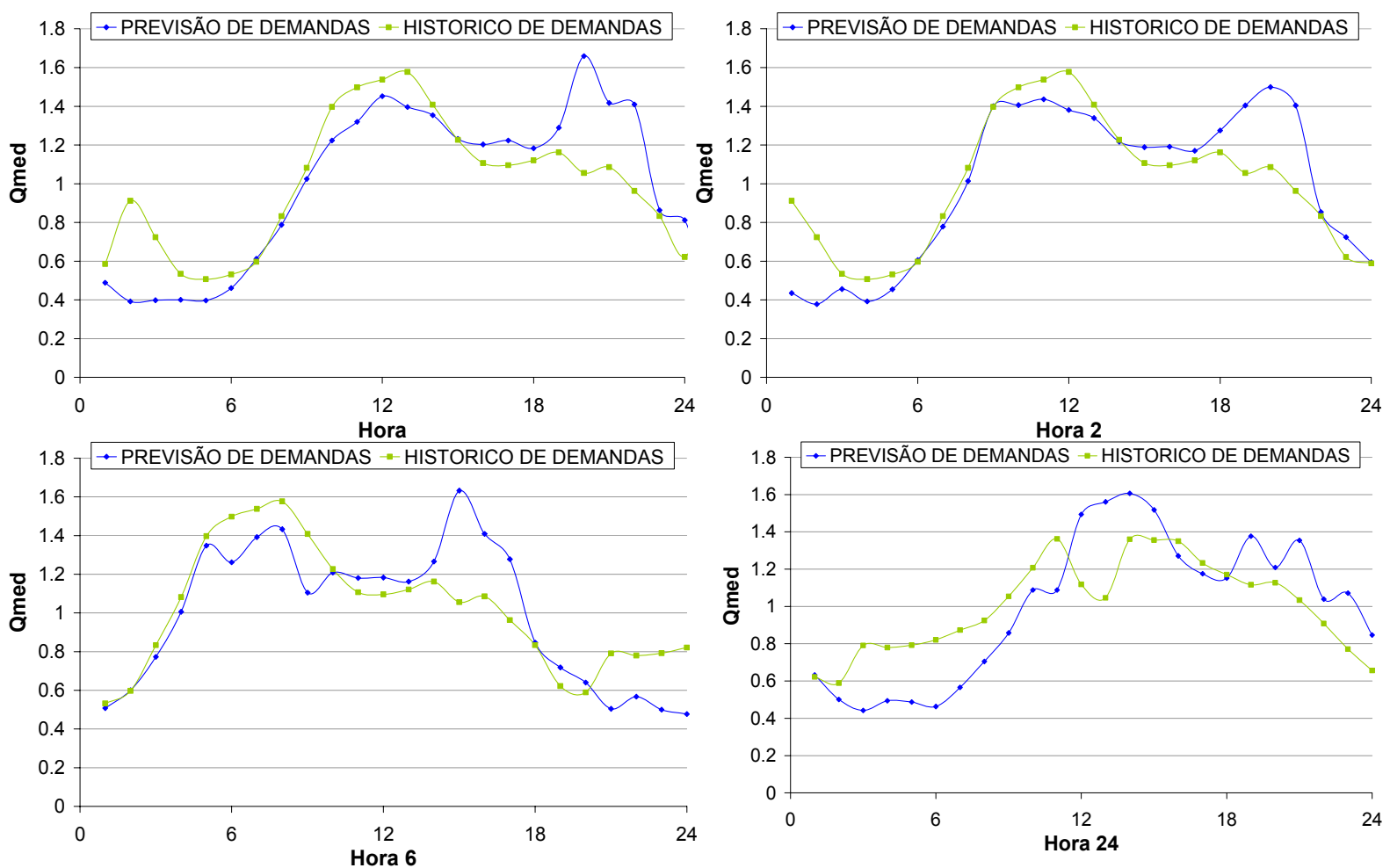

Figura 5.38 - Comparação das Demandas Reais Adimensionalizadas (Histórico) com as Demandas Previstas pelo módulo de Previsão de Demandas - Sábado (07/Fevereiro). 
Já na Figura 5.39 estão apresentadas as diferenças $\left(D_{\text {observada }}-D_{\text {prevista }}\right)$ entre as demandas observadas e previstas ao longo das primeiras 12 previsões horárias realizadas com horizonte de 24 horas (12 x 24), ilustrando claramente o desvio entre as respectivas demandas observadas e previstas. 


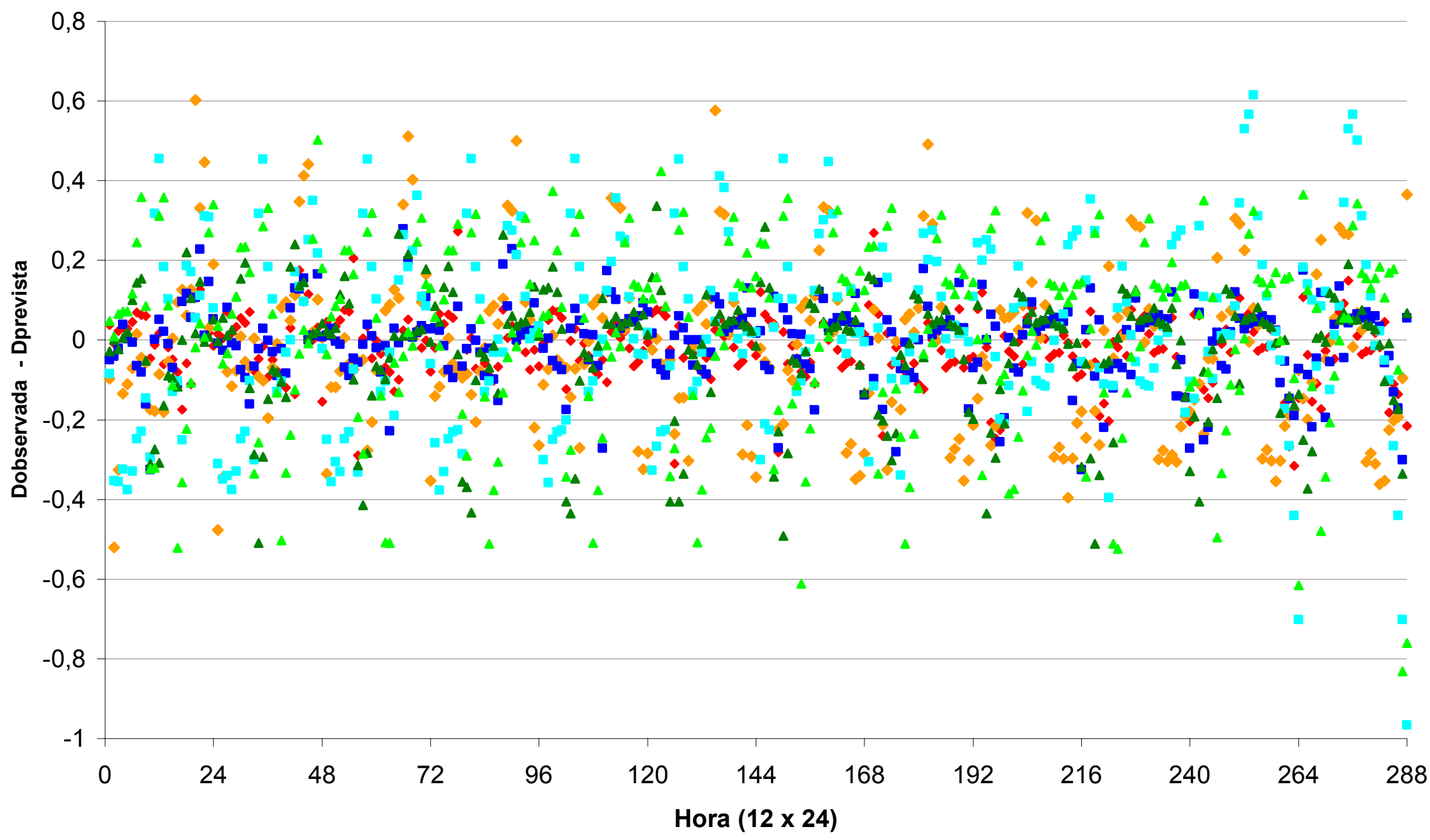

- sab 5/6/2004 sab 7/2/2004 - domingo 6/6/2004 - domingo 8/2/2004 ^ segunda 7/6/2004 ^ segunda 9/2/2004

Figura 5.39 - Diferença entre as Demandas Adimensionalizadas Observadas e Previstas. 


\section{CUSTO DE BOMBEAMENTO}

Os custos diários de bombeamento resultantes das otimizações em tempo real utilizando as demandas observadas e as demandas previstas estão sintetizados na Figura 5.40. Nota-se que as otimizações utilizando as demandas reais sempre geram menor custo com energia elétrica do que as utilizando as demandas previstas.

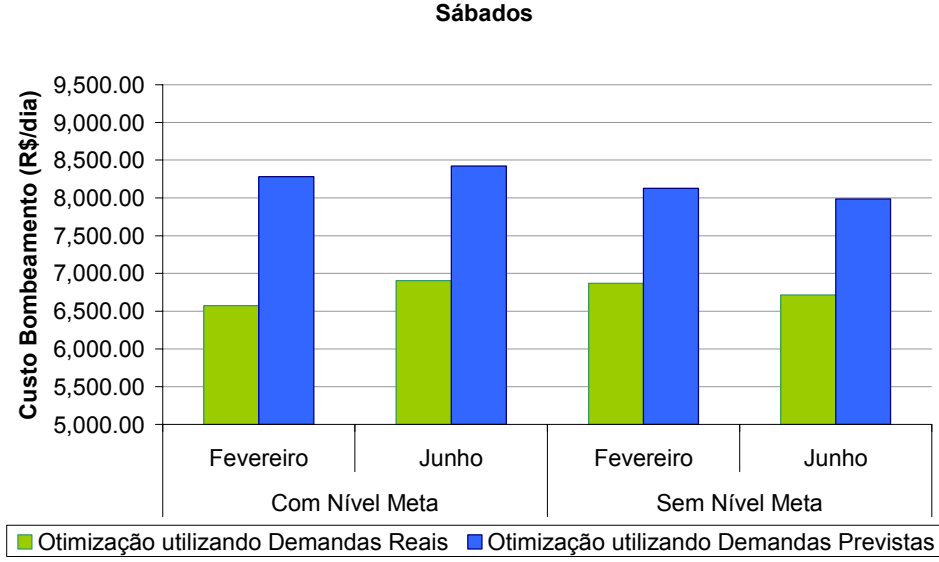

Domingos

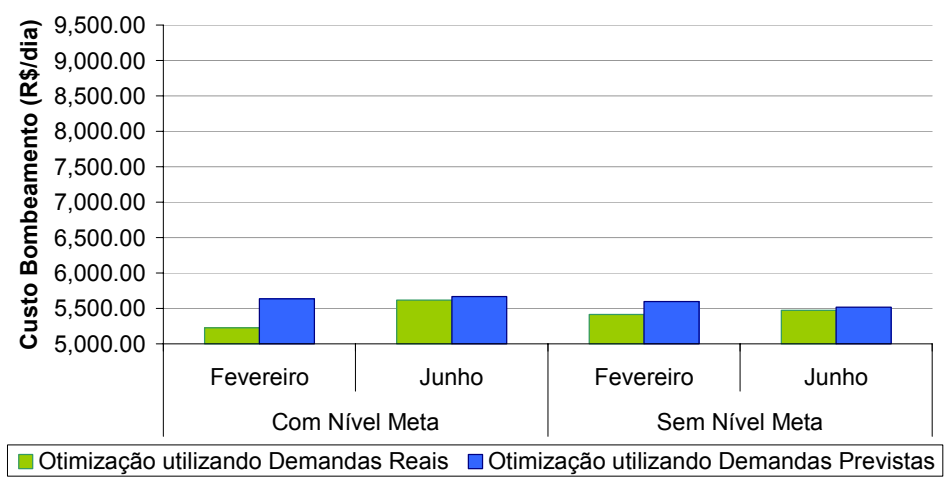

Segundas

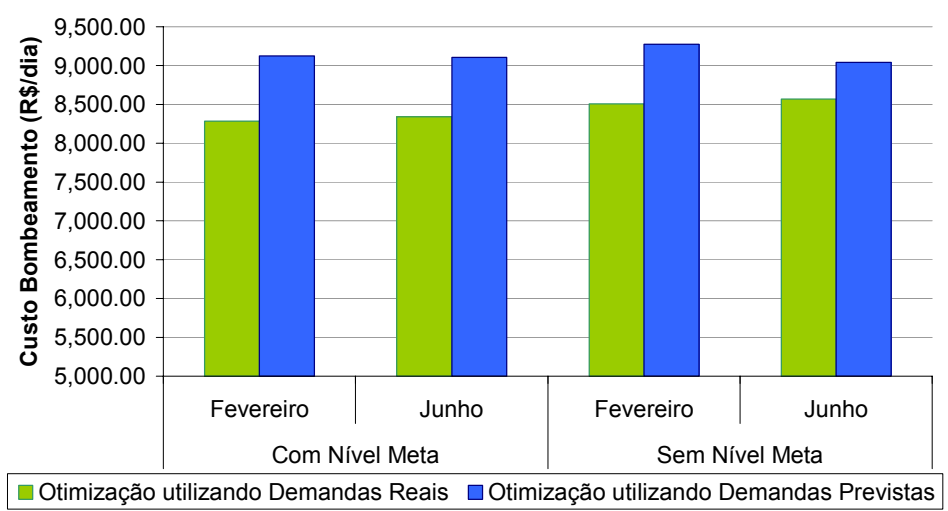

Figura 5.40 - Custos de Bombeamento otimizados utilizando demandas reais e previstas. 
Portanto, pode-se concluir que a qualidade dos dados gerados pelo módulo previsor de demandas influi diretamente nos resultados da otimização. No entanto, mesmo com grande diferença entre as demandas previstas e observadas, como foi o caso aqui estudado, a diferença entre os custos diários de bombeamento otimizados utilizando as demandas observadas e as demandas previstas é inferior a $5 \%$.

\section{ESQUEMAS OTIMIZADOS DE OPERAÇÃO DOS RESERVATÓRIOS}

Outro fato observado, e de fundamental importância, é que as grandes oscilações nos níveis dos reservatórios (Figuras 6.17, 6.18 e 6.19), resultantes da Otimização em Tempo Real utilizando as demandas previstas, são reduzidas quando da utilização do histórico de demandas, com exceção do R5 que ainda apresenta muita variação do nível d'água Figura 5.41 .

Ou seja, pode-se atribuir uma parcela desta grande oscilação dos níveis dos reservatórios ao erro da previsão de demandas e não somente ao processo de otimização em tempo real em si.

Lembrando que, apesar de buscar-se sempre o máximo aproveitamento de todo volume de reservação disponível, esta grande oscilação de níveis não é desejável operacionalmente. 

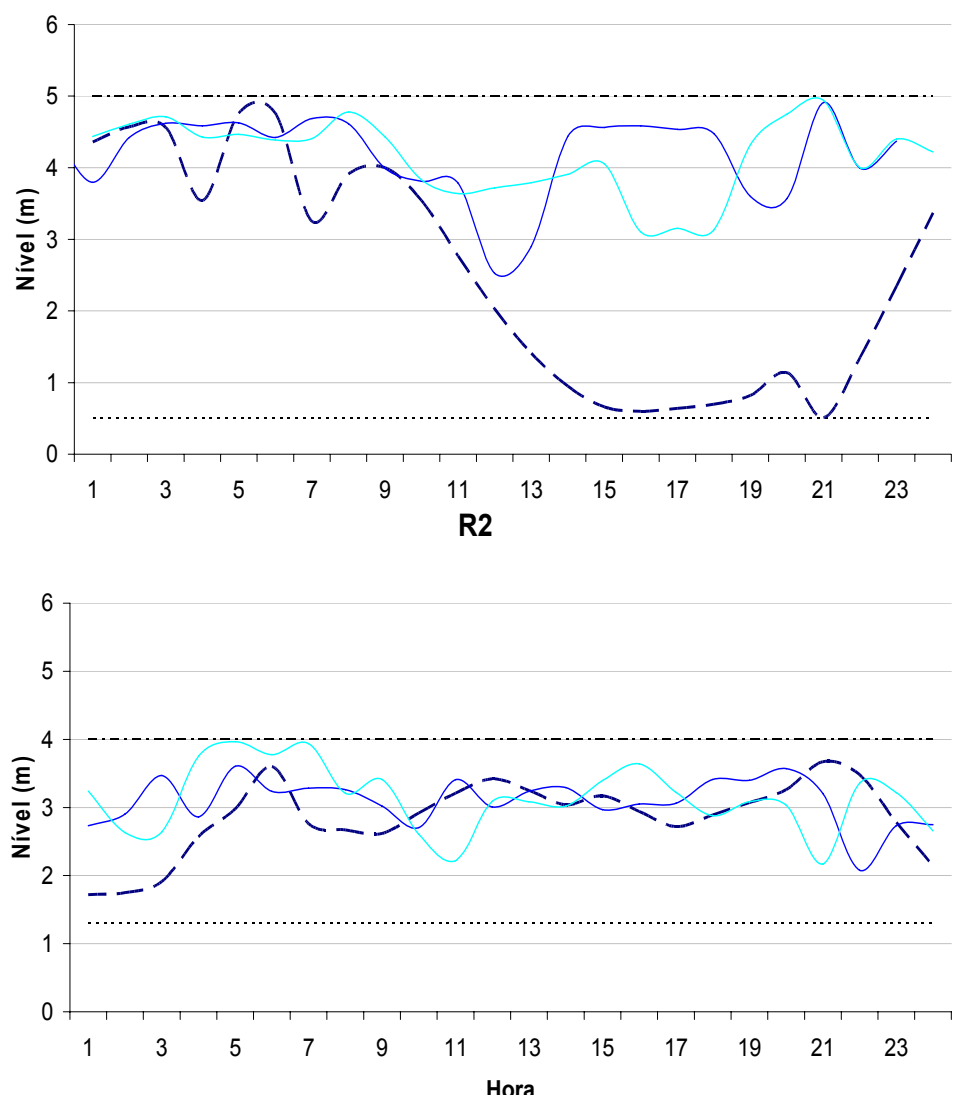

R4

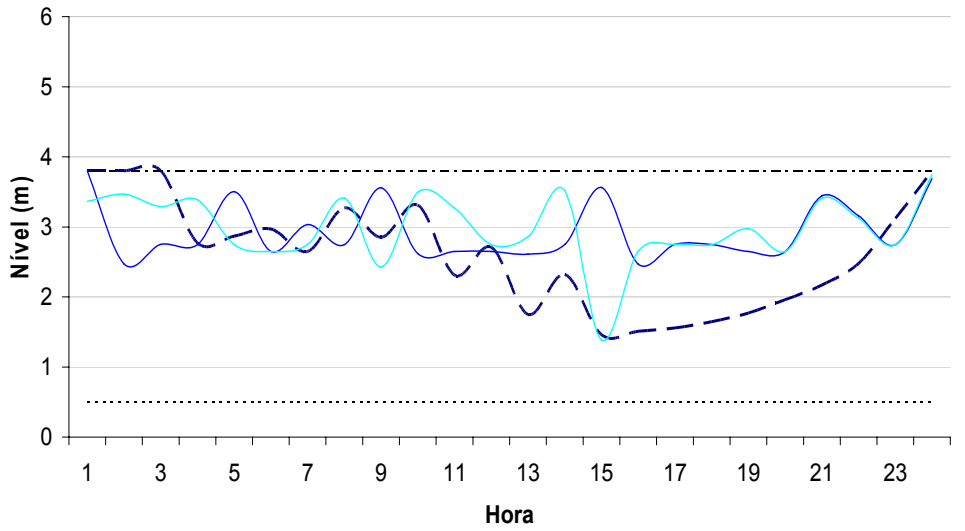

R5

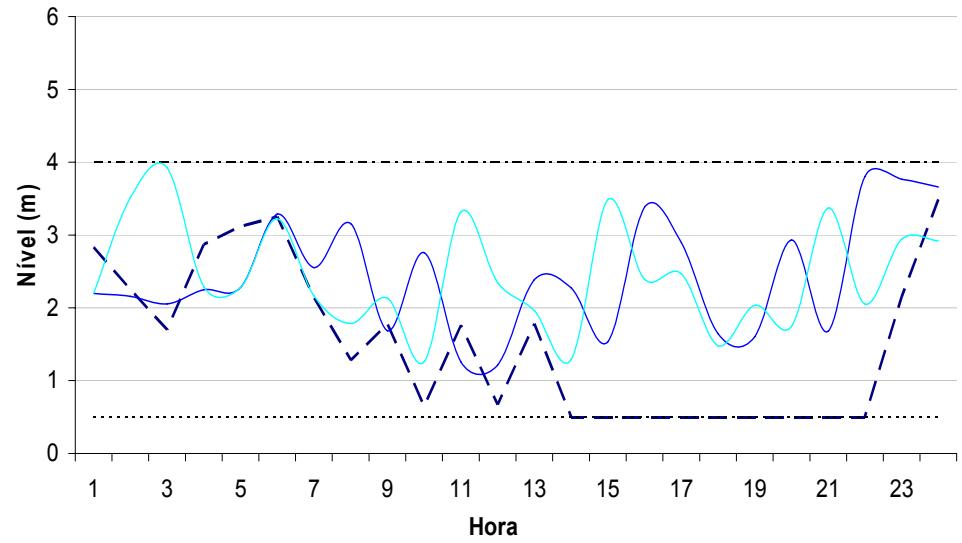

$$
\begin{array}{ll}
\text { - - Nível Meta R4 } & -\cdot-\text { NAmax } \\
\text { - Historico - Fevereiro } & \text { - Histórico - Junho }
\end{array}
$$$$
\text { … NAmin }
$$

Figura 5.41 - Níveis dos reservatórios - estratégias operacionais otimizadas em tempo real utilizando demandas observadas - Sábados. 


\section{$\underline{\text { TEMPO COMPUTACIONAL }}$}

Com relação aos tempos computacionais demandados para realizar as 24 otimizações, a otimização com as demandas reais apresenta tempo de processamento ligeiramente inferior à otimização utilizando as demandas previstas, conforme pode ser observado no gráfico da Figura 5.42.

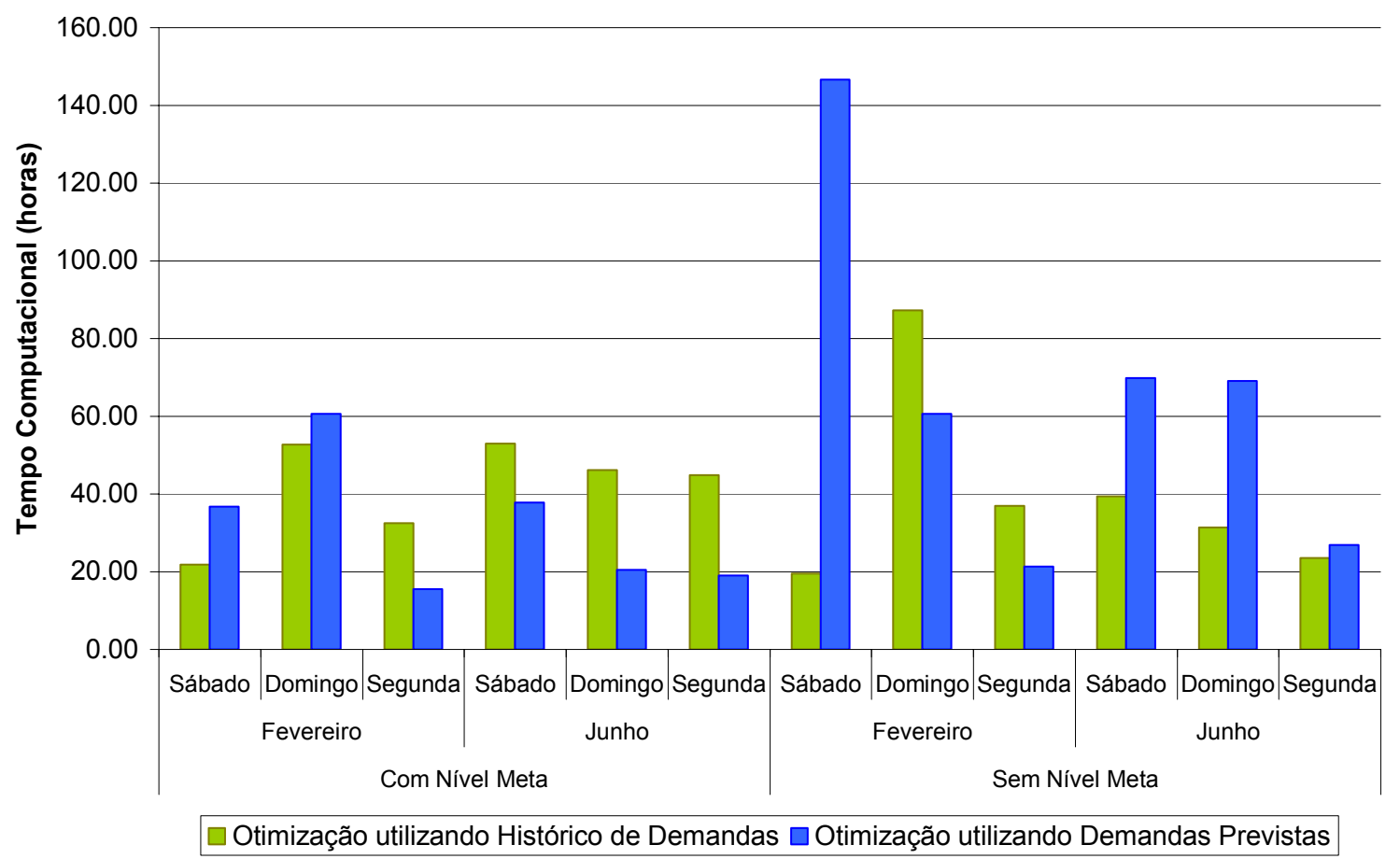

Figura 5.42 - Tempo Computacional das otimizações utilizando as demandas históricas e as demandas previstas.

\subsection{Aspectos Críticos}

Ao longo do desenvolvimento deste trabalho pode-se perceber que diversos fatores influenciaram os resultados obtidos. Alguns são intrínsecos à Otimização em Tempo Real, outros resultado da metodologia adotada e ainda do sistema objeto de estudo. A seguir realiza-se uma breve discussão sobre trais fatores. 


\section{$\underline{\text { ÁGUA E ENERGIA }}$}

Água e energia são intrinsecamente ligadas no contexto das companhias de saneamento. Essa ligação existe devido ao papel que a energia exerce no transporte de água para o consumidor final, assim como seu papel no tratamento de água e esgotos. Quando a água é desperdiçada num sistema, a energia é quase sempre dissipada.

Ao se otimizar energeticamente a operação de um sistema de abastecimento de água, provavelmente ocorrerá uma redução das pressões nesse sistema. Sabidamente perdas de água e pressão na rede são diretamente proporcionais. Portanto, a otimização energética poderá incorrer na redução das perdas do sistema e, consequentemente, em custos operacionais ainda menores, uma vez que, quanto menores forem as perdas, menor será o tempo de funcionamento dos conjuntos motobombas para atender aos usuários finais.

Os trabalhos existentes na literatura técnica sobre otimização da operação de sistemas de abastecimento não abordam tal consideração. As demandas não são separadas em consumo e perdas e os previsores de demanda não enfocam a redução das perdas (e das demandas) com a otimização.

A otimização em tempo real, com a previsão de demandas refeita a cada hora, pode atuar como meio de minimizar também a discrepância entre as demandas previstas e as demandas efetivas, uma vez que pode colaborar com a redução das perdas por vazamento.

\section{UTILIZAÇ̃̃o De SisTEMA HiPOTÉTICO}

O sistema aqui estudado, apesar de ser um sistema de abastecimento de água real (que abastece parte da cidade de João Pessoa, Paraíba), com os dados devidamente calibrados e modelados no EPANET, deve ser considerado um sistema hipotético uma vez que para Otimização foram adotadas demandas que não são próprias deste sistema. 
Portanto, apesar dos bons resultados obtidos com a aplicação do modelo desenvolvido, amplamente citados ao longo deste texto, sabe-se que a utilização de um sistema hipotético impede a avaliação mais profunda e implementação dos resultados obtidos. Observa-se que o modelo produz bons resultados em termos de redução dos custos com energia elétrica (representado pela função objetivo) mas não é possível uma avaliação completa das estratégias operacionais otimizadas do ponto de vista da operação.

Segundo Walski (2001), antes de se inicializar o desenvolvimento de um modelo de otimização, deve-se aprender sobre o projeto e funcionamento do sistema em estudo, para capturar a natureza multi-objetivo do problema.

Ou seja, além da função objetivo do modelo desenvolvido considerar apenas a minimização dos custos com energia elétrica (o que já indica que as soluções encontradas podem não ser tão boas do ponto de vista operacional e de confiabilidade do sistema, conforme detalhado no item 2.5 desta dissertação) não se dispõe do conhecimento sobre a operação do sistema necessário para avaliar as regras operacionais geradas. 
"Sessenta anos atrás eu sabia tudo, hoje sei que nada sei. A educação é o descobrimento progressivo da nossa ignorância.”

William James Durant

\section{Conclusões e Recomendações}

O modelo construído foi aplicado ao sistema estudado por Pedrosa (2006). O histórico de consumos horários de Moreira (2007), relativo ao sistema de abastecimento da cidade de São Carlos, SP, foi utilizado tal qual e para a realização de previsões de consumo, na alimentação do modelo. Assim, as estratégias operacionais produzidas não possuem referenciais para comparação pelo fato de, na verdade, estar-se trabalhando com um sistema hipotético.

Os resultados produzidos pelo modelo construído, que foi subdividido em modelos para a operação otimizada em nível estratégico e em tempo real, possibilitaram diversas conclusões, conforme se comenta a seguir.

Primeiramente, pode-se dizer que a qualidade dos resultados produzidos via AGs mostrou-se fortemente influenciada pelos valores dos coeficientes de penalidade e, principalmente, operadores e parâmetros genéticos usados no processo de otimização.

Acrescenta-se aqui o fato de que todos os ensaios de otimização realizados produziram estratégias operacionais factíveis de serem implementadas.

No que se refere ao teste comparativo efetuado, pode-se dizer que as estratégias operacionais produzidas pelo modelo para a operação otimizada em nível estratégico 
indicaram uma redução de custos da ordem de 8,5\% em relação aos custos diários de energia elétrica obtidos por Pedrosa (2006) para o mesmo sistema.

A utilização dos níveis meta na forma de restrição para produzir as soluções em tempo real não agilizaram o processo de otimização, como era esperado, e produziram soluções de maiores custos de bombeamento em relação àquelas obtidas sem considerar os níveis meta. A explicação para esse fato é a constatação de que as bombas precisavam ser acionadas para que os níveis dos reservatórios permanecessem superiores aos níveis meta.

A qualidade das previsões de consumo revelou ter influência direta sobre o resultado da otimização, de forma que os níveis dos reservatórios apresentaram maior oscilação ao longo das 24 horas do dia quando o modelo foi alimentado com dados de consumo previstos com base na série de Fourier que quando se empregou o suposto histórico de consumo.

Do ponto de vista computacional, o tempo de processamento, de 15 a 2.800 minutos gastos para a otimização de um ciclo diário completo (=24 x 24 horas), mostrou-se excessivamente longo para a aplicação do modelo em tempo real, sendo que o EPANET, usado como módulo auxiliar de simulação hidráulica de período estendido, constituiu o elemento crítico na velocidade do processo. Assim, apesar do sucesso da metodologia proposta em produzir soluções eficientes e robustas, deve-se pensar em utilizar modelos simplificados para a reprodução do comportamento do sistema, principalmente se ele apresentar maior grau de complexidade.

\subsection{Recomendações para Estudos Futuros}

Como trabalhos futuros utilizando nessa linha de pesquisa, recomenda-se realizar os seguintes estudos: 
- Investigar possibilidades de acelerar o processo de avaliação hidráulica do comportamento do sistema.

- Estudo mais detalhado dos operadores e parâmetros genéticos a utilizar, bem como dos coeficientes das penalidades, ou a utilização de métodos híbridos dos AGs.

- A determinação dos Níveis Metas através de otimização multi-objetivo. Como a otimização multi-objetivo é complexa demais para ser aplicada à otimização em tempo real, sugere-se a incorporação dos demais objetivos da operação do sistema (confiabilidade hidráulica, capacidade de reservação e outros) nos Níveis Metas. Assim, pressupõe-se que a otimização em tempo real, ao perseguir os níveis metas, estaria considerando de certa forma tais objetivos.

- A utilização do vetor solução da Otimização em Nível Estratégico como indivíduos das soluções iniciais da Otimização em Tempo Real. Este fato, apesar de poder levar à ocorrência de convergência prematura do algoritmo, pode acrescer agilidade na solução do problema, diminuindo a quantidade de gerações necessárias a otimização. 
“Quem conduz e arrasta o mundo não são as máquinas, mas as idéias.”

Victor Hugo

\section{Referências Bibliográficas}

Alvisi, S.; Franchini, M.; Marinelli, A. (2007). A Short-Term, Pattern-Based Water Demand-Forecasting Model. . Journal of Hydroinformatics, v. 09.1, p. 39-50.

Almeida, R.; Barbosa, P. S. F. (2002). Efeito da Reservação Inicial Sobre o Desempenho Operacional de Sistemas de Abastecimento de Água. In: SEMINÁRIO Planejamento, Projeto e Operação de Redes de Abastecimento de Água: O Estado da Arte e Questões Avançadas, João Pessoa-PB, Brasil. Anais do II SEREA, CD-ROM.

Carrijo, I.B. (2004). Extração de regras operacionais ótimas de sistemas de distribuição de água através de algoritmos genéticos multiobjetivo e aprendizado de máquina. São Carlos, SP. 217p. Tese (Doutorado) - Escola de Engenharia de São Carlos, Universidade de São Paulo.

Coulbeck, B.; Orr, C.H (1987). Optimal Control of Water Supply. IEE Colloquium on Control and Optimization Techniques for the Water Industry. May, p. $1-4$.

Coulbeck, B.; Orr, C.H.; Brdys, M. (1988). Real-time optimized control of water distribution systems. International Conference on Control. Abril, p. 634-640. 
De Montfort University (2002). FINESSE Technical Description and Capabilities. versão 4. Leicester - UK. http://www.eng.dmu.ac.uk/wssys/

Goldeberg, D. E. (1989). Genetic Algorithms in Search, Optimization and Machine Learning. Addison-Wesley, Reading, Mass.

Gomes, H. P. (2005). Eficiência hidráulica e energética em saneamento: análise econômica de projetos. Rio de Janeiro: ABES. p. 114.

Jamieson, D. G.; Shamir, U.; Martinez, F.; Franchini. M. (2007). Conceptual Design of a Generic, Real-Time, Near-Optimal Control System for WaterDistribution Networks. Journal of Hydroinformatics, v. 09.1, p. 3-14.

Lansey, K. E.; Awumah, K., (1994). Optimal Pump Operations Considering Pump Switches. Journal of Water Resources Planning and Management, Vol. 120, N01, p. 17-35.

Martínez, F.; Hernández, V.; Alonso, J. M.; Rao, Z.; Alvisi, S. (2007). Optimizing the Operation of the Valencia Water Distribution Network. Journal of Hydroinformatics, v. 09.1, p. 65-78.

Moraes, F.A. (2008). Calibração de modelo de decaimento de cloro aplicado a setor de rede de distribuição de água. São Carlos, SP. 211p. Dissertação (Mestrado) - Escola de Engenharia de São Carlos, Universidade de São Paulo.

Moreira, S. L. S. (2007). Otimização da Operação em Tempo Real Aplicado a Sistema de Distribuição da Água para Abastecimento. São Carlos, SP. 232p. Tese (Doutorado) - Escola de Engenharia de São Carlos, Universidade de São Paulo.

Nitivattananon, V.; Sadowski, E.C.; Quimpo, R.G. (1996). Optimization of Water Supply System Operation. Journal of Water Resources Planning and Management, v.122, n.5, September/October, p. 374-384. 
Pedrosa, L. A. F. (2006). Um Modelo de Operação de Sistemas Adutores de Abastecimento de Água com vistas a Minimização dos Custos Energéticos. Campina Grande, PB. 174 p. Tese (Doutorado) - Universidade Federal de Campina Grande.

Odan, F.K. (2008). Dissertação a ser apresentada à Escola de Engenharia de São Carlos.

Orr, C.; Boulos, P.F.; Stern, C.T.; Liu P.E.P. (1999). Developing Real-Time Models of Water Distribution Systems. In Water Industry Systems: Modelling and Optimisation Applications. (ed. D.A. Savic \& G.A. Walters), Research Studies Press Ltd., Baldock, UK, 175-186.

PROCEL SANEAR Programa Nacional de Conservação de Energia Elétrica no Setor de Saneamento. Disponível em: $<\mathrm{http}: / / \mathrm{www}$.eletrobras.com/procel $>$. Acesso em 08 de abril de 2008.

Rao, Z.; Alvarruiz, F. (2007). Use of an Artificial Neural Network to Capture the Domain Knowledge of a Conventional Hydraulic Simulation Model. Journal of Hydroinformatics, v. 09.1, p.15-24.

Rao, Z.; Salomons, E. (2007). Development of a Real-Time, Near Optimal Control Process for Water-Distribution Networks. Journal of Hydroinformatics, v. 09.1, p.25-38.

Rao, Z.; Wicks, J.; West, S. (2007). Optimising water supply and distribution operations. Water Management, v. 160 WM2, p. 95-101.

Ribeiro, G.P. (2005). Operação Otimizada do Sistema Adutor Metropolitano Utilizando Algoritmos Genéticos. Estudo de caso: SAM Leste da Região Metropolitana de São Paulo. São Paulo-SP. 239p. Tese (Doutorado) - Escola Politécnica, Universidade de São Paulo.

Rossman, L.A., (2000). EPANET2 - Users Manual, U.S. Environmental Protection Agency, Cincinnati, Ohio. 
Salomons, E.; Goryashko, A.; Shamir, U.; Rao, Z.; Alvisi, S. (2007). Optimizing the Operation of the Haifa-A Water-Distribution Network. Journal of Hydroinformatics, v. 09.1, p.51-64.

Schoenauer, M.; Mirchalewicz, Z. (1996). Evolutionary Computation at the Edge of Feasibility. InW. Ebeling \& H.-M. Voigt (Eds.), Proceeding of the Fourth Conference on Parallel Problem Solving from Nature, Berlin: Springer- Verlag.

Soares, A.K. (2003). Calibração de Modelos de Redes de Distribuição de Água para Abastecimento Considerando Vazamentos e Demandas Dirigidas pela Pressão. São Carlos-S.P. 153p. Dissertação (Mestrado) - Escola de Engenharia de São Carlos da Universidade de São Paulo.

Sousa C. A. M. (2007). Otimização Multicritério da Operação de Sistemas de Abastecimento de Água Utilizando Algoritmos Genéticos. Lisboa - Portugal. 207 p. Dissertação (Mestrado) - Instituto Superior Técnico, Universidade Técnica de Lisboa.

SNIS - Sistema Nacional de Informação em Saneamento. Programa de Modernização do Setor de Saneamento. Disponível em: <http://www.snis.gov.br $>$. Acesso em 08 de abril de 2008.

Tsutiya, M. T. (2004). Abastecimento de Água. São Paulo - SP. Departamento de Engenharia Hidráulica e Sanitária. 643 p.

Vicente R. V. (2005). Modelo de Operação para Centros de Controle de Sistemas de Abastecimento de Água - Estudo de Caso: Sistema Adutor Metropolitano de São Paulo. São Paulo-SP. 140 p. Dissertação (Mestrado) - Escola Politécnica da Universidade de São Paulo.

Walski, T.M. (2001). The Wrong Paradigm-Why Water Distribution Optimization Doesn't Work. Journal of Water Resources Planning and Management, v.122, n.4, July, p. 203-205. 
Wu, Y. Z.; Simpson, A. R. (2002). A Self-Adaptive Boundary Search Genetic Algorithm and Its Application to Water Distribution Systems. Journal of Hydraulic Research, Vol. 40, No 2, p.191-203.

Zahed Filho, K. (1990). Previsão de Demanda de Consumo em Tempo Real no Desenvolvimento Operacional de Sistemas de Distribuição de Água. São Paulo. 135p. Tese (Doutorado). Escola Politécnica da Universidade de São Paulo.

Zeferino, A. J., Antunes, A.P., Cunha, M.C. (2007). An Efficient Simulated Annealing Algorithm for Regional Wastewater Systems Planning. Joint International Conference on Computing and Decision Making in Civil and Building Engineering. June 14-16, 2006 - Montréal, Canada. 
Apêndice A - Rotinas do Otimizador em Tempo Real 


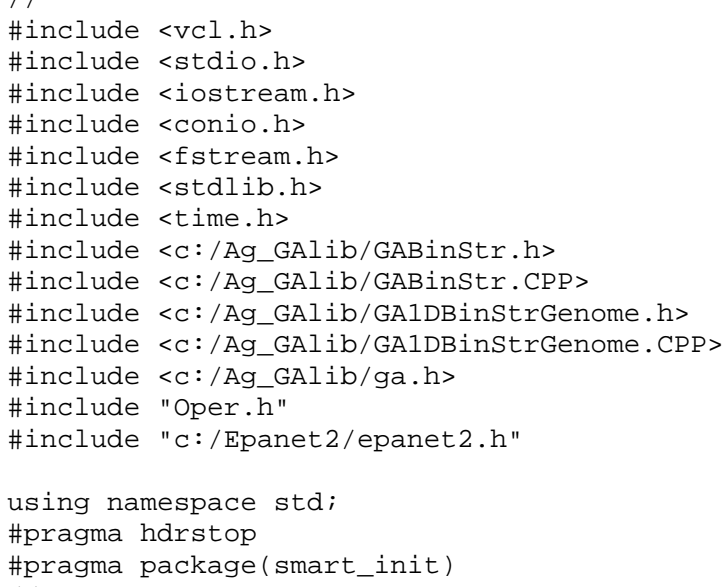


gaif.ignore(max,' \n'); //Tipo de recombinação - taxa de recombinação gaif $>$ crossover $\gg$ crossoverRate;

gaif.ignore (max, '\n');

gaif.ignore(max, '\n'); //Tipo de mutação - taxa de mutação

gaif > mutation > mutationRate:

gaif.ignore $\left(\max , ' \backslash \mathrm{n}^{\prime}\right)$;

gaif.ignore(max, '\n');//tamanho da população

gaif >> popsize;

gaif.ignore (max, '\n');

gaif.ignore(max, '\n');//numero de gerações

gaif >> ngen;

gaif.ignore(max, '\n');

gaif.ignore(max, '\n');//semente aleatória

gaif $>$ randomseed;

gaif.ignore( $\left.\max ,{ }^{\prime} \backslash \mathrm{n}^{\prime}\right)$;

gaif.ignore $(\max , ' \backslash n ')$;//maxima variancia de fitness

gaif > maxFitnessvariance;

gaif.ignore (max, '\n');

gaif $\gg$ Variaveis; //numero de controles

gaif.ignore( $\max , ' \backslash n ')$;

if (Variaveis $!=0$ )

\{

VariavelID1 = new int [Variaveis];

VariavelID2 = new int [Variaveis];

for $(i=0 ; i<$ Variaveis; $i++)$

gaif >> ID1 >> ID2;

gaif.ignore ( $\left.\max ,{ }^{\prime} \backslash \mathrm{n} '\right)$

VariavelID1[i] = ID1;

VariavelID2[i] = ID2;

gaif.ignore (max, ' $\backslash n$ ')

gaif > Horas; //numero de horas do horizonte de planejamento gaif.ignore (max, '\n');

length = Variaveis*Horas;

gaif.ignore(max, '\n');

gaif > Pmin; //pressão minima visada para a rede

gaif.ignore (max, ' \n'):

//Leitura dos arquivos de entrada com os dados para setar no EPANET

gaif.ignore(max, '\n'); // Número de nós com demanda

gaif $>N D$;

gaif.ignore( $\left.\max ,{ }^{\prime} \backslash \mathrm{n}^{\prime}\right)$;

gaif.ignore(max, '\n'); //ID dos nós com demanda

IDnodemanda $=$ new int $[\mathrm{ND}]$

for $(e=0 ; e<N D ; e++)$

\{

gaif >> NO;

gaif.ignore (max, ' $\backslash n$ ');

IDnodemanda $[\mathrm{e}]=\mathrm{NO}$

\}

gaif $\gg \mathrm{R}$; //Número de RNV

gaif.ignore (max, '\n');

Nivel = new float [R]; //Nível Atual dos Reservatórios

for $(\mathrm{e}=0 ; \mathrm{e}<\mathrm{R} ; \mathrm{e}++)$

gaif > nivelinicial;

gaif.ignore (max, '\n');

Nivel[e] = nivelinicial \}

gaif.ignore(max,' $\backslash n ')$; //Níveis Meta dos Reservatórios NivelMeta $=$ new float ${ }^{*}[$ Horas $]$ 
NivelMeta $[\odot]=$ new float $\left[\right.$ Horas $\left.^{*} \mathrm{R}\right] ;$

for $(\mathrm{k}=0 ; \mathrm{k}<$ Horas $; \mathrm{k}++)$

NivelMeta $[k]=\operatorname{NivelMeta}[0]+k{ }^{*}$;

for $(e=0 ; \quad e<R ; e++)$

for $(\mathrm{n}=0 ; \mathrm{n}<$ Horas; $\mathrm{n}++)$

\{

gaif $>$ meta;

gaif.ignore(max, '\n');

NivelMeta $[\mathrm{e}][\mathrm{n}]=$ meta;

\}

gaif.ignore(max, '\n'); // Demandas reais nós 22 e 34

DemandaReal $=$ new float* $[$ Horas $] ;$

DemandaReal $[0]=$ new float $\left[\right.$ Horas $\left.{ }^{*} \mathrm{ND}\right]$;

for $(k=0 ; k<$ Horas; $k++)$

DemandaReal $[k]=$ DemandaReal $[\Theta]+k^{*} N D$;

for $(\mathrm{e}=0 ; \mathrm{e}<\mathrm{ND} ; \mathrm{e}++)$

for $(\mathrm{n}=0 ; \mathrm{n}<$ Horas; $\mathrm{n++})$

\{

gaif > DR;

gaif.ignore (max, '\n'):

DemandaReal $[\mathrm{e}][\mathrm{n}]=\mathrm{DR}$;

//fout $<<" \backslash \mathrm{n} "<<$ DemandaReal $[\mathrm{e}][\mathrm{n}]$;

\}

gaif.ignore(max,' \n'); // Previsão de Demandas nós 22 e 34

Previsao $=$ new float $\left[\right.$ Horas ${ }^{*}$ Horas];

for $\left(\mathrm{e}=0 ; \mathrm{e}<\right.$ Horas; $\left.\mathrm{e}^{++}\right)$

for $(\mathrm{n}=0 ; \mathrm{n}<$ Horas; $\mathrm{n++})$

\{

gaif > PD;

gaif.ignore (max, '\n');

Previsao $\left[e^{*}\right.$ Horas $\left.+n\right]=P D$;

\}

gaif.close( );

demandTemp ( );

aloca ( );

GAParameterList params

GASimpleGA: : registerDefaultParameters (params);

GASteadyStateGA: : registerDefaultParameters (params);

params.set (ganpopulationsize, popsize);

params.set (ganpcrossover, crossoverRate)

params.set(gaNpMutation, mutationRate);

params.set(gaNnGenerations, ngen);

params.set (gaNnReplacement, nReplacement);

params.set(gaNpConvergence, maxFitnessvariance);

GARandomSeed (randomSeed);

GA1DBinaryStringGenome genome (length, objetivo);//Tipo de genoma a ser utilizado genome.initializer(:: Initializer);//Inicialização do genoma

GAStatistics stats;

GASimpleGA ga(genome);

ga.parameters (params);

ga.scoreFilename("FOGer.txt");

ga.scorefrequency (1);

ga.flushFrequency (1);

ga. selectScores(GAStatistics: : Allscores) ;

GALinearscaling lin;

ga.scaling(lin);

ga.minimize ( );

switch(Selector)

\{

case 0 :

\{

GARankSelector selector; 


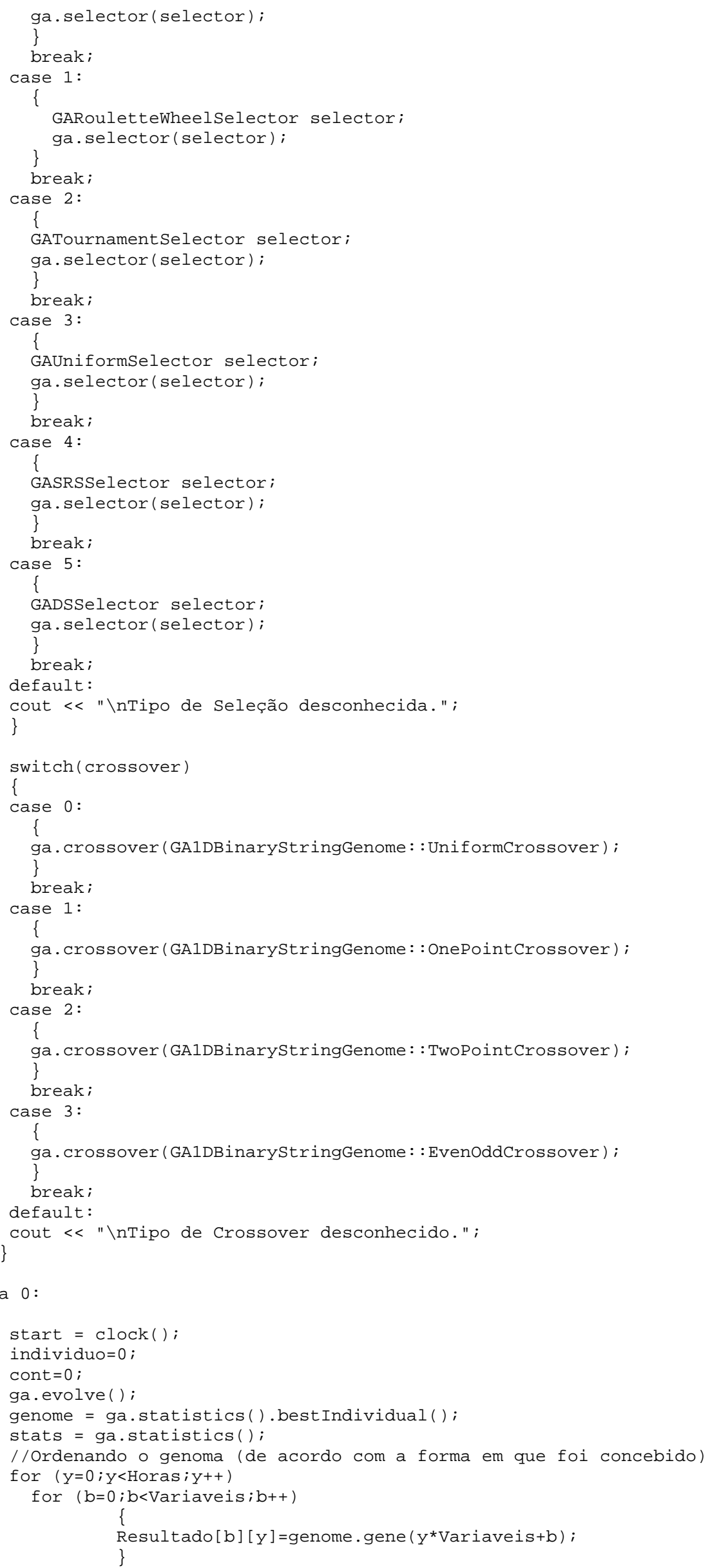




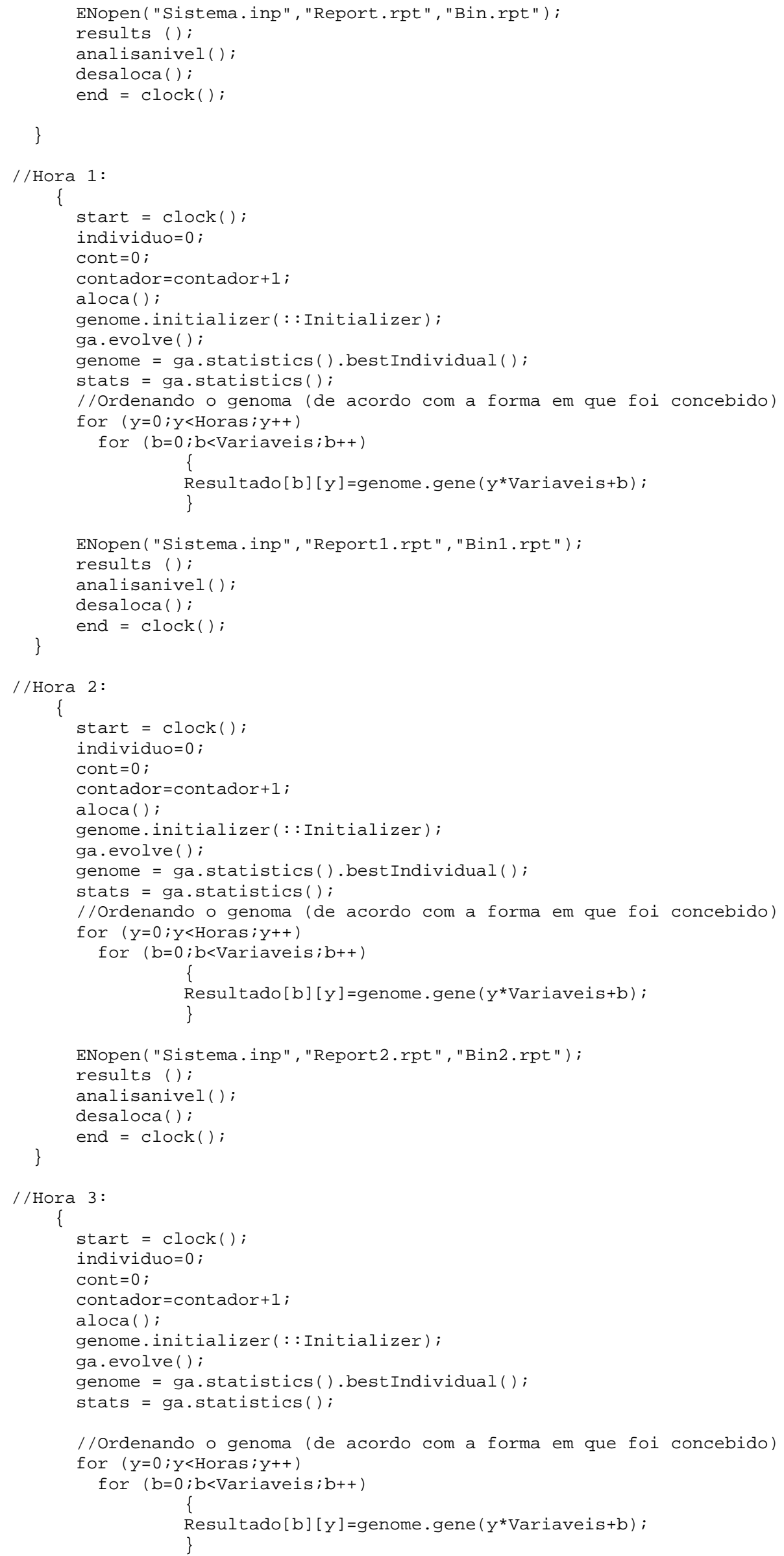




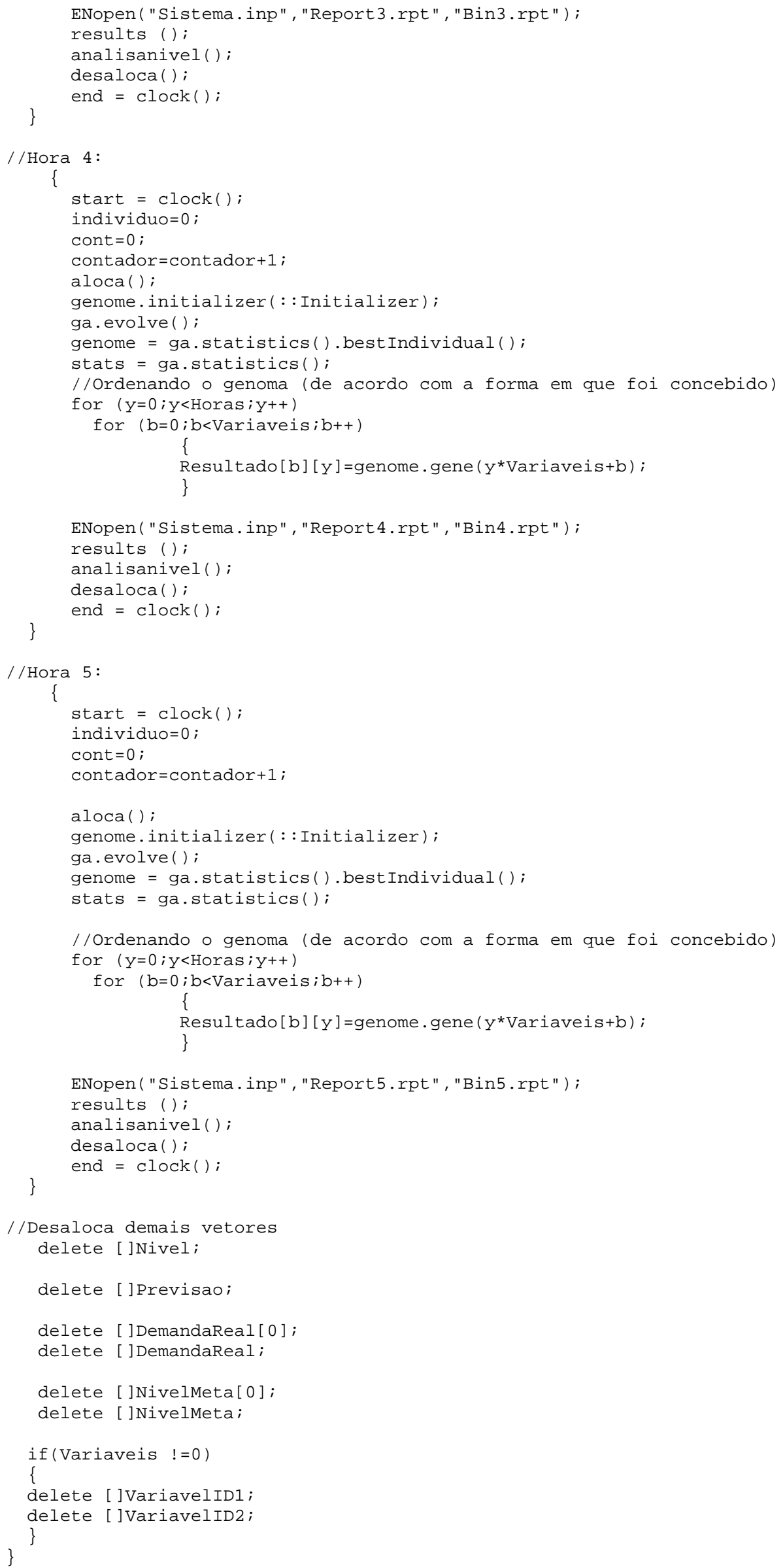


//

//Pega os dados necessários no EPANET e armazena nas respectivas variáveis void operation : : demandTemp()

\{

ENopen("Sistema.inp", "Report.rpt", " ");

ENgetcount (EN_NODECOUNT, \&NumNodes

ENgetcount (EN_TANKCOUNT, \&NumTanks

ENgetcount (EN_LINKCOUNT, \&NumLinks

NumJunctions $=$ NumNodes - NumTanks

ENclose( ) ;

\}

//Alocaça de espaça para os vetores

void operation : : aloca()

\{

int $i, j, k$;

Genoma $=$ new float $[$ length $]$

Resultado $=$ new float* $[$ Horas $] ;$

Resultado[○] = new float[Horas * NumJunctions];

for $(\mathrm{k}=1 ; \mathrm{k}<=$ Horas; $\mathrm{k}++)$

Resultado $[\mathrm{k}]=$ Resultado $[\Theta]+\mathrm{k}^{*}$ NumJunctions;

Level $=$ new float ${ }^{*}$ [NumJunctions $]$;

Level $[\Theta]=$ new float $[$ NumJunctions*Horas $] ;$

for $(\mathrm{k}=1 ; \mathrm{k}<=$ NumJunctions; $\mathrm{k}++)$

Level $[\mathrm{k}]=\operatorname{Level}[0]+\mathrm{k}^{*}$ Horas;

Estado $=$ new float $*$ NumLinks $]$

Estado $[0]=$ new float $[$ NumLinks*Horas $] ;$

for $(\mathrm{k}=1 ; \mathrm{k}<=$ NumLinks; $\mathrm{k}++)$

Estado $[\mathrm{k}]=$ Estado $[\Theta]+\mathrm{k}^{*}$ Horas

Energia $=$ new float $*$ [NumLinks $]$

Energia $[\odot]=$ new float $[$ NumLinks*Horas $] ;$

for $(\mathrm{k}=1 ; \mathrm{k}<=$ NumLinks; $\mathrm{k}++)$

Energia $[\mathrm{k}]=$ Energia $[0]+\mathrm{k}^{*}$ Horas;

\}

Initiallevel = new float[NumJunctions];

//Desalocação do espaço dos vetores

void operation : : desaloca()

\{

delete []Resultado[0];

delete []Resultado

delete []Level[0];

delete [] Level;

delete []InitialLevel;

delete []Genoma;

delete []Estado[0]:

delete []Estado;

delete []Energia[0];

delete []Energia; 
//Simulação Hidraúlica da solução gerada pelo AG

float operation : : run_epanet()

\{

int NumLinks, NumJunctions:

int $h, i, j, k, n, m, x, z, y, N A, E$, errcode, Df, Dp, D:

long $t$, tstep, t $t, z z$;

float pressure,Gv,Gb, RefDem, energy, status, initiallevel;

int $\mathrm{f}=0$;

int $\mathrm{a}=\odot$;

$\mathrm{Df}=\odot$;

$\mathrm{DP}=\mathrm{O}$;

$\mathrm{D}=0_{\text {; }}$

objF $=0$

$\mathrm{Cc}=\mathrm{O}$;

$\mathrm{Cd}=0$;

$\mathrm{Cb}=0$;

$\mathrm{P} 1=0 ;$

$\mathrm{P} 2=0 ;$

$\mathrm{P} 3=0 ;$

$\mathrm{P} 4=0$;

$\mathrm{P} 5=0 ;$

$\mathrm{tt}=0$;

$z z=0$;

ENopen("Sistema.inp", "LixoAG.rpt", " ");

ENopenH ( ) ;

ENinith $(00)$;

ENgetcount (EN_NODECOUNT, \&NumNodes);

ENgetcount (EN_LINKCOUNT, \&NumLinks);

for $(i=1 ; i<=$ NumNodes $; i++)$

\{

ENgetnodetype $(i, \& z)$;

if $(z==2) / /$ Typecode 2 para Tank

\{

ENsetnodevalue (i, EN_TANKLEVEL, Nivel[f]); $f=f+1$;

\}

\}

//Roda o EPANET, setando o genoma e obtendo os dados necessários

do

\{

ENgetcount(EN_NODECOUNT, \&NumNodes);

ENgetcount(EN_LINKCOUNT, \&NumLinks);

ENrunH(\&t); //Roda um único período de análise hidráulica

if $(\mathrm{t}==\mathrm{zz}))$

\{

//Armazena os valores do cromossomo corrente nas respectivas bombas e válvulas for $(\mathrm{n}=(\mathrm{tt} / 3600) ; \mathrm{n}<$ Horas $; \mathrm{n}++)$

\{

out $<<" \backslash n$ Hora $"<<$;

for $(i=1 ; i<=$ NumLinks; $i++)$

ENgetlinknodes ( $i, \& x, \& k)$

ENgetlinktype $(i, \& z)$;

for $(\mathrm{m}=0 ; \mathrm{m}<=$ Variaveis; $\mathrm{m++})$

if $(\mathrm{x}==$ VariavelID1[m] \&\& $\mathrm{k}==\operatorname{VariavelID2}[\mathrm{m}])$

ENsetlinkvalue(i,EN_STATUS, Genoma [n*Variaveis+m]) ;

\}

\}

\}

for $(i=1 ; i<=$ NumNodes $; i++)$

\{

ENgetnodetype $(i, \& z)$

if $(z==0) / /$ Typecode $\odot$ para node

if $(i==$ IDnodemanda $[\odot])$

previsaodemanda $=75^{*}$ Previsao $\left[\right.$ contador ${ }^{*}$ Horas $\left.+n\right]$; 


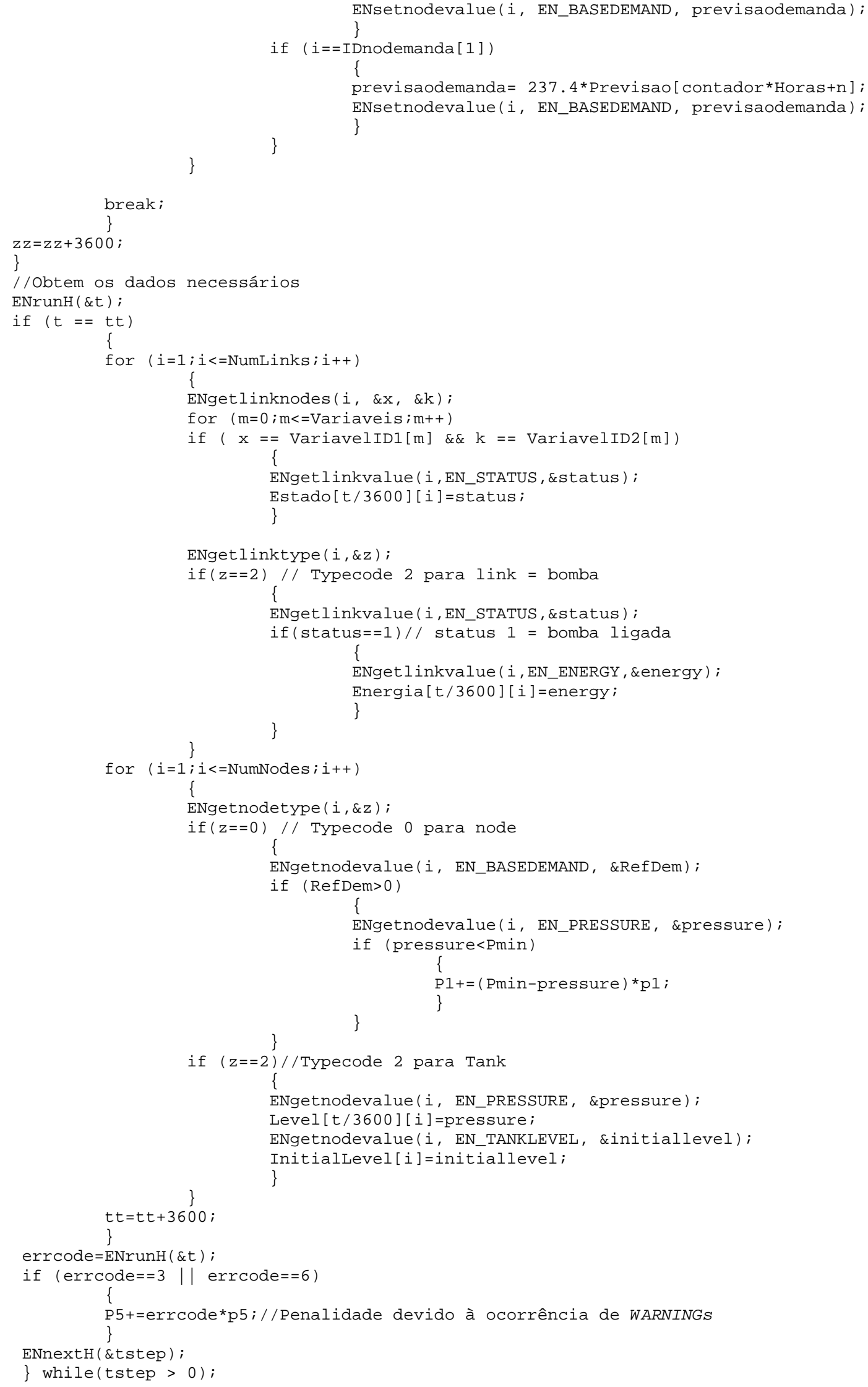

//Cálcula as Penalidades

for $(i=1 ; i<$ NumNodes $; i++)$ 


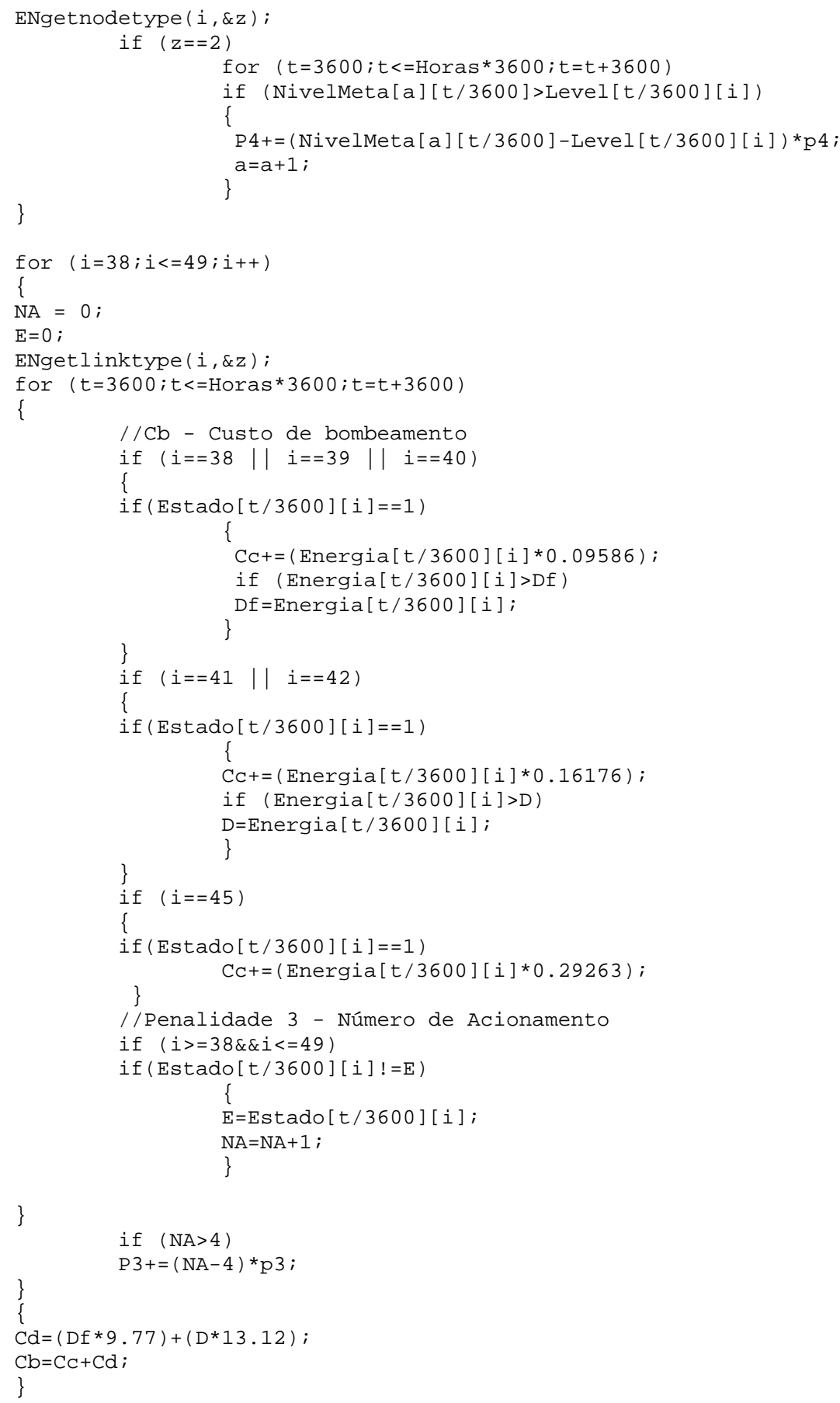


void operation : : results()

\{

//Setando o genoma no EPANET, para conferir os resultados obtidos

int NumLinks, NumJunctions;

int $i, j, k, n, m, x, z, y, b, N A, E$, errcode, Df, Dp, D;

long $t$, tstep, tt, $z z$;

float pressure, RefDem, energy, status, initiallevel;

int $\mathrm{f}=0$;

int $\mathrm{a}=0$;

$\mathrm{Df}=0$;

$\mathrm{Dp}=\odot$

$\mathrm{D}=0$;

$\mathrm{tt}=0$;

$\mathrm{zz}=0$;

$\mathrm{Cb}=0$

$\mathrm{Cc}=0$;

$\mathrm{Cd}=\odot$;

$\mathrm{P} 1=0$

$\mathrm{P} 2=0 ;$

$\mathrm{P} 3=0 ;$

$\mathrm{P} 4=0 ;$

$\mathrm{P} 5=0$;

obj $\mathrm{F}=\odot$;

ENopenH ( ) ;

ENinith(11);

ENgetcount (EN_NODECOUNT, \&NumNodes);

ENgetcount (EN_LINKCOUNT, \&NumLinks);

for $(i=1 ; i<=$ NumNodes; $i++)$

\{

ENgetnodetype $(i, \& z)$;

if $(z==2) / /$ Typecode 2 para Tank

ENsetnodevalue (i, EN_TANKLEVEL, Nivel[f])

\} $=f+1$;

\}

do \{

ENrunH(\&t)

if $(t==z z)$

\{

(EN_NODECOUNT, \&NumNodes);

ENgetcount (EN_LINKCOUNT, \&NumLinks);

for $(y=(t / 3600) ; y<$ Horas $; y++)$

\{

$b=0$;

for $(i=1 ; i<=$ NumLinks; $i++)$

\{

ENgetlinknodes $(i, \& x, \& k)$

ENgetlinktype $(i, \& z)$;

\{

for $(\mathrm{m}=0 ; \mathrm{m}<=$ Variaveis; $\mathrm{m}++)$

if $(x==$ VariavelID1[m] \&\& $k==\operatorname{VariavelID2[m])}$

\{

ENsetlinkvalue (i,EN_STATUS, Resultado[b][y]);

$\mathrm{b}=\mathrm{b}++$;

\}

for $(i=1 ; i<=$ NumNodes; $i++)$

ENgetnodetype $(i, \& z)$;

if $(z==0) / /$ Typecode $\odot$ para node

\{

if $(i==$ IDnodemanda $[\odot])$

previsaodemanda $=75^{*}$ Previsao $\left[\right.$ contador ${ }^{*}$ Horas $\left.+y\right]$;

ENsetnodevalue(i, EN_BASEDEMAND, previsaodemanda)

if $(i==I D n o d e m a n d a[1])$ 


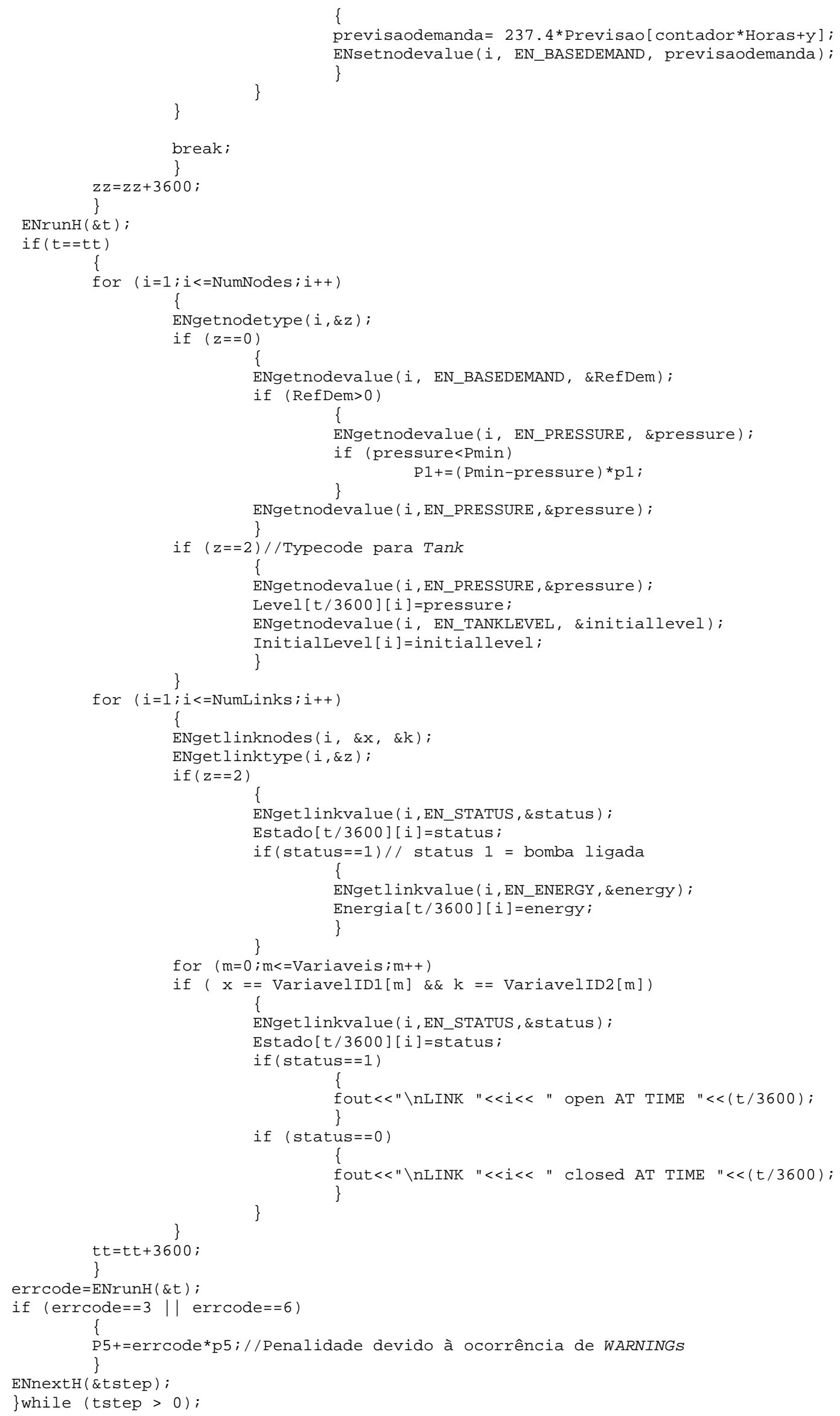




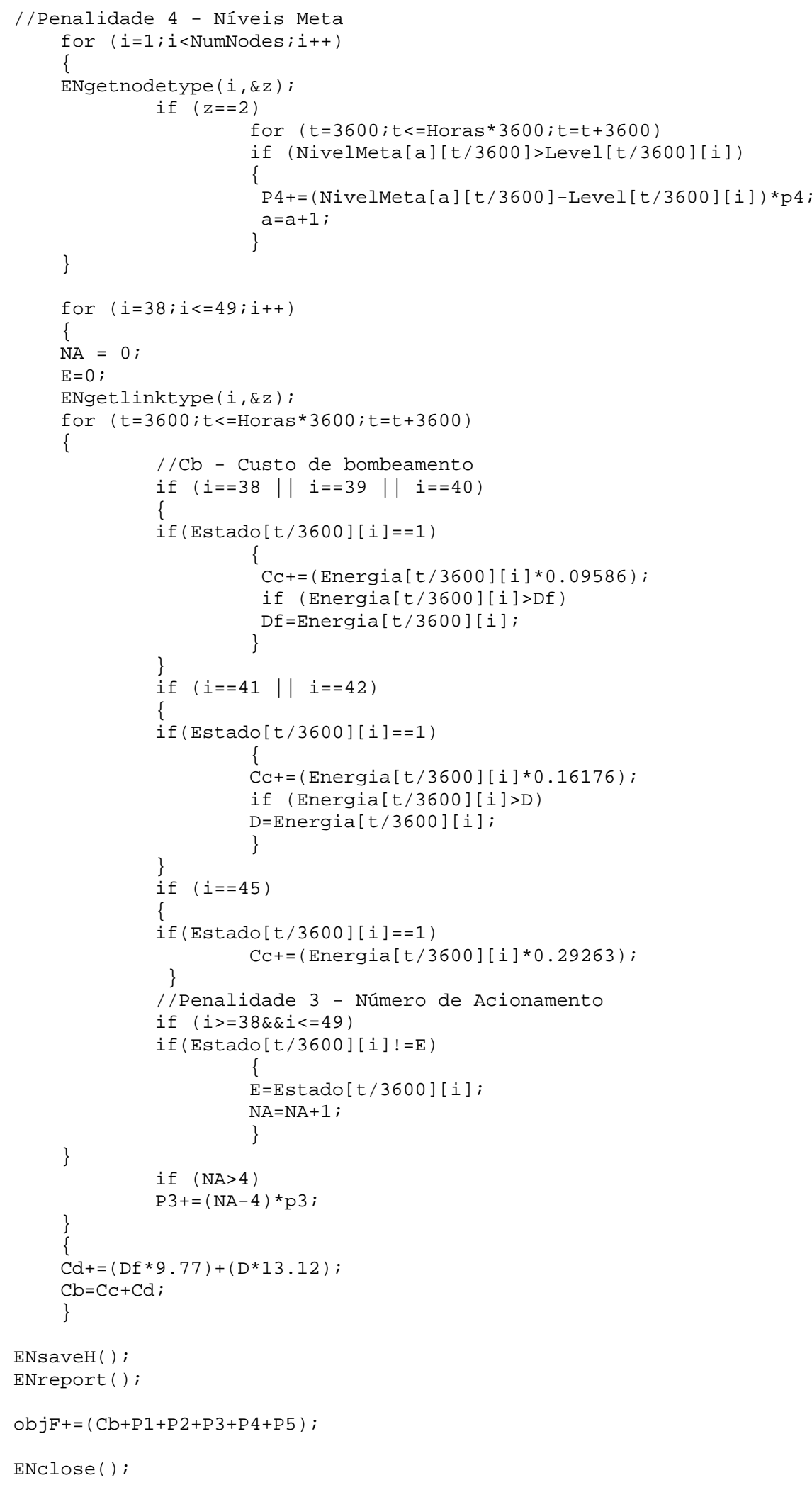




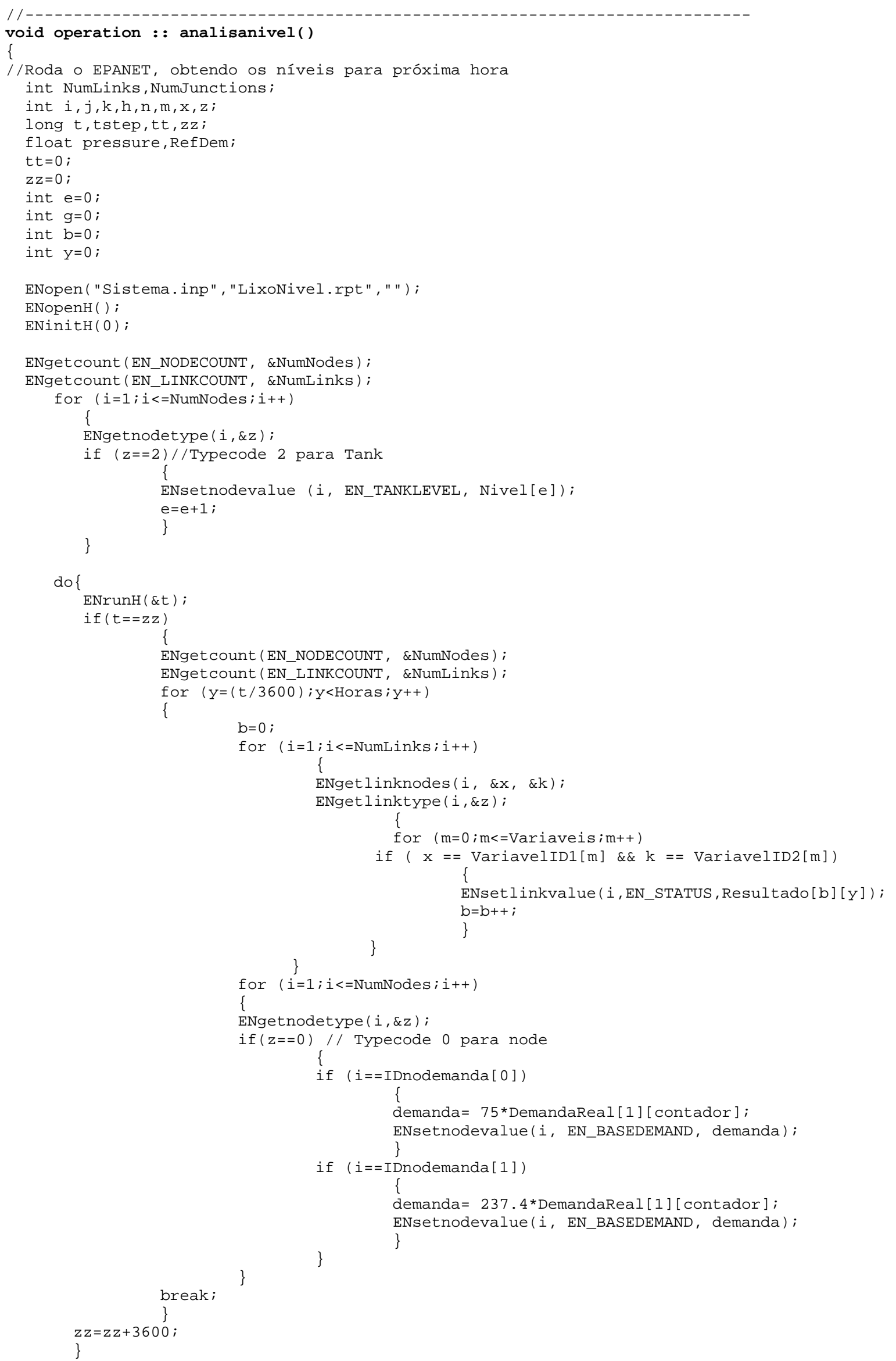




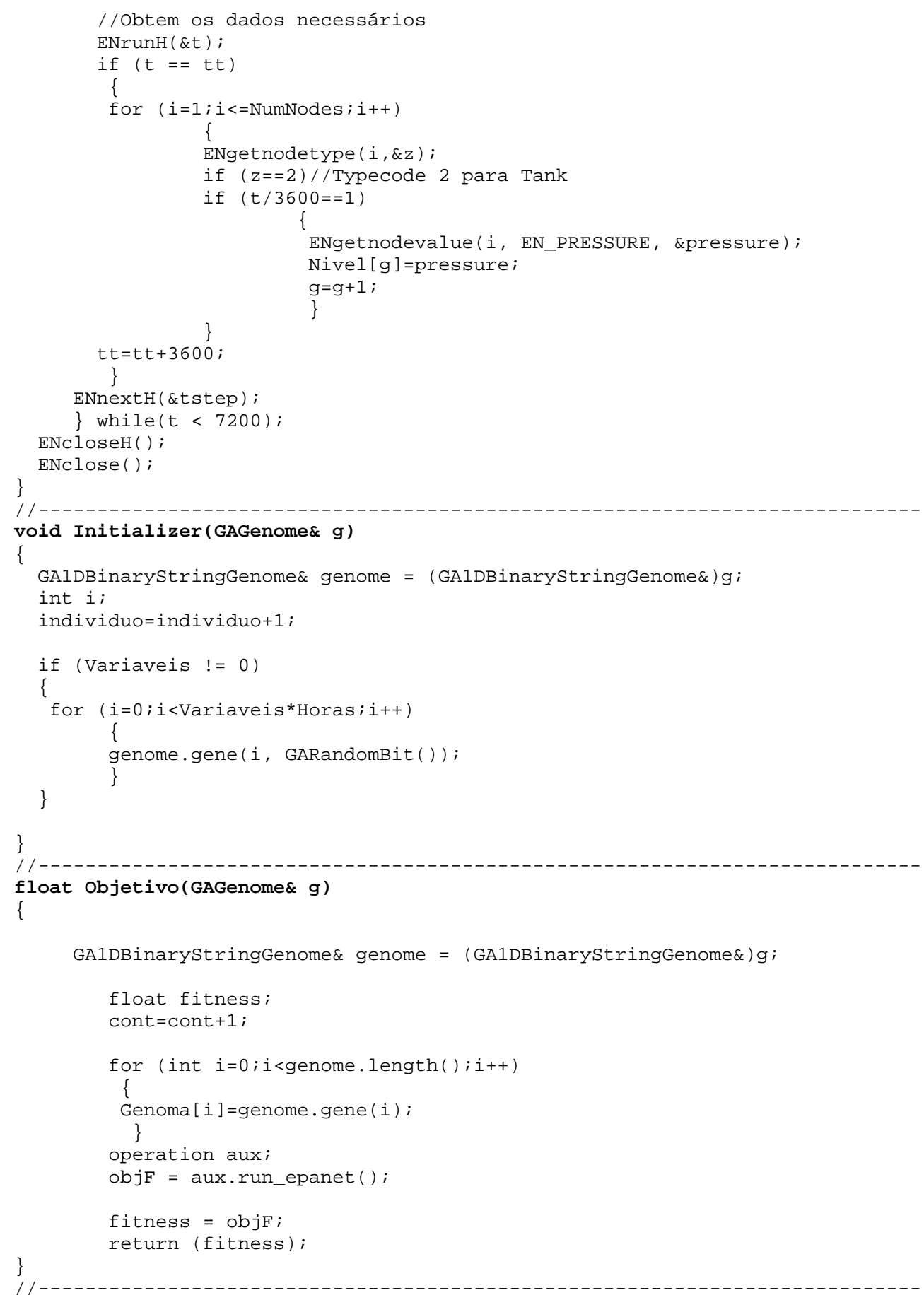


Apêndice B - Padrões de Demandas observadas e previstas utilizadas na Otimização em Tempo Real 
PADRÕES DE DEMANDA - FEVEREIRO.

\begin{tabular}{|c|c|c|c|c|c|c|c|c|c|c|c|c|c|c|c|c|c|c|c|c|c|c|c|c|c|c|}
\hline Data & Hora & Demanda & & & & & & & & & & & Previ & stao & & & & & & & & & & & & \\
\hline & & Observada & 1 & 2 & 3 & 4 & 5 & 6 & & 5 & 9 & 10 & 11 & 12 & 13 & 14 & 15 & 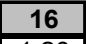 & & & 19 & 20 & 21 & 22 & 23 & 24 \\
\hline & 00:00 & 86 & 0.49 & 0.39 & 0.40 & 0.40 & 0.40 & 0.46 & 0.61 & 0.79 & 1.03 & 1.22 & 1.32 & 1.45 & 1.40 & 1.35 & 1.23 & 1.20 & 1.22 & 1.18 & 1.29 & 1.66 & 1.42 & 1.41 & 0.86 & 0.81 \\
\hline & 01:00 & 12 & 0.44 & 0.38 & 0.46 & 0.39 & 0.46 & 0.61 & 0.78 & 1.01 & 1.40 & 1.41 & \begin{tabular}{|l|}
1.44 \\
\end{tabular} & \begin{tabular}{|l|}
1.38 \\
\end{tabular} & 1.34 & 1.22 & 1.19 & \begin{tabular}{|l|}
1.19 \\
\end{tabular} & & 1.28 & 1.40 & 1.50 & 1.40 & 0.85 & 0.72 & 0.59 \\
\hline & $02: 00$ & 0.724 & 0.39 & 0.42 & 0.39 & 0.45 & 0.60 & 0.77 & 1.01 & 1.35 & \begin{tabular}{|l|}
1.45 \\
\end{tabular} & $\begin{array}{ll}1.26 \\
\end{array}$ & 1.37 & 1.33 & 1.21 & 1.18 & 1.19 & $\begin{array}{ll}1.25 \\
\end{array}$ & 1.27 & \begin{tabular}{|l|}
1.40 \\
\end{tabular} & 1.60 & 1.37 & & 0.72 & 0.76 & 0.44 \\
\hline & 03:00 & 0.535 & 0.39 & 0.39 & 0.45 & 0.60 & 0.77 & 1.01 & 1.30 & 1.41 & \begin{tabular}{|l|}
1.40 \\
\end{tabular} & \begin{tabular}{|l|l|}
1.37 \\
\end{tabular} & 1.33 & \begin{tabular}{|l|}
1.21 \\
\end{tabular} & 1.18 & 1.18 & 1.16 & \begin{tabular}{|l|l|}
1.27 \\
\end{tabular} & 1.39 & \begin{tabular}{|l|}
1.41 \\
\end{tabular} & \begin{tabular}{|l|}
1.46 \\
\end{tabular} & 0.85 & 0.72 & & 0.57 & 0.52 \\
\hline & $04: 00$ & 0.507 & 0.40 & 0.46 & 0.61 & 0.78 & 1.02 & 1.33 & 1.36 & 1.47 & \begin{tabular}{|l|}
1.31 \\
\end{tabular} & 1.35 & \begin{tabular}{|l|}
1.22 \\
\end{tabular} & 1.20 & 1.20 & 1.18 & 1.28 & \begin{tabular}{|l|l|}
1.41 \\
\end{tabular} & 1.43 & 1.30 & & & & & 0.46 & 0.51 \\
\hline & $05: 00$ & 0.532 & 0.51 & 0.60 & 0.77 & \begin{tabular}{|l|l}
1.01 \\
\end{tabular} & 1.35 & 1.26 & 1.39 & 1.43 & 1.11 & \begin{tabular}{|l|l|}
1.21 \\
\end{tabular} & \begin{tabular}{|l|}
1.18 \\
\end{tabular} & \begin{tabular}{|l|}
1.18 \\
\end{tabular} & 1.16 & 1.27 & 1.63 & \begin{tabular}{|l|l|}
1.41 \\
\end{tabular} & 1.28 & 0.85 & 0.72 & 0.64 & 0.50 & & 0.50 & 0.48 \\
\hline I & $06: 00$ & 0.597 & 0.58 & 0.78 & 1.01 & 1.43 & 1.28 & 1.33 & 1.50 & 1.31 & 1.22 & \begin{tabular}{|l|l|}
1.19 \\
\end{tabular} & \begin{tabular}{|l|}
1.19 \\
\end{tabular} & \begin{tabular}{|l|l|}
1.17 \\
\end{tabular} & 1.27 & 1.28 & 1.42 & \begin{tabular}{|l|}
1.29 \\
\end{tabular} & 0.85 & \begin{tabular}{|l|}
0.72 \\
\end{tabular} & 0.65 & 0.51 & 0.52 & 0.44 & 0.48 & 0.59 \\
\hline & $07: 00$ & 0.833 & 0.70 & \begin{tabular}{|l|l|}
1.16 \\
\end{tabular} & 1.40 & \begin{tabular}{|l|l|}
1.29 \\
\end{tabular} & 1.21 & \begin{tabular}{|l|l|}
1.42 \\
\end{tabular} & 1.41 & 1.05 & 1.16 & \begin{tabular}{|l|}
1.16 \\
\end{tabular} & \begin{tabular}{|l|}
1.14 \\
\end{tabular} & 1.24 & \begin{tabular}{|l|l|}
1.37 \\
\end{tabular} & \begin{tabular}{|l|l|}
1.58 \\
\end{tabular} & \begin{tabular}{|l|l|}
1.25 \\
\end{tabular} & \begin{tabular}{|l|}
0.83 \\
\end{tabular} & \begin{tabular}{|l|}
0.71 \\
\end{tabular} & \begin{tabular}{|l|}
0.63 \\
\end{tabular} & \begin{tabular}{|l|l|}
0.50 \\
\end{tabular} & 0.51 & 0.54 & \begin{tabular}{|l|l|}
0.47 \\
\end{tabular} & 0.57 & 0.71 \\
\hline 8 & $08: 00$ & & 0.94 & 1.36 & 1.43 & \begin{tabular}{|l}
1.27 \\
\end{tabular} & $\begin{array}{l}1.36 \\
\end{array}$ & \begin{tabular}{|l|l|}
1.48 \\
\end{tabular} & 1.28 & \begin{tabular}{|l|}
1.17 \\
\end{tabular} & \begin{tabular}{|l|}
1.17 \\
\end{tabular} & \begin{tabular}{|l|}
1.15 \\
\end{tabular} & \begin{tabular}{|l|}
1.25 \\
\end{tabular} & \begin{tabular}{|l|}
1.38 \\
\end{tabular} & \begin{tabular}{|l}
1.23 \\
\end{tabular} & \begin{tabular}{|l|l}
1.26 \\
\end{tabular} & \begin{tabular}{|l|l}
0.84 \\
\end{tabular} & \begin{tabular}{|l|}
0.71 \\
\end{tabular} & \begin{tabular}{|l|}
0.63 \\
\end{tabular} & 0.50 & \begin{tabular}{|l|}
0.51 \\
\end{tabular} & 0.49 & 0.43 & 0.58 & 0.72 & 0.88 \\
\hline & $\begin{array}{l}09: 00 \\
\end{array}$ & & 1.15 & \begin{tabular}{|l|l}
1.44 \\
\end{tabular} & 1.36 & \begin{tabular}{|l}
1.31 \\
\end{tabular} & 1.43 & \begin{tabular}{|l|l}
1.41 \\
\end{tabular} & 1.06 & 1.15 & \begin{tabular}{|l|l|}
1.13 \\
\end{tabular} & 1.23 & \begin{tabular}{|l|}
1.36 \\
\end{tabular} & \begin{tabular}{|l|l|}
1.37 \\
\end{tabular} & \begin{tabular}{|l}
.25 \\
\end{tabular} & \begin{tabular}{|l|l}
0.83 \\
\end{tabular} & \begin{tabular}{|l|l}
0.70 \\
\end{tabular} & \begin{tabular}{|l|}
0.62 \\
\end{tabular} & \begin{tabular}{|l|l|}
0.49 \\
\end{tabular} & \begin{tabular}{|l|}
0.50 \\
\end{tabular} & \begin{tabular}{|l|l|}
0.49 \\
\end{tabular} & 0.53 & 0.57 & 0.71 & 0.86 & 1.03 \\
\hline & $10: 00$ & 1.498 & 1.35 & 1.43 & 1.34 & \begin{tabular}{|l}
1.36 \\
\end{tabular} & 1.18 & 1.31 & 1.16 & 1.13 & 1.24 & .36 & 1.38 & 1.19 & 0.83 & 0.70 & 0.63 & \begin{tabular}{|l|}
0.49 \\
\end{tabular} & $\sqrt{51}$ & 0.49 & 047 & 0.57 & & 0.87 & 1.03 & 1.29 \\
\hline & 11:0 & & 1.39 & 1.38 & 1.30 & 1.39 & 1.36 & 1.05 & 12 & 27 & 1.34 & $\frac{35}{35}$ & 1.23 & 82 & & 1.6 & 10 & 0.50 & & 0.46 & & 170 & & .02 & & 1.48 \\
\hline & 12: & & 1.39 & 1.30 & 1.31 & 1.12 & 1.27 & 1.10 & 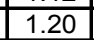 & 32 & 1.34 & 21 & 81 & 6 & ..6 & 0.48 & & 0.48 & ). & 0.6 & & 84 & & & $\frac{1.46}{1.6}$ & 53 \\
\hline & 11 & & 1.35 & 1.28 & 1.13 & .14 & $\overline{15}$ & .22 & 1.34 & & & 87 & 69 & & .4 & .5 & & $\overline{0.4}$ & & & & & & 48 & & \\
\hline & 114 & & $\overline{n n}$ & \begin{tabular}{|l|l}
1.27 \\
\end{tabular} & 1.12 & 5 & 1.19 & 31 & & 2 & $\overline{8.80}$ & 68 & 60 & $.4 \varepsilon$ & $\overline{0.4}$ & 5.4 & & 0.55 & & 0.8 &. & .24 & & & & $\frac{18}{28}$ \\
\hline & $\overline{1}$ & & 1.16 & 1.33 & 1.09 & 1. & $\overline{31}$ & 1.33 & & & .68 & $\overline{60}$ & 48 & $.4 ؟$ & $\overline{0.4}$ & $\overline{0.4}$ & 5 & 0.82 & 5. & $\overline{1.0}$ & 1.8 & 45 & & & & 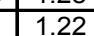 \\
\hline & & & 1.16 & $\begin{array}{ll}1.10 \\
\end{array}$ & 1.36 & 1. & 34 & 21 & & & & 48 & 0.49 & & 0.4 & & & 0.84 & & & & & & & 1.34 & \\
\hline & $17: 0$ & & 1.21 & 1.40 & 15 & & & 0.80 & & & 47 & & 0.47 & .45 & & 06 & & 0.99 & 1.24 & & & 56 & 1.47 & & 10 & \\
\hline & $18: 00$ & & 1.27 & 1.32 & 1.32 & 1.20 & $\overline{0.79}$ & 0.67 & $\overline{0.58}$ & $.4 \pi$ & $\overline{0.48}$ & .47 & 0.45 & .05 & & 0.94 & 0.99 & 1.23 & 1.44 & 1.5 & 1.5 & 1.47 & 1.24 & 1.29 & $\overline{1.0 \varepsilon}$ & 1.01 \\
\hline & $19: 00$ & & 1.32 & 1.17 & 1.23 & 0.82 & 0.69 & 0.62 & 0.49 & 0.50 & 0.48 & .46 & 0.56 & 0.70 & $\overline{0.85}$ & \begin{tabular}{|l|l|}
0.84 \\
\end{tabular} & 1.27 & \begin{tabular}{|l|}
1.49 \\
\end{tabular} & 1.55 & 1.60 & 1.5 & 1.17 & 1.37 & 1.23 & 1.05 & 1.06 \\
\hline & $20: 00$ & & 1.17 & 1.20 & 0.80 & \begin{tabular}{|l|l|}
0.68 \\
\end{tabular} & 0.60 & 0.48 & 0.48 & 0.47 & 0.45 & .55 & 0.68 & 0.83 & 0.95 & 1.24 & 1.45 & 1.52 & 1.5 & 1.47 & 1.23 & 1.26 & 1.27 & 1.08 & 1.26 & 131 \\
\hline & $21:$ & & 0.99 & 0.69 & 0.69 & \begin{tabular}{|l|}
0.61 \\
\end{tabular} & 47 & 0.50 & 0.48 & 0.46 & 0.56 & 70 & 0.85 & 1.05 & 1.26 & \begin{tabular}{|l|}
1.4 \\
\end{tabular} & 1.54 & 1.59 & 1.5 & 1.25 & 1.14 & 1.35 & 21 & 1.29 & 1.34 & 1.01 \\
\hline & $22: 0$ & & 0.78 & \begin{tabular}{|l}
0.57 \\
\end{tabular} & 0.62 & \begin{tabular}{|l|l|}
0.43 \\
\end{tabular} & 50 & $\begin{array}{l}0.49 \\
\end{array}$ & 0.46 & 0.56 & 0.70 & 0.86 & 109 & 127 & 149 & 1.5 & 1.60 & 15 & & 096 & & & 111 & & & $\frac{1.00}{1.02}$ \\
\hline & $23: 0$ & & 0.63 & \begin{tabular}{|l|l|}
0.50 \\
\end{tabular} & 0.44 & \begin{tabular}{|l|l|}
0.49 \\
\end{tabular} & 49 & \begin{tabular}{|l}
0.46 \\
\end{tabular} & 0.57 & 0.71 & \begin{tabular}{|l|}
0.86 \\
\end{tabular} & \begin{tabular}{|l|}
1.09 \\
\end{tabular} & \begin{tabular}{|l|}
1.09 \\
\end{tabular} & \begin{tabular}{|l|}
1.49 \\
\end{tabular} & \begin{tabular}{|l}
1.56 \\
\end{tabular} & \begin{tabular}{|l|l|}
1.61 \\
\end{tabular} & \begin{tabular}{|l|l|}
1.52 \\
\end{tabular} & \begin{tabular}{|l|}
1.27 \\
\end{tabular} & \begin{tabular}{|l|l}
1.18 \\
\end{tabular} & 1.15 & \begin{tabular}{|l|l|}
1.38 \\
\end{tabular} & 1.21 & 1.35 & \begin{tabular}{|l|l} 
& .00 \\
\end{tabular} & 1.07 & 0.85 \\
\hline & $\overline{00: 0}$ & & 0.51 & 0.44 & 0.43 & \begin{tabular}{|l|}
0.47 \\
\end{tabular} & 45 & 0.54 & 0.68 & 0.83 & \begin{tabular}{|l|}
1.06 \\
\end{tabular} & \begin{tabular}{|l|l|}
1.07 \\
\end{tabular} & \begin{tabular}{|l|}
1.44 \\
\end{tabular} & 1.50 & 1.54 & 1.46 & 1.22 & \begin{tabular}{|l|l|}
1.13 \\
\end{tabular} & 0.92 & & 1.30 & 1.09 & 02 & 1.08 & & $\overline{0.64}$ \\
\hline & 0 & & 48 & 0.43 & 45 & 0.45 & 54 & 68 & 83 & 11 & & 44 & 1.50 & .54 & & & 1113 & 1.14 & & & & 01 & & 1.01 & 0.78 & 52 \\
\hline & $0_{4}$ & & 0.53 & 0.44 & 0.52 & 0.5 & 0.68 & 0.82 & & & & & 54 & 46 & & & & $\overline{0 . c}$ & & 1. & & & & & 0.63 & 42 \\
\hline & 0 & & 0.53 & 0.44 & & 0.6 & & 98 & & & & & 7.4 & & & & & & & & & & & & & \\
\hline & 04: & & 52 & 0.52 & 0.6 & 0.8 & 0.9 & 16 & & & 1.5 & & 22 & & & & & 1.2 & & & & & & & & 0.48 \\
\hline & & & 0.55 & 0.66 & 0.82 & $\overline{0.5}$ & & 1.4 & & & 1. & & 1. & & & & 1.0 & 1. & & & & 0.5 & & 0.4 & & \\
\hline & & & & $\overline{0.8}$ & & & & & & & & & & & & & & & & & & & & & & \\
\hline & 0 & & 0.75 & 1.09 & 1.39 & 1.3 & 1.20 & 1. & 1 & 1.6 & 1. & 1.14 & 1.12 & & & & 1.0 & $0 . \varepsilon$ & & 0.5 & & & & 0. & & $\overline{0.6}$ \\
\hline & $\overline{08}$ & 1 & 0.97 & 1.33 & 1.47 & 1. & 1.25 & 1.34 & 1.18 & 1.13 & 1.14 & 1.12 & 1.25 & 1.30 & 1.2 & 1.1 & 0.85 & 0.6 & 0. & 0.4 & & 0.4 & 0.41 & 0. & & $0.7 \mathrm{~s}$ \\
\hline & $09: 0$ & & 1.23 & \begin{tabular}{|l|l|}
1.50 \\
\end{tabular} & 1.46 & 1. & 1.32 & 1.29 & 99 & 1.14 & & 1.25 & \begin{tabular}{|l|l}
1.30 \\
\end{tabular} & 1.22 & 1.06 & , & \begin{tabular}{|l|}
0.67 \\
\end{tabular} & 0.5 & 0. & 0. & & 0. & 0.52 & 0. & & .8 \\
\hline 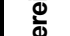 & 10: & & 1.45 & \begin{tabular}{|l|l|}
1.56 \\
\end{tabular} & 1.37 & 1. & 1.32 & 1.16 & 1.14 & 1.1 & & \begin{tabular}{|l|}
1.30 \\
\end{tabular} & 1.22 & & & 0.6 & 0 & \begin{tabular}{|l|}
0. \\
\end{tabular} & & \begin{tabular}{|l|l}
0.2 \\
\end{tabular} & & & 0.69 & & 0. & 0.73 \\
\hline 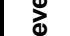 & 11 & & 1. & \begin{tabular}{|l|l}
1.47 \\
\end{tabular} & 1. & 1. & & 0.95 & & 1. & 1 & & 0 & \begin{tabular}{|l|}
0.85 \\
\end{tabular} & 0 & & $\overline{44}$ & $\begin{array}{l} \\
\end{array}$ & & & & & 0 & 0.85 & 0 & 1.02 \\
\hline 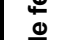 & 12: & & 1.43 & 1.36 & 1. & & & 1.12 & & & & & 85 & \begin{tabular}{|l|l|}
0.67 \\
\end{tabular} & & & & 0. & & & & \begin{tabular}{|l|l|} 
\\
\end{tabular} & & \begin{tabular}{|l|l|}
0.72 \\
\end{tabular} & 1. & 1.44 \\
\hline 2 & 13: & & 1.39 & \begin{tabular}{|l}
1.31 \\
\end{tabular} & & & & 1.25 & & & & & \begin{tabular}{|l|}
0.67 \\
\end{tabular} & & \begin{tabular}{|l}
0.45 \\
\end{tabular} & & & 0. & & 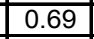 & & \begin{tabular}{|l|}
0.85 \\
\end{tabular} & 0.72 & \begin{tabular}{|l|l} 
\\
\end{tabular} & 1. & 1.17 \\
\hline & 14: & & 1.32 & 1.30 & 1.2 & & & 1.30 & & & & & \begin{tabular}{|l|}
0.54 \\
\end{tabular} & \begin{tabular}{|l|l|}
0.44 \\
\end{tabular} & 0 & 0. & \begin{tabular}{|l}
0 \\
\end{tabular} & 0. & & 0. & & \begin{tabular}{|l|}
0.72 \\
\end{tabular} & 1.01 & \begin{tabular}{|l|l|} 
& 1.44 \\
\end{tabular} & 1. & 1.17 \\
\hline g & $15: 0$ & & 1.30 & 1.29 & 1.20 & $\begin{array}{ll}1 . \\
\end{array}$ & 1.30 & 1.22 & 05 & 0.85 & & & \begin{tabular}{|l|}
0.45 \\
\end{tabular} & \begin{tabular}{|l|l|}
0.47 \\
\end{tabular} & \begin{tabular}{|l}
0.48 \\
\end{tabular} & 0. & & \begin{tabular}{|l|}
0. \\
\end{tabular} & & 0.8 & & \begin{tabular}{|l|}
1.07 \\
\end{tabular} & 1.44 & \begin{tabular}{|l|l}
1.41 \\
\end{tabular} & 1. & 1.06 \\
\hline है & 16: & & 1.27 & \begin{tabular}{|l}
1.26 \\
\end{tabular} & 1.05 & \begin{tabular}{|l}
1.30 \\
\end{tabular} & 1.22 & 1.05 & 0.85 & & & & \begin{tabular}{|l|}
0.47 \\
\end{tabular} & \begin{tabular}{|l|l|}
0.48 \\
\end{tabular} & \begin{tabular}{|l|l}
0.47 \\
\end{tabular} & 0.5 & .78 & \begin{tabular}{|l|l}
0.7 \\
\end{tabular} & \begin{tabular}{|l}
0. \\
\end{tabular} & \begin{tabular}{|l|} 
\\
\end{tabular} & & 1.44 & 1.41 & \begin{tabular}{|l|l}
1.14 \\
\end{tabular} & 0.95 & 0.64 \\
\hline & $17: 0$ & & 1.25 & 1.18 & 1.30 & \begin{tabular}{|l|l}
1.22 \\
\end{tabular} & 1.05 & 0.85 & 0.67 & 0.65 & \begin{tabular}{|l|}
0.44 \\
\end{tabular} & \begin{tabular}{|l|l|}
0.47 \\
\end{tabular} & \begin{tabular}{|l|}
0.48 \\
\end{tabular} & \begin{tabular}{|l|l|}
0.47 \\
\end{tabular} & \begin{tabular}{|l|l}
0.52 \\
\end{tabular} & \begin{tabular}{|l|}
0.82 \\
\end{tabular} & \begin{tabular}{|l|l}
0.67 \\
\end{tabular} & \begin{tabular}{|l|}
0.85 \\
\end{tabular} & \begin{tabular}{|l|l|}
0.72 \\
\end{tabular} & \begin{tabular}{|l|}
1.07 \\
\end{tabular} & \begin{tabular}{|l|l|}
1.44 \\
\end{tabular} & 1.41 & 1.05 & 0.95 & 0. & 0.72 \\
\hline & $18: 00$ & 1. & 1.22 & 1.30 & 1.22 & 1.05 & 0.85 & \begin{tabular}{|l|l}
0.67 \\
\end{tabular} & 0.51 & 0.45 & \begin{tabular}{|l|}
0.47 \\
\end{tabular} & \begin{tabular}{|l|}
0.48 \\
\end{tabular} & \begin{tabular}{|l|}
0.47 \\
\end{tabular} & 0.52 & \begin{tabular}{|l|l}
0.69 \\
\end{tabular} & \begin{tabular}{|l|}
0.78 \\
\end{tabular} & \begin{tabular}{|l|l|}
0.85 \\
\end{tabular} & \begin{tabular}{|l|}
0.72 \\
\end{tabular} & \begin{tabular}{|l|}
1.07 \\
\end{tabular} & \begin{tabular}{|c|}
1.44 \\
\end{tabular} & \begin{tabular}{|l|}
1.41 \\
\end{tabular} & 1.17 & 1.14 & \begin{tabular}{|l|l|}
0.64 \\
\end{tabular} & 0. & 0.81 \\
\hline & 19:00 & 1. & 1.12 & 1.22 & 1.05 & 0.85 & 0.6 & 0.55 & 0.45 & 0.47 & \begin{tabular}{l|l|}
0.48 \\
\end{tabular} & \begin{tabular}{|l|l|}
0.47 \\
\end{tabular} & 0.52 & 0.69 & 0.84 & \begin{tabular}{|l|l|}
0.71 \\
\end{tabular} & 0.72 & 1.07 & 1.44 & 1.2 & 4 & 1.06 & 0.64 & 0.72 & 0.81 & 0.88 \\
\hline & $20: 0$ & & 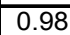 & 1.05 & 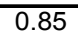 & 0.67 & 70 & 0.5 & & & 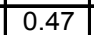 & & $\overline{0.8 c}$ & 5 & 870 & 0.60 & 1.07 & 1.44 & & & & & & 0 & 0.88 & 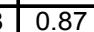 \\
\hline & $21: 00$ & & 1.05 & .85 & 0.67 & 0.55 & 0.4 & 0.47 & 0.48 & $\Delta$ & 0.5 & & 0.85 & 86 & 0.71 & 107 & 1.44 & 1.4 & & & & & & & & $\pi$ \\
\hline & & & 85 & 8.67 & & 0.36 & 0.4 & 0.48 & & .52 & & & 0.88 & .80 & & & & & & & & & & & & 8 \\
\hline & $23: 0$ & & 67 & .55 & 3.37 & 39 & 0.48 & & 53 & & 187 & $\overline{0.90}$ & .72 & & 1.44 & & & & & & & $\overline{8.88}$ & 8.8 & $\overline{0.81}$ & 8.8 & 1.0 \\
\hline
\end{tabular}




\begin{tabular}{|c|c|c|c|c|c|c|c|c|c|c|c|c|c|c|c|c|c|c|c|c|c|c|c|c|c|c|}
\hline \multirow{2}{*}{ Data } & \multirow{2}{*}{ Hora } & \multirow{2}{*}{$\begin{array}{l}\text { Demanda } \\
\text { Observada }\end{array}$} & \multicolumn{24}{|c|}{ Previsão de Demandas } \\
\hline & & & 1 & 2 & 3 & 4 & 5 & 6 & 7 & 8 & 9 & 10 & 11 & 12 & 13 & 14 & 15 & 16 & 17 & 18 & 19 & 20 & 21 & 22 & 23 & 24 \\
\hline \multirow{24}{*}{ 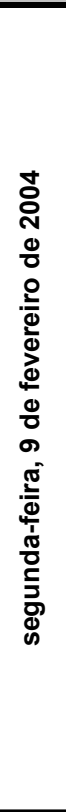 } & $00: 00$ & 0.541 & 0.55 & 0.49 & $\overline{0.60}$ & $\overline{0.61}$ & 0.59 & 0.66 & 0.87 & 1.11 & 1.06 & 0.91 & 1.13 & 1.82 & 1.79 & 1.47 & 1.20 & 0.78 & 0.91 & 1.03 & 1.11 & 1.10 & 1.02 & 1.05 & 1.12 & 1.01 \\
\hline & $01: 00$ & 0.479 & 0.52 & 0.47 & 0.50 & \begin{tabular}{|l|}
0.59 \\
\end{tabular} & 0.66 & 0.86 & 0.98 & 1.14 & 0.89 & 1.20 & 1.80 & 1.76 & 1.45 & 1.19 & 0.80 & 0.94 & 1.02 & 1.09 & 1.09 & 1.01 & 1.04 & 1.11 & \begin{tabular}{|l|}
1.17 \\
\end{tabular} & 0.76 \\
\hline & $02: 00$ & 433 & 0.50 & 0.59 & 0.61 & 0.65 & 0.85 & 0.98 & 1.14 & 1.04 & 1.17 & 1.78 & 177 & 1.44 & 1.18 & 0.79 & 0.76 & 1.20 & 1.08 & 1.08 & 1.00 & 1.03 & 1.10 & 0.98 & \begin{tabular}{|l|}
0.72 \\
\end{tabular} & 0.60 \\
\hline & $03: 00$ & 459 & 0.59 & 0.51 & 0.65 & .85 & 0.98 & 1.26 & 1.04 & 1.16 & 1.78 & 1.75 & 1.44 & 1.18 & 0.79 & 0.89 & 0.95 & 1.08 & 1.08 & 1.00 & 1.03 & 1.10 & 0.98 & 0.72 & \begin{tabular}{|l|}
0.72 \\
\end{tabular} & 0.49 \\
\hline & 04:00 & 447 & 0.58 & 0.61 & 1.00 & \begin{tabular}{|l}
0.98 \\
\end{tabular} & 1.05 & 0.89 & 1.18 & 1.78 & 1.75 & 1.44 & 1.18 & 0.79 & 0.89 & 1.01 & 1.20 & 1.08 & 1.00 & 1.03 & 1.10 & 0.98 & 0.72 & 0.60 & \begin{tabular}{|l}
0.57 \\
\end{tabular} & 0.60 \\
\hline & $05: 00$ & 528 & 0.65 & 0.78 & 1.17 & \begin{tabular}{|l}
1.06 \\
\end{tabular} & 0.89 & 1.18 & 1.79 & 1.75 & 1.44 & 1.18 & 0.79 & 0.90 & 1.01 & 0.99 & 1.08 & 1.00 & $\begin{array}{l}1.03 \\
\end{array}$ & 1.10 & 0.98 & 0.72 & 0.61 & 0.69 & \begin{tabular}{|l|}
0.60 \\
\end{tabular} & 0.61 \\
\hline & $06: 00$ & & 87 & 0.99 & 1.08 & \begin{tabular}{|l}
0.91 \\
\end{tabular} & 1.28 & 1.82 & 1.79 & 1.23 & 1.20 & 0.69 & \begin{tabular}{|l|}
0.91 \\
\end{tabular} & 1.03 & 1.11 & 1.10 & 1.02 & 1.05 & 1.12 & 1.00 & 0.74 & 0.62 & 0.59 & 0.55 & \begin{tabular}{|l|}
0.62 \\
\end{tabular} & 0.68 \\
\hline & $07: 00$ & & 0.98 & 1.21 & 0.89 & \begin{tabular}{|l}
1.32 \\
\end{tabular} & 1.80 & 1.76 & 1.26 & 1.07 & 0.79 & 0.90 & 1.02 & 1.09 & 1.09 & 1.01 & 1.04 & 1.11 & 0.98 & 0.73 & 0.61 & 0.59 & 0.65 & 0.61 & \begin{tabular}{|l|}
0.67 \\
\end{tabular} & 0.82 \\
\hline & $08: 00$ & 127 & 0.97 & 0.89 & 1.46 & 1.79 & 1.76 & 1.28 & 1.23 & 0.91 & 0.90 & 1.01 & 1.09 & 1.08 & 1.00 & 1.03 & 1.10 & 0.98 & \begin{tabular}{|l|}
0.72 \\
\end{tabular} & 0.61 & 0.58 & 0.60 & 0.54 & 0.67 & \begin{tabular}{|l|}
0.82 \\
\end{tabular} & 0.97 \\
\hline & $09: 00$ & & 0.89 & 1.48 & 1.78 & \begin{tabular}{|l}
1.75 \\
\end{tabular} & 1.25 & 1.31 & 0.79 & 0.75 & 1.01 & 1.08 & 1.08 & 1.10 & 1.03 & 1.10 & 0.97 & 0.72 & 0.60 & 0.58 & 0.60 & 0.64 & 0.66 & 0.81 & \begin{tabular}{|l|}
0.96 \\
\end{tabular} & 1.06 \\
\hline & & & 1.35 & 1.58 & 1.78 & \begin{tabular}{|l|}
1.31 \\
\end{tabular} & 1.43 & 0.80 & 0.94 & 1.03 & 1.10 & 1.10 & & 1.05 & & & 0.73 & 0.62 & 0.59 & 0.61 & 0.62 & 0.55 & 0.83 & 0.98 & \begin{tabular}{|l|}
1.08 \\
\end{tabular} & 0.97 \\
\hline & $11: 00$ & & 1.88 & 1.56 & 1.27 & 1.40 & 0.82 & 0.93 & 1.05 & 1.13 & 1.12 & 1.04 & 1.10 & 1.14 & 1.01 & 0.75 & 0.63 & 0.60 & \begin{tabular}{|l}
0.63 \\
\end{tabular} & 0.63 & 0.66 & 0.85 & 1.00 & 1.10 & \begin{tabular}{|l}
0.75 \\
\end{tabular} & 0.98 \\
\hline & $12: 00$ & & 1.86 & 1.43 & 1.27 & \begin{tabular}{|l}
0.83 \\
\end{tabular} & 0.94 & 1.03 & 1.14 & 1.14 & 1.06 & 0.92 & 1.31 & 1.03 & 0.76 & 0.64 & 0.61 & 0.64 & $\begin{array}{l}0.64 \\
\end{array}$ & 0.82 & 0.86 & 1.02 & 1.12 & 0.89 & \begin{tabular}{|l|}
1.04 \\
\end{tabular} & 1.01 \\
\hline & $13: 00$ & & 1.75 & 1.36 & 0.86 & \begin{tabular}{|l|}
0.98 \\
\end{tabular} & 1.27 & 1.18 & 1.18 & 1.09 & 1.13 & 1.05 & 1.0 & 0.79 & & 0. & 0.66 & 0.66 & $\begin{array}{l}0.72 \\
\end{array}$ & 0.89 & 1.05 & 1.16 & 0.92 & 0.87 & \begin{tabular}{|l|}
1.05 \\
\end{tabular} & 1.03 \\
\hline & $14: 00$ & & 1.30 & 0.87 & 0.99 & \begin{tabular}{|l}
1.11 \\
\end{tabular} & 1.12 & 1.19 & 1.11 & 1.14 & 1.22 & 1.25 & 0.80 & 0.67 & 0. & 0.6 & 0.67 & 0.73 & 0.87 & 1.07 & 1.17 & 0.94 & 1.05 & 1.24 & \begin{tabular}{|l|}
1.04 \\
\end{tabular} & 1.16 \\
\hline & $15: 00$ & 258 & 0.88 & 1.00 & 1.12 & \begin{tabular}{|l|}
1.36 \\
\end{tabular} & 1.20 & 1.11 & 1.15 & 1.23 & 0.99 & 0.80 & 0.67 & 0.65 & 0.67 & 0.68 & 0.74 & 1.05 & \begin{tabular}{|l|}
1.07 \\
\end{tabular} & 1.18 & 0.94 & 1.05 & 0.97 & 1.05 & \begin{tabular}{|l|}
1.18 \\
\end{tabular} & 1.25 \\
\hline & 1 & & 0.99 & 1.12 & 1.21 & \begin{tabular}{|l}
1.17 \\
\end{tabular} & 1.11 & 1.15 & 1.23 & 1.09 & 0.80 & 0.67 & 0.65 & 0.67 & 0.68 & 0.74 & 0.91 & 0.88 & 1.18 & 0.94 & 1.05 & 1.07 & 1.05 & 1.17 & \begin{tabular}{|l}
1.25 \\
\end{tabular} & 1.23 \\
\hline & & & 1.11 & 1.19 & 1.31 & \begin{tabular}{|l}
0.97 \\
\end{tabular} & 1.13 & 1.21 & 1.07 & 0.95 & 0.66 & 0.64 & 0 . & & & & 1.02 & 1.16 & 0.93 & 1.04 & 1.05 & 1.06 & 1.16 & 1.23 & \begin{tabular}{|l}
1.21 \\
\end{tabular} & 0.96 \\
\hline & $18: 00$ & & 1.19 & 1.19 & 1.14 & \begin{tabular}{|l}
1.14 \\
\end{tabular} & 1.21 & $\begin{array}{l}1.07 \\
\end{array}$ & 0.74 & 0.67 & 0.64 & 0.66 & $\begin{array}{l}0.67 \\
\end{array}$ & 0.73 & & 1.17 & 1.17 & 0.93 & 1.04 & 1.06 & 1.03 & 1.16 & 1.24 & 1.21 & \begin{tabular}{|l}
0.97 \\
\end{tabular} & 1.09 \\
\hline & 1 & & 1.20 & 1.11 & 0.97 & \begin{tabular}{|l}
1.22 \\
\end{tabular} & 1.09 & 0.80 & 0.67 & 0.65 & 0.67 & 0.68 & 0.74 & 0.91 & 1. & 1.01 & 0.94 & 1.05 & 1.07 & 1.05 & 1.17 & 1.25 & 1.23 & 0.97 & \begin{tabular}{|l|}
1.11 \\
\end{tabular} & 1.22 \\
\hline & - & & 1.10 & 1.13 & 1.21 & \begin{tabular}{|l}
1.07 \\
\end{tabular} & 0.79 & 0.69 & 0.64 & 0.66 & 0.67 & 0.73 & 0.9 & 1.23 & 1. & 0.8 & 1.04 & 1.05 & 1.03 & 1.16 & 1.23 & 1.21 & 0.96 & 1.09 & \begin{tabular}{|l}
1.20 \\
\end{tabular} & 1.22 \\
\hline & $21: 00$ & & 1.12 & 1.19 & 1.06 & \begin{tabular}{|l}
0.78 \\
\end{tabular} & 0.57 & 0.63 & 0.65 & 0.66 & 0.72 & 0.89 & 1.20 & 1.20 & 1. & 1.0 & 1.04 & 1.02 & 1.14 & 1.15 & 1.20 & 0.95 & 1.08 & 1.19 & \begin{tabular}{|l|}
1.21 \\
\end{tabular} & 1.30 \\
\hline & $22: 00$ & & 1.03 & 1.06 & 0.78 & \begin{tabular}{|l|l}
0.55 \\
\end{tabular} & 0.68 & 0.65 & 0.66 & 0.72 & 0.88 & 1.11 & 1.20 & 0.92 & & 1. & 1.02 & 1.14 & 1.22 & 1.20 & 0.95 & 1.08 & 1.19 & 1.20 & \begin{tabular}{|l|l}
1.29 \\
\end{tabular} & 1.48 \\
\hline & 0 & & 1.05 & 0.65 & 0.57 & \begin{tabular}{|l}
0.59 \\
\end{tabular} & 0.65 & \begin{tabular}{|l|}
0.65 \\
\end{tabular} & 0.71 & 0.87 & 1.08 & 1.16 & 0.91 & 1.13 & 0. & 1.01 & 1.13 & 1.20 & 1.18 & 0.94 & 1.07 & 1.17 & 1.19 & 1.51 & \begin{tabular}{|l|}
1.49 \\
\end{tabular} & 1.26 \\
\hline \multirow{24}{*}{ 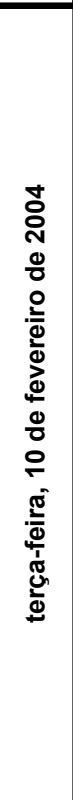 } & $\overline{00}$ & & 0,65 & 0,58 & 0,56 & 0,68 & 0,65 & 0,71 & 0,88 & 1,12 & 1,08 & 0,91 & 1,01 & 1,06 & 0,81 & 1,13 & 1,21 & 1,18 & 0,94 & 1,07 & 1,18 & 1,19 & 1,48 & 1,51 & 1,39 & 1,02 \\
\hline & 01:00 & & 0,57 & 0,54 & 0,56 & 0,64 & 0,69 & 0,85 & 1,20 & 1,03 & 0,88 & 0,98 & 1,00 & 0,93 & 1,1 & 1,17 & 1,15 & 1,08 & 1,04 & 1,14 & 1,16 & 1,41 & 1,39 & 1,38 & \begin{tabular}{|l|}
1,13 \\
\end{tabular} & 0,97 \\
\hline & 0 & & 0,54 & 0,53 & 0,68 & 0,70 & 0,86 & 1,01 & 1,11 & 0,89 & 0,99 & 1,01 & 1, & 1,10 & 1, & 1,1 & 0,82 & 1,04 & 1,15 & 1,17 & 1,25 & 1,47 & 1,21 & 1,29 & \begin{tabular}{|l}
0,93 \\
\end{tabular} & 0,82 \\
\hline & $03: 00$ & & 0,52 & 0,57 & 0,69 & \begin{tabular}{|l|}
0,85 \\
\end{tabular} & 1,00 & 1,21 & 0,87 & 0,98 & 0,99 & 0,97 & 0,9 & 1,16 & $\overline{1,}$ & 0,91 & 1,06 & 1,13 & 1,15 & 1,23 & 1,42 & 1,40 & 1,29 & 1,01 & 0,69 & 0,78 \\
\hline & $04: 00$ & & 0,52 & 0,66 & 0,83 & \begin{tabular}{|l}
0,97 \\
\end{tabular} & 1,07 & 0,86 & 0,95 & 0,97 & 0,95 & 1,15 & 1,13 & 1,11 & 0,8 & 1,00 & 1,27 & 1,12 & 1,20 & 1,44 & 1,31 & 1,25 & 1,06 & 0,78 & \begin{tabular}{|l}
0,76 \\
\end{tabular} & 0,75 \\
\hline & & & 0,57 & 0,86 & 0,99 & 1,09 & 0,87 & \begin{tabular}{|l}
0,97 \\
\end{tabular} & 0,98 & 0,96 & 1,08 & 1,02 & & & & 1,04 & 1,14 & 1,22 & 1,26 & 1,41 & 1,31 & 0,96 & 0,92 & 0,77 & \begin{tabular}{|l}
0,76 \\
\end{tabular} & 0,82 \\
\hline & 0 & & 0,69 & 1,06 & 1,08 & 0,86 & 0,96 & 0,98 & 0,95 & 1,07 & 1,19 & 1,12 & 0 , & $\sqrt{1}$ & 1, & 1,2 & 1,21 & 1,25 & 1,18 & 1,26 & 0,95 & 0,80 & 0,73 & 0,76 & 0,81 & 0,87 \\
\hline & 07:00 & & 0,86 & 1,28 & 0,86 & \begin{tabular}{|l}
0,96 \\
\end{tabular} & 0,98 & 0,95 & 1,07 & 1,14 & 1,01 & 0,76 & 1, & 1,11 & 1,0 & 1,21 & 1,25 & 1,18 & 1,32 & 0,95 & 0,80 & 0,83 & 0,76 & 0,82 & \begin{tabular}{|l}
0,87 \\
\end{tabular} & 1,00 \\
\hline & & & 1,07 & 0,86 & 0,96 & 0,97 & 0,95 & 1,07 & 1,14 & 1,20 & 0,82 & 1, & & & & & 1,17 & 1,10 & 0,95 & 0,80 & 0,77 & 0,70 & 81 & 0,87 & 1,00 & 1,08 \\
\hline & & & 0,84 & 0,94 & 0,95 & 0,93 & 1,04 & 1,11 & 1,09 & 0,93 & 0,98 & 1, & 1 & 1,18 & 1, & 1,1 & 1,07 & 0,93 & 0,78 & 0,75 & 0,76 & 0,80 & 0,85 & 0,98 & 1,06 & 1,27 \\
\hline & $10: 00$ & & 0,93 & 0,94 & 0,92 & 1,03 & 1,10 & 1,08 & 0,86 & 0,78 & 1,08 & 1,09 & 1, & 1,23 & 1, & 1,06 & 0,92 & 0,77 & 0,74 & 0,85 & 0,79 & 0,84 & 0,97 & 1,05 & \begin{tabular}{|l|}
1,26 \\
\end{tabular} & 1,41 \\
\hline & 11:00 & & 0,92 & 0,90 & 1,01 & 1,07 & 1,05 & 0,84 & 0,85 & 1,05 & 1,06 & 1, & 1, & 1,11 & & 0,8 & 0,75 & 0,72 & 0,71 & 0,72 & 0,82 & 0,94 & 1,02 & 1,22 & \begin{tabular}{|l}
1,37 \\
\end{tabular} & 1,62 \\
\hline & & & 0,86 & 0,97 & 1,03 & 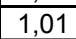 & 0,80 & 1,01 & 1,00 & 1,02 & 1,09 & 1 & 1 & 09 & & 07 & 0,70 & 0,69 & 0,78 & 0,79 & 0,91 & 0,98 & 1,18 & 1,31 & 1,56 & 1,59 \\
\hline & $13: 00$ & & 0,96 & 1,02 & 1,00 & 0,80 & 0,90 & 0,81 & 1,01 & 1,08 & 1,12 & 0,86 & 0,99 & 0,85 & 0 , & 0,69 & 0,68 & 0,84 & 0,65 & 0,90 & 0,97 & 1,16 & 1,30 & 1,54 & \begin{tabular}{|l}
1,57 \\
\end{tabular} & 1,59 \\
\hline & $14: 00$ & & 0,98 & 0,96 & 0,76 & 0,86 & 0,98 & 0,97 & 1,04 & 1,07 & 1,01 & 0,94 & $0, \varepsilon$ & 0,68 & 0 & 0,7 & 0,75 & 0,68 & 0,86 & 0,93 & 1,11 & 1,25 & 1,48 & 1,50 & \begin{tabular}{|l|}
1,52 \\
\end{tabular} & 1,48 \\
\hline & & & & 0,77 & 0,87 & 0,96 & 0,98 & 1,05 & 1,08 & 1,02 & 0,95 & 0,82 & & & & & 0,72 & 087 & 0,94 & 1,12 & 1,26 & 1,49 & 1,52 & 1,53 & \begin{tabular}{|l|}
1,22 \\
\end{tabular} & 1,04 \\
\hline & $16: 00$ & & 0,76 & 0,86 & 0,95 & 0,94 & 1,03 & 1,06 & 1,00 & 0,94 & 0,88 & 0,68 & 0,66 & 0,65 & 0,70 & 0,71 & 0,86 & 0,93 & 1,11 & 1,24 & 1,47 & 1,50 & 1,51 & 1,20 & 1,18 & 1,19 \\
\hline & $17: 00$ & & 0,84 & 0,93 & 1,07 & 1,01 & 1,04 & 0,98 & 0,92 & 0,65 & 0,67 & 0,64 & 0,64 & 0,73 & 0,70 & 0,73 & 0,91 & 1,09 & 1,22 & 1,44 & 1,47 & 1,49 & 1,45 & 1,20 & 1,00 & 1,20 \\
\hline & $18:$ & & 0,92 & 0,93 & 0,85 & 1,03 & 0,97 & 0,91 & 0,78 & 0,66 & 0,64 & 0,63 & 0, & & 0, & 0,90 & 1,07 & 1,20 & 1,42 & 1,45 & 1,47 & 1,43 & 1,18 & 1,12 & 1,18 & 1,19 \\
\hline & $19: 00$ & & 0,93 & 1,02 & 1,02 & 0,97 & 0,90 & 0,78 & 0,58 & 0,63 & 0,62 & 0,67 & 0,67 & 0,68 & 0, & 1,07 & 1,20 & 1,42 & 1,44 & 1,46 & 1,42 & 1,07 & 1,23 & 0,98 & 1,19 & 1,32 \\
\hline & $20: 00$ & & 0,96 & 0,82 & 0,94 & \begin{tabular}{|l|}
0,87 \\
\end{tabular} & 0,75 & 0,64 & 0,67 & 0,60 & 0,65 & 0,66 & 0,80 & 0,86 & 1,03 & 1,16 & 1,37 & 1,40 & 1,41 & 1,37 & 1,18 & 1,17 & 1,06 & 1,15 & 1,27 & 1,21 \\
\hline & 00 & & 1,00 & 0,94 & 0,88 & \begin{tabular}{|l|}
0,76 \\
\end{tabular} & 0,64 & 0,50 & 0,61 & 0,65 & 0,78 & 0,65 & 0,70 & 1,04 & 1,17 & 1,38 & 1,41 & 1,43 & 1,39 & 1,19 & 1,07 & 1,18 & 0,94 & 1,29 & \begin{tabular}{|l}
1,23 \\
\end{tabular} & 1,17 \\
\hline & & & 0,80 & 0,88 & 0,76 & \begin{tabular}{|l|l|}
0,64 \\
\end{tabular} & 0,62 & 0,63 & 0,65 & 0,81 & 0,66 & 0,87 & 1, & 1,17 & 1, & 1,4 & 1,42 & 1,39 & 1,19 & 0,89 & 1,22 & 1,11 & 1,28 & 1,22 & \begin{tabular}{|l}
1,17 \\
\end{tabular} & 0,78 \\
\hline & $3: 00$ & 0,641 & 0,88 & 0,76 & 0,64 & \begin{tabular}{|l|}
0,61 \\
\end{tabular} & 0,60 & 0,73 & 0,80 & 0,71 & 0,86 & 1,03 & 1,16 & 1,37 & 1,40 & 1,41 & 1,38 & 1,18 & 1,11 & 1,07 & 1,18 & 1,27 & 1,22 & 1,16 & \begin{tabular}{|l|l}
0,79 \\
\end{tabular} & 0,69 \\
\hline
\end{tabular}




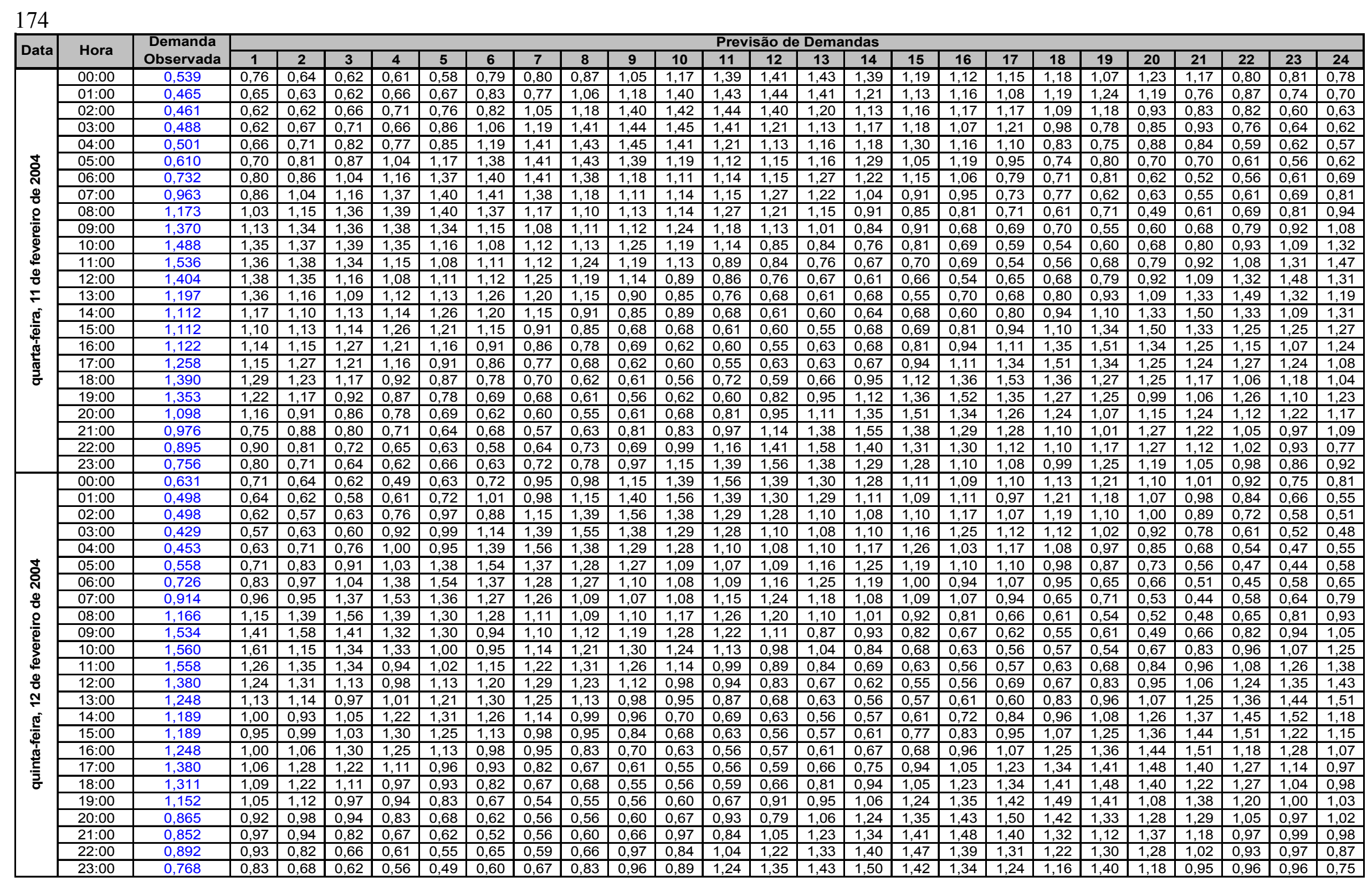




\begin{tabular}{|c|c|c|c|c|c|c|c|c|c|c|c|c|c|c|c|c|c|c|c|c|c|c|c|c|c|c|}
\hline \multirow{2}{*}{ Data } & \multirow{2}{*}{ Hora } & \multirow{2}{*}{$\begin{array}{l}\text { Demanda } \\
\text { Observada }\end{array}$} & \multicolumn{24}{|c|}{ Previsão de Demandas } \\
\hline & & & 1 & 2 & 3 & 4 & 5 & 6 & 7 & 8 & 9 & 10 & 11 & 12 & 13 & 14 & 15 & 16 & 17 & 18 & 19 & 20 & 21 & 22 & 23 & 24 \\
\hline \multirow{24}{*}{ 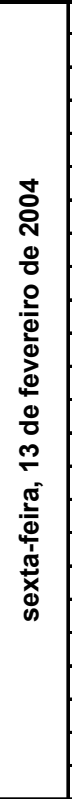 } & $00: 00$ & 0,592 & 0,67 & 0,62 & 0,55 & 0,56 & 0,65 & 0,66 & 0,82 & 0,96 & 0,89 & 1,23 & 1,34 & 1,42 & 1,49 & 1,41 & 1,33 & 1,24 & 1,19 & 1,33 & 1,30 & 1,01 & 0,91 & 0,96 & 0,83 & 0,63 \\
\hline & 01:00 & 0,494 & 0,63 & 0,56 & 0,57 & 0,49 & 0,67 & 0,83 & 1,06 & 0,96 & 1,25 & 1,36 & 1,44 & 1,51 & 1,43 & 1,35 & 1,25 & 1,21 & 1,19 & 1,12 & 1,20 & 0,96 & 0,97 & 0,75 & 0,62 & 0,62 \\
\hline & $02: 00$ & 0,437 & 0,56 & 0,56 & 0,60 & 0,64 & 0,96 & 1,01 & 0,95 & 1,24 & 1,35 & 1,42 & 1,50 & 1,42 & 1,33 & 1,24 & 1,20 & 1,19 & 1,11 & 1,32 & 1,02 & 0,91 & 0,74 & 0,61 & 0,51 & 0,61 \\
\hline & 03:00 & 0,467 & 0,57 & 0,60 & 0,67 & 0,82 & 1,01 & 1,00 & 1,25 & 1,36 & 1,43 & 1,50 & 1,42 & 1,34 & 1,25 & 1,20 & 1,19 & 1,19 & 1,11 & 1,18 & 0,93 & 0,74 & 0,61 & 0,52 & 0,61 & 0,48 \\
\hline & $04: 00$ & 0,437 & 0,63 & 0,70 & 0,87 & 0,97 & 1,07 & 1,05 & 1,42 & 1,50 & 1,57 & 1,48 & 1,40 & 1,30 & 1,26 & 1,24 & 1,00 & 1,16 & 1,06 & 0,86 & 0,78 & 0,64 & 0,54 & 0,57 & 0,51 & 0,44 \\
\hline & $05: 00$ & 0,471 & 0,70 & 0,87 & 0,85 & 1,08 & 1,10 & 1,42 & 1,50 & 1,57 & 1,49 & 1,40 & 1,30 & 1,26 & 1,24 & 1,17 & 1,23 & 1,06 & 0,86 & 0,78 & 0,64 & 0,54 & 0,57 & 0,51 & 0,44 & 0,44 \\
\hline & $06: 00$ & 0,537 & 0,88 & 1,01 & 1,01 & 1,13 & 1,44 & 1,52 & 1,60 & 1,51 & 1,42 & 1,33 & 1,28 & 1,27 & 1,19 & 1,01 & 1,08 & 0,87 & 0,79 & 0,65 & 0,55 & 0,58 & 0,52 & 0,45 & 0,45 & 0,49 \\
\hline & $07: 00$ & 789 & 1,01 & 1,13 & 1,12 & 1,16 & 1,53 & 1,60 & 1,52 & 1,43 & 1,33 & 1,28 & 1,27 & 1,19 & 1,19 & 1,25 & 0,87 & 0,79 & 0,66 & 0,55 & 0,59 & 0,52 & 0,45 & 0,45 & 0,49 & 0,62 \\
\hline & $\begin{array}{l}08: 00 \\
\end{array}$ & 083 & 1,14 & 1,34 & 1,18 & 1,54 & 1,62 & 1,53 & 1,44 & 1,35 & 1,30 & 1,28 & 1,21 & 1,20 & 1,00 & 0,88 & 0,80 & 0,66 & 0,56 & 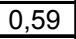 & 0,52 & 0,46 & 0,45 & 0,50 & 0,62 & 0,83 \\
\hline & 09:00 & 1,432 & 1,38 & 1,21 & 1,27 & 1,66 & 1,32 & 1,22 & 1,38 & 1,33 & 1,32 & 1,24 & 1,23 & 1,13 & 0,91 & 0,82 & 0,68 & 0,57 & 0,61 & 0,54 & 0,47 & 0,46 & 0,51 & 0,64 & 0,85 & 1,26 \\
\hline & 10:00 & 702 & 1,48 & 1,29 & 1,64 & 1,27 & 1,30 & 1,37 & 1,32 & 1,30 & 1,22 & 1,22 & 1,11 & 1,00 & 0,81 & 0,67 & 0,57 & 0,60 & 0,53 & 0,46 & 0,46 & 0,51 & 0,63 & 0,84 & 1,15 & 1,26 \\
\hline & $11: 00$ & 1,643 & 1,44 & 1,36 & 1,32 & 1,43 & 1,33 & 1,36 & 1,34 & 1,26 & 1,25 & 1,15 & 0,76 & 0,84 & 0,69 & 0,58 & 0,62 & 0,55 & 0,48 & 0,47 & 0,52 & 0,65 & 0,87 & 1,11 & 1,20 & 1,43 \\
\hline & $12: 00$ & 1,584 & 1,55 & 1,37 & 1,33 & 1,38 & 1,17 & 1,34 & 1,25 & 1,25 & 1,14 & 0,92 & 0,83 & 0,69 & 0,58 & 0,61 & 0,54 & 0,48 & 0,47 & 0,52 & 0,65 & 1,00 & 1,04 & 1,10 & 1,32 & 1,50 \\
\hline & 13:00 & 486 & 1,54 & 1,34 & 1,33 & 1,26 & 1,32 & 1,24 & 1,23 & 1,12 & 0,91 & 0,74 & 0,68 & 0,57 & 0,61 & 0,54 & 0,47 & 0,46 & 0,51 & 0,64 & 0,88 & 0,98 & 1,34 & 1,50 & 1,35 & 1,47 \\
\hline & $14: 00$ & 1,377 & 1,49 & 1,34 & 1,31 & 1,12 & 1,24 & 1,23 & 1,13 & 0,91 & 0,82 & 0,68 & 0,57 & 0,61 & 0,54 & 0,47 & 0,47 & 0,51 & 0,64 & 0,82 & 0,91 & 1,35 & 1,50 & 1,29 & 1,50 & 1,55 \\
\hline & $15: 00$ & 1,238 & 1,39 & 1,32 & 1,21 & 1,22 & 1,21 & 1,11 & 0,89 & 0,81 & 0,74 & 0,56 & 0,60 & 0,53 & 0,46 & 0,46 & 0,50 & 0,63 & 0,79 & 1,09 & 1,32 & 1,48 & 1,51 & 1,32 & 1,47 & 1,41 \\
\hline & 16:00 & 235 & 1,36 & 1,31 & 1,07 & 1,22 & 1,12 & 0,90 & 0,82 & 0,57 & 0,57 & 0,60 & 0,53 & 0,47 & 0,46 & 0,51 & 0,63 & 0,85 & 1,10 & 1,34 & 1,49 & 1,53 & 1,22 & 1,46 & 1,47 & 1,40 \\
\hline & $17: 00$ & 202 & 1,34 & 1,18 & 1,20 & 1,10 & 0,88 & 0,80 & 0,66 & 0,56 & 0,59 & 0,52 & 0,46 & 0,45 & 0,50 & 0,62 & 0,95 & 1,08 & 1,31 & 1,46 & 1,50 & 1,47 & 1,29 & 1,43 & 1,36 & 1,29 \\
\hline & $18: 00$ & 1,159 & 1,29 & 1,05 & 1,11 & 0,90 & 0,81 & 0,67 & 0,56 & 0,60 & 0,53 & 0,46 & 0,46 & 0,51 & 0,63 & 0,84 & 1,09 & 1,33 & 1,48 & 1,52 & 1,50 & 1,24 & 1,43 & 1,41 & 1,31 & 1,28 \\
\hline & 19:00 & 181 & 1,21 & 1,13 & 0,91 & 0,82 & 0,57 & 0,50 & 0,61 & 0,54 & 0,47 & 0,47 & 0,51 & 0,64 & 0,85 & 0,90 & 1,35 & 1,50 & 1,54 & 1,51 & 1,20 & 1,44 & 1,46 & 1,36 & 1,30 & 1,24 \\
\hline & $20: 00$ & 117 & 1,09 & 0,77 & 0,67 & 0,69 & 0,56 & 0,60 & 0,54 & 0,47 & 0,47 & 0,51 & 0,64 & 0,86 & 1,02 & 1,35 & 1,51 & 1,54 & 1,52 & 1,46 & 1,27 & 1,42 & 1,37 & 1,28 & 1,26 & 1,13 \\
\hline & $21: 00$ & 0,886 & 0,93 & 0,69 & 0,64 & 0,59 & 0,51 & 0,53 & 0,46 & 0,46 & 0,51 & 0,63 & 0,84 & 1,08 & 1,32 & 1,48 & 1,51 & 1,49 & 1,43 & 1,14 & 1,34 & 1,38 & 1,30 & 1,24 & 1,19 & 1,34 \\
\hline & $22: 00$ & 0,731 & 0,79 & 0,65 & 0,61 & 0,50 & 0,53 & 0,46 & 0,46 & 0,50 & 0,62 & 0,83 & 1,10 & 1,32 & 1,47 & 1,50 & 1,48 & 1,42 & 1,05 & 1,26 & 1,38 & 1,34 & 1,26 & 1,22 & 1,11 & 1,15 \\
\hline & $23: 00$ & 0,722 & 0,70 & 0,64 & 0,56 & 0,52 & 0,46 & 0,46 & 0,50 & 0,63 & 0,84 & 1,09 & 1,32 & 1,47 & 1,51 & 1,49 & 1,43 & 1,28 & 1,13 & 1,30 & 1,35 & 1,27 & 1,22 & 1,17 & 0,98 & 0,71 \\
\hline
\end{tabular}

Observação: Para se obter as demandas dos nós, multiplicou-se tais valores pela demandas base do nó correspondente. 
176

PAdRões de Demanda - JunHo.

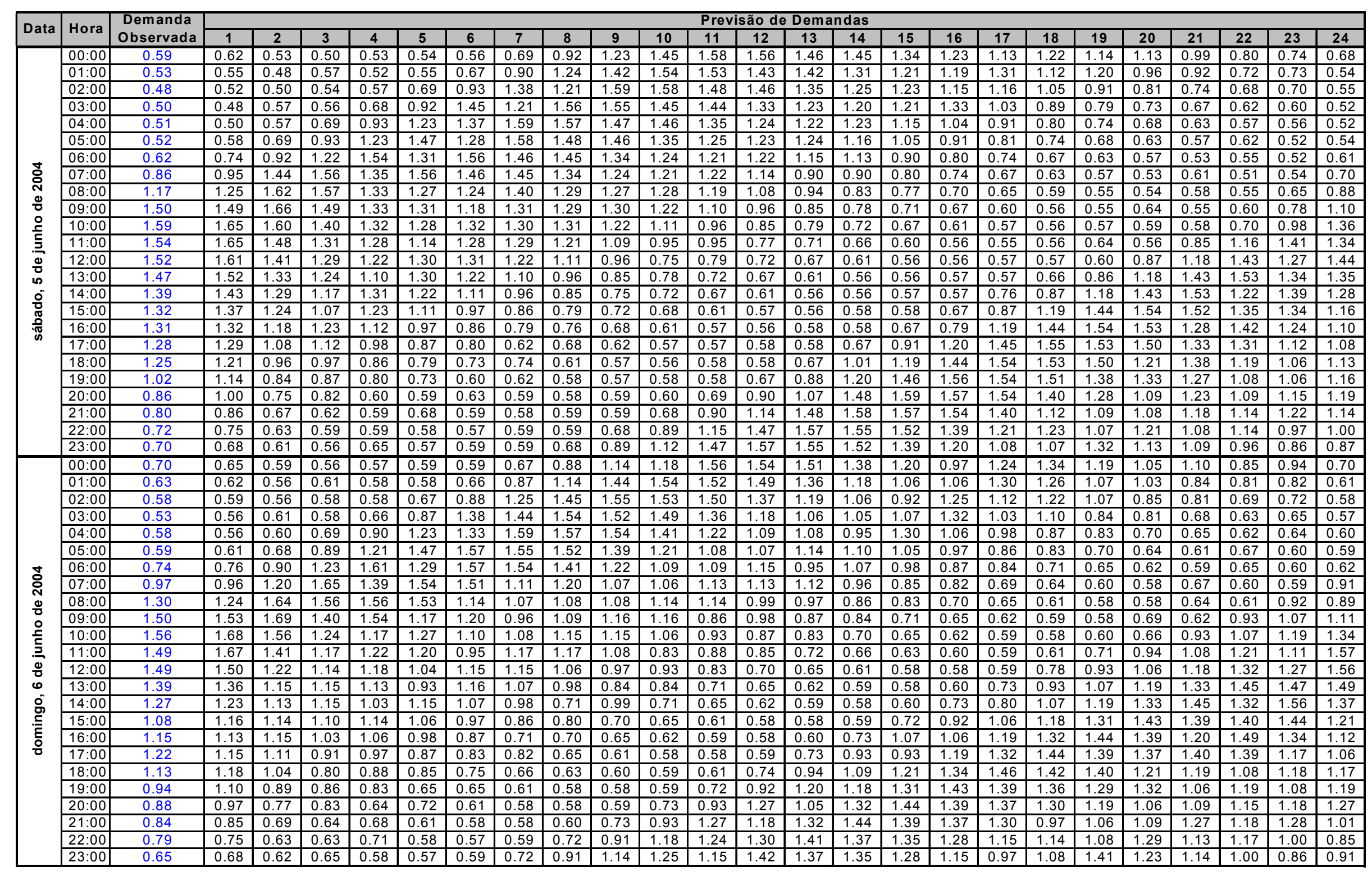




\begin{tabular}{|c|c|c|c|c|c|c|c|c|c|c|c|c|c|c|c|c|c|c|c|c|c|c|c|c|c|c|}
\hline \multirow{2}{*}{ Data } & \multirow{2}{*}{ ra } & ida & \multicolumn{24}{|c|}{ Previsão de Demandas } \\
\hline & & & 1 & & 3 & 4 & & 6 & & & 9 & 10 & & 12 & 13 & & 15 & 16 & 17 & 18 & 19 & 20 & 21 & & 23 & \\
\hline \multirow{24}{*}{ 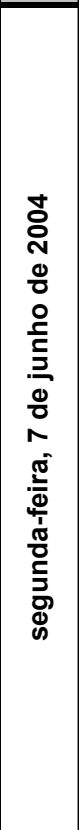 } & & $\overline{61}$ & & $\overline{0.62}$ & .57 & & 88 & $\overline{.71}$ & 0.91 & .12 & $\overline{10}$ & 10 & $\overline{1.40}$ & 1.36 & $\overline{1.34}$ & 1.27 & $\overline{1.14}$ & 1.04 & $\overline{1.13}$ & 1.37 & 1.29 & 1.12 & $\overline{1.12}$ & $\overline{0.85}$ & 0.76 & .73 \\
\hline & & & 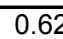 & 65 & .57 & 0.59 & 10 & 0.92 & 1.16 & 1.12 & 1.24 & 1.17 & 1.38 & 1.35 & 100 & 1.15 & 10 & 0.99 & 1.33 & 1.4 & 1.24 & & 0. & 7 & & $\bar{n}$ \\
\hline & & 54 & 62 & 58 & 59 & 72 & 92 & 1.06 & 1.14 & 22 & 1.26 & $\overline{39}$ & 1.36 & 1.29 & 1.16 & 06 & .09 & .16 & 1.45 & 1.1 & \begin{tabular}{|l|}
1.19 \\
\end{tabular} & 0.86 & .77 & 0.71 & $\pi$ & 0.55 \\
\hline & & 3 & $\frac{65}{65} \cdot 10 \cdot 10$ & 61 & \begin{tabular}{|l|l|}
0.74 \\
\end{tabular} & 95 & 08 & 1.21 & 17 & 1.31 & 1.24 & 1.40 & 1.33 & 1.19 & 1.09 & 1.12 & 1.02 & 1.45 & 1.14 & 1.03 & \begin{tabular}{|l|}
0.89 \\
\end{tabular} & \begin{tabular}{|l|}
0.79 \\
\end{tabular} & 0.73 & 0.65 & 69 & 0.56 \\
\hline & $04: 00$ & & 0.69 & 0.74 & 0.95 & 1.08 & 1.27 & 1.12 & 1.24 & 1.32 & 1.40 & 1.33 & 1.19 & 1.09 & 1.12 & 1.26 & 1.22 & \begin{tabular}{|l|}
1.14 \\
\end{tabular} & 1.03 & 0.89 & \begin{tabular}{|l|l|}
0.79 \\
\end{tabular} & 0.72 & 0.65 & \begin{tabular}{|l|}
0.59 \\
\end{tabular} & 0.61 & 0.57 \\
\hline & $05: 00$ & 076 & .77 & 1.10 & .09 & 1.33 & 1.12 & 1.47 & 1.26 & 1.17 & 1.34 & 8100 & 109 & 1.12 & 120 & 1.05 & 115 & 1.04 & 20 & & 270 & .65 & 0.60 & 0.58 & 0.58 & $\pi$ \\
\hline & & & 0.91 & 1.25 & 38 & 1.19 & 1.45 & 1.18 & 1.22 & 31 & 1.18 & 1.07 & 1.10 & 24 & 1.26 & 1.23 & 1.0 & 87 & 0.78 & $\overline{0.7}$ & .64 & 58 & 0.5 & 0.61 & 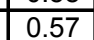 & 0.69 \\
\hline & \begin{tabular}{|l|l}
$07: 00$ \\
\end{tabular} & & 1.12 & 1.40 & \begin{tabular}{|l|l}
1.34 \\
\end{tabular} & $\begin{array}{ll}1.47 \\
\end{array}$ & 1.43 & 1.20 & 1.13 & 1.20 & 1.09 & 1.12 & 1.26 & 1.29 & 1.06 & 1.04 & 0.8 & \begin{tabular}{|l|}
0.80 \\
\end{tabular} & \begin{tabular}{|l|l}
0.73 \\
\end{tabular} & & \begin{tabular}{|l|}
0.60 \\
\end{tabular} & 58 & 0.58 & 0.59 & 64 & 0.80 \\
\hline & \begin{tabular}{|l}
$08: 00$ \\
\end{tabular} & & 1.33 & 1.43 & \begin{tabular}{|l|}
1.24 \\
\end{tabular} & 1.44 & 1.21 & 1.24 & $\begin{array}{l}1.02 \\
\end{array}$ & 1.10 & 1.13 & 1.27 & 1.29 & $\begin{array}{l}1.16 \\
\end{array}$ & $\begin{array}{l}1.04 \\
\end{array}$ & \begin{tabular}{|l|l|}
0.89 \\
\end{tabular} & 0.80 & \begin{tabular}{|l|}
0.73 \\
\end{tabular} & \begin{tabular}{|l|l|}
0.65 \\
\end{tabular} & 0.60 & \begin{tabular}{|l|}
0.58 \\
\end{tabular} & 0.59 & 0.63 & 0.75 & 1.99 & 0.90 \\
\hline & & & 1.47 & 1.38 & 16 & 1.16 & 1.30 & 1.18 & 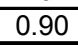 & 114 & 128 & 130 & 1.16 & 110 & & 0.80 & 0.74 & 066 & & & 050 & 77 & 770 & 100 & 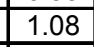 & 10 \\
\hline & & & $\overline{4 \varepsilon}$ & 1.26 & 42 & 1.16 & & \begin{tabular}{|l|l}
1.01 \\
\end{tabular} & 1.14 & 28 & & 1.16 & 0.86 & & & 0.74 & & & & & & & 1. & 1.08 & & \\
\hline & \begin{tabular}{|l|}
$11:$ \\
\end{tabular} & & $\overline{42}$ & 1.13 & 08 & 1.24 & 17 & 1.13 & 7 & 1.29 & 1.15 & 1.04 & 1.04 & 0.80 & 0.73 & \begin{tabular}{|l|l}
0.65 \\
\end{tabular} & 0.60 & .58 & 50 & 0.62 & \begin{tabular}{|l|l|}
0.72 \\
\end{tabular} & .99 & & 1.21 & & 1.43 \\
\hline & 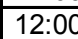 & & 1.26 & 1.33 & 1.10 & 1.17 & 0.98 & 1.26 & 28 & 1.14 & 1.03 & 0.86 & 0.79 & 0.72 & 0.65 & \begin{tabular}{|l|l}
0.59 \\
\end{tabular} & 20 & 0.58 & 0.62 & 0.8 & \begin{tabular}{|l|}
0.98 \\
\end{tabular} & \begin{tabular}{|l|l|}
1.06 \\
\end{tabular} & 1.20 & 1.32 & 1.20 & 1.45 \\
\hline & 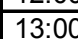 & & 1.13 & 1.06 & \begin{tabular}{|l|l|}
1.18 \\
\end{tabular} & 1.13 & 1.25 & \begin{tabular}{|l|l|}
1.27 \\
\end{tabular} & 1.13 & 1.1 & \begin{tabular}{|l|l|}
0.88 \\
\end{tabular} & .78 & 0.72 & 0.64 & 0 & \begin{tabular}{|l|l|}
0.57 \\
\end{tabular} & 0. & \begin{tabular}{|l|}
0.61 \\
\end{tabular} & 74 & 0. & \begin{tabular}{|l|l|}
1.05 \\
\end{tabular} & 19 & 1.31 & 1.37 & 36 & 1.49 \\
\hline & \begin{tabular}{|l|}
$14:$ \\
\end{tabular} & & tor & 1.15 & 21 & 1.01 & 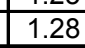 & 15 & & & & 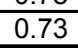 & 0.65 & & & 0.58 & & & & & & & & & & 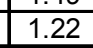 \\
\hline & \begin{tabular}{|l}
$15:$ \\
$15:$
\end{tabular} & & $\frac{\pi}{12}$ & 1.21 & \begin{tabular}{|l|l}
1.13 \\
\end{tabular} & $\begin{array}{ll}1.27 \\
\end{array}$ & 1.14 & 1.03 & $0.8 \varepsilon$ & 0.70 & 0.72 & 0.15 & 0.59 & 0.57 & 0.5 & \begin{tabular}{|l}
0.62 \\
\end{tabular} & 0.74 & \begin{tabular}{|l|}
0.1 \\
\end{tabular} & \begin{tabular}{|l}
0.02 \\
1.06
\end{tabular} & 1. & \begin{tabular}{|l|l|}
1.31 \\
\end{tabular} & 1.37 & 1.40 & 1.42 & .21 & 1.14 \\
\hline & $16: 00$ & & 18 & 1.22 & \begin{tabular}{|l|l}
1.04 \\
\end{tabular} & 1.15 & 1.04 & 0.89 & 0.64 & 0.73 & \begin{tabular}{|l|l}
0.65 \\
\end{tabular} & 60 & 0.58 & 0.59 & 0.6 & \begin{tabular}{|l}
0.75 \\
\end{tabular} & 1.14 & \begin{tabular}{|l|}
1.07 \\
\end{tabular} & 1.21 & 1. & \begin{tabular}{|l|}
1.39 \\
\end{tabular} & 1.41 & 1.27 & 1.23 & 15 & 1.13 \\
\hline & \begin{tabular}{|l|}
$17: 0$ \\
\end{tabular} & & 1.25 & 1.17 & \begin{tabular}{|l|l}
1.16 \\
\end{tabular} & 1.04 & 0.90 & \begin{tabular}{|l|l|}
0.80 \\
\end{tabular} & 0.71 & 0.66 & \begin{tabular}{|l|l|}
0.60 \\
\end{tabular} & .58 & 0.59 & 0.63 & 0.7 & \begin{tabular}{|l|l|}
0.99 \\
\end{tabular} & 0. & \begin{tabular}{|l|}
1.21 \\
\end{tabular} & 1.33 & 1. & \begin{tabular}{|l|}
1.42 \\
\end{tabular} & 15 & 1.23 & 1.16 & .14 & 1.16 \\
\hline & & & $\overline{20}$ & 1.03 & 07 & 0.88 & 7 & 63 & 0 & 0.0 & & & 61 & & & & & 1.31 & & & & & & & & \\
\hline & 9:00 & & $\overline{14}$ & 0.88 & 0.88 & 0.64 & 0.65 & \begin{tabular}{|l|}
0.75 \\
\end{tabular} & 0.59 & 0.57 & 0.58 & 0.61 & 0.74 & 0.97 & & 1.19 & 1. & 1.36 & 1.39 & 1. & 1.11 & 13 & 1. & 1.13 & .38 & 1.35 \\
\hline & $: 00$ & & 01 & 0.76 & \begin{tabular}{|l}
0.66 \\
\end{tabular} & 0.66 & 0.68 & 0.59 & 58 & 0.58 & \begin{tabular}{|l|l}
0.62 \\
\end{tabular} & .74 & 0.98 & 1.06 & 1. & \begin{tabular}{|l|}
1.31 \\
\end{tabular} & 1. & \begin{tabular}{|l|}
1.40 \\
\end{tabular} & 35 & & \begin{tabular}{|l|l|}
1.14 \\
\end{tabular} & 13 & 1.14 & 1.44 & 38 & 1.33 \\
\hline & 2 & & 0.84 & 0.67 & \begin{tabular}{|l|l}
0.63 \\
\end{tabular} & 0.62 & 0.57 & \begin{tabular}{|l|l}
0.56 \\
\end{tabular} & 0.56 & \begin{tabular}{|l|l}
0.60 \\
\end{tabular} & \begin{tabular}{|l|}
0.72 \\
\end{tabular} & 95 & 1.23 & 1.16 & 1.2 & \begin{tabular}{|l|}
1.34 \\
\end{tabular} & 1. & 1.31 & .18 & 1. & 1.09 & 11 & 1.39 & 1.28 & 27 & 1.15 \\
\hline & & & 75 & 65 & $\pi$ & 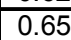 & 0.57 & 0.57 & 0 & 7 & & 19 & 1.24 & & & 1.39 & & $\overline{1.2}$ & & & & & & 1.5 & & 0 \\
\hline & 00 & & 0.68 & 0.62 & \begin{tabular}{|l|l|}
0.60 \\
\end{tabular} & 0.56 & 0.56 & 0.60 & 0.7 & 0.95 & 1.16 & 1.21 & 1.17 & 1.34 & 1.3 & 1.31 & 1.1 & .11 & 1.15 & $1.1 \mathrm{~T}$ & 1.2 & 1.37 & 1.2 & 0.9 & .8 & .92 \\
\hline \multirow{24}{*}{ 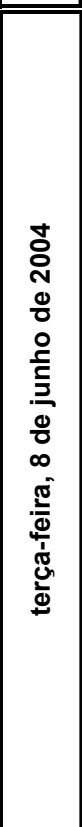 } & & & $\overline{c 12}$ & $\overline{\overline{\bar{n}}}$ & $\overline{\overline{63}}$ & $\overline{0,57}$ & $\overline{\overline{0}}$ & $\overline{\overline{0,73}}$ & 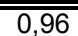 & & $\overline{1,16}$ & $\overline{\overline{23}}$ & $\overline{\overline{1,0}}$ & 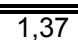 & & $\overline{\overline{1,15}}$ & & $=$ & & & $\overline{144}$ & $\overline{32}$ & $\overline{1100}$ & 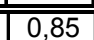 & $\overline{82}$ & $\overline{\overline{180}}$ \\
\hline & & & & & 7 & & & & & & & & & & & & & & & & & & & & & \\
\hline & & & 50 & 0,64 & 0,61 & 0,74 & 0,97 & 1,05 & 1 & & 1, & 15 & 04 & 1,2 & & 1,11 & & 1,3 & & & \begin{tabular}{|l|}
1,2 \\
\end{tabular} & 86 & 0,83 & 0,1 &, 02 & \\
\hline & & & & 71 & 0,74 & 0,97 & 1,05 & 1,26 & 1,1 & $\overline{1,2}$ & 1,27 & $\overline{34}$ & 1,21 & 1,13 & & 1,14 & & $\overline{1,2}$ & $\overline{15}$ & & $\overline{0,8}$ & 84 & 0,74 & $\overline{0,6}$ & 161 & 0, \\
\hline & & & & & 0,98 & 06 & 1 & \begin{tabular}{|l}
1,17 \\
\end{tabular} & & & \begin{tabular}{|l|}
1,21 \\
\end{tabular} & & 1,14 & & & & & & & & & & & & & \\
\hline & & & & 1,05 & \begin{tabular}{|l}
1, \\
\end{tabular} & 0 & & \begin{tabular}{|l|l|}
1,23 \\
\end{tabular} & $\frac{1,2}{1,3}$ & & \begin{tabular}{|l|l}
1,08 \\
\end{tabular} & $\frac{1,24}{1,16}$ & $\frac{1,14}{1,14}$ & 1 & & $\frac{1,0}{1,19}$ & & & & & & & & & 64 & 57 \\
\hline & $06:$ & & & & 1,1 & & & & & & & & & & & 1,3 & & 2 & & & 5. & & & & & \\
\hline & $7 \cdot 0$ & & 1 & & 1 & $\frac{1,5}{1,2}$ & & 1, & & & & & $\frac{1}{1,2}$ & 1, & & $\frac{1,}{1,2}$ & & 0,8 & & & & & & &,, 57 & 0 \\
\hline & & & & & 1,4 & 1 & & & & & 1 & & 1,2 & & & & & & & & & & & & & \\
\hline & $\overline{200}$ & & & & 1,27 & & & & & & & & 1,14 & & & & & & & & & & & & & \\
\hline & $10: 00$ & & & & \begin{tabular}{|l|}
1,2 \\
1,2
\end{tabular} & 1 & & & & 1, & \begin{tabular}{|l}
1, \\
\end{tabular} & $\frac{1,21}{1,15}$ & $\frac{1,14}{02}$ & 0 & & \begin{tabular}{|l|}
0,00 \\
0,74
\end{tabular} & & $\begin{array}{l}0,6 \\
0,6\end{array}$ & & & \begin{tabular}{|l|}
0, \\
0,
\end{tabular} & & 0 & 0 & & $\frac{1,05}{1,31}$ \\
\hline & 1. & & & & 1,2 & & & & & & & & & & & & & & & & & & & & & \\
\hline & 2.1 & & & & 1,2 & & & 11 & & & 0 & & 0,8 & & & 0,60 & & & & & 0, & & & & 26 & 1,54 \\
\hline & & & & & & & & & & & & & & & & & & & & & & & & & 47 & \\
\hline & & & & & 1,1 & 1, & & & & & & & & & & 0,5 & & & & & & 1 & & 1 & 1,32 & 1,45 \\
\hline & $5: 00$ & & & 1. & \begin{tabular}{|l}
1 \\
\end{tabular} & 1. & & 0.99 & & & \begin{tabular}{|l|l}
0,72 \\
\end{tabular} & & 0,60 & 0 & & \begin{tabular}{|l|l}
0,58 \\
\end{tabular} & 0 & 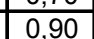 & & 0 & 4 & & 1, & & 47 & 1,26 \\
\hline & & & & & 1 & & & 4 & & & & & & & & & & & & & & & & & & \\
\hline & & & & & 0,9 & & & \begin{tabular}{|l}
0 \\
0,
\end{tabular} & & & \begin{tabular}{|l|l}
0 \\
\end{tabular} & & 0,56 & 0 & & \begin{tabular}{|l|}
0,95 \\
\end{tabular} & 0 & & & & & 5 & & & 1,34 & $1,1 \varepsilon$ \\
\hline & & & $\overline{1,3}$ & & & & & & & & & & 0,5 & & & \begin{tabular}{|l|}
1,05 \\
\end{tabular} & & 1, & & & & 1,23 & 1,21 & 1, & 1,23 & \\
\hline & & & 1,25 & 0,93 & \begin{tabular}{|l|l|}
0,87 \\
\end{tabular} & \begin{tabular}{|l|l|}
0,84 \\
\end{tabular} & 0,63 & \begin{tabular}{|l|}
0,62 \\
\end{tabular} & 0,6 & 0 & \begin{tabular}{|l|}
0,57 \\
\end{tabular} & 0,59 & 0,71 & 0,97 & & \begin{tabular}{|l|}
0,96 \\
\end{tabular} & 1, & \begin{tabular}{|l|}
1, \\
1,
\end{tabular} & \begin{tabular}{|l|l|}
1,44 \\
\end{tabular} & & 1. & \begin{tabular}{|l|}
1,24 \\
\end{tabular} & 1,22 & 1. & 1,22 & 1,26 \\
\hline & & 0 & 1,02 & 0,74 & \begin{tabular}{|l|}
0,82 \\
\end{tabular} & \begin{tabular}{|l|}
0,62 \\
\end{tabular} & 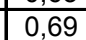 & \begin{tabular}{|l|l|}
0,60 \\
\end{tabular} & & 0 & \begin{tabular}{|l}
0,58 \\
\end{tabular} & 0,70 & 95 & 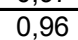 & & \begin{tabular}{|l|}
1,30 \\
\end{tabular} & 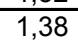 & 1, & 1 , & 1, & 1, & 1,2 & 1, & \begin{tabular}{|l|l}
1,18 \\
\end{tabular} & 17 & 1,2 \\
\hline & & & 0 & 0,82 & 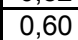 & & 0,60 & 0,56 & & 0,5 & 06 & 0 & 0,96 & & & & & & & & & & & & & \\
\hline & & & & 0, & 0,6 & & & $\frac{0,00}{0,55}$ & & & 0, & 0, & 1,26 & 1 & & 1,39 & 1, & 1,2 & 1,2 & & 1,1 & \begin{tabular}{|l|l|}
1,38 \\
\end{tabular} & 1,17 & 1,15 & $\frac{1,24}{1,16}$ & 1, \\
\hline & $23: 00$ & 0,70 & 1,65 & 0,61 & \begin{tabular}{|l|l}
0,63 \\
\end{tabular} & 0,56 & 0,55 & \begin{tabular}{|l|l}
0,57 \\
\end{tabular} & 0,69 & 93 & 0,95 & 1,28 & 15 & 1,36 & 39 & \begin{tabular}{|l|}
1,29 \\
\end{tabular} & 1,28 & 1,19 & \begin{tabular}{|l|}
1,05 \\
\end{tabular} & 1,16 & 1,21 & 1,33 & 1,18 & 1,18 & 0,92 &, 9 \\
\hline
\end{tabular}




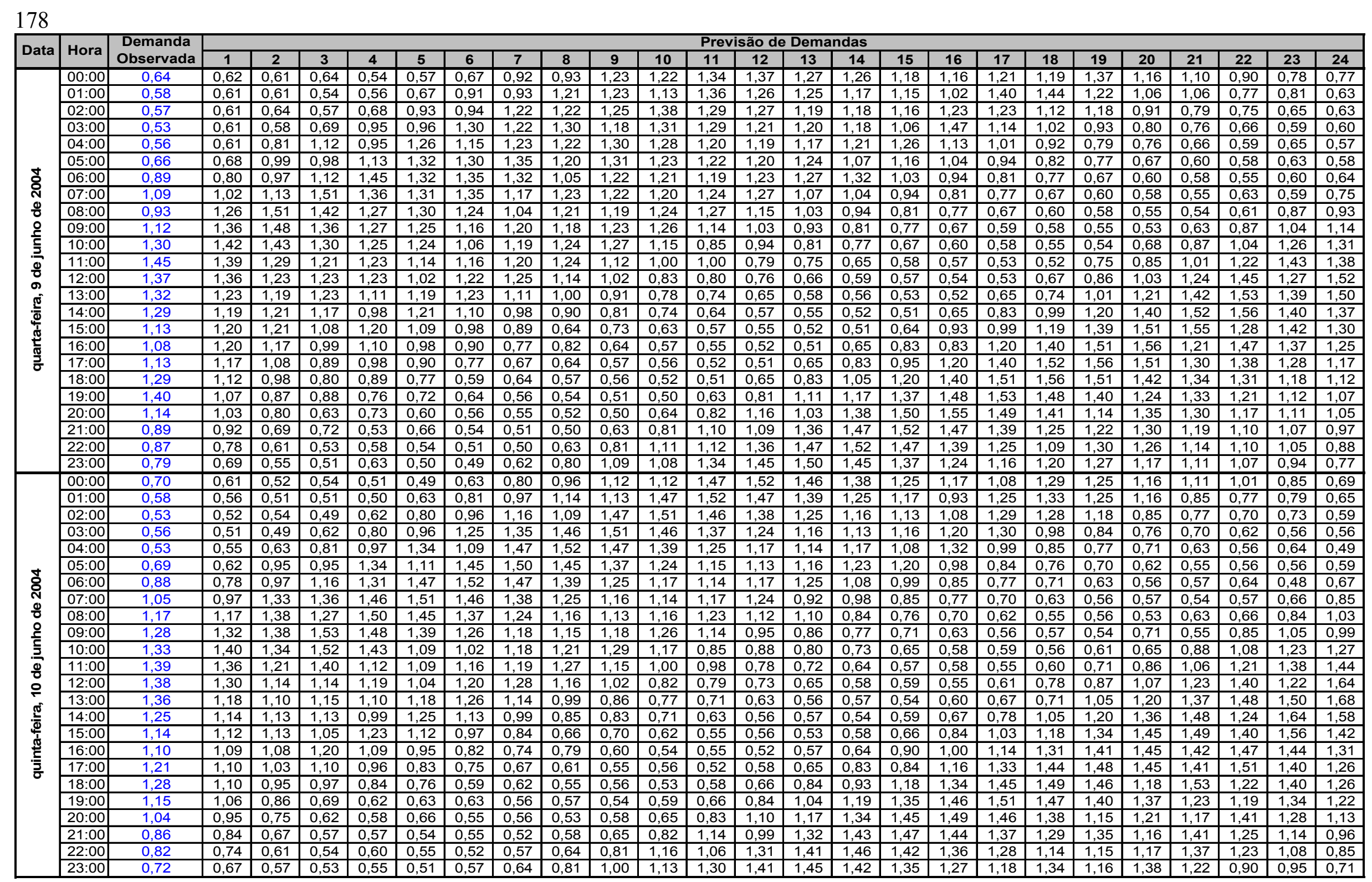




\begin{tabular}{|c|c|c|c|c|c|c|c|c|c|c|c|c|c|c|c|c|c|c|c|c|c|c|c|c|c|c|}
\hline \multirow{2}{*}{ Data } & \multirow{2}{*}{ Hora } & \multirow{2}{*}{$\begin{array}{c}\text { Demanda } \\
\text { Observada }\end{array}$} & \multicolumn{24}{|c|}{ Previsão de Demandas } \\
\hline & & & 1 & 2 & 3 & 4 & 5 & 6 & 7 & 8 & 9 & 10 & 11 & 12 & 13 & 14 & 15 & 16 & 17 & 18 & 19 & 20 & 21 & 22 & 23 & 24 \\
\hline \multirow{24}{*}{ 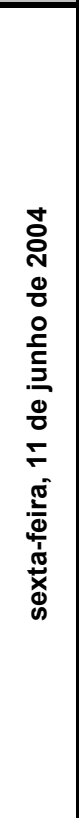 } & $\overline{D: 00}$ & 0,64 & 0,63 & 0,55 & 0,58 & 0,53 & 0,59 & 0,66 & 0,84 & 1,03 & 1,21 & 1,10 & 1,46 & 1,50 & 1,47 & 1,40 & 1,31 & 1,23 & 1,18 & 1,21 & 1,20 & 1,06 & 0,94 & 0,84 & 0,77 & 0,73 \\
\hline & $: 00$ & & 0,57 & 0,53 & 0,52 & 0,58 & 0,65 & 0,83 & 1,02 & 1,24 & 1,14 & 1,44 & 1,48 & 1,45 & 1,38 & 1,29 & 1,21 & 1,17 & 1,37 & 1,19 & 1,05 & 0,92 & 0,83 & 0,76 & 0,79 & \begin{tabular}{|l}
0,64 \\
\end{tabular} \\
\hline & \begin{tabular}{|l|l}
$02: 00$ \\
\end{tabular} & 50 & 0,53 & 0,57 & 0,58 & 0,65 & 0,83 & 1,02 & 1,27 & 1,16 & 1,44 & 1,48 & 1,45 & 1,38 & 1,30 & 1,21 & 1,17 & 1,17 & 1,19 & 1,05 & 0,93 & 0,84 & 0,76 & \begin{tabular}{|l|l|}
0,68 \\
\end{tabular} & 0,73 & 0,60 \\
\hline & $03: 00$ & & 0,51 & 0,66 & 0,64 & 0,82 & 1,01 & 1,30 & 1,16 & 1,43 & 1,47 & 1,44 & 1,37 & 1,29 & 1,20 & 1,16 & 1,18 & 1,36 & 1,04 & 0,92 & 0,83 & 0,76 & 0,67 & 0,61 & 0,65 & \begin{tabular}{|l}
0,55 \\
\end{tabular} \\
\hline & 04:00 & & 57 & 0,66 & 0,84 & 1,04 & 1,19 & 1,28 & 1,22 & 1,51 & 1,48 & 1,41 & 32 & 1,23 & 1,19 & 1,21 & 1,19 & 1,07 & 0,94 & 0,85 & 0,78 & 0,69 &, 62 & 0,57 &, 63 & 0,51 \\
\hline & \begin{tabular}{|l}
$05: 00$ \\
\end{tabular} & & 67 & 0,86 & 1,05 & 1,20 & 1,35 & 1,25 & 1,23 & 1,50 & 1,43 & 1,34 & 25 & 1,21 & 23 & 1,23 & 1,08 & 0,96 & 0,86 & 0,79 & 0,70 & 0,63 & 0,58 & 0,55 & 0,58 & \begin{tabular}{|l|l}
0,48 \\
\end{tabular} \\
\hline & \begin{tabular}{|l|l}
$06: 00$ \\
\end{tabular} & 0,88 & 0,82 & 1,21 & 1,19 & 1,37 & 1,24 & 1,24 & 1,48 & 1,41 & 1,33 & 1,24 & 1,20 & 1,22 & 1,22 & 1,20 & 0,95 & 0,85 & 0,78 & 0,70 & 0,63 & 0,57 & 0,55 & 0,62 & 0,51 & \begin{tabular}{|l|l}
0,48 \\
\end{tabular} \\
\hline & \begin{tabular}{|l}
$07: 00$ \\
\end{tabular} & & 1,04 & 1,42 & 1,48 & 1,32 & 1,26 & 1,26 & 1,44 & 1,36 & 1,27 & 1,22 & 1,25 & 1,24 & 0,96 & 0,97 & 0,87 & 0,80 & 0,71 & 0,64 & 0,59 & 0,56 & 0,56 & 0,59 & 0,49 & \begin{tabular}{|l|}
0,71 \\
\end{tabular} \\
\hline & \begin{tabular}{|l|l}
$08: 00$ \\
\end{tabular} & & 1,26 & 1,50 & 1,43 & 1,30 & 1,29 & 1,21 & 1,37 & 1,27 & 1,23 & 1,25 & 1, & 1,10 & 0,97 & 0,88 & 0,80 & 0,71 & 0,64 & 0,59 & 0,56 & 0,56 & 0,63 & \begin{tabular}{|l|}
0,53 \\
\end{tabular} & 0,72 & 0,96 \\
\hline & \begin{tabular}{|l|l}
$09: 00$ \\
\end{tabular} & & 1,41 & 1,50 & 1,37 & 1,29 & 1,26 & 1,11 & 1,28 & 1,23 & 1,26 & 1,25 & & 1,00 & & 0,80 & 0,72 & 0,64 & 0,59 & 0,56 & 0,56 & 0,67 & 0,57 & \begin{tabular}{|l}
0,72 \\
\end{tabular} & 0,96 & 1,28 \\
\hline & \begin{tabular}{|l|l}
$10: 00$ \\
\end{tabular} & 14 & 1,46 & 1,43 & 1,32 & 1,27 & 1,19 & 1,02 & 1,23 & 1,26 & 1,25 & 1,11 & 0,98 & 0,88 & 0,80 & 0,72 & 0,64 & 0,59 & 0,56 & 0,56 & 0,57 & 0,63 & 0,72 & 0,96 & 1,28 & \begin{tabular}{|l|}
1,57 \\
\end{tabular} \\
\hline & $11: 00$ & & 1,43 & 1,33 & 1,24 & 1,20 & 1,09 & 1,20 & 1,23 & 1,22 & 1,08 & 0,95 & 0,97 & 0,78 & 070 & 0,63 & 0,57 & 0,55 & 0,55 & 0,56 & 0,66 & 0,70 & 0,94 & 1,25 & 1,53 & 1,66 \\
\hline & $12: 00$ & & 1,39 & 1,28 & 1,25 & 1,19 & 1,01 & 1,25 & 1,25 & 1,10 & 0,97 & 0,76 & $\overline{0}$ & 0,71 & 64 &, 59 & 0,56 & 0,56 & 0,57 & 0,59 & 0,61 & 0,96 & 1,27 & 1,56 & 1,69 & \begin{tabular}{|l|}
1,47 \\
\end{tabular} \\
\hline & $13: 00$ & & 1,29 & 1,24 & 1,23 & 1,08 & 1,23 & 1,23 & 1,08 & 0,95 & 0,86 & 0,79 & 0,70 & 0,63 & 58 & 0,55 & 0,55 & 0,56 & 0,58 & 0,65 & 0,94 & 1,25 & 1,53 & 1,66 & 1,33 & \begin{tabular}{|l|}
1,51 \\
\end{tabular} \\
\hline & $14: 00$ & & 1,24 & 1,23 & 1,15 & 1,21 & 1,20 & 1,06 & 0,94 & 0,84 & 0,70 & 0,69 & 0,62 & 0,57 & 0,54 & 0,54 & 0,55 & 0,57 & 0,70 & 0,93 & 1,23 & 1,51 & 1,63 & 1,59 & 1,40 & \begin{tabular}{|l|}
1,38 \\
\end{tabular} \\
\hline & $15: 00$ & & 1,24 & 1,21 & 1,04 & 1,20 & 1,06 & 0,93 & 0,84 & 0,77 & 0,69 & 0,61 & 0,56 & 0,54 & 0,54 & 0,54 & 0,57 & 0,78 & 0,92 & 1,22 & 1,50 & 1,62 & 1,58 & 1,28 & 1,48 & 1,30 \\
\hline & & & 1,21 & 1,12 & 1,19 & 1,05 & 0,92 & 0,83 & 0,76 & 0,70 & 0,61 & 0,56 & $\overline{0}$ & 0,53 & 0,54 & 0,56 & 0,68 & 0,91 & 1,21 & 1,48 & 1,61 & 1,56 & 1,50 & 1,41 & 1,37 & 1,16 \\
\hline & \begin{tabular}{|l|l}
$17: 00$ \\
\end{tabular} & & 1,18 & 1,02 & 1,06 & 0,93 & 0,84 & 0,77 & 0,69 & 0,62 & 0,56 & 0,54 & 0,54 & 0,55 & 0,57 & 0,69 & 0,78 & 1,23 & 1,50 & 1,63 & 1,58 & 1,52 & 1,37 & 1,47 & 1,28 & 1,11 \\
\hline & \begin{tabular}{|l|l}
$18: 00$ \\
\end{tabular} & 0 & 1,11 & 0,92 & 0,76 & 0,84 & 0,77 & 0,69 & 0,62 & 0,57 & 0,54 & 0,54 & 0,55 & 0,57 & 0,69 & 0,88 & 1,23 & 1,50 & 1,63 & \begin{tabular}{|c|}
1,58 \\
\end{tabular} & 1,51 & 1,48 & 1,44 & 1,37 & 1,16 & 1,08 \\
\hline & \begin{tabular}{|l|l}
$19: 00$ \\
\end{tabular} & & 1,03 & 0,83 & 0,69 & 0,76 & 0,68 & 0,56 & 0,56 & 0,53 & 0,53 & 0,54 & 0,57 & 0,68 & 0,99 & 1,22 & 1,49 & 1,61 & 1,57 & 1,50 & 1,47 & 1,33 & 1,46 & 1,25 & 1,09 & \begin{tabular}{|l|}
1,07 \\
\end{tabular} \\
\hline & 0 & & $\overline{92}$ & 0,74 & 0,63 & 0,68 & 0,61 & 0,56 & 0,53 & 0,53 & 0,54 & 0,56 & 0,68 & 0,91 & 1,21 & 1,48 & 1,61 & 1,56 & 1,50 & 1,46 & 1,14 & 1,49 & 1,39 & 1,16 & 1,07 & 1,05 \\
\hline & & & 82 & 0,68 & 0,56 & 0,61 & 0,56 & 0,53 & 0,53 & 0,54 & 0,56 & 0,68 & & 0,99 & 1,48 & 1,61 & 1,56 & 1,49 & 1,46 & 1,34 & 1,33 & 1,44 & 1,24 & 1,07 & 1,04 & \begin{tabular}{|l|}
0,96 \\
\end{tabular} \\
\hline & \begin{tabular}{|l}
$22: 00$ \\
\end{tabular} & & 0,75 & 0,63 & 0,49 & 0,46 & 0,53 & 0,53 & 0,54 & 0,56 & 0,68 & 0,90 & 1,08 & 1,47 & 1,59 & 1,55 & 1,48 & 1,45 & 1,34 & 1,14 & 1,46 & 1,37 & 1,15 & 1,05 & 0,99 & \begin{tabular}{|l}
0,84 \\
\end{tabular} \\
\hline & $3: 00$ & 0,74 & 0,68 & 0,54 & 0,54 & 0,51 & 0,52 & 0,52 & 0,55 & 0,66 & 0,89 & 1,14 & 1,44 & 1,56 & 1,52 & 1,45 & 1,42 & 1,31 & 1,25 & 1,30 & 1,41 & 1,21 & 1,04 & 0,97 & 0,87 & 0,70 \\
\hline
\end{tabular}

Observação: Para se obter as demandas dos nós, multiplicou-se tais valores pela demandas base do nó correspondente. 